\author{
UNIVERSIDADE DE SÃO PAULO \\ FACULDADE DE ECONOMIA, ADMINISTRAÇÃO E CONTABILIDADE \\ DEPARTAMENTO DE ECONOMIA \\ PROGRAMA DE PÓS-GRADUAÇÃO EM ECONOMIA
}

\title{
ALOCAÇÃO DE ESTUDANTES AOS CENTROS DE PÓS-GRADUAÇÃO EM ECONOMIA NO BRASIL: UM EXPERIMENTO NATURAL EM ORGANIZAÇÃO DE MERCADO
}

Felipe Palmeira Bardella

Orientador(a): Profa. Dra. Marilda Antônia de Oliveira Sotomayor

SÃO PAULO

2005 
Prof. Dr. Adolfo José Melfi

Reitor da Universidade de São Paulo

Profa. Dra. Maria Tereza Leme Fleury

Diretora da Faculdade de Economia, Administração e Contabilidade

Prof. Dr. Ricardo Abramovay

Chefe do Departamento de Economia

Profa. Dra. Fabiana Rocha

Coordenadora do Programa de Pós-Graduação em Teoria Econômica 


\section{FELIPE PALMEIRA BARDELLA}

\section{ALOCAÇÃO DE ESTUDANTES AOS CENTROS DE PÓS-GRADUAÇÃO EM ECONOMIA NO BRASIL: UM EXPERIMENTO NATURAL EM ORGANIZAÇÃO DE MERCADO}

Dissertação apresentada ao Departamento de Economia da Faculdade de Economia, Administração e Contabilidade da Universidade de São Paulo como requisito para a obtenção do título de Mestre em Teoria Econômica.

Orientador(a): Profa. Dra. Marilda Antônia de Oliveira Sotomayor

SÃO PAULO

2005 
Dissertação apresentada e aprovada no Departamento de Economia da Faculdade de Economia, Administração e Contabilidade da Universidade de São Paulo - Programa de Pós-Graduação em Teoria Econômica pela seguinte banca examinadora:

Bardella, Felipe Palmeira

Alocação de estudantes aos centros de pós-graduação em economia no Brasil: um experimento natural em organização de mercado / Felipe Palmeira Bardella. -- São Paulo, 2005. $165 \mathrm{p}$.

Dissertação (Mestrado) - Universidade de São Paulo, 2005 Bibliografia.

1. Pós-graduação - Economia I. Universidade de São Paulo. Faculdade de Economia, Administração e Contabilidade II. Título.

CDD - 378.154 

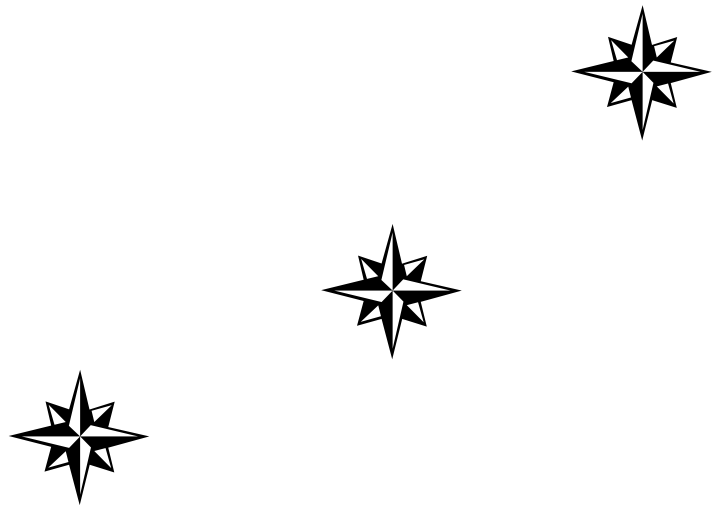

Às Três Marias, sempre presentes. 


\section{AGRADECIMENTOS}

Aos meus pais pela formação de meu caráter e apoio irrestrito.

À minha amada Paty por seu incomensurável amor.

Aos meus irmãos pelo apoio.

À minha orientadora Marilda Sotomayor pela sua atenção e sua confiança em meu trabalho.

Aos professores Décio Kadota e Fabiana Rocha pelas contribuições que deram desde o início da elaboração deste trabalho.

Ao professor Mauro Borges Lemos, Secretário Executivo da ANPEC, e aos demais coordenadores de todos os Centros de Pós-Graduação em Economia por todas as informações prestadas.

À professora Madalena, Coordenadora do Exame Nacional de Seleção da ANPEC, à Lázara e ao professor Antônio Dantas, Ex-Coordenador do Exame Nacional de Seleção da ANPEC, pelas informações sobre o Exame que me foram transmitidas.

Aos amigos que fiz durante o curso, especialmente Antônio Zanetti, Pedro Nunes e Bruno Giovannetti que muito contribuíram com esta dissertação.

À família Wermelinger, pela hospitalidade e pelo apoio que me deram em Brasília, durante a fase de conclusão deste trabalho.

À Valéria, ao Francisco e à Cida, na Secretaria de Pós-Graduação da FEA, e à Márcia e à Bete, na Secretaria de Pós-Graduação do Departamento de Economia, pelo auxílio nas questões relativas às normas e procedimentos da pós-graduação.

À Universidade de São Paulo e à FEA pelo apoio institucional e pelas facilidades oferecidas. Ao CNPq pelo financiamento da pesquisa. 
“O problema da vida não é o que se decide.

É o que se deixa de decidir. Decisão tomada, segue-se em frente sem olhar para trás.” Edivaldo Bardella 


\section{RESUMO}

Apresentamos a teoria sobre mercados de dois lados, centralizados e descentralizados, para analisar o mercado de admissão de estudantes aos Centros de Pós-graduação em Economia no Brasil ao longo dos últimos 15 anos. Iniciamos descrevendo a história da organização deste mercado até a época atual. As falhas do sistema descentralizado e as hipóteses sobre o insucesso do procedimento centralizado de 1997 são discutidas. Observações empíricas são utilizadas para propor um modelo teórico que represente aproximadamente o atual mecanismo descentralizado e explique a aparente duradoura aplicação desse mecanismo. Por fim, tecemos considerações a respeito das possibilidades de aprimoramento deste mercado com modificações do mecanismo existente. 


\begin{abstract}
We present the theory of two-sided matching markets, with centralized and decentralized mechanisms, in order to analyze a Brazilian market in which graduated students seek positions in postgraduate programs in economics. We first describe the institutional history of this market. The failures of the decentralized procedure and the hypothesis about the failure of the 1997 centralized mechanism are discussed. Empirical observations are used to propose a theoretical model that represents the actual decentralized matching procedure of the market. Based in this model we explain the apparent long-lasting use of this decentralized mechanism. Finally, we make considerations about the possibilities of developments in this market by modifying the mechanism used today.
\end{abstract}




\section{SUMÁRIO}

1. INTRODUÇÃO

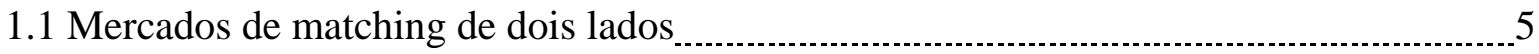

2. MODELO COOPERATIVO FORMAL PARA O MERCADO DE ADMISSÃO ÀS INSTITUIÇÕES

3. FORMAS DE ORGANIZAÇÃO DO MERCADO DE ADMISSÃO ÀS INSTITUIÇÕES

3.1 Mercado de admissão de médicos residentes a hospitais nos Estados Unidos _............ 16 4. MECANISMO CENTRALIZADO DE ADMISSÃO ÀS INSTITUIÇÕES _.................... 19

4.1 Algoritmo de Gale e Shapley com os candidatos fazendo as ofertas _......................... 20

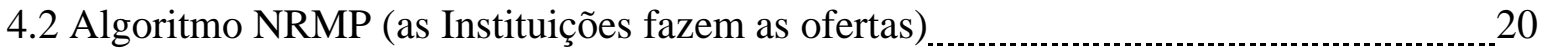

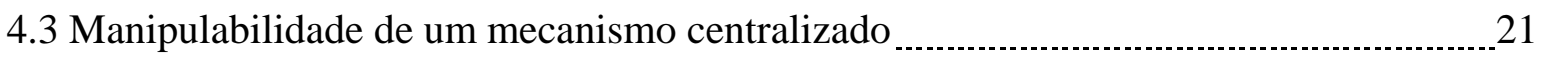

4.4 Razões de insucesso de mecanismos centralizados _.......................................... 27

4.4.1 Hipótese 1: Os mecanismos geram matchings instáveis _................................... 27

4.4.2 Hipótese 2: Mudanças nas condições de mercado, provocando diminuição da demanda dos candidatos pelas Instituições e conseqüente busca por parte das Instituições por arranjos fora do mecanismo $\ldots \ldots$

4.4.3 Hipótese 3: Falhas na implementação e operacionalização do mecanismo afetando a credibilidade dos participantes na alocação resultante

5. DESENHO DO MERCADO DA ANPEC 35

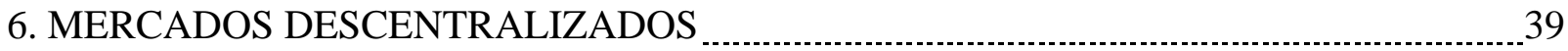

6.1 Mercado da ANPEC pós 1997: Mecanismo em vigor e observações empíricas _........... 40

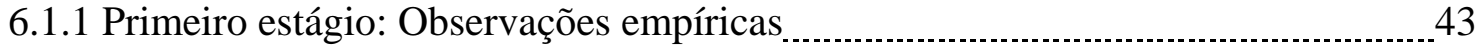

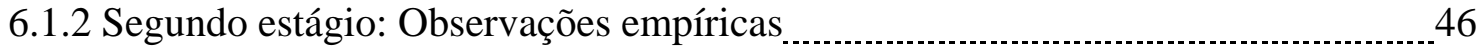

6.1.3 Resultado do matching: Observações empíricas _............................................. 47

6.1.4 Relatos de Centros e candidatos

6.2 Uma alternativa de aprimoramento do mercado descentralizado da ANPEC _.............. 57 
7.1 Hipótese 1: Os candidatos conhecem seus tipos no momento de declarar suas listas de Instituições aceitáveis

7.2 Hipótese 2: Os candidatos acreditam conhecer seus tipos no momento de declarar suas listas de Instituições aceitáveis, mas eles podem errar 72

7.3 Hipótese 3: Os candidatos não conhecem seus tipos no momento de declarar suas listas de Instituições aceitáveis

7.4 Comparação das simulações do modelo com o mercado da ANPEC

8. CONCLUSÃO E COMENTÁRIOS FINAIS

REFERÊNCIAS 90

APÊNDICE A 97 APÊNDICE B 101 APÊNDICE C 


\section{INTRODUÇÃO}

Desde o início da década de 80, a Associação Nacional dos Centros de Pós-Graduação em Economia - ANPEC - realiza anualmente um exame para classificar os candidatos à admissão nos cursos de pós-graduação em economia oferecidos pelos seus Centros Membros. Este exame consta de provas escritas sobre cinco disciplinas: Matemática, Estatística, Macroeconomia, Microeconomia e Economia Brasileira. Antes da realização das provas os candidatos apresentam à ANPEC uma lista de preferências, sem indicar as prioridades, em relação aos Centros Membros e os Centros apresentam uma lista de pesos para cada um dos exames, que será utilizado para computar o grau final dos candidatos. Após a realização dos exames a ANPEC divulga os graus dos estudantes e as respectivas classificações segundo os pesos de cada Centro. A partir de então, toda a interação entre Centros e candidatos é feita de forma descoordenada, com os Centros fazendo convites aos candidatos melhor colocados segundo seus critérios, dentre aqueles que os relacionaram em suas listas de preferências. Os candidatos, por sua vez, têm um prazo para aceitar os convites e, no caso de inicialmente receberem somente convites de Centros menos preferidos, devem decidir entre aceitá-los ou esperar por um convite de um Centro mais preferido. A partir de agora denominaremos “mercado da ANPEC” este processo de admissão de candidatos aos Centros de Pós-graduação em economia que adotam o exame da ANPEC como critério de seleção.

Conforme descrito em Sotomayor (1996a), muitos problemas foram observados ao longo dos anos neste mercado: os Centros menos procurados não conseguiam preencher suas vagas; alguns Centros desconsideravam os candidatos que não os tivessem escolhido em primeira opção por se sentirem desprestigiados e, consequentemente, alguns candidatos com rendimento mediano nos exames acabavam não sendo escolhidos por nenhum Centro; um candidato que recebia uma oferta após ter aceitado uma outra menos preferível, e um Centro que, para garantir o preenchimento de suas vagas, tivesse feito ofertas a candidatos menos preferidos se arrependiam das decisões tomadas. Para tentar contornar estes problemas, a ANPEC realizou várias mudanças na forma como os candidatos apresentavam suas listas de preferências. Até 1992 era solicitado que os candidatos relacionassem quatro Centros em ordem de preferência estrita. A partir de 1993 
os candidatos passaram a indicar somente três Centros sem revelar a ordem de preferências e, por fim, em 1996, esse número foi aumentado para seis, permanecendo a omissão de ordem por parte dos candidatos. Os Centros também mudavam sua forma de ação no mercado, aumentando ou reduzindo os prazos de resposta dados aos candidatos, na tentantiva de admitirem estudantes com melhores graus. Apesar de todas as mudanças, os problemas nunca foram totalmente resolvidos.

Em 1997, motivada pelo trabalho de Sotomayor (1996a), a ANPEC implementou uma forma coordenada de ação que produzia alocações estáveis em relação às preferências declaradas pelos estudantes e pelos Centros. Uma alocação é chamada estável se não exibe instabilidades. Uma alocação exibe uma instabilidade se existe um candidato potencial $c$ para algum Centro $i$, tal que $c$, ou não foi designado para nenhum Centro e prefere $i$ a ficar sem Centro, ou foi e prefere $i$ ao Centro para o qual foi designado; por sua vez, $i$, ou não preencheu todas as suas vagas e prefere admitir $c$ a ficar com vagas não preenchidas, ou o fez e prefere $c$ a algum dos estudantes designados a ele. Aconteceu que ainda observaram-se Centros que não conseguiram preencher todas as suas vagas na alocação final produzida pelo procedimento coordenado. Esses Centros buscaram arranjos subseqüentes para preencherem suas vagas remanescentes o que desencadeou uma série de instabilidades. Dessa forma, essas Instituições pressionaram a ANPEC para a volta do modelo antigo, o que foi concordado após votação apertada em 1998. Assim, voltou-se a aplicar o procedimento descoordenado, em que os candidatos indicam até seis Centros em sua lista de preferências sem revelar suas prioridades. Este procedimento tem sido usado, aparentemente sem nenhuma alteração, até os dias de hoje, o que nos sugere que as alocações resultantes têm sido, de certa forma, satisfatórias para Centros e candidatos.

A literatura existente sobre mercados de candidatos e Instituições indica que esses mercados evoluem naturalmente em direção a coordenação. Ou seja, com o crescimento dos mercados, os procedimentos descoordenados são repetidamente alterados até serem substituídos por um

procedimento coordenado que, em geral, permanece em aplicação de forma duradoura. A ANPEC experimentou este processo de mudanças no período compreendido entre o início da década de 90 e o ano de 1997, quando o procedimento coordenado foi implementado. No entanto, este procedimento coordenado implementado pela ANPEC foi abandonado no ano seguinte e o mercado voltou a funcionar de forma descoordenada. Desde então, o procedimento 
descoordenado aplicado neste mercado aparentemente não sofreu mudanças. Neste ponto surgem naturalmente duas questões intrigantes:

1) Por que o procedimento coordenado aplicado pela ANPEC em 1997, cujo modelo tem sido usado com sucesso em outros mercados, não foi bem sucedido e foi abandonado no ano seguinte?

2) Qual a diferença entre o mercado da ANPEC e os outros mercados encontrados na literatura que faz com que o procedimento descoordenado da ANPEC esteja em aplicação, aparentemente sem alterações, durante tanto tempo?

Todo o trabalho é organizado de forma a nos dar subsídio para responder às questões acima.

\subsection{Mercados de matching de dois lados}

O termo "dois lados” é usado para descrever mercados nos quais todos os participantes são de dois tipos distintos e um agente de um tipo não pode atuar no mercado como se fosse do outro tipo, por exemplo, o mercado de Centros de pós-graduação em economia no Brasil e de candidatos. Este mercado é diferente de um mercado de commodity, em que, a depender do preço, um agente pode ser vendedor ou comprador. Assim, como em qualquer mercado deste tipo, existem compradores e vendedores, mas a qualquer momento, um agente vendedor pode se tornar um agente comprador dependendo do preço vigente. Portanto, este não é um mercado de dois lados.

Como observado por Cournot, Edgeworth, Bohan-Barouk e outros, os mercados de dois lados são importantes, não somente pelos “insights” que eles podem dar para situações econômicas com muitos tipos diferentes de participantes, mas também porque em situações reais a maioria das transações são de fato bilaterais. 
Como descrito em Sotomayor (2005):

A Teoria de Matching para mercados de dois lados se iniciou com Gale e Shapley em 1962 com o artigo "College admissions and the stability of marriage". Ao longo dos anos, os modelos de matching de dois lados deixaram de constituir apenas um conjunto interessante de modelos matemáticos para se tornarem uma importante parte do campo de pesquisas emergente de Desenho de Mercados. Vêm contribuindo grandemente na compreensão do funcionamento de uma variedade de mercados, ajudando às Instituições que têm sido criadas para organizá-los. Atualmente existe uma vasta literatura, tanto teórica, quanto prática, referente a mercados de matching de dois lados.

Os mercados de matching de dois lados envolvem dois conjuntos finitos e disjuntos de participantes cuja atividade principal é a de formar parcerias com participantes do lado oposto. São exemplos de tais mercados certos mercados de trabalho de firmas e trabalhadores em nível de entrada, de médicos e hospitais, mercados de compra e venda, mercados de admissão de estudantes às universidades, dentre outros.

Neste trabalho vamos nos concentrar em mercados de dois lados que podem ser modelados como o "College Admission Model " introduzido por Gale e Shapley em 1962, que será denominado a partir de agora "Modelo de Admissão às Instituições". O modelo formal é descrito na próxima seção, a seguir. Na seção 3 apresentamos as formas de organização de mercados de dois lados, centralizados e descentralizados. Na seção 4 tratamos de mercados centralizados. Discutimos as razões pelas quais mecanismos centralizados têm falhado e apresentamos as observações do mercado da ANPEC em 1997. Na seção 5 identificamos alguns procedimentos que deveriam ser observados durante a transição de um mecanismo descentralizado para um mecanismo centralizado. Na seção 6 apresentamos alguns resultados experimentais sobre mercados descentralizados obtidos por Niederle e Roth em 2003, descrevemos uma série de observações do funcionamento do mecanismo descentralizado da ANPEC e discutimos uma alternativa de aprimoramento deste mercado descentralizado. Na seção 7 propomos um modelo teórico baseado nas observações sobre a organização atual do mercado da ANPEC e realizamos simulações deste modelo. Com base nos resultados obtidos propomos uma resposta à questão 2 acima e discutimos as possibilidades de aprimoramento do mercado da ANPEC com a aplicação de um mecanismo centralizado. Na seção 8 tecemos alguns comentários finais. No apêndice apresentamos alguns resultados já conhecidos sobre o modelo cooperativo formal descrito na seção 2, mostramos um retrato das alocações produzidas pelo mecanismo descentralizado da ANPEC nos últimos anos e reproduzimos todos os resultados simulados para o modelo teórico proposto na seção 7. 


\section{MODELO COOPERATIVO FORMAL PARA O MERCADO DE ADMISSÃO ÀS INSTITUIÇÕES}

Existem dois conjuntos finitos e disjuntos de participantes: $C$, com $m$ candidatos, e $I$, com $n$ Instituições. Cada Instituição $i$ possui uma cota $q_{i}$, representando o número de vagas que dispõe. Cada candidato $c$ tem uma ordenação de preferências estritas sobre o conjunto $I \cup\{c\}$. Denotaremos por $P(c)$ a lista de preferências de $c$. As Instituições aceitáveis para $c$ são aquelas preferíveis por $c$ a si mesmo. Portanto, se $P(c)=i_{1}, i_{4}, c$ e $I=\left\{i_{1}, i_{2}, i_{3}, i_{4}\right\}$, então $c$ deseja ingressar em $i_{1}$ e $i_{4}$, nesta ordem, mas $c$ prefere não ingressar em nenhuma Instituição a ingressar em $i_{2}$ ou $i_{3}$. Dadas duas Instituições $i$ e $i$, indicaremos que o candidato $c$ prefere (estritamente) $i$ a $i$ ' pela notação $i>_{c} i$ ' e indicaremos que $c$ prefere (estritamente) ingressar em $i$ a não ser admitido por nenhuma Instituição pela notação $i>_{c} c$. A preferência não estrita será denotada por $\geq_{c}$. Denotaremos por $P_{C}$ o conjunto de preferências de todos os candidatos, $P_{C}=\left\{P\left(c_{1}\right), P\left(c_{2}\right), \ldots\right.$, $\left.P\left(c_{m}\right)\right\}$. Representaremos por $P_{C} / P^{\prime}(c)$ o conjunto de preferências obtido de $P_{C}$ pela substituição de $P(c)$ por $P^{\prime}(c)$, mantendo as outras preferências inalteradas. Denotaremos que $i$ prefere (estritamente) $c$ a $c^{\prime}$ por $c>_{i} c^{\prime}$. Para a preferência não estrita usaremos $\geq_{i}$. Estaremos assumindo que as preferências das Instituições sobre grupos de candidatos são correspondentes às suas preferências sobre candidatos individualmente, isto é, se $A$ é um conjunto de candidatos com cardinalidade menor do que $q_{i}$ e $c$ e $c^{\prime}$ são dois candidatos não pertencentes ao conjunto $A$, então $A \cup\{c\}>_{i} A U\left\{c^{\prime}\right\}$ se e somente se $c>_{i} c^{\prime}$. Esse tipo de preferência é conhecido na literatura como "preferências correspondentes”. Denotaremos por $P_{I}$ o conjunto de preferências de todas as Instituições, $P_{I}=\left\{P\left(i_{1}\right), P\left(i_{2}\right), \ldots, P\left(i_{n}\right)\right\}$. Denotaremos por $P=\left\{P_{C}, P_{I}\right\}$ o sistema de preferências de candidatos e Instituições. Representaremos por $P / P^{\prime}(c)$ o sistema de preferências obtido de $P$ pela substituição de $P(c)$ por $P^{\prime}(c)$, mantendo as outras preferências inalteradas. Finalmente, o mercado é representado por $M=(C, I, P, q)$, onde $q$ é o vetor de cotas das Instituições.

A função do mercado é encontrar um matching, isto é, uma alocação dos candidatos para as Instituições que respeite as cotas dos participantes. Cada candidato é designado a, no máximo, uma Instituição; cada Instituição pode admitir, no máximo, sua cota de candidatos. O candidato 
que não for admitido por nenhuma Instituição será designado a si mesmo e será chamado “autodesignado”. Uma Instituição que tiver algum número de vagas não preenchidas será designada a si mesma em cada uma dessas vagas. Um matching é bilateral, no sentido que, se um candidato é designado a uma Instituição então o candidato pertence ao grupo ao qual a Instituição foi designada. Formalmente:

Definição 1. Um matching $\mu$ é uma função do conjunto $C \cup I$ no conjunto das famílias não ordenadas de elementos de C UI tal que:

1. $\mu(c)$ tem um elemento para todo candidato c e se $\mu(c) \notin I$ então $\mu(c)=c$;

2. $\mu(i)$ tem $q_{i}$ elementos para toda Instituição $i$, e se o número de candidatos em $\mu(i)$ for menor que $q_{i}$, digamos $k$, então $\mu(i)$ contém $q_{i}-k$ cópias de $i$;

3. $\mu(c)=i$ se e somente se c estiver em $\mu(i)$

Assim $\mu(c)=i$ denota que o candidato $c$ foi designado à Instituição $i$ pelo matching $\mu, \mu(i)=\left\{c_{l}\right.$, $c_{2}, i, i$ \} denota que a Instituição $i$, com cota de 4, admitiu os candidatos $c_{1}$ e $c_{2}$ e tem duas vagas não preenchidas. Representaremos matchings graficamente, por exemplo,

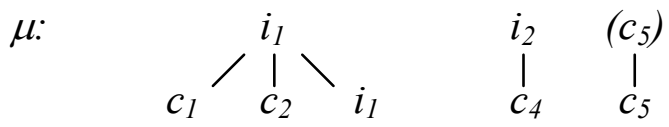

representa um matching no qual a Instituição $i_{1}$, com três vagas, admite dois candidatos $c_{1}$ e $c_{2}$; a Instituição $i_{2}$, com uma vaga, admite o candidato $c_{4}$, e o candidato $c_{5}$ é auto-designado.

Definição 2. Um matching $\mu$ é individualmente racional se para todo par $(c, i)$ tal que $\mu(c)=i$, c é aceitável para i e i é aceitável para c.

Definição 3. Um matching $\mu$ é estável se é individualmente racional e não existem um candidato c e uma Instituição $i$, não associados pelo matching $\mu$ e tal que i) $i>_{c} \mu(c)$ e ii) $c>_{i} \tau$, para algum $\tau$ em $\mu(i)$. 
Portanto, num matching estável, todos os pares associados pelo matching são mutuamente aceitáveis. Além disso, não existem um candidato e uma Instituição, não designados um ao outro pelo matching, tal que o candidato prefere a Instituição àquela a qual foi designado e, paralelamente, a Instituição em questão prefere este candidato a algum candidato designado à ela pelo matching. Um candidato $c$ e uma Instituição $i$, como na Definição 3, são ditos bloquear $o$ matching $\mu$ ou causar uma instabilidade em $\mu$.

Definição 4. $O$ matching estável $\mu_{C}$ é chamado ótimo para os candidatos se $\mu_{C}(c) \geq_{c} \mu(c)$ para todo candidato c e para todo matching estável $\mu$. O matching estável $\mu_{I}$ é chamado ótimo para as Instituições se $\mu_{I}(i) \geq_{i} \mu(i)$ para toda Instituição i e para todo matching estável $\mu$.

A existência de matchings estáveis para este modelo foi demonstrada por Gale e Shapley (1962) por meio de um algoritmo que produz o matching estável ótimo para os candidatos. Revertendose os papéis entre candidatos e Instituições no algoritmo obtém-se o matching estável ótimo para as Instituições. Uma demonstração não construtiva da existência de matchings estáveis foi obtida em Sotomayor (1996b) através de uma nova abordagem que enfoca matchings onde somente participantes de um dado lado, que não estão negociando, podem participar de um par bloqueante. Esta abordagem vem sendo utilizada com êxito para tratar de problemas de existência em jogos coalizionais mais complexos. (Ver Sotomayor (2005a), (2005b)). Ao longo deste trabalho denotaremos por $\mu_{C}$ (resp. $\mu_{I}$ ) o matching estável ótimo para os candidatos (resp. Instituições) para o mercado $(C, I, P, q)$.

Definição 5. Uma Instituição i é dita alcançável para um candidato c se existir um matching estável $\mu$ tal que $\mu(c)=i$. Analogamente, um candidato c é dito alcançável para uma Instituição $i$ se existir um matching estável $\mu^{\prime}$ tal que $c \in \mu^{\prime}(i)$.

Decorre da Proposição A5 (Apêndice A) e da Definição 5 que $\mu_{I}(i)$ é o conjunto dos $q_{i}$ mais preferidos candidatos alcançáveis para $i$. 


\section{FORMAS DE ORGANIZAÇÃO DO MERCADO DE ADMISSÃO ÀS INSTITUIÇÕES}

Existem na literatura registros de diversos tipos de mercados de matching de dois lados que podem ser modelados como um “Mercado de Admissão às Instituições”. Esses mercados podem diferir em relação à forma de organização: regras para submissão das listas de preferências; forma de condução das ofertas; determinação do tempo de espera em relação à resposta de ofertas; existência ou não de um agente que recebe as listas de preferências e coordena o matching, etc. Denominam-se mercados centralizados aqueles em que o matching é realizado de forma coordenada, a partir das listas de preferências, entre os participantes, com a presença, ou não, de um “agente centralizador”. Quando há a presença deste agente, o matching é exclusivamente definido por ele, sem a participação dos demais participantes. O resultado do matching é comunicado aos candidatos e Instituições, que nada mais podem fazer. Os mercados descentralizados são aqueles em que não existe o agente centralizador e o matching é realizado descoordenadamente, pelos próprios participantes, através de negociação segundo suas listas de preferências.

Na granda maioria dos casos existentes na literatura, os mercados de dois lados historicamente migram da forma de organização descentralizada para a forma centralizada. Em muitos dos casos a organização centralizada se torna duradoura enquanto que em outros os mercados retornam à organização descentralizada.

Roth e Xing (1994) investigaram uma variedade de mercados de dois lados com diversos tipos de organização e propuseram uma classificação para o grau de evolução temporal desses mercados, em quatro diferentes estágios, que tende, naturalmente, em direção à centralização. A tabela 1 reproduz os resultados obtidos por Roth e Xing (1994). 
Tabela 1 - Mercados de matching de dois lados e sua organização

\begin{tabular}{|c|c|c|}
\hline Mercado & Agente Organizador & Estágio \\
\hline Postseason college football bowls & $\begin{array}{l}\text { National Collegiate Athletic Association } \\
\text { (NCAA) }\end{array}$ & 1 e 3 \\
\hline \multicolumn{3}{|c|}{ Acesso ao Mercado de Trabalho - Firmas e Trabalhadores } \\
\hline Federal court clerkships & Judicial conferences & 2,1 \\
\hline American law firms & National Student Matching Program & 1 \\
\hline Canadian articling positions & Articling Student Matching Program & \\
\hline Toronto & & 4 \\
\hline Vancouver & & 3 ou 4 \\
\hline Alberta (Calgary and Edmonton) & & 3 \\
\hline \multicolumn{3}{|c|}{ Acesso a Escolas de Business } \\
\hline New MBA’s & & 1 \\
\hline New marketing professors & & 1 \\
\hline \multicolumn{3}{|c|}{ Acesso ao Mercado de Trabalho } \\
\hline Japanese university graduates & Ministry of Labor: Nikkeiren & 2 \\
\hline Clinical psychology internships & $\begin{array}{l}\text { Association of Psychology Internship } \\
\text { Centers }\end{array}$ & 2 \\
\hline $\begin{array}{l}\text { Dental residencies (3 especialidades e } 2 \\
\text { programas gerais) }\end{array}$ & Postdoctoral Dental Matching Program & 3 \\
\hline Optometry residencies & Optometric Residency Matching Services & 1 e 3 \\
\hline \multicolumn{3}{|c|}{ Outros Mercados de Dois Lados } \\
\hline Fraternity rush & & 1 \\
\hline Sorority rush & National Panhellenic Conference & 3 \\
\hline \multicolumn{3}{|c|}{ Acesso a Residências Médicas nos EUA e Canadá } \\
\hline $\begin{array}{l}\text { American first-year postgraduate (PGY1) } \\
\text { positions }\end{array}$ & $\begin{array}{l}\text { National Resident Matching Program } \\
\text { (NRMP) }\end{array}$ & 3 \\
\hline Canadian first-year positions & $\begin{array}{l}\text { Canadian Intern \& Resident Matching } \\
\text { Service }\end{array}$ & 3 \\
\hline \multicolumn{3}{|c|}{ Acesso a Residências Médicas no Reino Unido } \\
\hline Edinburgh & Regional health authorities & 3 \\
\hline Cardiff & Regional health authorities & 3 \\
\hline Birmingham & Regional health authorities & 4,1 \\
\hline Newcastle & Regional health authorities & 4,1 \\
\hline Sheffield & Regional health authorities & 3 ou 4,1 \\
\hline Cambridge & Regional health authorities & 3 \\
\hline
\end{tabular}




\begin{tabular}{|l|l|l|}
\hline London Hospital Acesso a Outras Especialidades de Residência nos EUA & 4 \\
\hline \multicolumn{2}{|c|}{ Regional health authorities } \\
\hline Ophthalmology & & 3 \\
\hline Otolaryngology & Otolaryngology Matching Program & 3 \\
\hline Urology & AUA Residency Matching Program & 3 \\
\hline Radiation Oncology & Radiation Oncology Matching Program & 1 e 3 \\
\hline Other specialties Acesso a Especialidades Médicas Avançadas nos EUA & 3 e 4 \\
\hline & NRMP & 3 \\
\hline 12 surgical specialties & Specialties Matching Services & 3 \\
\hline 3 medial subspecialties & Medial Specialties Matching Prog. & 3 \\
\hline 4 ophthalmology subspecialties & Ophthalmology Fellowship Match & 3 \\
\hline Plastic surgery & Plastic Surgery Matching Program & \multicolumn{2}{|l}{} \\
\hline
\end{tabular}

Cada um dos estágios é descrito a seguir:

Estágio 1: Em geral, os mercados de dois lados, quando são formados, se iniciam no estágio 1. A organização do mercado é descentralizada, sem padronização em relação ao momento em que as ofertas devem ser feitas nem em relação ao prazo de resposta (No exemplo do mercado de pósgraduação em economia no Brasil, quando os primeiros Centros ofereceram vagas para seus cursos, o fizeram de forma descoordenada e sem nenhuma padronização). Tem-se observado que à medida que o mercado cresce, aumentando o número de Instituições e candidatos, os participantes passam a fechar acordos cada vez mais cedo, devido à competição das Instituições pelos melhores candidatos. Este fenômeno é conhecido na literatura como “antecipação”. Paralelamente, os prazos de resposta tendem a ficar cada vez mais reduzidos para evitar ofertas abertas, enquanto outros participantes fecham acordos. Este tipo de oferta tende a evoluir para a “oferta explosiva”, em que o candidato é pressionado a aceitar ou recusar a oferta no momento em que a recebe. Para os participantes dos dois lados emerge, neste contexto, uma grande variedade de possíveis comportamentos estratégicos. O estágio 1 termina quando as primeiras normas de conduta são impostas para frear o processo de antecipação, fato que marca o início do estágio 2, ou quando o mercado implementa um mecanismo centralizado, o que marca o início do estágio 3. 
Estágio 2: É caracterizado por um mercado descentralizado, mas com normas definindo o período em que as ofertas devem ser feitas e, às vezes, o prazo em que elas devem permanecer abertas. Este estágio se estende até o momento em que um mecanismo centralizado é implementado, o que marca o início do estágio 3, ou até o momento em que as normas são abandonadas, o que marca o retorno ao estágio 1.

No início do estágio 2, geralmente é constituída uma associação das Instituições que estabelece as regras para tentar frear o processo de antecipação. É estabelecida uma data antes da qual nenhuma oferta pode ser feita e um período mínimo em que a oferta deve permanecer válida para o candidato. No entanto, os participantes ainda têm incentivo de burlar as regras e fazer ofertas mais cedo. Quando isso ocorre, aqueles que as obedeceram percebem que estão em desvantagem e têm incentivo ainda maior de não cumprir as datas no ano seguinte. Dessa forma, quando não há, por parte da associação, um mecanismo para assegurar a todos que as regras serão cumpridas, essa tentativa de organização do mercado tende a não ser bem sucedida e o mercado retorna ao estágio 1.

Por outro lado, quando as regras são estabelecidas e mantidas, o mercado geralmente apresenta congestionamento e comportamento caótico nos momentos próximos às datas limites de aceitação das ofertas. Cada Instituição deseja saber se as ofertas feitas serão respondidas a tempo de, em caso de rejeição, fazer ofertas aos próximos candidatos na sua lista de preferências antes que estes tenham aceitado alguma outra oferta. E os candidatos, que receberam ofertas de Instituições que não são as suas preferidas, desejam esperar até o último momento antes de aceitá-las, na esperança de receber ofertas melhores. Geralmente uma parcela dos candidatos recebe e mantém em aberto mais de uma oferta até o final do prazo que lhes foi dado para responder. Isto significa que, momentos antes da data limite, muitos arranjos ainda devem ser feitos. As Instituições que têm suas primeiras ofertas recusadas podem, por exemplo, perceber que os próximos candidatos da sua lista já aceitaram outras ofertas e, alguns candidatos que já haviam aceitado alguma oferta anterior podem, ainda, receber ofertas mais preferidas. Em alguns mercados os compromissos podem ser desfeitos, enquanto em outros eles devem ser honrados. Em ambos os casos, quando se encerra a data limite para fazer os arranjos, podem existir Instituições e candidatos que gerem instabilidades no matching. Quando isso ocorre é natural que, 
para o matching seguinte, os participantes desenvolvam comportamentos estratégicos para evitar arranjos próximos da data limite, e então, em conseqüência disso, novas regras são estabelecidas. Após algum tempo experimentando este processo, alguns mercados abandonam as regras e retornam ao estágio 1, enquanto outros implementam um mecanismo centralizado e avançam ao estágio 3.

Estágio 3: É caracterizado por um mercado centralizado, sem processo de antecipação. Inicia-se quando um mecanismo centralizado de matching é implementado, com a participação de forma voluntária ou obrigatória das Instituições e dos candidatos. Os participantes normalmente podem previamente fazer contatos diretos para adquirir informações uns dos outros, mas depois se submetem ao procedimento centralizado de matching, ao invés de fazer seus arranjos independentemente do mecanismo. Alguns mercados implementam o mecanismo centralizado quando já estão em processo de antecipação acentuado. Outros o implementam como uma forma de prevenir um futuro processo de antecipação.

Há na literatura pelo menos três classes distintas de procedimentos centralizados, mas uma destaca-se como a utilizada na grande maioria dos mercados que se encontram no estágio 3 de evolução: o mecanismo com "agente centralizador”. Este é um "mecanismo de revelação das preferências” operacionalizado por uma Central que recebe as listas ordenadas de preferências das Instituições e dos candidatos e determina um matching segundo alguma regra préestabelecida ou algoritmo. A partir deste ponto, quando falarmos em mecanismo centralizado, estaremos sempre nos referindo ao mecanismo com agente centralizador.

Uma segunda classe de procedimento centralizado é o mecanismo de "seleção ordenada". Segundo este procedimento, as Instituições são ordenadas por algum critério pré-estabelecido e cada Instituição seleciona um candidato por vez. Dessa forma, somente as preferências das Instituições são consideradas. Em muitas categorias esportivas nos Estados Unidos, os atletas recém profissionalizados são contratados pelas equipes esportivas segundo este mecanismo. A terceira classe é o procedimento que ocorre no mercado de equipes e empresários de futebol americano nos Estados Unidos. Existe um complexo sistema de contratos sobrepostos entre 
equipes, grupos de equipes, empresários e grupos de empresários que definem as equipes que disputarão os jogos finais da temporada.

Embora raramente, os mecanismos centralizados podem não ser bem sucedidos e, conseqüentemente, abandonados em alguns mercados, que retornam ao estágio 1. No entanto, há muitos exemplos de mecanismos centralizados que são duradouros e, para estes mercados, o estágio 3 é o estágio final de evolução.

Estágio 4: É caracterizado por um mercado centralizado com presença de processo de antecipação no período anterior à aplicação do mecanismo centralizado. Os participantes podem formar acordos vantajosos anteriormente e utilizar o mecanismo somente como ferramenta de formalização desses arranjos. Com o tempo, o processo de antecipação se acentua e o mecanismo centralizado acaba sendo abandonado, com o mercado retornando ao estágio 1.

\subsection{Mercado de admissão de médicos residentes a hospitais nos Estados Unidos}

O exemplo mais conhecido de um mercado de de dois lados que evoluiu da forma de organização descentralizada para a centralizada, passando pelos estágios 1,2 e 3, é o mercado de médicos residentes e hospitais nos Estados Unidos. Os programas de residência médica para médicos recém graduados em hospitais nos Estados Unidos foram iniciados no começo do século XX. Nos primeiros anos, os hospitais conduziam seus processos de seleção de residentes durante o último trimestre dos cursos de medicina. Com a abertura de novos programas de residências, surgiu uma competição natural dos hospitais pelos melhores cadidatos. Com isso, no intuito de abordar primeiro os candidatos e, assim, admitirem os melhores médicos, alguns hospitais passaram a fazer suas seleções no início do último semestre dos cursos de medicina. Este é o início do processo de antecipação. Os demais hospitais também se sentiram obrigados a anteciparem seus processos de seleção ano a ano. Dessa forma, o processo de antecipação se acentuou até que, no anos 40, as seleções dos hospitais estavam sendo feitas no início do "junior year” dos cursos de medicina, ou seja, dois anos antes dos estudantes se formarem. Com isso, os alunos se prejudicavam nas atividades do curso de medicina para participarem dos processos 
seletivos. Nessa fase o mercado se encontrava no estágio 1, com o processo de antecipação bastante acentuado. Durante este período, algumas medidas para tentar frear o processo foram tomadas pela Associação Americana de Faculdades de Medicina e pela Associação Americana de Hospitais, sempre sem sucesso. O mercado já estava tentando avançar ao estágio 2. Finalmente, em 1945, a Associção Americana de Faculdades de Medicina determinou que nenhuma informação sobre os alunos dos cursos de medicina seriam enviadas aos hospitais antes de uma data pré-estabelecida. Com esta medida, o processo de antecipação foi vencido e os hospitais passaram novamente a fazer suas seleções durante o último ano dos cursos de medicina. Nesta fase o mercado experimentava o estágio 2. No entanto, nos anos seguintes, os hospitais passaram a conceder prazos de resposta cada vez mais reduzidos, no intuito de não ficarem com ofertas em aberto por muito tempo. Os prazos se reduziram ano a ano até que as ofertas passaram a ser explosivas.

Em 1951 foi implementado o mecanismo centralizado com “agente centralizador”, inicialmente em caráter experimental e, a partir de 1952, em caráter definitivo. Os candidatos e hospitais declaravam suas listas de preferências e o “agente centralizador”, chamado National Resident Matching Program - NRMP, localizado em Evanston, Illinois, realizava o matching. Este procedimento centralizado foi utilizado até 1998, realizando anualmente a alocação dos médicos às 20.000 vagas oferecidas pelos hospitais. Portanto, este mercado evoluiu até o estágio 3 e se tornou duradouro. Em 1998 o procedimento foi alterado de forma a incentivar os casais de médicos a participarem. Estes, cada vez mais, estavam preferindo fazer seus arranjos com os hospitais independentemente do mecanismo.

Podemos considerar que este mercado nos ofereceu uma das maiores aplicações de Teoria do Jogos à Economia. A constatação da teoria na prática. De fato, através de um experimento realizado por cerca de cinqüenta anos, os jogadores desse mercado aprenderam a jogar em “equilíbrio”.

Gale e Sotomayor (1985) mostraram que a alocação produzida desde então tem sido uma alocação estável, e, portanto, segundo a Teoria do Jogos, uma alocação de equilíbrio cooperativo. 


\section{MECANISMO CENTRALIZADO DE ADMISSÃO ÀS INSTITUIÇÕES}

Este é o procedimento de alocação dos participantes mais utilizado em mercados centralizados. Este mecanismo utiliza como "input” as preferências submetidas pelos participantes para algum algoritmo que produz como “output” um matching entre eles.

Um tal mecanismo induz um jogo na forma estratégica. Os jogadores são os candidatos e as Instituições; o conjunto de estratégias de cada jogador são todas as possíveis listas ordenadas de preferências deste jogador sobre os jogadores do lado oposto. Em cada jogada, cada participante se depara com a situação de decidir que estratégia selecionar. Como se espera que um jogador deva se comportar quando é chamado a tomar suas decisões e a explicação desse comportamento são os assuntos de interesse central da Teoria dos Jogos Não Cooperativos.

Tendo cada participante escolhido sua estratégia, o mecanismo, então, produz um matching. Naturalmente os jogadores avaliam matchings em termos de suas verdadeiras preferências. São estas verdadeiras preferências que determinam seu comportamento.

Um mecanismo é estável se ele produz sempre um matching estável para as preferências submetidas.

Gale e Shapley descobriram em 1962 um algoritmo que produz um matching estável, num número finito de etapas, que é proporcional ao quadrado do número de candidatos e Instituições. O matching obtido por este modo é o matching estável ótimo para os candidatos. Invertendo-se os papéis, no algoritmo, entre candidatos e Instituições, obtém-se o matching estável ótimo para as Instituições. Este algoritmo tem sido usado como mecanismo de alocação em inúmeros mercados. A National Resident Matching Program - NRMP, por exemplo, utilizou de 1951 a 1998 um algoritmo equivalente ao algoritmo de Gale e Shapley que produz o matching estável ótimo para as Instituições, como procedimento de alocação dos médicos residentes nos hospitais dos EUA. Este mercado apresenta grande similaridade com o mercado da ANPEC. As duas formas do algoritmo de Gale e Shapley são apresentadas a seguir. 


\subsection{Algoritmo de Gale e Shapley com os candidatos fazendo as ofertas}

A seguinte descrição é cotada de Sotomayor (1996a):

Cada candidato se candidata à admissão na sua Instituição favorita, isto é, na primeira Instituição de sua lista. As Instituições com excesso de candidatos aceitarão, temporariamente, os melhores candidatos que preencherem as suas vagas e rejeitarão os demais. Esta é a primeira etapa do algoritmo. Na segunda etapa, os candidatos rejeitados se candidatam à admissão na sua segunda Instituição favorita e novamente as Instituições com excesso de candidatos preencherão as suas vagas, temporariamente, com os melhores candidatos e rejeitarão os demais, etc. O algoritmo terminará quando todo candidato for admitido temporariamente ou tiver sido rejeitado por todas as Instituições de sua lista.

Daqui para frente nos referiremos a este algoritmo simplesmente como algoritmo de GaleShapley.

\subsection{Algoritmo NRMP (as instituições fazem as ofertas)}

A descrição deste algoritmo é também cotada de Sotomayor (1996a):

Cada Instituição $i$, com $q_{i}$ vagas, faz uma oferta de admissão aos $q_{i}$ candidatos mais preferidos de sua lista. Os candidatos que receberem ofertas de mais do que uma Instituição aceitarão, temporariamente, aquela que eles preferirem e recusarão as outras. Seus nomes são então removidos das listas de todas as Instituições cujas ofertas tenham sido recusadas por eles. Esta é a primeira etapa do algoritmo. As Instituições que não tiverem preenchido suas vagas, novamente, farão uma oferta ao conjunto de candidatos mais preferidos de suas listas de forma a não ultrapassar a sua cota. Os candidatos que receberem novas ofertas, novamente rejeitarão todas, exceto a sua favorita. Esta é a segunda etapa, etc. O algoritmo terminará quando, depois de alguma etapa, nenhuma Instituição puder fazer mais ofertas, ou porque sua cota estiver preenchida, ou porque já tiver esgotado sua lista.

Um simples exemplo com dois candidatos e duas Instituições mostra que os dois algoritmos acima não necessitam dar o mesmo resultado. Além disso, o matching estável ótimo para os candidatos (resp. Instituições) é o pior matching para as Instituições (resp. candidatos). (Ver Roth e Sotomayor, 1990).

Além da estabilidade é desejável que um mecanismo centralizado gere incentivo para que os participantes declarem suas verdadeiras preferências, pois, dessa forma, o resultado do matching será estável em relação às verdadeiras preferências dos participantes. Isto ocorre quando um 
participante não tem nenhum benefício em adulterar suas preferêcias no momento de submetê-las ao mecanismo. Este é o conceito de manipulabilidade de um mecanismo, que é detalhado na seção a seguir.

\subsection{Manipulabilidade de um mecanismo centralizado}

Suponha que um mecanismo estável é utilizado e um grupo de participantes tenha informação completa sobre as preferências de todos os outros. A questão é então saber se este grupo poderia tirar vantagem disto, informando preferências diferentes de suas verdadeiras preferências.

Um mecanismo é à prova de estratégia ou não manipulável individualmente se, em todo jogo induzido pelo mecanismo, nenhum jogador puder se beneficiar por usar como estratégia um conjunto de preferências diferente das suas verdadeiras preferências. Um mecanismo é coletivamente não manipulável se em todo jogo induzido pelo mecanismo nenhum conjunto de jogadores puder, adulterando suas verdadeiras preferências, obter um resultado mais vantajoso para cada um de seus membros.

Se um mecanismo estável é à prova de estratégia, em qualquer jogo induzido por este mecanismo cada participante tem o incentivo de revelar suas verdadeiras preferências, o que garante a estabilidade dos resultados em relação a estas preferências. Infelizmente, não existe nenhum mecanismo estável que seja não manipulável (ver Roth (1982) e Roth e Sotomayor (1990)) ${ }^{1}$. Entretanto, o mecanismo de matching que produz sempre o matching estável ótimo para os candidatos é não manipulável individualmente e coletivamente pelos candidatos (mas ainda é manipulável pelas Instituições). De fato, Dubins e Freedman mostraram que nenhum conjunto de candidatos pode, adulterando suas preferências, forçar um matching que seja preferível ao matching estável ótimo para os candidatos por todos os candidatos do conjunto. Formalmente,

\footnotetext{
${ }^{1}$ Encontrar condições que garantam a existência de um mecanismo estável não manipulável tem sido objeto de interesse de alguns autores. Nesta direção podemos citar Alcalde e Barberà (1994) que provaram que se o domínio das preferências das Instituições for restrito a uma certa classe de preferências, o mecanismo estável ótimo para os candidatos é não manipulável. O mesmo resultado foi obtido em Sotomayor (1996a), supondo que as preferências das Instituições são fixas.
} 
Teorema 1 - Teorema da Não-manipulabilidade. (Dubins-Friedman (1981) e Gale e Sotomayor (1985)). Seja P uma estrutura de preferências para os candidatos e Instituições. Seja P' obtida de $P$ pela substituição de $P(c)$ por $P^{\prime}(c)$ para todo $c \in C^{\prime}$. Então não existe nenhum matching estável para $P^{\prime}$, que seja preferido ao matching estável ótimo para os candidatos por todos os membros de C'.

Em 1985, Roth mostrou que o mecanismo que produz o matching estável ótimo para as Instituições não é à prova de estratégia (isto é, é manipulável individualmente), nem para as Instituições e nem para os candidatos.

Quando as Instituições têm a possibilidade de jogar qualquer lista de preferências e, portanto, o mecanismo que produz o matching estável ótimo para os candidatos se torna manipulável por elas, uma forma de manipulação natural para uma Instituição é submeter sua lista de preferências verdadeira truncada. Seja a lista de preferências verdadeira de uma Instituição $i, P(i)=c_{2}, c_{4}, c_{l}$, $c_{5}, c_{6}, i$. Uma lista $P^{\prime}(i)$ é uma lista de preferências verdadeira truncada se $P^{\prime}(i)$ é obtida de $P(i)$, pela remoção de todos os candidatos menos preferidos que um $c_{j} \operatorname{com} c_{j}$ pertencente a $P(i)$, por exemplo, $P^{\prime}(i)=c_{2}, c_{4}, c_{1}, i$. Diremos que uma Instituição manipula “por truncagem” quando ela se beneficia submetendo ao mecanismo uma lista de preferências verdadeira truncada. A Proposição 1 nos dá condições suficientes para que o mecanismo que produz o matching estável ótimo para os candidatos seja manipulável individualmente por uma Instituição por truncagem.

Proposição 1. Considere o mercado $(C, I, P, q)$ e uma Instituição $i$. Se $\mu_{I}(i) \neq \mu_{C}(i)$ então a Instituição $i$ pode manipular por truncagem qualquer mecanismo estável. Se o mecanismo produz o matching estável ótimo para os candidatos então $i$ pode obter $\mu_{I}(i)$.

Demonstração: Seja $q_{i}$ a cota de $i$. Como $\mu_{I}(i) \neq \mu_{C}(i)$ então $i$ preenche sua cota em $\mu_{C}$ e em $\mu_{\text {I }}$, pela Proposição A2 do apêndice A. Pela Proposição A1, $i$ preenche sua cota em qualquer outro matching estável para $(C, I, P, q)$. Como $\mu_{C}(i) \neq \mu_{I}(i)$ temos que $\mu_{I}(i)>_{i} \mu_{C}(i)$ pela Definição 4. Seja $c_{m}$ o candidato menos preferido por $i$ em $\mu_{I}(i)$. Trunque a lista de preferências verdadeira de $i$ em $c_{m}$. Chame a nova lista de $P^{\prime}(i)$. Seja $\mu$ o matching estável para $(C, I, P, q)$ produzido pelo mecanismo. É claro que $\mu_{I}$ é estável para $M^{\prime}=\left(C, I, P / P^{\prime}(i), q\right)$. Como $i$ preenche suas vagas em $\mu_{I}$ 
temos, pela Proposição A1, que $i$ preenche suas vagas em $\mu^{\prime}$, o matching estável para $M^{\prime}$ produzido pelo mecanismo. Vamos mostrar que $\mu^{\prime}(i) \geq_{i} \mu_{I}(i)$. De fato, caso contrário, existiria um candidato $c \in \mu^{\prime}(i)-\mu_{I}(i)$ e $c_{m}>_{i} c$, pela Proposição A5. Mas isto é um absurdo desde que a nova lista está truncada em $c_{m}$. Então, truncando sua lista de preferências verdadeira em $c_{m}$, a Instituição $i$ obtém $\mu^{\prime}(i)$, com $\mu^{\prime}(i) \geq_{i} \mu_{I}(i)>_{i} \mu_{C}(i) z_{i} \mu(i)$. Logo, $\mu^{\prime}(i)>_{i} \mu(i)$ e $i$ consegue manipular o mecanismo. Para ver que $i$ obtém $\mu_{I}(i)$ quando o mecanismo produz o matching estável ótimo para os candidatos observe que $\mu_{I}(i) \geq_{i} \mu^{\prime}(i)$, pela Proposição A6. Daí segue que $\mu^{\prime}(i)=\mu_{I}(i)$, como queríamos demonstrar.

No entanto, a condição da Proposição 1 para a possibilidade de manipulação por truncagem de uma Instituição é uma condição suficiente mas não necessária. Podemos demonstrar este fato com o exemplo abaixo.

Exemplo 1. Considere o seguinte mercado com três Instituições $\left\{i_{1}, i_{2}, i_{3}\right\}$ e quatro candidatos $\left\{c_{1}, c_{2}, c_{3}, c_{4}\right\}$. A Instituição $i_{1}$ tem cota dois e as outras duas têm cota um. As listas de preferências verdadeiras são dadas a seguir:

$$
\begin{gathered}
P\left(i_{1}\right)=c_{1}, c_{2}, c_{3}, c_{4} \\
P\left(i_{2}\right)=c_{3}, c_{1}, c_{4} \\
P\left(i_{3}\right)=c_{2}, c_{4} \\
P\left(c_{1}\right)=i_{2}, i_{1} \\
P\left(c_{2}\right)=i_{3}, i_{1} \\
P\left(c_{3}\right)=i_{1}, i_{2} \\
P\left(c_{4}\right)=i_{1}, i_{2}, i_{3}
\end{gathered}
$$

Nesse mercado o matching estável ótimo para os candidatos é igual ao matching estável ótimo para as Instituições. Dessa forma, aplicando os algoritmos de Gale-Shapley e NRMP encontramos $\mu_{C}=\mu_{\text {I. }}$

$$
\mu_{C}=\mu_{I}:\left.\quad \overbrace{c_{3} c_{4}}^{i_{1}}{\stackrel{l}{c_{1}}}_{c_{2}}^{i_{2}}\right|_{c_{3}} ^{i_{3}}
$$


Suponha que $i_{1}$ tente manipular o mecanismo que produz o matching estável ótimo para os candidatos declarando a lista truncada $P^{\prime}(i)=c_{1}, c_{2}$. Se todos os outros jogadores declaram suas verdadeiras preferências, o resultado do algoritmo de Gale-Shapley é:

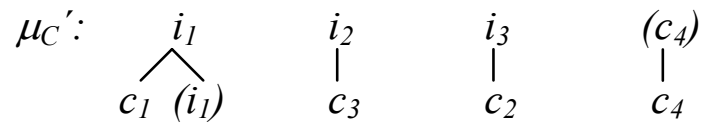

Acontece que podemos ter $\left\{c_{1}, i_{1}\right\}>_{i 1}\left\{c_{3}, c_{4}\right\}$ e, dessa forma, o mecanismo que produz o matching estável ótimo para os candidatos é manipulável por truncagem por $i_{1}$ mesmo com $\mu_{I}(i)$ $=\mu_{C}(i)$.

Portanto, retomando o resultado da Propsição 1 temos que, quando $\mu_{I}(i) \neq \mu_{C}(i)$, para manipular um mecanismo estável por truncagem, basta que a Instituição $i$ conheça o seu candidato menos preferido em $\mu_{I}(i)$ (que denominamos $c_{m}$ ) e trunque a lista nele. Assim a Instituição conseguirá ter um resultado mais preferido que o resultado de $\mu_{C}(i)$. Além disso, truncando em $c_{m}$ a Instituição obterá o matching $\mu_{I}(i)$ quando o mecanismo produz o matching estável ótimo para os candidatos. No entanto, a Proposição 2 nos mostra que existem riscos para esta manipulação, pois se a Instituição truncar a lista declarada em algum candidato melhor colocado que $c_{m}$ ela ficará com vagas não preenchidas.

Proposição 2. Considere o mercado $(C, I, P, q)$ e uma Instituição $i$. Suponha que exista $c_{m} \in \mu_{I}(i)$ tal que $c_{m}$ é o candidato menos preferido fracamente por $i$ em $\mu_{I}(i)$ e $c_{m}$ não é o candidato mais preferido por $i$ em $P(i)$. Se a Instituição $i$ truncar $P(i)$ em $c_{j}$, com $c_{j}>_{i} c_{m}$, então ela não preencherá todas as suas vagas em qualquer mecanismo estável.

Demonstração: Seja $c_{j} \in C$ tal que $c_{j}>_{i} c_{m}>_{i} i$. Seja $P^{\prime}(i)$ a truncagem de $P(i)$ em $c_{j}$. Suponha que existe $\mu^{\prime}$, estável para $\left(C, I, P / P^{\prime}(i), q\right)$ com $i$ preenchendo sua cota em $\mu$ '. Então $\mu^{\prime}$ também é estável para $(C, I, P, q)$. Mas existe $c \in \mu^{\prime}(i)-\mu_{I}(i)$ tal que $c>_{i} c_{m}$, o que contradiz a otimalidade de $\mu_{I}$. 
Para finalizar o argumento anterior vamos apresentar, a título de ilustração, o exemplo abaixo.

Exemplo 2. Considere o seguinte mercado de Instituições e candidatos em que cada Instituição tem cota 2. Este exemplo é muito mais simples que o mercado da ANPEC, mas os resultados demonstrados acima são evidentemente válidos para ambos. Suponhamos este mercado com três Instituições $\left\{i_{1}, i_{2}, i_{3}\right\}$ e seis candidatos $\left\{c_{1}, c_{2}, c_{3}, c_{4}, c_{5}, c_{6}\right\}$ com as seguintes listas de preferências.

$$
\begin{aligned}
& P\left(i_{1}\right)=c_{1}, c_{5}, c_{2}, c_{3}, c_{4}, c_{6} \\
& P\left(i_{2}\right)=c_{1}, c_{5}, c_{2}, c_{4}, c_{6}, c_{3} \\
& P\left(i_{1}\right)=c_{1}, c_{5}, c_{3}, c_{6}, c_{4}, c_{2}
\end{aligned}
$$

$$
\begin{aligned}
& P\left(c_{1}\right)=i_{1}, i_{2}, i_{3} \\
& P\left(c_{2}\right)=i_{2}, i_{1}, i_{3} \\
& P\left(c_{3}\right)=i_{3}, i_{2}, i_{1} \\
& P\left(c_{4}\right)=i_{3}, i_{2}, i_{1} \\
& P\left(c_{5}\right)=i_{1}, i_{2}, i_{3} \\
& P\left(c_{6}\right)=i_{2}, i_{3}, i_{1}
\end{aligned}
$$

Esse mercado apresenta somente dois matchings estáveis que são exatamente o matching estável ótimo para os candidatos e o matching estável ótimo para as Instituições. Dessa forma, aplicando os algoritmos de Gale-Shapley e NRMP podemos encontrar, respectivamente, $\mu_{C}$ e $\mu_{I}$.

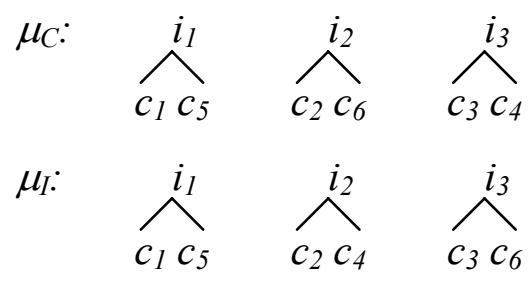

Como $\mu_{I}\left(i_{2}\right) \neq \mu_{C}\left(i_{2}\right)$, a Proposição 1 implica que a Instituição $i_{2}$ pode manipular o algoritmo de Gale-Shapley truncando sua lista de preferências verdadeira. Suponha que $i_{2}$ sabe que $c_{4}$ é o candidato menos preferido que ela recebe no matching ótimo para as Instituições. Então, basta $i_{2}$ truncar sua lista de preferências em $c_{4}$ para obter um resultado preferido. Ou seja, se $i_{2}$ declara a 
lista de preferências $P^{\prime}\left(i_{2}\right)=c_{1}, c_{5}, c_{2}, c_{4}, i_{2}$ e todos os outros participantes declaram suas verdadeiras preferências, o resultado do algoritmo de Gale-Shaley é $\mu_{C}{ }^{\prime}=\mu_{I}$.

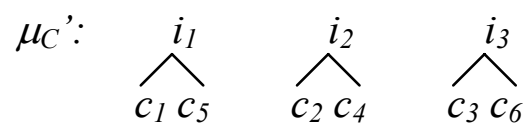

Agora suponhamos que $i_{2}$ desconhece quem é o candidato menos preferido que ela recebe no matching ótimo para as Instituições, mas $i_{2}$ decide tentar manipular o algoritmo de Gale-Shapley declarando a lista de preferências $P$ " $\left(i_{2}\right)=c_{1}, c_{5}, c_{2}, i_{2}$. Se todos os outros jogadores declaram suas verdadeiras preferências, o resultado é $\mu_{C}$ ".

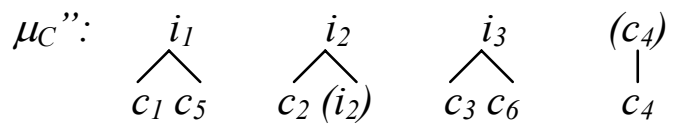

Como $i_{2}$ truncou sua lista de preferências antes de $c_{4}$ ela ficou com uma vaga não preenchida em $\mu_{C}$ ", o que ilustra o resultado da Proposição 2. Por fim, este resultado não é estável para as verdadeiras preferências, pois o par $\left(i_{2}, c_{4}\right)$ bloqueia $\mu_{C}$ ". Com isso, $i_{2}$ tem incentivo em buscar um arranjo subseqüente com $c_{4}$, e isso pode nem sempre ser possível e permitido pelo mecanismo.

Este exemplo ilustra bem o risco que a Instituição $i$ corre ao tentar manipular o algoritmo GaleShapley sem saber exatamente quem é o candidato $c_{m} \in \mu_{I}(i)$, que é o menos preferido fracamente por $i$ em $\mu_{I}(i)$.

Em relação aos candidatos, a Proposição 3 nos dá uma condição necessária e suficiente para que um candidato possa manipular um dado mecanismo estável.

Proposição 3 (Sotomayor 1996a). Considere o mercado (C,I,P,q) e um candidato $c$. Um mecanismo estável que produz o matching $\mu$ é manipulável por $c$ se e somente se $\mu_{C}(c) \neq \mu(c)$. 
O mercado de médicos e residentes descrito na seção anterior teve grande sucesso na implementação de um mecanismo centralizado que aplicava o algoritmo NRMP. Esse mecanismo foi utilizado por quase cinqüenta anos, até sofrer pequenos ajustes em 1998. O algoritmo foi aprimorado e o mecanismo centralizado continua em aplicação de forma bastante satisfatória até hoje. A exemplo deste mercado, os casos de sucesso de mecanismos centralizados são inúmeros, como indicam vários artigos, dentre os quais se destacam os trabalhos de Roth (1984a, 1989b, 1990). No entanto, também existem casos de insucesso na aplicação de mecanismos centralizados, o que será discutido na seção a seguir.

\subsection{Razões de insucesso de mecanismos centralizados}

Como existem casos de mecanismos centralizados que não são bem sucedidos e acabam sendo abandonados em alguns mercados, podemos concluir que não basta a aplicação de um mecanismo centralizado para resolver os problemas de organização dos mercados. Este mecanismo também deve ter alguma característica particular para que seja bem sucedido e permaneça em aplicação de forma duradoura.

Com base nesta constatação e avaliando alguns casos de insucesso com mecanismos centralizados, Roth (1989b) e McKinney, Niederle e Roth (2004) determinaram duas hipóteses para explicar falhas em mecanismos centralizados que, conseqüentemente, provocam a descontinuidade no uso desses mecanismos.

Uma terceira hipótese, não relacionada às apontadas nos artigos acima, é introduzida aqui. Ela emerge da análise do insucesso do mecanismo centralizado da ANPEC em 1997.

\subsubsection{Hipótese 1: Os mecanismos geram matchings instáveis}

Para testar esta hipótese, Roth (1989b) analisou oito mercados independentes de residência médica, no Reino Unido, que implementaram mecanismos centralizados, quase que simultaneamente, e tiveram resultados totalmente distintos: enquanto alguns obtiveram bastante 
sucesso e mantiveram o mecanismo em operação até os dias de hoje, outros se viram obrigados a alterar seus algoritmos ou os abandonaram definitivamente alguns anos depois.

Roth observou que os mercados que obtiveram sucesso implementaram o algoritmo de Gale e Shapley, alguns gerando o matching ótimo para as Instituições e outros gerando o matching ótimo para os candidatos. Nestes mercados os mecanismos centralizados geram matchings estáveis.

Os mercados que não foram bem sucedidos implementaram algoritmos que geravam matchings instáveis. Como nestes mercados a participação no mecanismo era obrigatória para todos os candidatos aos programas de residência médica, estes não podiam buscar arranjos independentes. Devido à instabilidade da alocação produzida pelo mecanismo, estes mercados experimentaram um processo de antecipação no período anterior à aplicação do mesmo. Os candidatos e Instituições buscavam arranjos mais favoráveis que seriam garantidos pelo mecanismo através da submissão das preferências adequadas (este processo corresponde ao estágio 4 descrito na seção anterior). Dessa forma, nesses mercados, não era uma estratégia dominante para qualquer jogador submeter suas verdadeiras preferências. Também havia múltiplos equilíbrios estratégicos nos quais todos os jogadores submetiam uma única opção. Quando estes mecanismos foram abandonados, cerca de 80\% das alocações eram arranjadas antes da aplicação do mecanismo.

Com base nas experiências destes mercados ingleses, Roth (1989b) conclui que uma condição necessária para que um mecanismo centralizado seja bem sucedido e tenha uma aplicação duradoura é que ele gere matchings estáveis.

\subsubsection{Hipótese 2: Mudanças nas condições de mercado, provocando diminuição da demanda dos candidatos pelas Instituições e conseqüente busca por parte das Instituições por arranjos fora do mecanismo}

Esta hipótese surgiu da experiência ocorrida no mercado de residência médica para a especialidade de gastroenterologia nos Estados Unidos. Este mercado passou pelos primeiros dois estágios de evolução antes de ter um mecanismo centralizado implementado em 1986, através do 
algoritmo NRMP, que foi usado com sucesso por dez anos consecutivos. É importante mencionar que os mercados americanos em sua maioria determinam participação no mecanismo centralizado de forma voluntária, tanto para candidatos quanto para Instituições. Neste período de dez anos em que o mercado de gastroenterologia foi bem sucedido, o índice de eficiência (índice médio de parcerias arranjadas pelo mecanismo centralizado em relação ao total de parcerias do mercado) era de 90\%. A partir de 96 este índice caiu drasticamente. O que ocorreu foi que o Conselho Americano de Gastroenterologia determinou, em 1996, uma política de redução de 25\% a 50\% no número de programas de residência ao longo dos cinco anos seguintes e um aumento de dois para três anos no período de residência. Este anúncio resultou numa redução imediata na demanda. Os médicos recém graduados perderam o interesse pela especialidade de gastroenterologia, de forma que, neste mesmo ano e nos anos subseqüentes, houve menos candidatos que vagas disponíveis no mercado. Em decorrência disso, as Instituições iniciaram, a partir de 1997, o processo de antecipação para formar arranjos fora do mecanismo e não correr o risco de ficar com vagas não preenchidas. A partir de então, o processo de antecipação se intensificou e o índice de eficiência do mecanismo caiu ano a ano até ser formalmente abandonado em 2000. Atualmente este mercado é descentralizado.

Dessa experiência pode-se concluir que mudanças drásticas nas características do mercado gerando uma diminuição da demanda dos candidatos pelas Instituições podem provocar o fracasso de mecanismos centralizados, mesmo daqueles que geram matchings estáveis. (Ver McKinney, Niederle e Roth, 2004).

\subsubsection{Hipótese 3: Falhas na implementação e operacionalização do mecanismo afetando a credibilidade dos participantes na alocação resultante}

Esta hipótese decorre da experiência de 1997 com o mercado da ANPEC, que relatamos a seguir.

No ano de 1997 a ANPEC implementou um mecanismo centralizado como uma tentativa definitiva de resolver os problemas enfrentados nos anos anteriores. A discussão sobre o assunto foi travada na reunião do Conselho Deliberativo da ANPEC e a aprovação do algoritmo de Gale- 
Shapley se deu de forma quase unânime na votação realizada pelos Centros Membros: onze votos a favor, um contra e uma abstenção.

Dadas as características deste mercado, o algoritmo implementado em 1997 gerava resultados estáveis. Por outro lado, como o algoritmo de Gale-Shapley gera o matching ótimo para os candidatos, segundo o Teorema da Não-manipulabilidade, o mecanismo centralizado usado em 1997 pela ANPEC é não manipulável individualmente e coletivamente pelos candidatos.

O interesse cada vez maior por parte de economistas e novos Centros de pós-graduação em economia, ao longo dos anos, de ingressar no mercado tem levado o mercado da ANPEC a apresentar crescimento estável da oferta e da demanda desde o início da década de 90, com o número de candidatos sempre superando bastante o número de vagas ofertadas pelos Centros de pós-graduação.

A tabela 2 mostra que o número de Centros de pós-graduação participantes do mercado da ANPEC cresceu gradativamente desde 97.

Tabela 2 - Número de Centros participantes do mercado da ANPEC nos últimos anos

\begin{tabular}{|l|c|c|c|c|c|c|c|c|}
\hline Ano & 1997 & 1998 & 1999 & 2000 & 2001 & 2002 & 2003 & 2004 \\
\hline $\mathrm{N}^{\circ}$ de Centros & 19 & 20 & 20 & 21 & 21 & 22 & 23 & 24 \\
\hline
\end{tabular}

Através do gráfico 1 pode-se observar que o crescimento da demanda por vagas nos Centros de pós-graduação se deu de forma mais intensa, principalmente nos últimos anos, e essa demanda sempre suplantou bastante a oferta de vagas no mercado da ANPEC.

Entretanto o mecanismo centralizado foi abandonado em 1998, por decisão dos Centros Membros do Conselho Deliberativo da ANPEC (6 votos contra o mecanismo, 5 a favor e 3 abstenções). 


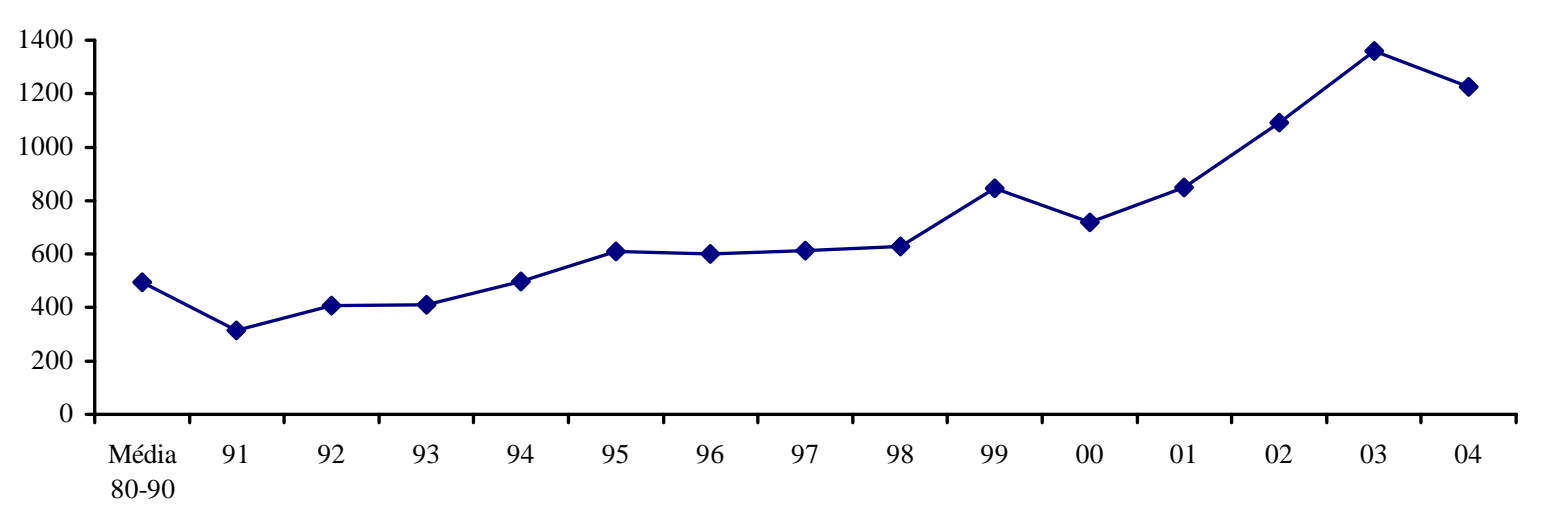

Gráfico 1 - Número de candidatos participantes do mercado da ANPEC nas últimas décadas

Diferentemente do que ocorreu nos mercados observados por Roth, houve falhas na implementação e operacionalização do mecanismo centralizado da ANPEC que concorreram para o seu insucesso, e que relatamos a seguir.

A. Não houve tempo, nem divulgação suficiente, para que os participantes aprendessem o mecanismo, confiassem nele e se acostumassem com a nova forma de organização do mercado.

De fato, o mecanismo centralizado foi apresentado para os coordenadores dos Centros em uma curta palestra durante a reunião do Conselho Deliberativo da ANPEC, em abril de 1997. Nesta reunião foi acordado que o mecanismo seria aplicado em caráter experimental naquele ano. Os estudantes declarariam suas preferências para a ANPEC e o algoritmo seria aplicado como uma simulação. O matching definitivo seria gerado pela operação descentralizada e, então, estudantes e Centros poderiam comparar os dois resultados e comprovar a eficiência do mecanismo centralizado. A simulação teria como objetivo divulgar e ensinar o mecanismo e, assim, fazer com que os participantes confiassem na nova forma de organização desse mercado. (Esta aplicação, em caráter experimental, foi feita de forma bem sucedida no mercado de admissão de médicos residentes a hospitais nos Estados Unidos antes da implementação definitiva do mecanismo com o algoritmo NRMP). Entretanto, numa decisão tomada posteriormente, os Centros decidiram pular esta etapa e aplicar o mecanismo de forma definitiva em 1997. 
Nenhum outro procedimento junto às Instituições e candidatos foi realizado até a aplicação do mecanismo, com o intuito de ensinar o seu funcionamento e a maneira correta de elaborar as listas de preferências. Dessa forma, os estudantes não estavam cientes de que era ótimo para eles revelar suas verdadeiras preferências e nem as Instituições estavam cientes das conseqüências de uma truncagem incorreta das listas de preferências.

B. Os estudantes tinham de declarar suas preferências no momento de se inscrever para realizar os testes.

Acontece que, para muitos estudantes, essas preferências seriam melhor definidas após as informações derivadas da classificação dos candidatos nos testes. Alguns Centros, após os resultados dos testes, organizavam visitas que contribuiam significativamente na definição das preferências dos candidatos. Isto ocorre porque as informações sobre os Centros não eram divulgadas por um canal eficiente, como "home page”. Dessa forma, as visitas eram, para alguns estudantes, a única fonte de informação sobre os Centros. Além disso, o fato de cada Instituição se desdobrar em duas: Instituição com bolsa de estudos e Instituição sem bolsa de estudos, confundiu os candidatos que não tinham bem definidas suas preferências. Assim, muitos candidatos mudaram suas preferências após a submissão de suas listas, como ficou patente depois do resultado do algoritmo. Se as listas de preferências fossem submetidas após o resultado dos testes e após as entrevistas, a probalidade de mudança por parte dos candidatos seria praticamente nula.

No modelo atual os estudantes também declaram uma lista quando se inscrevem para realizar os exames. No entanto, trata-se de uma lista de Centros aceitáveis, sem ordenação de preferências. Só depois de divulgados os resultados dos testes e feitas as visitas aos Centros que os candidatos decidem qual oferta aceitar. É neste momento que muitos deles, de fato, declaram suas listas de preferências no atual modelo.

O problema que este modelo pode causar no mercado descentralizado aplicado desde 1996 será discutido mais adiante na seção 7. Está relacionado com a exigência de que as listas devem conter, no máximo, seis Centros. 
C. A primeira aplicação do algoritmo teve falhas técnicas que beneficiaram Centros menos concorridos e prejudicaram alguns dos maiores Centros, provocando insegurança dos participantes em relação à alocação resultante e abalando a credibilidade do mecanismo.

De fato, este incidente, juntamente com a falta de conhecimento sobre as propriedades do mecanismo, fizeram com que o algoritmo passasse a ser visto por Centros médios e menos concorridos como um procedimento "milagroso", capaz de atender às demandas pelos melhores estudantes. Assim, na segunda aplicação do algoritmo, após o reparo do software, esses Centros reduziram o número de candidatos aceitáveis em suas listas, truncando-as em posições inadequadas, na certeza de receber os melhores estudantes.

O exemplo 2 da seção 4.3 ilustra bem o risco que a Instituição corre ao tentar manipular o algoritmo Gale-Shapley via truncamento das preferências, sem saber exatamente que candidato deve ser o último aceitável de sua lista. Pela Proposição 2, se a Instituição truncar incorretamente, ela ficará com vagas não preenchidas. Isto ocorreu com vários Centros, como, por exemplo, a UFRGS. Estes Centros truncaram suas listas em posições inadequadas, na esperança de receber os melhores estudantes. Com a aplicação do algoritmo Gale-Shapley esses Centros ficaram com vagas não preenchidas e depois tentaram buscar arranjos subseqüentes com os candidatos aceitáveis para eles, mas que não haviam sido declarados em suas listas. Isto gerou algumas instabilidades, pois alguns desses estudantes já estavam comprometidos com outros Centros e, quando recebiam os convites, abandonavam os arranjos anteriores abrindo outras vagas nos Centros em que já haviam se comprometido pelo mecanismo. Com isso esses Centros também buscaram outros arranjos subseqüentes para preencher as suas vagas e assim por diante.

Vimos que a Proposição 1 dá condições para que uma Instituição possa se beneficiar com o truncamento de suas preferências. Ela necessita conhecer o grupo dos candidatos que seria alocado a ela no matching estável ótimo para as Instituições. Segundo o Teorema A1, esta informação pode ser simples de ser obtida pelas melhores Instituições, em que os dois matchings ótimos lhes dão os mesmos candidatos. Neste caso, porém, a Instituição não tem como manipular por truncagem o mecanismo, pela Proposição 1. Mas este não é o caso das Instituições médias, 
em que os grupos de candidatos nos dois matchings são distintos e portanto o nível de informação requerida para uma manipulação bem sucedida é alto.

Com a credibilidade do algoritmo de Gale-Shapley abalada, uma nova votação realizada pelos Centros Membros no Conselho Deliberativo da ANPEC no ano seguinte determinou que o mecanismo centralizado fosse abandonado. 


\section{DESENHO DO MERCADO DA ANPEC}

As falhas $(A),(B)$ e $(C)$ apontadas na Hipótese 3 da seção anterior compõem a resposta a nossa questão número 1 formulada na Introdução. Nesta seção propomos um novo desenho para o mercado da ANPEC onde as alocações dos estudantes aos Centros serão feitas por um mecanismo centralizado que gera a alocação ótima estável para os estudantes. Com base nas observações feitas previamente podemos identificar alguns procedimentos regulatórios que devem ser observados para fins de implementação e operacionalização de um tal mecanismo.

\section{(1) Ampla divulgação do mecanismo entre os participantes do mercado}

A divulgação ampla da mudança e da nova forma de organização do mercado é, seguramente, a primeira medida que deve ser tomada para que a implementação de um mecanismo centralizado tenha sucesso. A ANPEC deve instituir uma política de divulgação em todas os Centros que participam do mercado, com repetidas palestras presenciais, livretos impressos, comunicação pela internet, etc. É importante que os Centros e os estudantes conheçam bem o mecanismo e o algoritmo. Para os estudantes é imprescindível a segurança que o algoritmo transmite, pelo fato de ser não manipulável por estes. Os Centros devem estar cientes de que não é fácil se beneficiar com a manipulação e que necessitam, em geral, de um alto grau de informação sobre as preferências dos outros participantes para adulterar com sucesso suas preferências. Dessa forma, as visões "milagrosas" e "desastrosas” do algoritmo serão abolidas e, conseqüentemente, o mecanismo centralizado será implementado com maior credibilidade por parte dos participantes.

\section{(2) Aplicação em caráter experimental}

Esta é uma medida que reforça a política de divulgação, pois os participantes poderão comparar as duas formas de organização do mercado e, assim, tirar conclusões práticas a respeito dos benefícios do mecanismo centralizado. A simulação também é útil para que os participantes realmente aprendam na prática a atuar no mercado centralizado e se sintam mais seguros em relação às novas regras. 
(3) Obtenção do máximo de informação possível antes da submissão das listas de preferências

No período em que os participantes submetem suas listas eles devem ter recebido o máximo de informação possível sobre os outros participantes, para evitar a possibilidade de mudança nas suas preferências. Assim, para o mercado da ANPEC temos duas alternativas.

Na primeira, os candidatos submetem suas listas antes da realização dos exames. O benefício é evitar que as Instituições se sintam tentadas a contactar os candidatos para fazerem arranjos fora do mecanismo. Dessa forma também seria eliminado o processo de visitas, que gera um custo elavado para os Centros. Para organizar uma visita o Centro gasta anualmente de 10 a 15 mil reais, recurso este que poderia ser direcionado para outra finalidade. Outros Centros gostariam de organizar visitas, mas somente os maiores dispõem de recurso para tal. Porder-se-ia argumentar que as visitas são fundamentais na definição das preferências dos candidatos. De fato, elas contribuem pelas informações sobre produtividade acadêmica que os Centros apresentam. No entanto, tais informações poderiam ser encaminhadas aos candidatos por outro canal, tão eficiente quanto as visitas, e menos custoso, como uma boa "home page” da Instituição. Seria inclusive uma comunicação mais objetiva e mais impessoal. O ponto negativo que se deve destacar nesta alternativa é que, os candidatos, ao terem que declarar suas listas sem saber os resultados dos testes, deverão buscar informações e definir as preferências sobre todos os Centros, o que pode ser difícil inclusive pelo fato de cada Centro se desdobrar em dois: com bolsa e sem bolsa.

Na segunda alternativa, os participantes informam suas listas após a divulgação dos resultados dos exames e após as entrevistas que, por acaso, existirem por parte de algumas Instituições e candidatos. O benefício é evitar que os candidatos tenham que definir preferências sobre todos os Centros, pois, se um candidato sabe sua classificação, ele pode se concentrar nas Centros que historicamente admitem candidatos classificados na faixa em que este candidato se encontra. Dessa forma, ele pode definir melhor suas preferências. Por outro lado, se os Centros conhecem as classificações dos candidatos, eles se sentem tentados a buscar arranjos independentes, o que pode prejudicar o mecanismo centralizado. 
(4) As listas de preferências dos estudantes são conhecidas apenas pela Central

Isto é importante para que os candidatos não se sintam constrangidos e as Instituições não se sintam desprestigiadas em receber candidatos que não as tenham declarado como suas primeiras opções.

\section{(5) Nenhum arranjo independente entre uma Instituição e um candidato será admissivel.}

Desta forma, nenhuma oferta pode ser feita aos candidatos pelas Instituições, nem durante as entrevistas (se houver) nem depois do resultado do mecanismo. Existe, portanto, um compromisso das Instituições de aceitarem a alocação produzida pelo mecanismo.

Algumas Instituições podem, no afã de competir pelos melhores estudantes, querer fazer arranjos com um grupo de candidatos no sentido de obter deles o comprometimento de listá-la em primeiro lugar para que sejam alocados para ela pelo mecanismo. Como as listas de preferências só são conhecidas pela Central, este compromisso por parte dos candidatos não tem nenhum valor. Um candidato, agindo estrategicamente, poderia aceitar a proposta da Instituição para que ela não retirasse seu nome de sua lista, mas no final submeteria a sua lista verdadeira. Se acontecer dele ser alocado para a dada Instituição pelo mecanismo ela acreditará que ele cumpriu o acordo; caso contrário, ela perceberá que ele não a listou em primeiro lugar, mas ele não se importará com a opinião dela, pois terá sido designado a uma Instituição preferível. Assim, tal atitude por parte de uma Instituição não a beneficia. Esta medida visa respeitar as escolhas dos estudantes. Afinal, as Instituições existem para que eles possam estudar nelas!

Uma Instituição só terá incentivo em fazer uma oferta a um candidato posterior ao resultado do mecanismo no caso dela possuir alguma vaga não preenchida. Como a alocação produzida é estável, ela só obterá sucesso com essa oferta se o candidato em questão não tiver sido listado por ela. Então, se ela tiver interesse nesse candidato é porque ele é aceitável para ela e ela truncou sua lista de candidatos aceitáveis antes dele. Esta medida visa evitar tentativas de manipulação por parte das Instituições como ilustrado no exemplo 2: a Instituição tenta se beneficiar truncando sua lista verdadeira mas fica com vagas sem preencher. Em conseqüência disto ela parte em busca de novos arranjos, fora do mecanismo, para preencher as suas vagas. Se bem sucedida, suas vagas serão preenchidas por candidatos que provavelmente já estavam alocados a outras Instituições 
pelo algoritmo, acarretando novos arranjos fora do mecanismo e assim por diante. Assim, o fato dos arranjos independentes serem inadmissíveis desestimula as Instituições a tentar manipular o mecanismo, incentivando-as a listar todos os candidatos realmente aceitáveis por elas.

No modelo atual os Centros costumam convidar para as visitas os estudantes que as tenham declarado na lista de aceitáveis com o objetivo de influenciar a decisão futura desses estudantes. No modelo centralizado, o caráter das visitas nos Centros será somente de disponibilizar informações para auxiliar na definição das preferências dos candidatos. 


\section{MERCADOS DESCENTRALIZADOS}

Nesta seção nos propomos a analisar o atual funcionamento do mercado da ANPEC como um mercado descentralizado. Apresentamos uma série de observações do funcionamento deste mercado e descrevemos as possibilidades de comportamento estratégico que surgem para os participantes. Em seguida, propomos uma alternativa de aprimoramento do mercado descentralizado da ANPEC.

Analisar mercados descentralizados é muito difícil pela falta de informação e pela vasta quantidade de ações estratégicas possíveis para os participantes.

Niederle e Roth, em seu artigo de 2003, realizaram uma série de experimentos laboratoriais com estudantes, simulando um mercado descentralizado de Instituições e candidatos. Neste mercado os candidatos conheciam as Instituições e tinham as mesmas preferências sobre elas (as preferências dos candidatos sobre as Instituições eram iguais) desde o início do procedimento, enquanto que as Instituições recebiam informações graduais sobre os candidatos e definiam suas preferências também de forma gradual a partir das informações que recebiam. As Instituições podiam fazer ofertas aos candidatos a qualquer momento. As simulações foram conduzidas com o mercado experimentando três tipos de regras em relação às ofertas das Instituições e às respostas dos candidatos.

$1^{a}$ Regra: Mercado Explosivo: As Instituições podem fazer ofertas explosivas e os candidatos não podem voltar atrás nos compromissos firmados.

$2^{a}$ Regra: Mercado com Comprometimento: As Instituições só podem fazer ofertas abertas (sem prazo de resposta definido) e os candidatos não podem voltar atrás nos compromissos firmados.

$3^{a}$ Regra: Mercado sem Comprometimento: As Instituições podem fazer ofertas explosivas e os candidatos podem voltar atrás nos compromissos firmados. 
Realizando repetidas simulações para cada um dos mercados descritos, Niederle e Roth observaram que no mercado explosivo grande parte das ofertas é explosiva e as alocações geradas apresentam muitas instabilidades, enquanto que nos outros dois mercados as ofertas são, em grande maioria, abertas e as alocações geradas apresentam poucas instabilidades sendo, portanto, resultados não objetáveis para a grande maioria dos participantes.

\subsection{Mercado da ANPEC pós 1997: Mecanismo em vigor e observações empíricas}

O mercado da ANPEC voltou a operar, a partir de 1998, através do mesmo mecanismo descentralizado que foi usado em 1996. Segundo este mecanismo, os estudantes, ao se inscreverem no concurso, submetem listas de preferências não ordenadas com, no máximo, seis Centros. Depois da realização das provas, a ANPEC publica a classificação dos estudantes segundo o critério de cada Centro. De posse das listas, os Centros fazem ofertas aos candidatos melhor colocados, dentre aqueles que os relacionaram em suas listas de preferências, até preencherem suas vagas. Dessa forma, podemos dizer que o mecanismo atual da ANPEC induz um jogo dinâmico com dois estágios. No primeiro estágio do jogo os candidatos são chamados a informar as suas listas de Instituições aceitáveis. O conjunto de ações de cada candidato são todas as possíveis listas com, no máximo, seis Centros. No segundo estágio do jogo, tendo sido tornadas públicas as preferências dos Centros pelos candidatos, as Instituições fazem suas ofertas e os candidatos retornam com suas respostas. Uma ação para um Centros é fazer, ou uma oferta aberta, ou uma oferta explosiva, para um dado conjunto de candidatos selecionados pelo Centro. Os candidatos podem escolher entre 3 tipos de ações: ação "moderada" (aceitar a oferta mais preferida no momento até receber outra melhor); ação "de risco" (recusar todas as ofertas até receber a primeira mais preferida) ou ação "de segurança” (aceitar a oferta disponível mais preferida no momento e se comprometer com ela até o final do mecanismo, mesmo que receba outras melhores posteriormente). Em geral, no estágio 2, os Centros não são informados sobre que estudantes já foram admitidos por outros Centros e os estudantes não são informados sobre que Centros já preencheram suas vagas. 
O jogo continua com sucessivas repetições do estágio 2 até que todos os Centros tenham preenchido suas vagas ou, aqueles que não tenham preenchido todas as suas vagas, já tenham feito ofertas a todos os candidatos aceitáveis.

As ações dos jogadores em cada um dos estágios do jogo são reguladas por um conjunto de regras determinadas pela ANPEC a fim de estabelecer um mínimo de organização no mercado. As atuais normas que regulam este mercado descentralizado da ANPEC são descritas a seguir:

1. Os candidatos submetem suas listas contendo no máximo seis Centros, sem ordem de prioridade, três meses antes de realizarem os testes.

2. Nenhum Centro pode fazer ofertas antes da divulgação dos resultados dos testes.

3. Depois de divulgado os resultados dos testes os Centros podem fazer ofertas para todos os candidatos que desejarem, e da forma que desejarem: ofertas explosivas ou abertas.

4. Cada Centro pode definir seu prazo de resposta para as ofertas abertas, podendo este prazo ser indeterminado. De fato, existem Centros que não estabelecem prazo de resposta para os candidatos, deixando-os totalmente à vontade para responderem quando quiserem.

5. A ANPEC solicita que os Centros enviem uma lista com os estudantes aceitos 10 dias após a divulgação dos resultados dos testes e outra 20 dias após. Esta solicitação nem sempre é cumprida pelas Centros como, por exemplo, o NAEA/UFPA e o PIMES/UFPE.

6. A ANPEC consolida tais informações e divulga aos Centros a relação total dos estudantes aceitos em cada Centro, na mesma periodicidade do item anterior. Este procedimento objetiva identificar os estudantes que tenham aceitado o convite de mais de um Centro. No entanto, apesar do edital do concurso determinar a eliminação do candidato que agir desta forma, isto de fato não ocorre. A ANPEC apenas informa para os Centros quem são estes candidatos e cabe aos Centros envolvidos exigirem uma definição por parte do estudante.

7. Não há data determinada para o encerramento do mercado, ou seja, os Centros podem fazer ofertas e admitir candidatos a qualquer tempo após a publicação dos resultados dos testes. 
Apesar das regras determinarem claramente as ações dos jogadores no início do jogo dinâmico, elas são muito vagas na definição do tempo de operacionalização do mercado, pois não determinam os prazos em que as ofertas devem permanecer abertas, o prazo de resposta dos estudantes e nem mesmo o prazo de encerramento do jogo. Com isso, as transações neste mercado se desenvolvem ao longo de semanas a partir da divulgação dos resultados dos testes, existindo ainda, alguns Centros que só dão como encerradas as negociações com os candidatos meses após o resultado dos testes. Diante desta constatação, podemos fazer uma observação importante com a Proposição 4.

Proposição 4. Assumindo que não existe uma data determinada para o encerramento do mercado, se todos os candidatos só jogam a ação “moderada”, então o matching final será o matching estável ótimo para as Instituições, segundo as preferências usadas no decorrer do mecanismo, independentemente das Instituições fazerem ofertas abertas ou explosivas.

Demonstração: Se os candidatos agem dessa forma, a evolução do mecanismo se dará exatamente como uma simulação do algoritmo NRMP. Inicialmente as Instituições farão uma oferta, aberta ou explosiva, ao conjunto de candidatos mais preferidos de suas listas de forma a não ultrapassar a sua cota. Os candidatos que receberem ofertas rejeitarão todas, exceto a sua favorita. A seguir as Instituições que ainda não tiverem preenchido suas vagas farão novas ofertas, abertas ou explosivas, ao conjunto de candidatos mais preferidos dentre os que ainda não recusaram ofertas dessas Instituições. Os candidatos novamente recusam todas as ofertas, exceto a sua favorita. As Instituições e candidatos seguem agindo assim até que todas as Instituições tenham preenchido suas cotas ou, aquelas que não o tenham, já tenham feito ofertas a todos os candidatos aceitáveis. O algoritmo NRMP produz o matching ótimo para as Instituições.

A seguir apresentamos os fatos observados em cada uma das etapas do mecanismo descentralizado da ANPEC ao longo dos últimos anos. 


\subsubsection{Primeiro estágio: Observações empíricas}

Ao analisar o primeiro estágio do jogo, verificamos que, ao longo dos últimos anos, o percentual de candidatos que declara seis Centros em suas listas aumentou de 48 para 73\%, como mostra o gráfico 2.

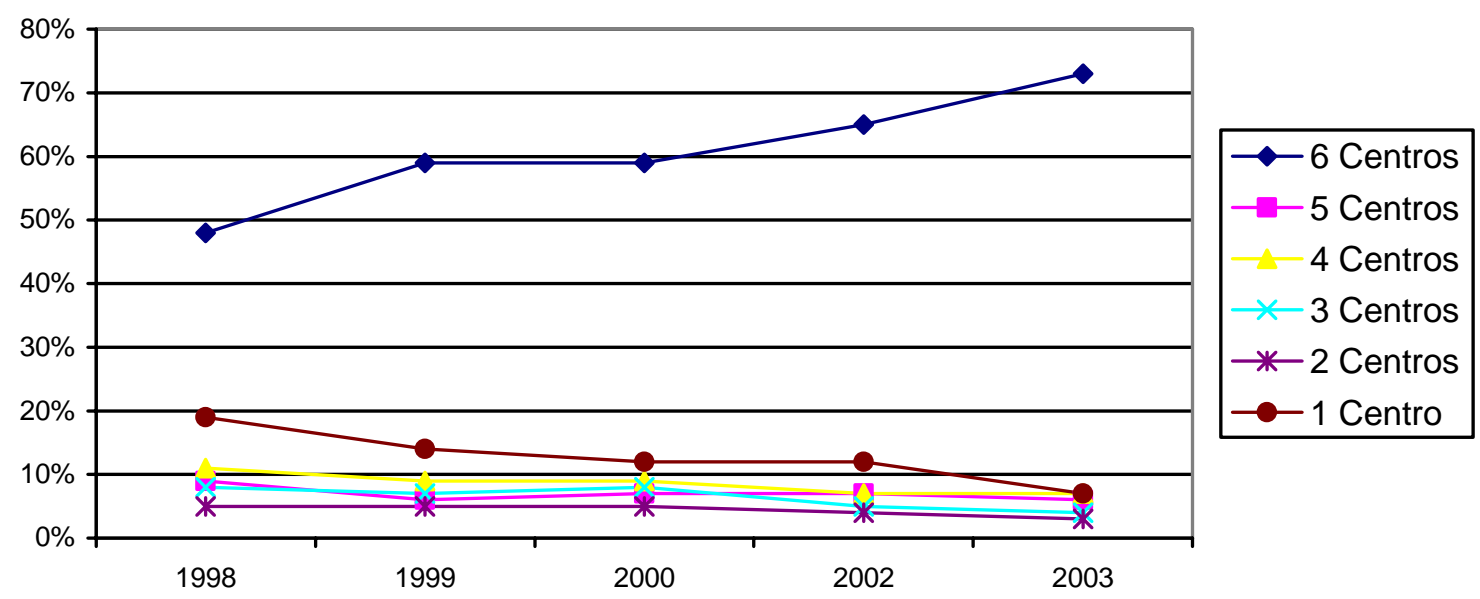

Gráfico 2 - Percentual de candidatos que declara 6 Centros

Podemos supor que os candidatos acreditem que seja o melhor para eles agir desta forma. Um candidato que declara seis Centros em sua lista pode pensar que maximiza a quantidade de ofertas que recebe no segundo estágio do jogo e, assim, tem mais opções para decidir. No entanto, esta ação pode não ser a melhor para os candidatos, dentre as que podem ser tomadas no $1^{\circ}$ estágio do jogo, como ilustrado a seguir.

Exemplo 2 (Continuação). Considere o mesmo mercado anterior com três Instituições $\left\{i_{1}, i_{2}, i_{3}\right\}$ e seis candidatos $\left\{c_{1}, c_{2}, c_{3}, c_{4}, c_{5}, c_{6}\right\}$ e com as mesmas listas de preferências.

$$
\begin{aligned}
& P\left(i_{1}\right)=c_{1}, c_{5}, c_{2}, c_{3}, c_{4}, c_{6} \\
& P\left(i_{2}\right)=c_{1}, c_{5}, c_{2}, c_{4}, c_{6}, c_{3} \\
& P\left(i_{3}\right)=c_{1}, c_{5}, c_{3}, c_{6}, c_{4}, c_{2}
\end{aligned}
$$

$$
\begin{aligned}
& P\left(c_{1}\right)=i_{1}, i_{2}, i_{3} \\
& P\left(c_{2}\right)=i_{2}, i_{1}, i_{3}
\end{aligned}
$$




$$
\begin{aligned}
& P\left(c_{3}\right)=i_{3}, i_{2}, i_{1} \\
& P\left(c_{4}\right)=i_{3}, i_{2}, i_{1} \\
& P\left(c_{5}\right)=i_{1}, i_{2}, i_{3} \\
& P\left(c_{6}\right)=i_{2}, i_{3}, i_{1}
\end{aligned}
$$

Vimos que esse mercado apresenta somente dois matchings estáveis que são exatamente o matching estável ótimo para os candidatos e o matching estável ótimo para as Instituições, respectivamente, $\mu_{C}$ e $\mu_{I}$.

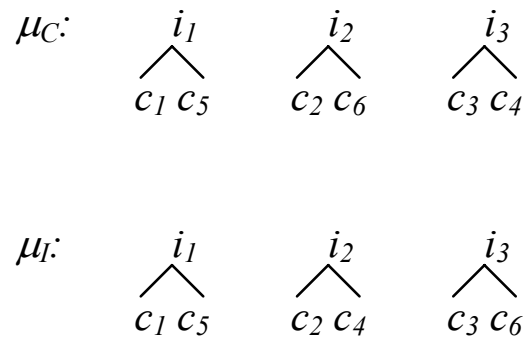

Suponha agora que $c_{6}$ declare somente sua Instituição mais preferida como aceitável, ou seja, $P^{\prime}\left(c_{6}\right)=i_{2}$, enquanto que todos os outros jogadores declaram suas verdadeiras preferências. Aplicando o algoritmo NRMP o matching resultante é $\mu_{I}{ }^{\prime}=\mu_{C}$, que é preferido por $c_{6}$ a $\mu_{I}$.

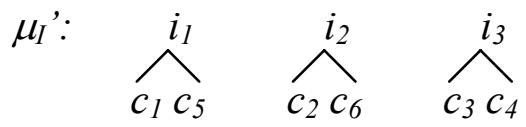

De outra forma, se todos os candidatos declararem somente sua Instituição mais preferida e as Instituições declararem suas verdadeiras preferências, o matching gerado pelo algoritmo NRMP também é $\mu_{I} "=\mu_{C}$. Portanto, como no mecanismo descentralizado da ANPEC são as Instituições que fazem as ofertas, a seqüência de ofertas e respostas segue o algoritmo NRMP. Conseqüentemente os candidatos também podem fazer a manipulação acima no mecanismo da ANPEC. 
Do exposto, podemos concluir que os candidatos não conhecem essa possibilidade de manipulação do mecanismo da ANPEC, ou a conhecem, mas não têm as informações necessárias para ralizá-la.

Ainda no primeiro estágio, podemos avaliar quais são os Centros mais preferidos pelos candidatos com base na quantidade de vezes que cada Centro aparece nas listas de preferências dos candidatos. Os dados de 1998 e 2003 nos mostram que existem sete Centros que são mais procurados pelos candidatos. Isto é mostrado no gráfico 3 a seguir.

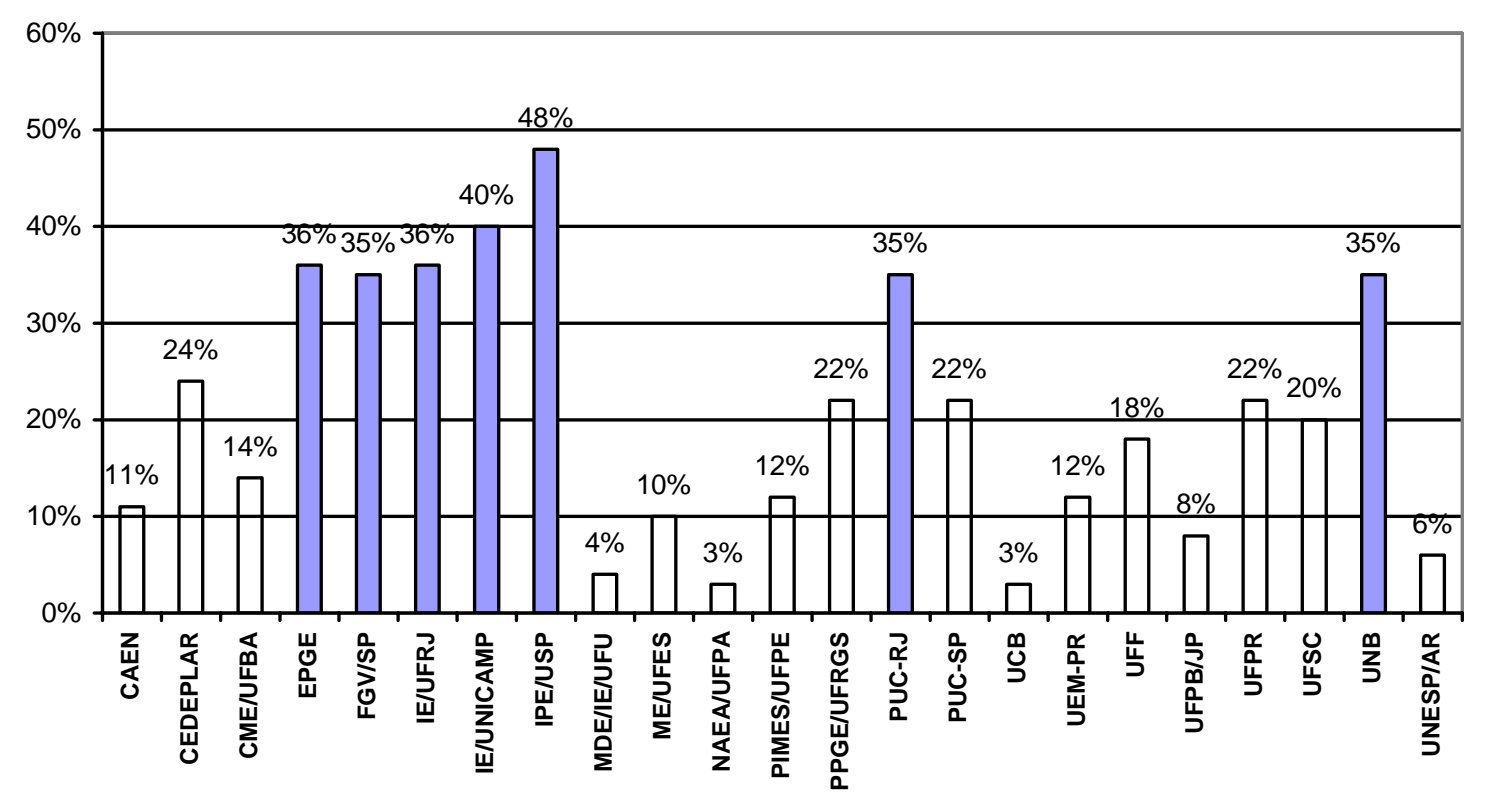

Gráfico 3 - Percentual médio de candidatos que declara cada Centro (1998 - 2003)

Os sete Centros mais preferidas são: IPE/USP, IE/UNICAMP, EPGE/FGV-RJ, IE/UFRJ, PUCRJ, UNB e FGV-SP. O IPE/USP, por sua vez, oferece dois cursos distintos de pós-graduação, o curso de Teoria Econômica e o curso de Economia das Instituições e Desenvolvimento. No entanto, o candidato que declara IPE/USP em sua lista de preferências, concorre a vagas nos dois cursos, como se tivesse declarado os dois. Dessa forma, para efeito de modelagem teórica, vamos considerar dois Centros distintos. Assim temos um total de oito Centros mais preferidos: IPE/USP(TE), IPE/USP(EID), IE/UNICAMP, EPGE/FGV-RJ, IE/UFRJ, PUC-RJ, UNB e FGVSP. 


\subsubsection{Segundo estágio: Observações empíricas}

No estágio 2 do jogo os Centros fazem suas ofertas e os candidatos respondem, dentro do tempo oferecido, aceitando ou não essas ofertas, ambos seguindo as ações descritas anteriormente. Alguns Centros fazem suas ofertas por telefone logo após a publicação dos resultados dos testes. Outros primeiramente convidam os candidatos para as visitas e só durante as visitas formalizam as ofertas.

Através de entrevistas com os coordenadores dos Centros, observamos que o comportamento em relação às ofertas é variado. Há Centros mais agressivos, que determinam prazos de resposta mais curtos e pressionam os candidatos por respostas mais rápidas, mas também há Centros que deixam os estudantes à vontade para tomarem suas decisões quando quiserem. No entanto, a grande maioria dos Centros, mesmo os mais agressivos, realmente só faz ofertas abertas. Aqueles que determinam prazos de resposta mais curtos costumam ainda conceder ampliações desse prazo quando solicitadas por candidatos que possuem ofertas de outros Centros.

Observamos também que os Centros mais procurados convocam os candidatos melhor colocados em suas listas para uma visita, na tentativa de influenciar a decisão dos candidatos. Estes Centros coordenam as datas de suas visitas e os prazos de suas ofertas a fim de que:

i) não coincidam as datas das visitas (de forma que os candidatos possam participar de todas);

ii) a data limite de suas ofertas abertas seja posterior às datas de todas as visitas (de forma que o candidato possa decidir com o máximo de informação possível sobre os Centros).

Os Centros mais procurados também costumam fazer ofertas para uma quantidade de estudantes maior que suas cotas, pois, como será mostrado na seção seguinte, os conjuntos dos melhores candidatos de cada Centro contêm a maioria dos candidatos em comum. Dessa forma, os Centros mais procurados acabam todos fazendo ofertas para praticamente o mesmo grupo de candidatos e, assim, cada um recebe somente uma parcela desses estudantes. Com isso, cada Centro pode fazer ofertas para um número maior que sua cota tendo "certa" segurança de que apenas uma parcela menor ou igual a sua cota será aceita. 
Analisando as listas consolidadas divulgadas pela ANPEC aos Centros, como descrito nas regras do mercado, podemos observar ser comum a presença de estudantes comprometidos com mais de uma Instituição. Isto significa que os estudantes estão dispostos a voltar atrás em compromissos assumidos, agindo de acordo com a ação “moderada”. Questionando os coordenadores dos Centros a esse respeito obtivemos confirmação de que esses casos ocorrem todo ano em grande parte das Instituições. Por outro lado, os candidatos utilizam os prazos dados pelos Centros para adquirir o máximo de informação e, assim, tomar uma decisão mais “segura”. Dessa forma os candidatos agem como se definissem, de fato, suas preferências sobre os Centros após receber todas as ofertas e colher todas as informações necessárias. Se isto ocorre, então uma possível pressão por parte de um Centro para uma definição rápida, ou mesmo uma oferta explosiva, pode ser vista de forma negativa por um candidato, pois este não tem tempo de colher as informações sobre os Centros. Assim, esta pressão pode contribuir negativamente na definição das preferências do candidato. Se a pressão for muito forte, o candidato acaba aceitando a oferta sem muita convicção e, posteriormente, pode voltar atrás na decisão. Isto explica o fato dos Centros evitarem ofertas explosivas e concederem ampliação do prazo de resposta quando solicitados pelos estudantes.

Por fim, dado o exposto acima, as repetições do estágio 2 tornam-se lentas, e o mecanismo de matching acaba sendo um processo demorado, que se desenrola ao longo de algumas semanas, envolvendo camadas sucessivas de Centros, com os mais procuradas liderando o processo e, assim, definindo seus futuros alunos mais rapidamente.

\subsubsection{Resultado do matching: Observações empíricas}

O primeiro ponto a se destacar em relação ao resultado do matching é que os oito Centros mais preferidos geralmente recebem os melhores estudantes em suas listas. Mais que isto, existem três Centros que se destacam mais que os outros e, via de regra, completam suas turmas com candidatos classificados até a posição de número cinqüenta em suas listas. Esses três Centros serão referenciadas a partir de agora como Instituições tipo 1. Os outros cinco Centros mais procurados costumam preencher a maioria de suas vagas com candidatos classificados no intervalo entre o número cinqüenta e o número cento e vinte nas suas listas. Estes cinco Centros 
serão referenciadas a partir de agora como Instituições tipo 2. Por fim, os outros dezesseis Centros recebem candidatos classificados a partir da posição cento e vinte em suas listas. Estas dezesseis Instituições serão referenciadas a partir de agora como Instituições tipo 3. As ilustrações B1, B2, e B3 do apêndice B apresentam as turmas de candidatos admitidos por cada Centro por faixa de classificação dos candidatos segundo o critério próprio do Centro. As ilustrações B4, B5 e B6 apresentam as turmas de candidatos admitidos por cada Centro por faixa de classificação dos candidatos segundo o critério da ANPEC (que aplica pesos iguais para todas as provas).

Outro ponto importante que se observa é que a intersecção dos conjuntos de candidatos melhor colocados segundo o critério da ANPEC e segundo o critério de cada Centro é muito grande. Em média, quase $70 \%$ dos cinqüenta melhores candidatos segundo a classificação da ANPEC também está entre os cinqüenta melhores pelos critérios de todos os outros Centros. Quando consideramos somente $80 \%$ dos Centros, essa média sobe para 85\%. Ou seja, 85\% dos melhores candidatos pelo critério da ANPEC também são os melhores candidatos para, pelo menos, 80\% dos Centros. Por outro lado, para os candidatos com classificação entre 50 e 120 pelo critério da ANPEC, 45\% tem classificação na mesma faixa pelos critérios de todos os outros Centros. Quando consideramos somente 80\% dos Centros esse índice sobe consideravelmente para 74\%, em média. Por fim, 85\% dos candidatos com classificação entre 120 e 300 pelo critério da ANPEC tem classificação na mesma faixa pelos critérios de todos os outros Centros. Considerando somente $80 \%$ dos Centros, a média sobe para 95\%. Com isso, vamos usar a mesma referência definida para os Centros para representar os candidatos, ou seja, os candidatos classificados até a posição de número cinqüenta pelo critério da ANPEC serão chamados candidatos tipo 1, os com classificação entre cinqüenta e cento e vinte serão chamados candidatos tipo 2, e os demais serão chamados candidatos tipo 3. Os dados completos sobre as intersecções dos conjuntos de candidatos de mesmo tipo para os Centros são apresentados na tabela B1 do apêndice B. Pelos dados da tabela podemos afirmar que, apesar desses conjuntos não serem iguais, as intersecções são muito grandes.

Vale lembrar que oito Centros, sendo três do tipo 2 e cinco do tipo 3 também ponderam a nota da prova discursiva de Economia Brasileira na formação de suas listas de preferências, mas este 
fator não aparece nas estatísticas acima, pois as provas discursivas são corrigidas pelos próprios Centros e incorporados nas listas publicadas pela ANPEC posteriormente. Como não temos tais informações, não foi possível adicioná-las nas estatísticas apresentadas. No entanto, o coordenador de um desses Centros nos informou que a avaliação das provas discursivas não provoca grandes alterações na lista publicada pela ANPEC.

Os três Centros tipo 1 somam juntos cinqüenta vagas, sendo vinte da EPGE/FGV-RJ, quinze do IPE/USP(TE) e quinze da PUC-RJ. Os cinco Centros tipo 2 somam setenta e nove vagas e os Centros tipo 3, 232 vagas. Dessa forma, cada Centro oferece, em média, 15 vagas. A tabela abaixo apresenta todos os Centros com a classificação proposta por tipos e o número de vagas oferecidas. (Baseado no edital do concurso ANPEC do ano de 2003).

Com base nestas novas informações podemos agora retomar algumas questões discutidas na seção anterior. Inicialmente, como os Centros tipo 1 concorrem pelo mesmo grupo de candidatos, observamos que eles coordenam suas ações em relação às visitas e as datas limites de aceite. Assim, podemos supor que os candidatos, em geral, preferem qualquer Centro tipo 1 a qualquer Centro de outro tipo, no entanto, quando se inicia o segundo estágio do jogo, os candidatos não têm clara suas preferências em relação aos três Centros tipo 1. Isto justifica todo o esforço de organizar uma visita por parte dos Centros tipo 1, na tentativa de fazer com que os candidatos definam suas preferências em seu favor. Isto também justifica, de forma mais clara, porque os Centros tipo 1 não fazem ofertas explosivas. Imagine que o candidato tipo 1 receba uma oferta explosiva de um Centro tipo 1. Este candidato sabe que é tipo 1 (pois as listas dos Centros são publicadas) e que receberá outras duas ofertas tipo 1 (pois os conjuntos dos candidatos tipo 1 de todos os Centro têm grande intersecção). Se este candidato não tem suas preferências sobre os Centros tipo 1 bem definidas, ele deseja conhecer os dois outros Centros tipo 1 antes de decidir e, assim, ficará melhor se jogar a ação "moderada", aceitando esta oferta explosiva. Com isso ele pode conhecer os outros dois Centros e decidir, de fato, posteriormente. No caso da decisão favorecer algum dos outros dois Centros ele declina do compromisso com a oferta explosiva. Dessa forma, a oferta explosiva de um Centro tipo 1 para um candidato tipo 1 não beneficia o Centro que faz a oferta explosiva. 
Tabela 3 - Classificação dos Centros por tipos

\begin{tabular}{|c|c|c|}
\hline Tipo & Centro & $\mathrm{N}^{\circ}$ de Vagas \\
\hline \multirow{3}{*}{ Tipo 1} & EPGE/FGV-RJ & 20 \\
\hline & \begin{tabular}{|l|} 
IPE/USP(TE) \\
\end{tabular} & 15 \\
\hline & PUC-RJ & 15 \\
\hline \multirow{5}{*}{ Tipo 2} & FGV-SP & 16 \\
\hline & IE/UFRJ & 20 \\
\hline & IE/UNICAMP & 15 \\
\hline & IPE/USP(EID) & 10 \\
\hline & UNB & 18 \\
\hline \multirow{16}{*}{ Tipo 3} & CAEN/UFC & 15 \\
\hline & \begin{tabular}{|l|} 
CEDEPLAR/UFMG \\
\end{tabular} & 15 \\
\hline & CME/UFBA & 20 \\
\hline & ME/UFES & 15 \\
\hline & ME/UFU & 10 \\
\hline & NAEA/UFPA & 12 \\
\hline & PIMES/UFPE & 20 \\
\hline & \begin{tabular}{|l} 
PPGE/UFRGS \\
\end{tabular} & 15 \\
\hline & PUC-SP & 20 \\
\hline & UCB & 12 \\
\hline & \begin{tabular}{|l|} 
UEM-PR \\
\end{tabular} & 15 \\
\hline & UFF & 15 \\
\hline & UFPB/JP & 06 \\
\hline & UFPR & 12 \\
\hline & UFSC & 15 \\
\hline & UNESP/AR & 15 \\
\hline
\end{tabular}

Analogamente, os Centros tipo 2 concorrem pelo mesmo grupo de candidatos e coordenam suas ações em relação às visitas e as datas limites de aceite. Da mesma forma, podemos supor que os candidatos, em geral, preferem Centros tipo 2 a Centros tipo 3, no entanto, inicialmente os candidatos não têm clara qual sua preferência em relação aos cinco Centros tipo 2. Isto justifica todo o esforço de organizar uma visita por parte dos Centros tipo 2, na tentativa de fazer com que os candidatos definam suas preferências em seu favor. Isto também justifica, de forma mais clara porque os Centros tipo 2 não fazem ofertas explosivas. Usando o mesmo raciocínio anterior, 
podemos concluir que a oferta explosiva de um Centro tipo 2 para um candidato tipo 2 não beneficia o Centro que faz a oferta explosiva. Imagine agora que um Centro tipo 2 faça uma oferta explosiva a um candidato tipo 1 . Como ele sabe que é tipo 1, ele sabe que vai receber pelo menos uma oferta de um Centro tipo 1, portanto pode aceitar a oferta e declinar posteriormente, segundo a ação "moderada”, ou pode inclusive jogar a ação "de risco" rejeitando a oferta tipo 2 para esperar a oferta tipo 1 (que ele sabe que receberá). Dessa forma, os Centros tipo 2 não se beneficiam com a oferta explosiva.

Por fim, temos a mesma questão para os Centros tipo 3. No entanto, como os Centros tipo 3 concorrem em um grupo maior de candidatos, elas não costumam fazer visitas. Também podemos supor que os candidatos inicialmente têm suas preferências em relação aos Centros tipo 3 indefinidas e o argumento contrário a ofertas explosivas para candidatos tipo 3 é o mesmo.

Do exposto acima, podemos concluir que a ação "moderada" sempre dá aos candidatos uma alocação melhor que a ação "de segurança”. Dessa forma, os Centros não tem incentivo de fazer ofertas explosivas. De fato, dado que o candidato não usa a ação "de segurança”, se o Centro fizer uma oferta explosiva e o candidato aceitá-la até o final do jogo, este candidato também iria aceitá-la até o final do jogo se esta oferta fosse aberta. Por outro lado, se o candidato aceitar a oferta explosiva e recusá-la posteriormente, ele também iria recusá-la caso a oferta fosse aberta. Neste caso, no entanto, o Centro que acreditara já ter preenchido esta vaga, terá que entrar novamente no jogo em busca de outro candidato para preenchê-la. Portanto, em todos os casos, o Centro fica melhor ou igual lançando uma oferta aberta ao que ficaria lançando uma oferta explosiva.

No mercado da ANPEC também não ocorre o processo de antecipação, observados em vários mercados estudados em Roth e Xing (1994), por uma simples razão: de fato, os Centros só podem fazer ofertas depois que o resultado das provas é publicado pela ANPEC. Dessa forma, não há como os Centros se anteciparem para fazer ofertas mais cedo. Portanto, estamos lidando com um mercado descentralizado que não experimenta o processo de antecipação nem ofertas explosivas. 
Quando comparado com os outros mercados de dois lados apresentados anteriormente, o mercado da ANPEC apresenta características, principalmente em relação à informação disponível para os participantes, que o tornam diferenciado. No mercado de residências médicas, por exemplo, quando um candidato recebe uma oferta, ele não sabe sua posição na lista de preferências do hospital que está fazendo a oferta, nem na lista dos demais hospitais do mercado. Isto o torna mais susceptível a aceitar uma oferta explosiva e se comprometer com ela. No mercado da ANPEC, o candidato que recebe uma oferta tem informação completa sobre as listas de preferências de todos os Centros, portanto, ele pode avaliar com "boa" segurança as possibilidades de receber outras ofertas melhores. Dessa forma, o candidato se torna mais avesso a ofertas explosivas, como já discutido anteriormente. Por outro lado, no mercado de residências médicas, os hospitais definem suas preferências de forma gradual. Essas preferências são baseadas nas notas dos estudantes durante todo o curso de graduação em medicina. Assim, os hospitais tinham que decidir entre fazer uma oferta para um estudante que tinha tido ótimas notas no início da universidade ou esperar até o final do curso para se certificar que aquele era realmente um bom candidato. No mercado da ANPEC isto não ocorre, a informação completa sobre os candidatos já está disponível para os Centros quando o resultado dos exames é publicado. Quanto aos candidatos, muitos definem suas preferências sobre Centros de mesmo tipo de forma gradual, baseados nas informações que recebem dos Centros durante as visitas. Enfim, a maneira diferenciada como as informações sobre os participantes de um lado do mercado se tornam disponíveis para os participantes do outro lado caracterizam o mercado da ANPEC de forma bastante diferenciada em relação a todos os encontrados na literatura.

Uma outra característica também marcante no mercado da ANPEC é a indústria de preparação para as provas que surgiu os últimos anos. Existem cursinhos especializados, materiais didáticos específicos para estudar para os exames e, ainda, livros com as provas dos últimos anos resolvidas e comentadas. Por outro lado, como as notas nos exames e as classificações dos candidatos são divulgadas pela ANPEC todo ano, os estudantes estimam com boa aproximação que notas precisam ter para serem aceitos em determinado Centro. Com tudo isso, os candidatos podem ter uma "boa” avaliação sobre seu tipo quando declaram suas listas truncadas. 
Como dito anteriormente, este mercado descentralizado da ANPEC está se repetindo desde 1998. Isto possibilitou que os participantes experimentassem um processo de aprendizado. Atualmente os candidatos se sentem encorajados a voltar atrás em acordos firmados quando recebem ofertas mais preferidas. Dessa forma, eles aprenderam que a ação "moderada" lhes dá sempre um resultado melhor que a ação "de segurança”. O crescimento do mercado, demonstrado no gráfico 1 também pode ter contribuído para este comportamento dos estudantes, pois uma quebra de acordo em um mercado maior é menos evidente para um candidato. Os Centros, por sua vez, aprenderam que fazer ofertas explosivas não é a melhor opção. De fato, observa-se que os Centros tipo 1 e 2 dão um tempo de resposta suficiente para os candidatos decidirem. Os Centros tipo 2 costumam dar um tempo maior ainda que os Centros tipo 1. Os Centros tipo 3, em parte, também tiveram esse aprendizado. Os tempos de resposta concedidos por uma parte dos Centros tipo 3 é maior que o tempo dos Centros tipo 2. Uma outra parte, no entanto, ainda não percebeu este fato. Identificamos Centros tipo 3 que pressionam os candidatos por respostas mais rápidas, outros que mudam seus prazos de resposta repetidamente, aumentando num ano e reduzindo no outro. Estes Centros ainda estão em fase de aprendizado. Evidentemente, apesar do processo de aprendizado por parte dos candidatos, não podemos descartar o fato de existirem pessoas que não se sentem confortáveis em quebrar suas palavras. Quando um candidato como este recebe uma oferta de um Centro 3 mais agressivo, surge a possibilidade de alocações instáveis no atual mecanismo.

Portanto, para os Centros tipo 1 e 2, o atual mecanismo descentralizado é uma simulação aproximada do algoritmo NRMP, pois, mesmo que existam alguns candidatos que não usem a ação "moderada", os Centros dão tempo suficiente para que eles decidam da melhor forma. Para os Centros tipo 3 essa conclusão não é tão clara. Como alguns ainda reduzem o prazo de resposta, um candidato que ainda não tenha aprendido a usar a ação "moderada” pode provocar uma intabilidade no matching resultante. Um outro problema também acontece na alocação dos candidatos para os Centros tipo 3: o fato das listas de Centros aceitáveis serem truncadas em até seis. Isto será abordado na seção 7 . 


\subsubsection{Relatos de Centros e candidatos}

Nesta seção apresentaremos testemunhos dos coordenadores de alguns Centros e de alguns estudantes que participaram do mercado. Os fatos relatados reforçam as observações descritas nas seções anteriores e apontam possibilidades de falhas no matching resultante com o atual mecanismo descentralizado.

O primeiro depoimento, dado pelo coordenador do IE/UNICAMP, classificado como tipo 2, aponta a forma descoordenada com que o processo de matching é conduzido durante o estágio 2 do jogo como fonte de imperfeição informacional, em que os candidatos não sabem se os Centros já preencheram suas vagas e os Centros não sabem se os candidatos já tomaram suas decisões.

O mercado pouco organizado, com grande número de Centros ofertantes e candidatos demandantes de vagas e assimetria de informação, forma um jogo complexo, demorado, trabalhoso. Gera desgaste emocional e perda de tempo para todos.

Este mesmo coordenador sugere, para melhorar o processo de matching, que as listas declaradas pelos candidatos contenham uma ordem de preferência estrita.

Gostaria que se considerasse a possibilidade de que os candidatos enunciassem uma ordem de preferência. [...]. Isto poderia sinalizar mais claramente ao Centro a possibilidade de que um aluno venha de fato a optar por ele.

O coordenador da UNB, outro Centro classificado como tipo 2, identifica o prazo para aceite diferenciado e a pressa dos Centros para entrar em contato com os candidatos após a divulgação dos resultados como fontes de distúrbios ao mecanismo. Ele sugere, como uma forma de melhoria de procedimento, que as repetições do segundo estágio tenham prazos de aceite comuns.

Creio que a corrida por alunos que ocorre logo após a divulgação do resultado possui efeitos ruins sobre a seleção. As rodadas de convocação deveriam ter prazos comuns a todos os Centros. Desta forma o aluno receberia a convocação de todos os Centros pelos quais optou e foi aceito e teria uma data para dar a resposta (data comum a todos os Centros). Os Centros participariam de sucessivas rodadas até preencher por completo suas vagas.

Outro relato, agora do coordenador do PPGE/UFRGS, classificada como tipo 3, indica que a necessidade de esperar que os Centros mais concorridos (tipos 1 e 2) definam suas turmas prejudica sua própria seleção. Isto corrobora a observação de que o matching pelo atual 
mecanismo descentralizado é um processo demorado no qual os Centros menos concorridos definem suas turmas depois dos mais concorridas.

A necessidade de espera dos melhores colocados em decidir em que Centro querem ir, dentro do numero limitado de bolsas. Isto atrapalha a chamada de outros alunos, não tão bem colocados (ou seja, com capacidade de aceite entre os melhores Centros (EPGE/FGV-RJ, PUC-RJ, IPE/USP(TE)).

O comportamente dos candidatos seguindo a ação "moderada” foi apontado pelo coordenador do ME/UFU, outro Centro classificado como tipo 3, como um problema para sua seleção. Ele caracteriza de leilão as ações dos Centros para influenciar a definição de preferências dos candidatos e, assim, conseguir o comprometimento definitivo por parte do candidato.

O processo de escolha de 6 Centros alternativos acaba transformando o exame em um leilão. Para os Centros de menor porte fica muito difícil selecionar.

O coordenador do UFPB/JP também identifica esse comportamento dos candidatos como problemático. No entanto, os candidatos estão agindo estrategicamente.

O aluno passou as duas semanas e no final disse que não queria ingressar no mestrado porque um outro programa ofereceu a ele melhores condições (não raras foram as vezes que o aluno queria negociar, do tipo, eles me deram isto e se vocês me dessem eu ia para seu programa). [...]. Leilão é o procedimento que faz revelar o que tem de pior num aluno.

O coordenador da EPGE/FGV-RJ, classificada como tipo 1, argumenta que um mecanismo centralizado de matching poderia ser aplicado no mercado da ANPEC.

Um modelo de matching poderia ser aplicado após a semana de visitas aos Centros, que é fundamental para que os alunos adquiram informações mais detalhadas sobre os Centros para os quais foram chamados. Ao invés de aceitar todos os alunos chamados que vão para a visita, o que implica em risco de se ter uma turma muito grande, os Centros poderiam chamar os alunos em que têm interesse, e depois o matching alocaria os alunos aos Centros. A operacionalização seria assim: após a semana de visitas os Centros enviariam à ANPEC a lista com a ordenação dos alunos e o tamanho desejado da turma condicionado à classificação do último aluno que o Centro aceita. [...]. Por sua vez, os alunos enviariam à ANPEC a ordenação dos Centros. Os alunos também enviariam à ANPEC o conjunto dos Centros que não gostariam de estudar. A ANPEC rodaria o modelo e alocaria os alunos nos Centros.

Finalmente, temos a experiência de um candidato que participou do mecanismo em 2003. Depois de realizadas as provas e divulgado o resultado final, este candidato, que será denominado $c_{1}$, recebeu um convite do Centro (denominaremos $I_{2}$ ) que estava em segundo lugar na sua lista de preferências. Na expectativa de receber um convite do Centro mais preferido (denominaremos $\left.I_{1}\right), c_{1}$ resolveu esperar todo o prazo que $I_{2}$ havia determinado antes de dar sua resposta. Passados 
alguns dias, $c_{l}$ entrou em contato com $I_{1}$ e foi informado que era o primeiro na lista de espera, ou seja, se $I_{1}$ tivesse alguma recusa dos candidatos inicialmente convidados, $c_{1}$ seria convidado por $I_{1}$. Dessa forma $c_{1}$ resolveu esperar até o último instante por um convite de $I_{1}$. Por sua vez $I_{2}$, ao se aproximar o final do prazo de aceite dado, pressionava $c_{1}$ por uma definição, através de sucessivas chamadas telefônicas. O mecanismo ficou bloqueado até que o coordenador de $I_{l}$, conhecendo a situação de $c_{1}$, entrou em contato com o coordenador de $I_{2}$ e foi informado que havia um outro candidato (denominaremos $c_{2}$ ) que fora convidado por $I_{1}$ e era o primeiro na lista de espera de $I_{2}$. Como $c_{2}$ preferia $I_{2}$ a $I_{1}$, ele também estava esperando até o último momento por um convite de $I_{2}$. Com essas informações, $I_{1}$ e $I_{2}$ estabeleceram uma ação coordenada de tal forma que $c_{1}$ recusou o convite de $I_{2}, c_{2}$ recusou o convite de $I_{1}, c_{1}$ foi convidado por $I_{1}$ e $c_{2}$ foi convidado por $I_{2}$.

Dessa forma, a alocação final não apresentou instabilidades. Por outro lado, se $c_{1}$ e $c_{2}$ continuassem jogando a ação "moderada” e não houvesse a ação coordenada de $I_{1}$ e $I_{2}$, o matching resultante seria $\left(c_{1}, I_{2}\right),\left(c_{2}, I_{1}\right)$, que também é estável, mais preferido pelas Instituições que o anterior, mas menos preferido pelos candidatos. No entanto, imagine se $c_{1}$ jogasse a ação “de risco”, rejeitando o convite de $I_{2}$ na esperança de receber o convite de $I_{1}$ e $c_{2}$ jogasse a ação “de segurança”, aceitando a oferta de $I_{1}$. Assim, o resultado final seria instável, pois $c_{1}$ não receberia o convite de $I_{l}$ e, se recebesse outro convite, seria por um Centro menos preferido que $I_{2}$. $I_{2}$ por sua vez faria o convite a um candidato com resultado pior nos exames que o de $c_{1}$. Com isso o par $\left(c_{1}, I_{2}\right)$ representaria uma instabilidade à alocação final.

Por outro lado, este exemplo também pode ilustar a questão da manipulabilidade. Devido a ação coordenada dos Centros envolvidos, o matching resultante foi melhor para os estudantes que seria pelo algoritmo NRMP. Imagine se os Centros não tivessem interesse em satisfazer a vontade dos candidatos. Então estes candidatos poderiam manipular o procedimento. Para isso, bastava $c_{1}$ não listar $I_{2}$ na sua lista de aceitáveis e $c_{2}$ não listar $I_{1}$ na sua. Esta seria uma forma de manipulação coletiva possível se os dois candidatos se conhecessem, por exemplo, tivessem sido colegas durante o curso de graduação, ou mesmo durante algum curso de preparação para os exames da ANPEC. O algoritmo NRMP é manipulável individualmente e coletivamente pelos candidatos. 


\subsection{Uma alternativa de aprimoramento do mercado descentralizado da ANPEC}

Em 1997 Roth e Xing analisaram o funcionamento do mercado descentralizado de Residências em Psicologia nos Estados Unidos. Este mercado determinou um dia específico, chamado "Dia de Seleção”, no qual todas as transações deveriam ser realizadas, via telefone, no horário das 9:00 às 16:00h. As normas do mercado determinavam que nenhuma oferta poderia ser feita antes das 9:00h do dia de seleção e que todas as ofertas deveriam permanecer abertas até as 16:00h do mesmo dia. Isto eliminava o processo de antecipação e as ofertas explosivas. Para tanto, este mercado desenvolveu um detalhado conjunto de regras que, embora simples, definem de forma completa as possíveis ações dos candidatos e das Instituições e o prazo de duração do mercado. A seguir transcrevemos de Roth e Xing (1997) as regras de 3 a 6.

3. Nenhuma oferta pode ser feita antes do dia de seleção.

3a. A única informação que as Instituições podem comunicar aos candidatos antes deste dia é se os candidatos são aceitáveis ou não. A intenção deste item é evitar a comunicação da posição de determinado candidato na lista das Instituições antes do dia de seleção.

3b. Candidatos suplentes podem ser informados de seu status a qualquer tempo depois do início do dia de seleção. Candidatos não podem receber a informação se são suplentes ou candidatos prioritários antes deste momento.

3c. As Instituições não podem solicitar informação a respeito da lista de nenhum candidato ou sua intenção de aceitar ou rejeitar uma oferta antes da oferta ser oficialmente feita.

4. Os candidatos devem responder a todas as ofertas até a hora de encerramento do dia de seleção.

4a. Este limite se aplica a todas as ofertas inclusive àquelas a aplicantes inicialmente considerados suplentes que recebem uma oferta a qualquer momento anterior ao final do dia de seleção.

4b. As Instituições podem questionar sobre o progresso da decisão do candidato a qualquer tempo após a oferta ter sido feita. No entanto, as Instituições não podem, sob nenhuma circunstância, ameaçar implícita ou explicitamente retirar a oferta se a decisão do candidato ainda não estiver tomada antes do encerramento do dia de seleção (exceto nos casos do item 6).

4c. É do interesse de todos que os candidatos tomem e comuniquem as decisões de aceitar ou rejeitar cada oferta o mais rapidamente possível.

4d. Qualquer oferta que não tenha sido aceita é válida até o final do dia de seleção.

5. Um candidato deve responder imediatamente a cada oferta que recebe de uma das três maneiras. A oferta deve ser "aceita", "rejeitada" ou "segurada".

5a. "Aceitar" uma oferta constitui um compromisso firme entre a Instituição e o candidato.

5b. "Recusar" uma oferta anula todas as obrigações de ambas as partes e libera a Instituição para oferecer aquela vaga a outro candidato.

5c. "Segurar" uma oferta significa que a oferta permanece válida até que o candidato comunique à Instituição sua recusa ou aceitação, ou até o final do dia de seleção.

6. Um candidato não pode "segurar" mais de uma oferta ativa de cada vez. 
6a. Se um candidato está segurando uma oferta de uma Instituição e recebe uma oferta de outra Instituição mais preferida, ele deve aceitar ou "segurar" a segunda oferta e comunicar imediatamente à Instituição menos preferida que está recusando a primeira.

6b. Se uma Instituição confirma que um candidato está segurando mais de uma oferta, a Instituição é livre para retirar sua oferta a este candidato e, após comunicá-lo de sua decisão, oferecer a vaga a outro candidato.

Podemos verificar que a estrutura básica de organização desse mercado é dada pelas regras transcritas acima. As regras 3 e 4 determinam o tempo de duração do mercado. As regras 5 e 6 determinam que as ofertas serão feitas pelas Instituições e respondidas pelos candidatos de acordo com a seqüência descrita no algoritmo NRMP. Ou seja, o mercado de residências em psicologia desenvolveu um mecanismo descentralizado que reproduz o algoritmo NRMP.

Se o tempo de duração do mercado é suficiente para que todas as transações possíveis sejam realizadas, então o resultado do matching será o matching ótimo para as Instituições. No entanto, as transações levam tempo para serem realizadas. O tempo em que um candidato segura uma oferta antes de rejeitá-la, o tempo para que uma Instituição que teve uma oferta rejeitada contate outro candidato. O tempo que este outro candidato, ao segurar esta nova oferta, leva para rejeitar uma outra oferta que estava segurando e assim por diante. Portanto, estes mercados não podem chegar a um equilíbrio instantâneo, pois eles ficam congestionados. Quando um mercado tem um prazo determinado para terminar, corre-se o risco deste prazo se esgotar e nem todas as transações terem efetivamente se realizado. Nesse sentido, o pior que pode acontecer para uma Instituição é ter uma ou mais ofertas rejeitadas momentos antes do prazo do mercado se esgotar, de forma que ela não tenha tempo de fazer outras ofertas (pois quando o mercado termina todos os candidatos aceitam a oferta que estavam segurando). Esta Instituição ficará então com vagas não preenchidas ou aceitará candidatos que não receberam oferta de nenhuma outra Instituição e, portanto, também ficaram sem par no encerramento do mercado. Este tipo de arranjo é chamado de "mercado tardio". Muito provavelmente o matching resultante será instável, pois esta Instituição não teve tempo de fazer ofertas aos candidatos mais preferidos de sua lista. Portanto, quando o tempo de duração do mercado é curto em relação ao tempo de realização das transações, o resultado do matching provavelmente não será o ótimo para as Instituições. Mais ainda, o matching provavelmente será instável. Roth e Xing argumentam ainda que, ao se expandir o tempo de duração de um mercado, também se expande o tempo de realização das transações, pois os candidatos e as Instituições não estarão mais sempre ao lado do telefone. Essa 
foi a motivação pela qual o mercado de residência em psicologia determinou o período de um dia para a duração do mercado. Com o período curto, os participantes estariam ao lado do telefone durante todo o dia e o tempo de realização do mercado seria reduzido.

Quando as Instituições são pegas de surpresa no encerramento do mercado sem terem preenchido todas as suas vagas e sem tempo para fazer novas ofertas elas têm incentivo de, no ano seguinte, identificar e fazer ofertas para aqueles candidatos mais propensos a aceitá-las rapidamente, mesmo que não sejam seus preferidos, ou, em último caso, desrespeitar as regras do mercado. Os candidatos, por sua vez, têm incentivo de sinalizar suas preferências a fim de se apresentarem como propensos a aceitar ofertas rapidamente e, assim, evitar o risco de não receber nenhuma oferta antes do fim do mercado. Com os participantes agindo segundo esses incentivos, o mercado descentralizado já não segue mais o algoritmo NRMP.

O mercado da ANPEC não tem prazo determinado para terminar. Em realidade o mercado se inicia em novembro, com a publicação dos resultados dos exames, e termina no início de janeiro, quando começam os cursos em alguns Centros. Em outros somente em março. Com isso, caso a ANPEC adote algumas das regras do mercado de residências em psicologia, teríamos um intervalo de quase dois meses para que as transações fossem realizadas. Como o uso da telefonia celular está bastante difundido no Brasil, por mais que o tempo de realização das transações aumente como argumentado por Roth e Xing, os celulares não deixariam que esse tempo aumentasse significativamente. Assim, é muito provável que este período de quase dois meses seja mais que suficiente para que todas as transações no mercado da ANPEC sejam realizadas. Dessa forma podemos propor as seguintes regras para o mercado da ANPEC.

1. Ao se inscreverem nos exames os candidatos não declaram nenhuma lista de preferências.

2. Nenhuma oferta pode ser feita antes do resultados dos testes.

3. Todas as ofertas são válidas até o encerramento do mercado a ser determinado no edital do concurso (respeitando o período mínimo de um mês de funcionamento do mercado).

3a. A partir da data da divulgação dos resultados as Instituições devem disponibilizar todas as informações possíveis aos candidatos. Visitas e entrevistas podem ser organizadas pelas Instituições. 
3b. Candidatos em lista de espera podem ser informados de seu status a qualquer tempo depois da divulgação do resultado dos resultados.

3c. As Instituições não podem solicitar informação a respeito da lista de nenhum candidato ou sua intenção de aceitar ou rejeitar uma oferta antes da oferta ser oficialmente feita.

4. Os candidatos devem responder a todas as ofertas até o dia de encerramento do mercado a ser determinado no edital do concurso (respeitando um período mínimo de um mês de funcionamento do mercado).

4a. Este limite se aplica a todas as ofertas inclusive àquelas a aplicantes inicialmente em lista de espera que recebem uma oferta a qualquer momento anterior ao dia de encerramento do mercado.

4b. As Instituições podem questionar sobre o progresso da decisão do candidato a qualquer tempo após a oferta ter sido feita. No entanto, as Instituições não podem, sob nenhuma circunstância, ameaçar implícita ou explicitamente retirar a oferta se a decisão do candidato ainda não estiver tomada antes do encerramento do mercado (exceto nos casos do item 5).

4c. É do interesse de todos que os candidatos tomem e comuniquem as decisões de aceitar ou rejeitar cada oferta o mais rapidamente possível.

5. Um candidato deve responder imediatamente a cada oferta que recebe de uma das três maneiras. A oferta deve ser "aceita”, "rejeitada” ou "segurada".

5a. "Aceitar" uma oferta constitui um compromisso firme entre a Instituição e o candidato.

5b. "Recusar" uma oferta anula todas as obrigações de ambas as partes e libera a Instituição para oferecer aquela vaga a outro candidato.

5c. "Segurar" uma oferta significa que a oferta permanece válida até que o candidato comunique à Instituição sua recusa ou aceitação, ou até o final do mercado.

6. Um candidato não pode "segurar" mais de uma oferta ativa de cada vez.

6a. Se um candidato está segurando uma oferta de uma Instituição e recebe uma oferta de outra Instituição mais preferida, ele deve aceitar ou "segurar" a segunda oferta e comunicar imediatamente à Instituição menos preferida que está recusando a primeira oferta. 
6b. Se uma Instituição confirma que um candidato está segurando mais de uma oferta, a Instituição é livre para retirar sua oferta a este candidato e, após comunicá-lo de sua decisão, oferecer a vaga a outro candidato.

7. O mercado se encerra na data determinada no edital do concurso, ou quando não houver mais nenhuma Instituição fazendo novas ofertas, o que ocorrer primeiro.

Com estas regras as transações seriam realizadas no mercado da ANPEC conforme a seqüência do algoritmo NRMP. Se o período de duração do mercado fosse suficiente para que todas as transações sejam realizadas, então o resultado do matching seria o ótimo para as Instituições, segundo as preferências usadas pelos participantes ao longo do mecanismo. Portanto, este sistema de regras configurar-se-ia como uma alternativa de aprimoramento do mercado da ANPEC.

Por outro lado, apesar desta nova forma de organização do mercado da ANPEC representar uma melhoria em relação ao modelo atual, esta melhoria retratar-se-ia apenas no resultado final do matching, pois no modelo proposto o resultado seria o estável ótimo para as Instituições, enquanto que no modelo atual o matching resultante possivelmente exiba instabilidades. No entanto, o custo operacional do modelo proposto seria tão grande quanto o do modelo atual. O processo de matching se prolonga por semanas. As Instituições e candidatos se envolvem num processo desgastante de ofertas e respostas, que geram custos telefônicos para ambos. As Instituições mais concorridas incorrem num elevado custo financeiro para organizar as visitas aos Centros. Pelo menos um funcionário da Instituição se vê deslocado de suas funções habituais para se dedicar ao processo de matching. Os candidatos, por sua vez, se vêem obrigados a retardar algumas decisões sobre seu futuro, pois o matching resultante implica, para muitos candidatos, em uma mudança de cidade. A fiscalização do cumprimento das regras é uma tarefa difícil para a ANPEC. Por fim, além de produzir este elevado custo financeiro e operacional, o modelo proposto, ao reproduzir o algoritmo NRMP, torna-se manipulável pelos candidatos, o que pode não ser desejável para o mercado da ANPEC. Todas estas desvantagens são eliminadas num mecanismo centralizado que determina o resultado do matching quase instantaneamente, sem custos, sem desgaste emocional para os participantes e sem necessidade de fiscalização e controle por parte da ANPEC. O mecanismo centralizado também pode gerar o matching estável ótimo para os candidatos, que é não manipulável pelos candidatos. 


\section{MODELO TEÓRICO E RESULTADOS EXPERIMENTAIS}

Nesta seção apresentamos um modelo de mercado descentralizado baseado nas observações do mercado da ANPEC e fazemos simulações desse modelo a fim de tirar conclusões que possam ser válidas para analisarmos o próprio mercado da ANPEC. As simulações serão realizadas assumindo três hipóteses distintas em relação ao grau de conhecimento que os candidatos têm sobre seus tipos. Estamos interessados em identificar possibilidades de ocorrência de alocações instáveis no matching resultante do mecanismo descentralizado para avaliarmos a eficiência deste mecanismo em produzir matchings estáveis. Com isso, podemos apontar alguns problemas que podem estar ocorrendo também no mercado da ANPEC.

O mercado com o qual são feitas as simulações será composto por menos jogadores que o mercado da ANPEC, mas mantendo a mesma relação proporcional entre os jogadores e a mesma estrutura de tipos descrita na seção anterior.

Este mercado teórico é composto por cinqüenta candidatos, sendo quatro do tipo 1, seis do tipo 2 e quarenta do tipo 3, e por quatorze Instituições, sendo duas do tipo 1, três do tipo 2 e nove do tipo 3. Cada Instituição possui uma cota igual a dois, representando o número de vagas de que dispõe. Denotaremos por $N(j)$ o conjunto de Instituições do tipo $j=1,2,3$. Definimos $N(1)=\left\{i_{1}\right.$, $\left.i_{12}\right\}, N(2)=\left\{i_{21}, i_{22}, i_{23}\right\}$ e $N(3)=\left\{i_{31}, i_{32}, \ldots, i_{39}\right\}$. Denotaremos por $M(j)$ o conjunto de candidatos do tipo $j=1,2,3$. Definimos $M(1)=\left\{c_{11}, c_{12}, c_{13}, c_{14}\right\}, M(2)=\left\{c_{21}, c_{22}, \ldots, c_{26}\right\}$, e $M(3)=\left\{c_{31}, c_{32}, \ldots\right.$, $c_{340\}}$. Sobre as preferências das Instituições estaremos assumindo o seguinte: as preferências das Instituições sobre o grupo de candidatos são correspondentes (como definido na seção 2) e todas as Instituições têm as mesmas preferências $P(i)$ sobre os candidatos, $P(i)=c_{11}, c_{12}, c_{13}, c_{14}, c_{21}$, $c_{22}, c_{23}, c_{24}, c_{25}, c_{26}, c_{31}, c_{32}, c_{33}, \ldots, c_{340}$, para todo $i \in N(1) \cup N(2) \cup N(3)$. Sobre as preferências dos candidatos assumimos: todas as Instituições são aceitáveis por todos os candidatos; todo candidato $c$ prefere qualquer Instituição do tipo 1 a qualquer Instituição do tipo 2, e prefere qualquer Instituição do tipo 2 a qualquer Instituição do tipo 3; dado um candidato $c$, uma Instituição do tipo 1 , $i_{1}$, uma Instituição do tipo 2 , $i_{2}$ e uma Instituição do tipo 3 , $i_{3}$, a probabilidade de $i_{1}$ ocupar a posição 1 (ou a posição 2) na lista de preferências verdadeira de $c$ é 
1/2 e de ocupar qualquer outra posição é zero; a probabilidade de $i_{2}$ ocupar qualquer posição de 3 a 5 é $1 / 3$ e de ocupar qualquer outra posição é zero; a probabilidade de $i_{3}$ ocupar qualquer posição de 6 a 14 é 1/9 e de ocupar qualquer outra posição é zero. Isto é, seja $a(k)$ a k-ésima posição na lista de preferências verdadeira de $c$ e $p(a(k)=i)$ a probabilidade de uma instituição $i$ preencher a k-ésima posição na lista de preferências verdadeiras de $c$. Então:

i) $p\left(a(1)=i_{1}\right)=p\left(a(2)=i_{1}\right)=1 / 2$; e $p\left(a(k)=i_{1}\right)=0, \forall k$ tal que $2<k \leq 14$

ii) $p\left(a(3)=i_{2}\right)=p\left(a(4)=i_{2}\right)=p\left(a(5)=i_{2}\right)=1 / 3$; e $p\left(a(k)=i_{2}\right)=0, \forall k \leq 2$ e $\forall k$ tal que $5<k \leq 14$

iii) $p\left(a(6)=i_{3}\right)=p\left(a(7)=i_{3}\right)=\ldots=p\left(a(14)=i_{3}\right)=1 / 9$; e $p\left(a(k)=i_{3}\right)=0, \forall k \leq 5$

Assim como no mercado da ANPEC o processo de matching é um jogo dinâmico que ocorre em dois estágios. No primeiro os candidatos submetem uma lista de Instituições aceitáveis com, no máximo, quatro Instituições. No segundo as Instituições fazem as ofertas e os candidatos, já conhecendo seus tipos, respondem. Estaremos assumindo que os candidatos sempre usam a ação "moderada” no segundo estágio. Assumimos também que não há uma data determinada para o encerramento do mercado. Dessa forma, o processo de matching mimifica o algoritmo NRMP. Por outro lado, como os candidatos sempre jogam a ação "moderada" no segundo estágio, podemos assumir que a estratégia de um candidato no jogo dinâmico é determinada apenas pela ação escolhida para o primeiro estágio do jogo. Com isso, iremos identificar as estratégias dos candidatos com as ações que eles jogam no primeiro estágio.

A seguir apresentamos as simulações do modelo assumindo três hipóteses distintas em relação ao grau de conhecimento que os candidatos têm sobre seus tipos no primeiro estágio: os candidatos conhecem seus tipos; os candidatos acreditam conhecer seus tipos, mas eles podem errar; os candidatos não conhecem seus tipos.

Pelo resultado da Proposição A7 (Apêndice A), este modelo só tem um matching estável segundo as verdadeiras preferências de candidatos e Instituições (matching este que seria obtido se os candidatos pudessem listar todas as Instituições). 
Também pela Proposição A7, este modelo só tem um matching estável segundo as verdadeiras preferências das Instituições e as preferências verdadeiras dos candidatos sobre as quatro Instituições listadas. Observe que essas preferências dos candidatos não são necessariamente as suas verdadeiras preferências sobre todas as Instituições disponíveis no mercado.

\subsection{Hipótese 1: Os candidatos conhecem seus tipos no momento de declarar suas listas de Instituições aceitáveis}

Assim sendo, os candidatos tipo 1 deverão listar ambas as Instituições tipo 1, as candidatos tipo 2 deverão listar todas as Instituições tipo 2 e, como todas as Instituições são aceitáveis para qualquer candidato, no matching resultante as Instituições tipo 1 e 2 preencherão suas vagas com candidatos tipo 1 e 2, respectivamente. Assim, os candidatos tipo 3 deverão listar apenas Instituições tipo 3. Como existem quarenta candidatos tipo 3 e somente dezoito vagas em Instituições tipo 3, vinte e dois candidatos ficarão sem Instituição. Embora um candidato saiba que é tipo 3, ele não sabe qual sua posição na lista das Instituições no momento de submeter sua lista. Assim, se um tal candidato vem a ser, por exemplo, o nono colocado do tipo 3 na lista das Instituições, pode acontecer dos oito primeiros candidatos tipo 3 nesta lista serem alocados para precisamente as mesmas quatro Instituições tipo 3 listadas pelo dado candidato. Neste caso, o candidato ficará sem Instituição. Assumindo que qualquer lista de quatro Instituições tipo 3 dá ao candidato a mesma chance de ficar sem Isntituição, podemos concluir que listar as quatro Instituições tipo 3 mais preferidas oferece ao candidato sua melhor alocação esperada.

Vejamos abaixo a formalização dessa discussão.

Lema 1. Seja $c$ um candidato de qualquer tipo e seja $L(c)$ a lista de Instituições aceitáveis declarada por $c$ ao mecanismo. Então $c$ não pode se beneficiar declarando um subconjunto próprio de Instituições aceitáveis de $L(c)$.

Demonstração: Considere o mercado onde o conjunto verdadeiro de Instituições aceitáveis para cada candidato é o declarado em sua lista ao mecanismo. Pelo resultado da Proposição A7 este 
mercado só tem um único matching estável, que é, portanto, ótimo para os candidatos. Denotaremos por $\mu_{C}$ este matching. Pela construção do mecanismo, $\mu_{C}$ é o matching resultante. Portanto, pelo Teorema da Não-manipulabilidade, este mecanismo é não manipulável individualmente pelos candidatos, o que implica que $c$ não poderá ser designado a uma Instituição preferida à $\mu_{C}(c)$ quando adultera sua lista de Instituições aceitáveis. Logo, $c$ não poderá se beneficiar declarando um subconjunto próprio de Instituições aceitáveis da lista $L(c)$.

Proposição 5. É uma estratégia fracamente dominante para os candidatos tipo 1 declarar todas as Instituições tipo 1 em suas listas de Instituições aceitáveis.

Demonstração. Seja $c_{1 k}$ um candidato tipo 1. Como a soma das cotas das Instituições tipo 1 é igual ao total de candidatos tipo 1 , se $c_{l k}$ declarar todas as Instituições tipo 1 ele receberá pelo menos uma oferta de alguma Instituição tipo 1. Por outro lado, se ele deixar de declarar uma Instituição tipo 1, pode ocorrer de todas as outras Instituições tipo 1 preencherem suas vagas com candidatos preferidos a $c_{1 k}$ e, então, $c_{l k}$ não receberá nenhuma oferta de Instituição tipo 1. Por fim, o fato de não declarar uma Instituição tipo 1 não pode beneficiar o candidato $c_{1 k}$. De fato, seja $L\left(c_{1 k}\right)$ a lista de Instituições aceitáveis para $c_{1 k}$ declarada ao mecanismo, contendo todas as Instituições do tipo 1. Seja $L^{\prime}\left(c_{1 k}\right)$ uma lista qualquer onde as Instituições do tipo 1 não são todas declaradas. Considere $L^{*}\left(c_{1 k}\right)=L\left(c_{1 k}\right) \cup L^{\prime}\left(c_{1 k}\right)$. Sejam $\mu$ e $\mu^{*}$ os matchings produzidos pelo mecanismo correspondentes a $L\left(c_{1 k}\right)$ e $L^{*}\left(c_{1 k}\right)$, respectivamente. Sabemos que $\mu\left(c_{1 k}\right)$ é uma Instituição do tipo 1. É claro que $c_{1 k}$ receberá oferta de $\mu\left(c_{1 k}\right)$ em $L^{*}\left(c_{1 k}\right)$. Como as Instituições acrescentadas à lista de $c_{1 k}$ são do tipo 2 ou 3, e são portanto menos preferidas do que $\mu\left(c_{1 k}\right)$, temos que $\mu^{*}\left(c_{1 k}\right)=\mu\left(c_{1 k}\right)$. Temos também que $L^{\prime}\left(c_{1 k}\right) \subsetneq L^{*}\left(c_{1 k}\right)$. O resultado segue do Lema 1 .

Proposição 6. É uma estratégia fracamante dominante para os candidatos tipo 2 declarar todas as Instituições tipo 2 em suas listas de Instituições aceitáveis.

Demonstração. Seja $c_{2 k}$ um candidato tipo 2. Como a soma das cotas das Instituições tipo 1 é igual ao total de candidatos tipo 1 e os candidatos tipo 1 declaram, de forma fracamente dominante, todas as Instituições tipo 1 em suas listas de aceitáveis, nenhuma Instituição tipo 1 é 
alcançável para $c_{2 k}$. Como a soma das cotas das Instituições tipo 2 é igual ao total de candidatos tipo 2 temos o argumento análogo ao da Proposição 5.

Proposição 7. Suponha que os candidatos tipo 1 e 2 seguem as estratégias fracamente dominantes especificadas nas Proposições 5 e 6. A estratégia de preencher suas listas de Instituições aceitáveis somente com Instituições tipo 3 e com as quatro mais preferidas dentre estas dá aos candidatos tipo 3 a melhor alocação esperada.

Demonstração: Seja $c_{3 k}$ um candidato tipo 3. Como a soma das cotas das Instituições tipo 1 é igual ao total de candidatos tipo 1 e os candidatos tipo 1 declaram, de forma fracamente dominante, todas as Instituições tipo 1, a soma das cotas das Instituições tipo 2 é igual ao total de candidatos tipo 2 e os candidatos tipo 2 declaram, de forma fracamente dominante, todas as Instituições tipo 2, nenhuma Instituição tipo 1 ou tipo 2 faz uma oferta a $c_{3 k}$. Então, sem perda de generalidade, podemos supor que $c_{3 k}$ somente lista Instituições tipo 3. Se $L\left(c_{3 k}\right)$ tem quatro Instituições, pelo Lema 1, declarar um subconjunto próprio de Instituições aceitáveis de $L\left(c_{3 k}\right)$ não beneficia o candidato para toda lista $L\left(c_{3 k}\right)$. Logo, podemos assumir que $c_{3 k}$ lista quatro Instituições aceitáveis do tipo 3. Por fim, dada a estrutura de preferências dos candidatos sobre as Instituições tipo 3 , a probabilidade de $c_{3 k}$ não receber nenhuma oferta, dado que ele é o k-ésimo candidato tipo 3 na lista de preferência das Instituições, independe do conjunto de quatro Instituições que $c_{3 k}$ declarar em sua lista. Portanto, declarando as quatro Instituições tipo 3 mais preferidas $c_{3 k}$ recebe a melhor alocação esperada.

Proposição 8. Suponha que os candidatos seguem as estratégias especificadas nas Proposições 5, 6 e 7. Então, nenhuma Instituição consegue preencher uma vaga com um candidato de tipo inferior ao seu.

Demonstração: Como a soma das cotas das Instituições tipo 1 é igual ao total de candidatos tipo 1 e a soma das cotas das Instituições tipo 2 é igual ao total de candidatos tipo 2 e supondo que os candidatos seguem as estratégias determinadas nas Proposições 5, 6 e 7, então todos os candidatos tipo 1 serão alocados em Instituições tipo 1 e todos os candidatos tipo 2 serão 
alocados em Instituições tipo 2. As Instituições tipo 3, por fim, receberão somente candidatos tipo 3.

Supondo que os participantes do mercado seguem as estratégias determinadas nas Proposições 5, 6 e 7, ou seja, candidatos tipo 1 declaram somente as duas Instituições tipo 1, candidatos tipo 2 declaram as três Instituições tipo 2, candidatos tipo 3 declaram as quatro Instituições tipo 3 mais preferidas, podemos realizar alguns testes computacionais do modelo com esta hipótese 1 . Como este mecanismo descentralizado mimifica o algoritmo NRMP, então devemos analisar somente os problemas decorrentes do truncamento das listas pelos candidatos.

Fizemos 10 simulações do modelo. Para estas simulações as preferências dos candidatos sobre Instituições do mesmo tipo foram formadas aleatoriamente através do gerador de números aleatórios do software econométrico Eviews 4.0. Os resultados obtidos são apresentados na tabela 4.

Tabela 4 - Número de instabilidades nos matchings simulados com a hipótese 1

\begin{tabular}{|l|c|c|c|c|c|c|c|c|c|c|c|}
\hline Matching & $\mu_{1 \mathrm{~A}}$ & $\mu_{1 \mathrm{~B}}$ & $\mu_{1 \mathrm{C}}$ & $\mu_{1 \mathrm{D}}$ & $\mu_{1 \mathrm{E}}$ & $\mu_{1 \mathrm{~F}}$ & $\mu_{1 \mathrm{G}}$ & $\mu_{1 \mathrm{H}}$ & $\mu_{1 \mathrm{I}}$ & $\mu_{1 \mathrm{~J}}$ & Média \\
\hline $\mathrm{N}^{\mathrm{o}}$ total de instabilidades & 3 & 3 & 6 & 0 & 2 & 0 & 6 & 1 & 4 & 3 & 2.8 \\
\hline $\begin{array}{l}\mathrm{N}^{\circ} \text { de instabilidades } \\
\text { com Centros tipo 1 }\end{array}$ & 0 & 0 & 0 & 0 & 0 & 0 & 0 & 0 & 0 & 0 & 0.0 \\
\hline $\begin{array}{l}\mathrm{N}^{\mathrm{o}} \text { de instabilidades } \\
\text { com Centros tipo 2 }\end{array}$ & 0 & 0 & 0 & 0 & 0 & 0 & 0 & 0 & 0 & 0 & 0.0 \\
\hline $\begin{array}{l}\mathrm{N}^{\mathrm{o}} \text { de instabilidades } \\
\text { com Centros tipo 3 }\end{array}$ & 3 & 3 & 6 & 0 & 2 & 0 & 6 & 1 & 4 & 3 & 2.8 \\
\hline $\begin{array}{l}\mathrm{N}^{\mathrm{o}} \text { de instabilidades } \\
\text { com candidatos tipo 1 }\end{array}$ & 0 & 0 & 0 & 0 & 0 & 0 & 0 & 0 & 0 & 0 & 0.0 \\
\hline $\begin{array}{l}\mathrm{N}^{\mathrm{o}} \text { de instabilidades } \\
\text { com candidatos tipo 2 }\end{array}$ & 0 & 0 & 0 & 0 & 0 & 0 & 0 & 0 & 0 & 0 & 0.0 \\
\hline $\begin{array}{l}\mathrm{N}^{\mathrm{o}} \text { de instabilidades } \\
\text { com candidatos tipo 3 }\end{array}$ & 3 & 3 & 6 & 0 & 2 & 0 & 6 & 1 & 4 & 3 & 2.8 \\
\hline
\end{tabular}

Pela tabela podemos observar que em apenas $20 \%$ dos casos o mecanismo gera um matching estável (matchings $\mu_{I D}$ e $\mu_{I F}$ ). Nos restantes $80 \%$ temos a presença de pelo menos uma 
instabilidade. Em dois casos, matchings $\mu_{1 C}$ e $\mu_{1 G}$, encontramos o máximo de 6 instabilidades, que pode ser considerado uma quantidade pequena, dado o grande número de jogadores do modelo. Também podemos destacar que todas as instabilidades encontradas ocorrem entre candidatos tipo 3 e Instituições tipo 3, sendo estes candidatos aqueles com as piores colocações nas listas das Instituições, dentre os que têm alguma Instituição tipo 3 alcançável. Por fim, o principal resultado que desejamos destacar é que, mesmo com a hipótese muito forte de que os candidatos sabem seus tipos, o mecanismo de matching descentralizado com lista de aceitáveis truncada, na melhor situação, gera resultados instáveis em $80 \%$ dos casos, ainda que as instabilidades ocorram com os últimos candidatos tipo 3. A presença de instabilidades decorre das listas de aceitáveis declaradas pelos candidatos serem truncadas, pois, apesar do truncamento ser suficiente para que os candidatos tipo 1 declarem todas as Instituições tipo 1 e para que os candidatos tipo 2 declarem todas as Instituições tipo 2, ele não permite que os candidatos tipo 3 declarem todas as Instituições tipo 3 realmente aceitáveis. Dessa forma, as Instituições tipo 1 e 2 obtêm o matching ótimo para as Instituições, como demonstrado na Proposição 1, enquanto que as Instituições tipo 3 obtêm resultados instáveis.

Para ilustrar esse resultado mostraremos o matching $\mu_{1 G}$, que apresenta o máximo de instabilidades do conjunto de simulações. A tabela a seguir apresenta a lista de preferências de cada candidato (construídas com o gerador de números aleatórios), a lista declarada segundo as Proposições 5, 6 e 7, e o matching resultante.

Tabela 5 - Matching $\mu_{1 \mathrm{G}}$

\begin{tabular}{|l|l|l|l|}
\hline Candidato & Lista de Preferências & L. Declarada & Matching \\
\hline$c_{11}$ & $i_{11}, i_{12}, i_{23}, i_{21}, i_{22}, i_{37}, i_{33}, i_{36}, i_{31}, i_{34}, i_{38}, i_{39}, i_{32}, i_{35}$ & $i_{11}, i_{12}$ & $i_{11}$ \\
\hline$c_{12}$ & $i_{12}, i_{11}, i_{21}, i_{23}, i_{22}, i_{35}, i_{38}, i_{32}, i_{33}, i_{34}, i_{36}, i_{37}, i_{31}, i_{39}$ & $i_{12}, i_{11}$ & $i_{12}$ \\
\hline$c_{13}$ & $i_{12}, i_{11}, i_{22}, i_{21}, i_{22}, i_{38}, i_{35}, i_{32}, i_{37}, i_{31}, i_{33}, i_{39}, i_{34}, i_{36}$ & $i_{12}, i_{11}$ & $i_{12}$ \\
\hline$c_{14}$ & $i_{12}, i_{11}, i_{22}, i_{21}, i_{23}, i_{39}, i_{37}, i_{32}, i_{31}, i_{38}, i_{36}, i_{34}, i_{35}, i_{33}$ & $i_{12}, i_{11}$ & $i_{11}$ \\
\hline$c_{21}$ & $i_{11}, i_{12}, i_{21}, i_{23}, i_{22}, i_{38}, i_{33}, i_{31}, i_{35}, i_{32}, i_{34}, i_{36}, i_{37}, i_{39}$ & $i_{23}, i_{22}$ & $i_{21}$ \\
\hline$c_{22}$ & $i_{11}, i_{12}, i_{22}, i_{23}, i_{21}, i_{31}, i_{37}, i_{33}, i_{34}, i_{35}, i_{36}, i_{38}, i_{39}, i_{32}$ & $i_{22}, i_{23}, i_{21}$ & $i_{22}$ \\
\hline$c_{23}$ & $i_{12}, i_{11}, i_{21}, i_{22}, i_{23}, i_{36}, i_{37}, i_{39}, i_{33}, i_{31}, i_{38}, i_{32}, i_{35}, i_{34}$ & $i_{21}$ \\
\hline$c_{24}$ & $i_{11}, i_{12}, i_{22}, i_{23}, i_{21}, i_{35}, i_{32}, i_{38}, i_{34}, i_{33}, i_{39}, i_{36}, i_{31}, i_{37}$ & $i_{22}, i_{23}, i_{21}$ & $i_{22}$ \\
\hline$c_{25}$ & $i_{12}, i_{11}, i_{23}, i_{22}, i_{21}, i_{31}, i_{35}, i_{34}, i_{36}, i_{32}, i_{37}, i_{39}, i_{38}, i_{33}$ & $i_{23}, i_{22}, i_{21}$ & $i_{23}$ \\
\hline
\end{tabular}




\begin{tabular}{|c|c|c|c|}
\hline $\mathrm{C}_{26}$ & $\mathrm{i}_{12}, \mathrm{i}_{11}, \mathrm{i}_{23}, \mathrm{i}_{22}, \mathrm{i}_{21}, \mathrm{i}_{31}, \mathrm{i}_{36}, \mathrm{i}_{32}, \mathrm{i}_{34}, \mathrm{i}_{35}, \mathrm{i}_{33}, \mathrm{i}_{38}, \mathrm{i}_{37}, \mathrm{i}_{39}$ & $\mathrm{i}_{23}, \mathrm{i}_{22}, \mathrm{i}_{21}$ & $\mathrm{i}_{23}$ \\
\hline $\mathrm{C}_{31}$ & $i_{11}, i_{12}, i_{23}, i_{21}, i_{22}, i_{38}, i_{36}, i_{34}, i_{33}, i_{37}, i_{32}, i_{39}, i_{31}, i_{35}$ & $\mathrm{i}_{38}, \mathrm{i}_{36}, \mathrm{i}_{34}, \mathrm{i}_{33}$ & $\mathrm{i}_{38}$ \\
\hline $\mathrm{C}_{32}$ & $i_{11}, i_{12}, i_{23}, i_{21}, i_{22}, i_{37}, i_{36}, i_{39}, i_{32}, i_{31}, i_{33}, i_{38}, i_{35}, i_{34}$ & $\mathrm{i}_{37}, \mathrm{i}_{36}, \mathrm{i}_{39}, \mathrm{i}_{32}$ & $\mathrm{i}_{37}$ \\
\hline $\mathrm{C}_{33}$ & $i_{12}, i_{11}, i_{21}, i_{23}, i_{22}, i_{35}, i_{33}, i_{36}, i_{38}, i_{32}, i_{39}, i_{31}, i_{34}, i_{37}$ & $\mathrm{i}_{35}, \mathrm{i}_{33}, \mathrm{i}_{36}, \mathrm{i}_{38}$ & $\mathrm{i}_{35}$ \\
\hline $\mathrm{C}_{34}$ & $i_{11}, i_{12}, i_{23}, i_{22}, i_{21}, i_{36}, i_{33}, i_{39}, i_{31}, i_{34}, i_{38}, i_{37}, i_{32}, i_{35}$ & $\mathrm{i}_{36}, \mathrm{i}_{33}, \mathrm{i}_{39}, \mathrm{i}_{31}$ & $\mathrm{i}_{36}$ \\
\hline $\mathrm{C}_{35}$ & $i_{11}, i_{12}, i_{22}, i_{23}, i_{21}, i_{31}, i_{38}, i_{32}, i_{34}, i_{36}, i_{35}, i_{33}, i_{39}, i_{37}$ & $\mathrm{i}_{31}, \mathrm{i}_{38}, \mathrm{i}_{32}, \mathrm{i}_{34}$ & $\mathrm{i}_{31}$ \\
\hline $\mathrm{C}_{36}$ & $i_{12}, i_{11}, i_{22}, i_{21}, i_{23}, i_{37}, i_{33}, i_{34}, i_{35}, i_{38}, i_{39}, i_{32}, i_{36}, i_{31}$ & $\mathrm{i}_{37}, \mathrm{i}_{33}, \mathrm{i}_{34}, \mathrm{i}_{35}$ & $\mathrm{i}_{37}$ \\
\hline $\mathrm{C}_{37}$ & $i_{12}, i_{11}, i_{22}, i_{23}, i_{21}, i_{37}, i_{33}, i_{36}, i_{35}, i_{34}, i_{32}, i_{38}, i_{31}, i_{39}$ & $\mathrm{i}_{37}, \mathrm{i}_{33}, \mathrm{i}_{36}, \mathrm{i}_{35}$ & $\mathrm{i}_{33}$ \\
\hline $\mathrm{C}_{38}$ & $i_{11}, i_{12}, i_{21}, i_{23}, i_{22}, i_{34}, i_{39}, i_{38}, i_{36}, i_{35}, i_{33}, i_{31}, i_{37}, i_{32}$ & $\mathrm{i}_{34}, \mathrm{i}_{39}, \mathrm{i}_{38}, \mathrm{i}_{36}$ & $\mathrm{i}_{34}$ \\
\hline $\mathrm{C}_{39}$ & $i_{12}, i_{11}, i_{22}, i_{21}, i_{23}, i_{36}, i_{38}, i_{34}, i_{31}, i_{32}, i_{35}, i_{39}, i_{33}, i_{37}$ & $i_{36}, i_{38}, i_{34}, i_{31}$ & $\mathrm{i}_{36}$ \\
\hline $\mathrm{C}_{310}$ & $i_{12}, i_{11}, i_{22}, i_{21}, i_{23}, i_{38}, i_{31}, i_{33}, i_{37}, i_{36}, i_{39}, i_{32}, i_{34}, i_{35}$ & $\mathrm{i}_{38}, \mathrm{i}_{31}, \mathrm{i}_{33}, \mathrm{i}_{37}$ & $\mathrm{i}_{38}$ \\
\hline $\mathrm{C}_{311}$ & $i_{11}, i_{12}, i_{23}, i_{22}, i_{21}, i_{31}, i_{34}, i_{33}, i_{35}, i_{37}, i_{38}, i_{39}, i_{32}, i_{36}$ & $i_{31}, i_{34}, i_{33}, i_{35}$ & $\mathrm{i}_{31}$ \\
\hline $\mathrm{C}_{312}$ & $i_{12}, i_{11}, i_{22}, i_{21}, i_{23}, i_{33}, i_{37}, i_{39}, i_{35}, i_{38}, i_{36}, i_{32}, i_{31}, i_{34}$ & $i_{33}, i_{37}, i_{39}, i_{35}$ & $\mathrm{i}_{33}$ \\
\hline $\mathrm{C}_{313}$ & $i_{12}, i_{11}, i_{21}, i_{23}, i_{22}, i_{33}, i_{36}, i_{35}, i_{39}, i_{31}, i_{37}, i_{34}, i_{38}, i_{32}$ & $i_{33}, i_{36}, i_{35}, i_{39}$ & $\mathrm{i}_{35}$ \\
\hline $\mathrm{C}_{314}$ & $i_{11}, i_{12}, i_{21}, i_{22}, i_{23}, i_{38}, i_{34}, i_{36}, i_{39}, i_{37}, i_{31}, i_{33}, i_{32}, i_{35}$ & $i_{38}, i_{34}, i_{36}, i_{39}$ & $\mathrm{i}_{34}$ \\
\hline $\mathrm{C}_{315}$ & $i_{11}, i_{12}, i_{23}, i_{22}, i_{21}, i_{36}, i_{38}, i_{34}, i_{37}, i_{35}, i_{31}, i_{39}, i_{32}, i_{33}$ & $i_{36}, i_{38}, i_{34}, i_{37}$ & $\mathrm{C}_{315}$ \\
\hline $\mathrm{C}_{316}$ & $i_{11}, i_{12}, i_{22}, i_{21}, i_{23}, i_{33}, i_{32}, i_{34}, i_{38}, i_{31}, i_{36}, i_{35}, i_{37}, i_{39}$ & $\mathrm{i}_{33}, \mathrm{i}_{32}, \mathrm{i}_{34}, \mathrm{i}_{38}$ & $\mathrm{i}_{32}$ \\
\hline $\mathrm{C}_{317}$ & $i_{12}, i_{11}, i_{21}, i_{23}, i_{22}, i_{33}, i_{35}, i_{37}, i_{36}, i_{32}, i_{38}, i_{39}, i_{34}, i_{31}$ & $i_{33}, i_{35}, i_{37}, i_{36}$ & $\mathrm{C}_{317}$ \\
\hline $\mathrm{C}_{318}$ & $i_{11}, i_{12}, i_{23}, i_{22}, i_{21}, i_{36}, i_{34}, i_{35}, i_{33}, i_{37}, i_{39}, i_{31}, i_{32}, i_{38}$ & $\mathrm{i}_{36}, \mathrm{i}_{34}, \mathrm{i}_{35}, \mathrm{i}_{33}$ & $\mathrm{C}_{318}$ \\
\hline $\mathrm{C}_{319}$ & $i_{12}, i_{11}, i_{21}, i_{23}, i_{22}, i_{38}, i_{39}, i_{35}, i_{36}, i_{34}, i_{33}, i_{31}, i_{37}, i_{32}$ & $i_{38}, i_{39}, i_{35}, i_{36}$ & $\mathrm{i}_{39}$ \\
\hline $\mathrm{C}_{320}$ & $i_{12}, i_{11}, i_{21}, i_{23}, i_{22}, i_{31}, i_{37}, i_{32}, i_{34}, i_{35}, i_{33}, i_{36}, i_{38}, i_{39}$ & $i_{31}, i_{37}, i_{32}, i_{34}$ & $\mathrm{i}_{32}$ \\
\hline $\mathrm{C}_{321}$ & $\mathrm{i}_{12}, \mathrm{i}_{11}, \mathrm{i}_{22}, \mathrm{i}_{23}, \mathrm{i}_{21}, \mathrm{i}_{35}, \mathrm{i}_{39}, \mathrm{i}_{38}, \mathrm{i}_{37}, \mathrm{i}_{32}, \mathrm{i}_{36}, \mathrm{i}_{34}, \mathrm{i}_{33}, \mathrm{i}_{31}$ & $\mathrm{i}_{35}, \mathrm{i}_{39}, \mathrm{i}_{38}, \mathrm{i}_{37}$ & $\mathrm{i}_{39}$ \\
\hline $\mathrm{C}_{322}$ & $i_{11}, i_{12}, i_{22}, i_{21}, i_{23}, i_{35}, i_{36}, i_{38}, i_{31}, i_{39}, i_{34}, i_{33}, i_{32}, i_{37}$ & $i_{35}, i_{36}, i_{38}, i_{31}$ & $\mathrm{C}_{322}$ \\
\hline $\mathrm{C}_{323}$ & $i_{12}, i_{11}, i_{22}, i_{23}, i_{21}, i_{37}, i_{34}, i_{35}, i_{39}, i_{32}, i_{38}, i_{33}, i_{36}, i_{31}$ & $i_{37}, i_{34}, i_{35}, i_{39}$ & $\mathrm{C}_{323}$ \\
\hline $\mathrm{C}_{324}$ & $i_{12}, i_{11}, i_{22}, i_{23}, i_{21}, i_{38}, i_{34}, i_{37}, i_{32}, i_{36}, i_{33}, i_{35}, i_{39}, i_{31}$ & $\mathrm{i}_{38}, \mathrm{i}_{34}, \mathrm{i}_{37}, \mathrm{i}_{32}$ & $\mathrm{C}_{324}$ \\
\hline $\mathrm{C}_{325}$ & $i_{12}, i_{11}, i_{21}, i_{22}, i_{23}, i_{33}, i_{34}, i_{39}, i_{31}, i_{35}, i_{36}, i_{32}, i_{38}, i_{37}$ & $i_{33}, i_{34}, i_{39}, i_{31}$ & $\mathrm{C}_{325}$ \\
\hline $\mathrm{C}_{326}$ & $i_{11}, i_{12}, i_{23}, i_{22}, i_{21}, i_{36}, i_{34}, i_{31}, i_{32}, i_{38}, i_{35}, i_{33}, i_{37}, i_{39}$ & $i_{36}, i_{34}, i_{31}, i_{32}$ & $\mathrm{C}_{326}$ \\
\hline $\mathrm{C}_{327}$ & $i_{12}, i_{11}, i_{23}, i_{22}, i_{21}, i_{38}, i_{37}, i_{31}, i_{39}, i_{35}, i_{32}, i_{34}, i_{36}, i_{33}$ & $\mathrm{i}_{38}, \mathrm{i}_{37}, \mathrm{i}_{31}, \mathrm{i}_{39}$ & $\mathrm{C}_{327}$ \\
\hline $\mathrm{C}_{328}$ & $i_{11}, i_{12}, i_{23}, i_{22}, i_{21}, i_{31}, i_{35}, i_{36}, i_{33}, i_{32}, i_{37}, i_{34}, i_{38}, i_{39}$ & $\mathrm{i}_{31}, \mathrm{i}_{35}, \mathrm{i}_{36}, \mathrm{i}_{33}$ & $C_{328}$ \\
\hline $\mathrm{C}_{329}$ & $i_{12}, i_{11}, i_{22}, i_{21}, i_{23}, i_{31}, i_{36}, i_{38}, i_{33}, i_{32}, i_{35}, i_{39}, i_{34}, i_{37}$ & $\mathrm{i}_{31}, \mathrm{i}_{36}, \mathrm{i}_{38}, \mathrm{i}_{33}$ & $\mathrm{C}_{329}$ \\
\hline $\mathrm{C}_{330}$ & $\mathrm{i}_{11}, \mathrm{i}_{12}, \mathrm{i}_{22}, \mathrm{i}_{23}, \mathrm{i}_{21}, \mathrm{i}_{36}, \mathrm{i}_{31}, \mathrm{i}_{33}, \mathrm{i}_{38}, \mathrm{i}_{32}, \mathrm{i}_{37}, \mathrm{i}_{39}, \mathrm{i}_{35}, \mathrm{i}_{34}$ & $\mathrm{i}_{36}, \mathrm{i}_{31}, \mathrm{i}_{33}, \mathrm{i}_{38}$ & $\mathrm{C}_{330}$ \\
\hline $\mathrm{C}_{331}$ & $\mathrm{i}_{12}, \mathrm{i}_{11}, \mathrm{i}_{21}, \mathrm{i}_{22}, \mathrm{i}_{23}, \mathrm{i}_{39}, \mathrm{i}_{31}, \mathrm{i}_{34}, \mathrm{i}_{37}, \mathrm{i}_{33}, \mathrm{i}_{38}, \mathrm{i}_{32}, \mathrm{i}_{35}, \mathrm{i}_{36}$ & $\mathrm{i}_{39}, \mathrm{i}_{31}, \mathrm{i}_{34}, \mathrm{i}_{37}$ & $\mathrm{C}_{331}$ \\
\hline $\mathrm{C}_{332}$ & $i_{11}, i_{12}, i_{23}, i_{22}, i_{21}, i_{34}, i_{31}, i_{32}, i_{37}, i_{33}, i_{35}, i_{38}, i_{36}, i_{39}$ & $\mathrm{i}_{34}, \mathrm{i}_{31}, \mathrm{i}_{32}, \mathrm{i}_{37}$ & $\mathrm{C}_{332}$ \\
\hline $\mathrm{C}_{333}$ & $i_{12}, i_{11}, i_{23}, i_{22}, i_{21}, i_{31}, i_{33}, i_{32}, i_{36}, i_{35}, i_{37}, i_{38}, i_{39}, i_{34}$ & $\mathrm{i}_{31}, \mathrm{i}_{33}, \mathrm{i}_{32}, \mathrm{i}_{36}$ & $\mathrm{C}_{333}$ \\
\hline $\mathrm{C}_{334}$ & $\mathrm{i}_{12}, \mathrm{i}_{11}, \mathrm{i}_{21}, \mathrm{i}_{22}, \mathrm{i}_{23}, \mathrm{i}_{37}, \mathrm{i}_{36}, \mathrm{i}_{31}, \mathrm{i}_{33}, \mathrm{i}_{39}, \mathrm{i}_{34}, \mathrm{i}_{32}, \mathrm{i}_{35}, \mathrm{i}_{38}$ & $\mathrm{i}_{37}, \mathrm{i}_{36}, \mathrm{i}_{31}, \mathrm{i}_{33}$ & $\mathrm{C}_{334}$ \\
\hline $\mathrm{C}_{335}$ & $\mathrm{i}_{12}, \mathrm{i}_{11}, \mathrm{i}_{21}, \mathrm{i}_{22}, \mathrm{i}_{23}, \mathrm{i}_{32}, \mathrm{i}_{34}, \mathrm{i}_{37}, \mathrm{i}_{33}, \mathrm{i}_{39}, \mathrm{i}_{35}, \mathrm{i}_{36}, \mathrm{i}_{38}, \mathrm{i}_{31}$ & $\mathrm{i}_{32}, \mathrm{i}_{34}, \mathrm{i}_{37}, \mathrm{i}_{33}$ & $\mathrm{C}_{335}$ \\
\hline
\end{tabular}




\begin{tabular}{|l|l|l|l|}
\hline$c_{336}$ & $i_{12}, i_{11}, i_{21}, i_{22}, i_{23}, i_{35}, i_{31}, i_{36}, i_{39}, i_{38}, i_{33}, i_{32}, i_{34}, i_{37}$ & $i_{35}, i_{31}, i_{36}, i_{39}$ & $c_{336}$ \\
\hline$c_{337}$ & $i_{12}, i_{11}, i_{23}, i_{22}, i_{21}, i_{36}, i_{33}, i_{34}, i_{31}, i_{32}, i_{37}, i_{39}, i_{38}, i_{35}$ & $i_{36}, i_{33}, i_{34}, i_{31}$ & $c_{337}$ \\
\hline$c_{338}$ & $i_{12}, i_{11}, i_{21}, i_{22}, i_{23}, i_{37}, i_{36}, i_{35}, i_{34}, i_{32}, i_{38}, i_{39}, i_{31}, i_{33}$ & $i_{36}, i_{35}, i_{34}$ & $c_{338}$ \\
\hline$c_{339}$ & $i_{11}, i_{12}, i_{22}, i_{23}, i_{21}, i_{34}, i_{37}, i_{39}, i_{36}, i_{33}, i_{35}, i_{38}, i_{31}, i_{33}$ & $i_{36}$ & $c_{339}$ \\
\hline$c_{340}$ & $i_{12}, i_{11}, i_{23}, i_{22}, i_{21}, i_{31}, i_{36}, i_{32}, i_{34}, i_{35}, i_{33}, i_{38}, i_{37}, i_{39}$ & $i_{31}, i_{36}, i_{32}, i_{34}$ & $c_{340}$ \\
\hline
\end{tabular}

Da tabela acima, observamos que as seis instabilidades ocorrem entre só três candidatos e duas Instituições: candidatos $c_{315}, c_{317}$ e $c_{318}$ e as Instituições $i_{32}$ e $i_{39}$. Como estes três candidatos estão classificados entre os 18 melhores candidatos do tipo 3 e, por hipótese, todas as Instituições são aceitáveis para eles, então eles deveriam ter sido alocados para alguma Instituição. Ocorre que as quatro Instituições declaradas por estes candidatos em suas listas de aceitáveis preencheram todas as suas vagas com candidatos classificados até a posição 14 dos candidatos tipo 3 e, como não declararam $i_{32}$ e $i_{39}$, eles não receberam ofertas dessas Instituições que ainda tinham vagas não preenchidas. No entanto, $c_{315}, c_{317}$ e $c_{318}$ preferiam ser alocados às Instituições $i_{32}$ e $i_{39}$ e as Instituições $i_{32}$ e $i_{39}$ preferiam $c_{315}, c_{317}$ e $c_{318}$ a algum dos candidatos alocados para elas em $\mu_{1 \mathrm{G}}$. Podemos representar as instabilidades da seguinte forma:

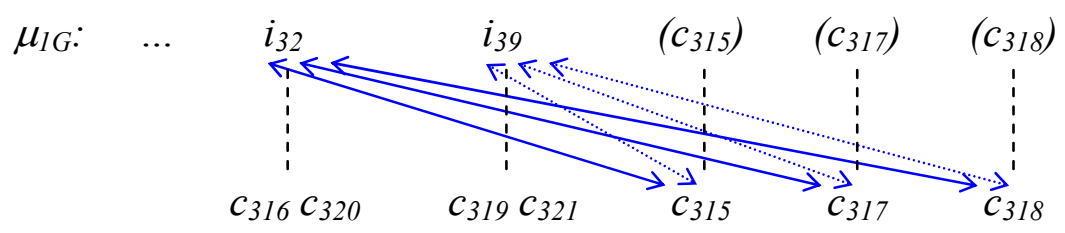

Na representação acima, cada seta dupla indica uma instabilidade, ou seja, os pares Instituiçãocandidato $\left(i_{32}, c_{315}\right),\left(i_{32}, c_{317}\right),\left(i_{32}, c_{318}\right),\left(i_{39}, c_{315}\right),\left(i_{39}, c_{317}\right),\left(i_{32}, c_{318}\right)$ preferem estar juntos aos matchings que obtiveram pelo mecanismo. Os demais matchings simulados com a hipótese 1 são apresentados no apêndice C. 


\subsection{Hipótese 2: Os candidatos acreditam conhecer seus tipos no momento de declarar suas listas de Instituições aceitáveis, mas eles podem errar}

Neste caso incluimos uma probabilidade de erro por parte dos candidatos. Este erro é modelado da seguinte forma: suponhamos que cada candidato efetivamente do tipo 1 tenha $10 \%$ de probabilidade de acreditar ser de outro tipo, sendo $5 \%$ de se declarar do tipo 2 e $5 \%$ de se declarar do tipo 3. Cada candidato tipo 2 tem probabilidade de $5 \%$ de se declarar do tipo 1 e de $5 \%$ de se declarar do tipo 3 . Por fim, cada candidato do tipo 3 tem probabilidade de $5 \%$ de se declarar do tipo 1 e de $5 \%$ de se declarar do tipo 2 .

Como os candidatos não conhecem essa possibilidade de erro, uma vez que eles se declaram de um tipo $t, t \in\{1,2,3\}$, eles jogam as mesmas estratégias descritas nas Proposições 5, 6 e 7 para cada tipo $t$. Fizemos então 10 simulações do modelo. As preferências dos candidatos sobre Instituições do mesmo tipo e as probabilidades de erro foram geradas aleatoriamente através do gerador de números aleatórios do software econométrico Eviews 4.0. Os resultados são apresentados na tabela 6 .

Tabela 6 - Número de instabilidades nos matchings simulados com a hipótese 2

\begin{tabular}{|l|c|c|c|c|c|c|c|c|c|c|c|}
\hline Matching & $\mu_{2 \mathrm{~A}}$ & $\mu_{2 \mathrm{~B}}$ & $\mu_{2 \mathrm{C}}$ & $\mu_{2 \mathrm{D}}$ & $\mu_{2 \mathrm{E}}$ & $\mu_{2 \mathrm{~F}}$ & $\mu_{2 \mathrm{G}}$ & $\mu_{2 \mathrm{H}}$ & $\mu_{2 \mathrm{I}}$ & $\mu_{2 \mathrm{~J}}$ & Média \\
\hline $\mathrm{N}^{\circ}$ total de instabilidades & 41 & 10 & 20 & 23 & 90 & 101 & 20 & 0 & 31 & 44 & 38.0 \\
\hline $\begin{array}{l}\mathrm{N}^{\circ} \text { de instabilidades } \\
\text { com Inst. tipo 1 }\end{array}$ & 37 & 0 & 8 & 0 & 77 & 81 & 0 & 0 & 0 & 39 & 24.2 \\
\hline $\begin{array}{l}\mathrm{N}^{\circ} \text { de instabilidades } \\
\text { com Inst. tipo 2 }\end{array}$ & 3 & 0 & 0 & 0 & 3 & 3 & 0 & 0 & 23 & 3 & 3.5 \\
\hline $\begin{array}{l}\mathrm{N}^{\circ} \text { de instabilidades } \\
\text { com Inst. tipo 3 }\end{array}$ & 1 & 10 & 12 & 23 & 10 & 17 & 20 & 0 & 8 & 2 & 10.3 \\
\hline $\begin{array}{l}\mathrm{N}^{\circ} \text { de instabilidades } \\
\text { com cand. tipo 1 }\end{array}$ & 4 & 0 & 2 & 0 & 7 & 9 & 0 & 0 & 0 & 5 & 2.7 \\
\hline $\begin{array}{l}\mathrm{N}^{\circ} \text { de instabilidades } \\
\text { com cand tipo 2 }\end{array}$ & 6 & 0 & 15 & 0 & 21 & 21 & 0 & 0 & 1 & 6 & 7.0 \\
\hline $\begin{array}{l}\mathrm{N}^{\circ} \text { de instabilidades } \\
\text { com cand. tipo 3 }\end{array}$ & 31 & 10 & 3 & 23 & 62 & 71 & 20 & 0 & 30 & 33 & 28.3 \\
\hline
\end{tabular}


Através dos resultados apresentados na tabela 6 observamos que em apenas um dos matchings o mecanismo proposto gera um matching estável (matching $\mu_{2 H}$ ). Nos outros nove temos a presença de instabilidades. Tais instabilidades são encontradas em quantidade muito maior que no caso anterior e envolvem todos os tipos de Instituições e candidatos. Isto ocorre quando os candidatos erram seus tipos. Por exemplo, se um candidato tipo 1 joga como se fosse tipo 2 ou tipo 3, uma das Instituições tipo 1 vai ficar sem preencher uma de suas vagas com este candidato e receberá um candidato tipo 2 ou tipo 3 que tenha jogado como se fosse tipo 1. Dessa forma, as instabilidades geradas são mais críticas que as do caso anterior, pois envolvem os melhores candidatos e as Instituições mais procuradas.

Para ilustrar esse resultado mostraremos o matching $\mu_{2 F}$, que apresenta o máximo de instabilidades desta simulação. A tabela a seguir apresenta a lista de preferências de cada candidato (construídas com o gerador de números aleatórios), a lista declarada segundo as Proposições 5, 6 e 7, e o matching resultante.

Tabela 7 - Matching $\mu_{2 F}$

\begin{tabular}{|c|c|c|c|}
\hline Candidato & Lista de Preferências & L. Declarada & Matching \\
\hline $\mathrm{C}_{11}$ & $\mathrm{i}_{11}, \mathrm{i}_{12}, \mathrm{i}_{22}, \mathrm{i}_{23}, \mathrm{i}_{21}, \mathrm{i}_{32}, \mathrm{i}_{33}, \mathrm{i}_{31}, \mathrm{i}_{39}, \mathrm{i}_{37}, \mathrm{i}_{34}, \mathrm{i}_{35}, \mathrm{i}_{38}, \mathrm{i}_{36}$ & $\mathrm{i}_{22}, \mathrm{i}_{23}, \mathrm{i}_{21}$ & $\mathrm{i}_{22}$ \\
\hline $\mathrm{C}_{12}$ & $\mathrm{i}_{12}, \mathrm{i}_{11}, \mathrm{i}_{23}, \mathrm{i}_{22}, \mathrm{i}_{21}, \mathrm{i}_{38}, \mathrm{i}_{36}, \mathrm{i}_{37}, \mathrm{i}_{35}, \mathrm{i}_{34}, \mathrm{i}_{32}, \mathrm{i}_{33}, \mathrm{i}_{39}, \mathrm{i}_{31}$ & $\mathrm{i}_{38}, \mathrm{i}_{36}, \mathrm{i}_{37}, \mathrm{i}_{35}$ & $\mathrm{i}_{38}$ \\
\hline $\mathrm{C}_{13}$ & $\mathrm{i}_{12}, \mathrm{i}_{11}, \mathrm{i}_{21}, \mathrm{i}_{22}, \mathrm{i}_{23}, \mathrm{i}_{34}, \mathrm{i}_{36}, \mathrm{i}_{32}, \mathrm{i}_{37}, \mathrm{i}_{39}, \mathrm{i}_{38}, \mathrm{i}_{33}, \mathrm{i}_{35}, \mathrm{i}_{31}$ & $\mathrm{i}_{12}, \mathrm{i}_{11}$ & $\mathrm{i}_{12}$ \\
\hline $\mathrm{C}_{14}$ & $i_{12}, i_{11}, i_{22}, i_{23}, i_{21}, i_{35}, i_{39}, i_{34}, i_{36}, i_{31}, i_{37}, i_{33}, i_{38}, i_{32}$ & $\mathrm{i}_{22}, \mathrm{i}_{23}, \mathrm{i}_{21}$ & $i_{22}$ \\
\hline $\mathrm{C}_{21}$ & $\mathrm{i}_{12}, \mathrm{i}_{11}, \mathrm{i}_{22}, \mathrm{i}_{21}, \mathrm{i}_{23}, \mathrm{i}_{33}, \mathrm{i}_{39}, \mathrm{i}_{32}, \mathrm{i}_{34}, \mathrm{i}_{37}, \mathrm{i}_{31}, \mathrm{i}_{36}, \mathrm{i}_{35}, \mathrm{i}_{38}$ & $\mathrm{i}_{22}, \mathrm{i}_{21}, \mathrm{i}_{23}$ & $\mathrm{i}_{21}$ \\
\hline $\mathrm{C}_{22}$ & $i_{12}, i_{11}, i_{23}, i_{22}, i_{21}, i_{35}, i_{37}, i_{31}, i_{36}, i_{32}, i_{38}, i_{34}, i_{39}, i_{33}$ & $\mathrm{i}_{23}, \mathrm{i}_{22}, \mathrm{i}_{21}$ & $i_{23}$ \\
\hline $\mathrm{C}_{23}$ & $\mathrm{i}_{12}, \mathrm{i}_{11}, \mathrm{i}_{23}, \mathrm{i}_{21}, \mathrm{i}_{22}, \mathrm{i}_{34}, \mathrm{i}_{32}, \mathrm{i}_{39}, \mathrm{i}_{33}, \mathrm{i}_{31}, \mathrm{i}_{38}, \mathrm{i}_{36}, \mathrm{i}_{37}, \mathrm{i}_{35}$ & $\mathrm{i}_{23}, \mathrm{i}_{21}, \mathrm{i}_{22}$ & $\mathrm{i}_{23}$ \\
\hline $\mathrm{C}_{24}$ & $i_{11}, i_{12}, i_{21}, i_{23}, i_{22}, i_{31}, i_{35}, i_{37}, i_{34}, i_{39}, i_{36}, i_{38}, i_{33}, i_{32}$ & $\mathrm{i}_{21}, \mathrm{i}_{23}, \mathrm{i}_{22}$ & $i_{21}$ \\
\hline $\mathrm{C}_{25}$ & $\mathrm{i}_{12}, \mathrm{i}_{11}, \mathrm{i}_{23}, \mathrm{i}_{21}, \mathrm{i}_{22}, \mathrm{i}_{39}, \mathrm{i}_{36}, \mathrm{i}_{35}, \mathrm{i}_{33}, \mathrm{i}_{34}, \mathrm{i}_{38}, \mathrm{i}_{31}, \mathrm{i}_{32}, \mathrm{i}_{37}$ & $\mathrm{i}_{39}, \mathrm{i}_{36}, \mathrm{i}_{35}, \mathrm{i}_{33}$ & $\mathrm{i}_{39}$ \\
\hline $\mathrm{C}_{26}$ & $i_{11}, i_{12}, i_{22}, i_{23}, i_{21}, i_{34}, i_{32}, i_{38}, i_{31}, i_{35}, i_{33}, i_{36}, i_{39}, i_{37}$ & $\mathrm{i}_{22}, \mathrm{i}_{23}, \mathrm{i}_{21}$ & $\mathrm{C}_{26}$ \\
\hline $\mathrm{C}_{31}$ & $\mathrm{i}_{11}, \mathrm{i}_{12}, \mathrm{i}_{22}, \mathrm{i}_{23}, \mathrm{i}_{21}, \mathrm{i}_{39}, \mathrm{i}_{32}, \mathrm{i}_{31}, \mathrm{i}_{38}, \mathrm{i}_{33}, \mathrm{i}_{37}, \mathrm{i}_{34}, \mathrm{i}_{36}, \mathrm{i}_{35}$ & $i_{39}, i_{32}, i_{31}, i_{38}$ & $\mathbf{i}_{39}$ \\
\hline $\mathrm{C}_{32}$ & $i_{12}, i_{11}, i_{23}, i_{21}, i_{22}, i_{31}, i_{39}, i_{38}, i_{35}, i_{33}, i_{32}, i_{37}, i_{36}, i_{34}$ & $\mathrm{i}_{23}, \mathrm{i}_{21}, \mathrm{i}_{22}$ & $\mathrm{C}_{32}$ \\
\hline $\mathrm{C}_{33}$ & $\mathrm{i}_{12}, \mathrm{i}_{11}, \mathrm{i}_{23}, \mathrm{i}_{21}, \mathrm{i}_{22}, \mathrm{i}_{37}, \mathrm{i}_{38}, \mathrm{i}_{36}, \mathrm{i}_{35}, \mathrm{i}_{33}, \mathrm{i}_{39}, \mathrm{i}_{31}, \mathrm{i}_{32}, \mathrm{i}_{34}$ & $\mathrm{i}_{37}, \mathrm{i}_{38}, \mathrm{i}_{36}, \mathrm{i}_{35}$ & $i_{37}$ \\
\hline $\mathrm{C}_{34}$ & $i_{12}, i_{11}, i_{23}, i_{22}, i_{21}, i_{35}, i_{36}, i_{33}, i_{32}, i_{39}, i_{38}, i_{31}, i_{37}, i_{34}$ & $\mathrm{i}_{35}, \mathrm{i}_{36}, \mathrm{i}_{33}, \mathrm{i}_{32}$ & $\mathrm{i}_{35}$ \\
\hline $\mathrm{C}_{35}$ & $\mathrm{i}_{12}, \mathrm{i}_{11}, \mathrm{i}_{22}, \mathrm{i}_{21}, \mathrm{i}_{23}, \mathrm{i}_{39}, \mathrm{i}_{32}, \mathrm{i}_{35}, \mathrm{i}_{31}, \mathrm{i}_{34}, \mathrm{i}_{36}, \mathrm{i}_{38}, \mathrm{i}_{33}, \mathrm{i}_{37}$ & $\mathrm{i}_{39}, \mathrm{i}_{32}, \mathrm{i}_{35}, \mathrm{i}_{31}$ & $i_{32}$ \\
\hline $\mathrm{C}_{36}$ & $\mathrm{i}_{11}, \mathrm{i}_{12}, \mathrm{i}_{21}, \mathrm{i}_{22}, \mathrm{i}_{23}, \mathrm{i}_{34}, \mathrm{i}_{37}, \mathrm{i}_{32}, \mathrm{i}_{38}, \mathrm{i}_{36}, \mathrm{i}_{33}, \mathrm{i}_{31}, \mathrm{i}_{39}, \mathrm{i}_{35}$ & $i_{34}, i_{37}, i_{32}, i_{38}$ & $\mathrm{i}_{34}$ \\
\hline
\end{tabular}




\begin{tabular}{|c|c|c|c|}
\hline $\mathrm{C}_{37}$ & $\mathrm{i}_{11}, \mathrm{i}_{12}, \mathrm{i}_{21}, \mathrm{i}_{23}, \mathrm{i}_{22}, \mathrm{i}_{32}, \mathrm{i}_{34}, \mathrm{i}_{38}, \mathrm{i}_{37}, \mathrm{i}_{33}, \mathrm{i}_{35}, \mathrm{i}_{31}, \mathrm{i}_{36}, \mathrm{i}_{39}$ & $\mathrm{i}_{32}, \mathrm{i}_{34}, \mathrm{i}_{38}, \mathrm{i}_{37}$ & $\mathrm{i}_{32}$ \\
\hline $\mathrm{C}_{38}$ & $i_{12}, i_{11}, i_{23}, i_{22}, i_{21}, i_{39}, i_{33}, i_{31}, i_{32}, i_{38}, i_{34}, i_{35}, i_{36}, i_{37}$ & $\mathrm{i}_{39}, \mathrm{i}_{33}, \mathrm{i}_{31}, \mathrm{i}_{32}$ & $\mathrm{i}_{33}$ \\
\hline $\mathrm{C}_{39}$ & $i_{11}, i_{12}, i_{23}, i_{22}, i_{21}, i_{31}, i_{39}, i_{33}, i_{34}, i_{35}, i_{36}, i_{37}, i_{38}, i_{32}$ & $\mathrm{i}_{31}, \mathrm{i}_{39}, \mathrm{i}_{33}, \mathrm{i}_{34}$ & $\mathrm{i}_{31}$ \\
\hline $\mathrm{C}_{310}$ & $i_{11}, i_{12}, i_{22}, i_{21}, i_{23}, i_{37}, i_{36}, i_{35}, i_{32}, i_{34}, i_{39}, i_{31}, i_{38}, i_{33}$ & $\mathrm{i}_{37}, \mathrm{i}_{36}, \mathrm{i}_{35}, \mathrm{i}_{32}$ & $\mathbf{i}_{37}$ \\
\hline $\mathrm{C}_{311}$ & $i_{11}, i_{12}, i_{21}, i_{22}, i_{23}, i_{31}, i_{36}, i_{33}, i_{39}, i_{34}, i_{32}, i_{35}, i_{37}, i_{38}$ & $\mathrm{i}_{31}, \mathrm{i}_{36}, \mathrm{i}_{33}, \mathrm{i}_{39}$ & $\mathrm{i}_{31}$ \\
\hline $\mathrm{C}_{312}$ & $i_{12}, i_{11}, i_{21}, i_{23}, i_{22}, i_{39}, i_{32}, i_{36}, i_{35}, i_{38}, i_{31}, i_{33}, i_{37}, i_{34}$ & $\mathrm{i}_{39}, \mathrm{i}_{32}, \mathrm{i}_{36}, \mathrm{i}_{35}$ & $\mathrm{i}_{36}$ \\
\hline $\mathrm{C}_{313}$ & $i_{11}, i_{12}, i_{23}, i_{21}, i_{22}, i_{33}, i_{36}, i_{37}, i_{32}, i_{39}, i_{34}, i_{31}, i_{38}, i_{35}$ & $i_{33}, i_{36}, i_{37}, i_{32}$ & $\mathrm{i}_{33}$ \\
\hline $\mathrm{C}_{314}$ & $i_{12}, i_{11}, i_{23}, i_{21}, i_{22}, i_{37}, i_{32}, i_{38}, i_{31}, i_{39}, i_{36}, i_{33}, i_{35}, i_{34}$ & $\mathrm{i}_{37}, \mathrm{i}_{32}, \mathrm{i}_{38}, \mathrm{i}_{31}$ & $\mathrm{i}_{38}$ \\
\hline $\mathrm{C}_{315}$ & $i_{11}, i_{12}, i_{21}, i_{22}, i_{23}, i_{34}, i_{39}, i_{32}, i_{36}, i_{37}, i_{35}, i_{38}, i_{31}, i_{33}$ & $\mathrm{i}_{34}, \mathrm{i}_{39}, \mathrm{i}_{32}, \mathrm{i}_{36}$ & $\mathrm{i}_{34}$ \\
\hline $\mathrm{C}_{316}$ & $i_{12}, i_{11}, i_{21}, i_{23}, i_{22}, i_{35}, i_{39}, i_{34}, i_{31}, i_{37}, i_{38}, i_{36}, i_{32}, i_{33}$ & $i_{35}, i_{39}, i_{34}, i_{31}$ & $\mathrm{i}_{35}$ \\
\hline $\mathrm{C}_{317}$ & $i_{12}, i_{11}, i_{21}, i_{23}, i_{22}, i_{35}, i_{31}, i_{34}, i_{36}, i_{33}, i_{32}, i_{37}, i_{38}, i_{39}$ & $\mathrm{i}_{35}, \mathrm{i}_{31}, \mathrm{i}_{34}, \mathrm{i}_{36}$ & $\mathrm{i}_{36}$ \\
\hline $\mathrm{C}_{318}$ & $i_{11}, i_{12}, i_{22}, i_{21}, i_{23}, i_{36}, i_{39}, i_{34}, i_{32}, i_{35}, i_{31}, i_{37}, i_{38}, i_{33}$ & $\mathrm{i}_{36}, \mathrm{i}_{39}, \mathrm{i}_{34}, \mathrm{i}_{32}$ & $\mathrm{C}_{318}$ \\
\hline $\mathrm{C}_{319}$ & $i_{11}, i_{12}, i_{22}, i_{21}, i_{23}, i_{34}, i_{33}, i_{31}, i_{38}, i_{36}, i_{39}, i_{37}, i_{35}, i_{32}$ & $\mathrm{i}_{34}, \mathrm{i}_{33}, \mathrm{i}_{31}, \mathrm{i}_{38}$ & $\mathrm{C}_{319}$ \\
\hline $\mathrm{C}_{320}$ & $i_{11}, i_{12}, i_{22}, i_{23}, i_{21}, i_{39}, i_{33}, i_{32}, i_{35}, i_{31}, i_{38}, i_{34}, i_{36}, i_{37}$ & $\mathrm{i}_{39}, \mathrm{i}_{33}, \mathrm{i}_{32}, \mathrm{i}_{35}$ & $\mathrm{C}_{320}$ \\
\hline $\mathrm{C}_{321}$ & $i_{11}, i_{12}, i_{23}, i_{21}, i_{22}, i_{32}, i_{31}, i_{33}, i_{36}, i_{39}, i_{37}, i_{38}, i_{35}, i_{34}$ & $\mathrm{i}_{32}, \mathrm{i}_{31}, \mathrm{i}_{33}, \mathrm{i}_{36}$ & $\mathrm{C}_{321}$ \\
\hline $\mathrm{C}_{322}$ & $i_{11}, i_{12}, i_{21}, i_{23}, i_{22}, i_{37}, i_{31}, i_{34}, i_{39}, i_{36}, i_{38}, i_{33}, i_{32}, i_{35}$ & $\mathrm{i}_{37}, \mathrm{i}_{31}, \mathrm{i}_{34}, \mathrm{i}_{39}$ & $\mathrm{C}_{322}$ \\
\hline $\mathrm{C}_{323}$ & $i_{12}, i_{11}, i_{22}, i_{23}, i_{21}, i_{33}, i_{34}, i_{36}, i_{39}, i_{35}, i_{31}, i_{38}, i_{32}, i_{37}$ & $\mathrm{i}_{33}, \mathrm{i}_{34}, \mathrm{i}_{36}, \mathrm{i}_{39}$ & $\mathrm{C}_{323}$ \\
\hline $\mathrm{C}_{324}$ & $i_{12}, i_{11}, i_{21}, i_{22}, i_{23}, i_{35}, i_{39}, i_{38}, i_{33}, i_{37}, i_{34}, i_{36}, i_{31}, i_{32}$ & $\mathrm{i}_{35}, \mathrm{i}_{39}, \mathrm{i}_{38}, \mathrm{i}_{33}$ & $\mathrm{C}_{324}$ \\
\hline $\mathrm{C}_{325}$ & $i_{12}, i_{11}, i_{21}, i_{22}, i_{23}, i_{31}, i_{38}, i_{39}, i_{37}, i_{35}, i_{33}, i_{36}, i_{32}, i_{34}$ & $\mathrm{i}_{12}, \mathrm{i}_{11}$ & $\mathrm{i}_{12}$ \\
\hline $\mathrm{C}_{326}$ & $i_{12}, i_{11}, i_{23}, i_{22}, i_{21}, i_{34}, i_{33}, i_{39}, i_{38}, i_{35}, i_{32}, i_{36}, i_{31}, i_{37}$ & $\mathrm{i}_{34}, \mathrm{i}_{33}, \mathrm{i}_{39}, \mathrm{i}_{38}$ & $\mathrm{C}_{326}$ \\
\hline $\mathrm{C}_{327}$ & $i_{12}, i_{11}, i_{22}, i_{21}, i_{23}, i_{38}, i_{39}, i_{31}, i_{32}, i_{36}, i_{35}, i_{34}, i_{33}, i_{37}$ & $\mathrm{i}_{22}, \mathrm{i}_{21}, \mathrm{i}_{23}$ & $\mathrm{C}_{327}$ \\
\hline $\mathrm{C}_{328}$ & $\mathrm{i}_{11}, \mathrm{i}_{12}, \mathrm{i}_{22}, \mathrm{i}_{21}, \mathrm{i}_{23}, \mathrm{i}_{34}, \mathrm{i}_{37}, \mathrm{i}_{39}, \mathrm{i}_{36}, \mathrm{i}_{33}, \mathrm{i}_{38}, \mathrm{i}_{31}, \mathrm{i}_{35}, \mathrm{i}_{32}$ & $\mathrm{i}_{34}, \mathrm{i}_{37}, \mathrm{i}_{39}, \mathrm{i}_{36}$ & $\mathrm{C}_{328}$ \\
\hline $\mathrm{C}_{329}$ & $i_{12}, i_{11}, i_{22}, i_{23}, i_{21}, i_{39}, i_{37}, i_{38}, i_{34}, i_{31}, i_{33}, i_{32}, i_{35}, i_{36}$ & $\mathrm{i}_{39}, \mathrm{i}_{37}, \mathrm{i}_{38}, \mathrm{i}_{34}$ & $\mathrm{C}_{329}$ \\
\hline $\mathrm{C}_{330}$ & $i_{12}, i_{11}, i_{22}, i_{23}, i_{21}, i_{37}, i_{31}, i_{36}, i_{35}, i_{38}, i_{34}, i_{33}, i_{32}, i_{39}$ & $\mathrm{i}_{37}, \mathrm{i}_{31}, \mathrm{i}_{36}, \mathrm{i}_{35}$ & $\mathrm{C}_{330}$ \\
\hline $\mathrm{C}_{331}$ & $i_{11}, i_{12}, i_{22}, i_{23}, i_{21}, i_{36}, i_{31}, i_{34}, i_{37}, i_{35}, i_{32}, i_{33}, i_{39}, i_{38}$ & $\mathrm{i}_{36}, \mathrm{i}_{31}, \mathrm{i}_{34}, \mathrm{i}_{37}$ & $\mathrm{C}_{331}$ \\
\hline $\mathrm{C}_{332}$ & $i_{12}, i_{11}, i_{22}, i_{21}, i_{23}, i_{37}, i_{32}, i_{34}, i_{36}, i_{31}, i_{38}, i_{35}, i_{39}, i_{33}$ & $i_{37}, i_{32}, i_{34}, i_{36}$ & $\mathrm{C}_{332}$ \\
\hline $\mathrm{C}_{333}$ & $i_{11}, i_{12}, i_{21}, i_{22}, i_{23}, i_{33}, i_{39}, i_{31}, i_{35}, i_{34}, i_{36}, i_{38}, i_{37}, i_{32}$ & $\mathrm{i}_{33}, \mathrm{i}_{39}, \mathrm{i}_{31}, \mathrm{i}_{35}$ & $\mathrm{C}_{333}$ \\
\hline $\mathrm{C}_{334}$ & $\mathrm{i}_{11}, \mathrm{i}_{12}, \mathrm{i}_{21}, \mathrm{i}_{23}, \mathrm{i}_{22}, \mathrm{i}_{35}, \mathrm{i}_{36}, \mathrm{i}_{31}, \mathrm{i}_{34}, \mathrm{i}_{32}, \mathrm{i}_{37}, \mathrm{i}_{38}, \mathrm{i}_{33}, \mathrm{i}_{39}$ & $\mathrm{i}_{21}, \mathrm{i}_{23}, \mathrm{i}_{22}$ & $\mathrm{C}_{334}$ \\
\hline $\mathrm{C}_{335}$ & $i_{12}, i_{11}, i_{22}, i_{21}, i_{23}, i_{34}, i_{37}, i_{31}, i_{35}, i_{38}, i_{32}, i_{36}, i_{33}, i_{39}$ & $\mathrm{i}_{34}, \mathrm{i}_{37}, \mathrm{i}_{31}, \mathrm{i}_{35}$ & $\mathrm{C}_{335}$ \\
\hline $\mathrm{C}_{336}$ & $\mathrm{i}_{11}, \mathrm{i}_{12}, \mathrm{i}_{23}, \mathrm{i}_{22}, \mathrm{i}_{21}, \mathrm{i}_{37}, \mathrm{i}_{32}, \mathrm{i}_{35}, \mathrm{i}_{34}, \mathrm{i}_{31}, \mathrm{i}_{39}, \mathrm{i}_{33}, \mathrm{i}_{38}, \mathrm{i}_{36}$ & $\mathrm{i}_{37}, \mathrm{i}_{32}, \mathrm{i}_{35}, \mathrm{i}_{34}$ & $\mathrm{C}_{336}$ \\
\hline $\mathrm{C}_{337}$ & $\mathrm{i}_{12}, \mathrm{i}_{11}, \mathrm{i}_{22}, \mathrm{i}_{21}, \mathrm{i}_{23}, \mathrm{i}_{35}, \mathrm{i}_{32}, \mathrm{i}_{34}, \mathrm{i}_{38}, \mathrm{i}_{36}, \mathrm{i}_{37}, \mathrm{i}_{33}, \mathrm{i}_{31}, \mathrm{i}_{39}$ & $\mathrm{i}_{22}, \mathrm{i}_{21}, \mathrm{i}_{23}$ & $\mathrm{C}_{337}$ \\
\hline $\mathrm{C}_{338}$ & $\mathrm{i}_{12}, \mathrm{i}_{11}, \mathrm{i}_{21}, \mathrm{i}_{23}, \mathrm{i}_{22}, \mathrm{i}_{34}, \mathrm{i}_{37}, \mathrm{i}_{38}, \mathrm{i}_{33}, \mathrm{i}_{32}, \mathrm{i}_{35}, \mathrm{i}_{36}, \mathrm{i}_{31}, \mathrm{i}_{39}$ & $\mathrm{i}_{21}, \mathrm{i}_{23}, \mathrm{i}_{22}$ & $\mathrm{C}_{338}$ \\
\hline $\mathrm{C}_{339}$ & $i_{11}, i_{12}, i_{23}, i_{21}, i_{22}, i_{35}, i_{31}, i_{37}, i_{38}, i_{36}, i_{32}, i_{34}, i_{33}, i_{39}$ & $\mathrm{i}_{35}, \mathrm{i}_{31}, \mathrm{i}_{37}, \mathrm{i}_{38}$ & $\mathrm{C}_{339}$ \\
\hline $\mathrm{C}_{340}$ & $\mathrm{i}_{12}, \mathrm{i}_{11}, \mathrm{i}_{23}, \mathrm{i}_{22}, \mathrm{i}_{21}, \mathrm{i}_{38}, \mathrm{i}_{31}, \mathrm{i}_{37}, \mathrm{i}_{34}, \mathrm{i}_{32}, \mathrm{i}_{33}, \mathrm{i}_{36}, \mathrm{i}_{39}, \mathrm{i}_{35}$ & $\mathrm{i}_{38}, \mathrm{i}_{31}, \mathrm{i}_{37}, \mathrm{i}_{34}$ & $\mathrm{C}_{340}$ \\
\hline
\end{tabular}


O primeiro ponto que destacamos no resultado acima é que três dos quatro candidatos tipo 1 não se declaram do tipo 1. Os candidatos $c_{11}$ e $c_{14}$ se declararam de tipo 2 e o candidato $c_{12}$ se declarou de tipo 3. Evidentemente que este resultado não é muito provável, pois modelamos em $10 \%$ a probabilidade de cada candidato tipo 1 não se declarar do tipo 1 . No entanto, como o resultado foi gerado de forma aleatória, ele se torna válido para avaliarmos que tipo de problemas podemos encontrar neste mercado descentralizado.

Como todas as Instituições tipo 2 e 3 fazem ofertas a qualquer candidato tipo 1 , os candidatos $c_{11}$, $c_{12}$ e $c_{14}$ recebem, pelo mecanismo, a Instituição mais preferida dentre aquelas pertencentes as suas respectivas listas de aceitáveis declaradas. Dessa forma, temos as seguintes parcerias geradas pelo mecanismo: $\left(i_{22}, c_{11}\right),\left(i_{38}, c_{12}\right),\left(i_{22}, c_{14}\right)$. As Instituições tipo 1 , por sua vez, não conseguem preencher suas vagas com os candidatos tipo 1 . A Instituição $i_{12}$ só termina de preencher suas vagas com o candidato $c_{325}$ que, apesar de ser do tipo 3 , cometeu o erro de se declarar do tipo 1 . A Instituição $i_{11}$ fica com as duas vagas não preenchidas, pois não há nenhum outro candidato que se declara do tipo 1. Como os candidatos $c_{11}$ e $c_{14}$ efetivamente preferem qualquer Instituição tipo 1 a qualquer Instituição tipo 2 e as Instituições tipo 1 ou têm vagas não preenchidas ou recebem candidatos tipo 2 ou 3, o mecanismo gera várias instabilidades entre esses candidatos e as duas Instituições tipo 1. Por outro lado, o par $\left(i_{38}, c_{12}\right)$ também gera instabilidades entre o candidato $c_{12}$, as duas Instituições tipo 1 e as três Instituições tipo 2. Nestes casos, o fato dos candidatos tipo 1 terem errado seus tipos precipitou sérias falhas no mecanismo.

Apenas um candidato tipo 2, $c_{25}$, errou seu tipo e se declarou tipo 3. Dessa forma, ele recebeu a Instituição $i_{39}$, quando poderia ter recebido as duas Instituições tipo 1 , caso tivesse se declarado tipo 1 . O candidato $c_{26}$, apesar de ter acertado seu tipo, não recebeu nenhuma Instituição, pois as Instituições tipo 2 já haviam preenchido suas vagas com os candidatos tipo 1 e tipo 2 melhor colocados. No entanto, $c_{26}$ poderia ter recebido qualquer Instituição tipo 3 se tivesse se declarado tipo 3.

Os candidatos tipo 3 melhor colocados acertaram seus tipos, com exceção de $c_{32}$, que se declarou do tipo 2, e, por esta razão, ficou sem Instituição. No entanto, $c_{32}$ poderia ter recebido qualquer 
Instituição tipo 3 , exceto $i_{39}$, se tivesse se declarado tipo 3 , ou ainda poderia ter recebido as duas Instituições tipo 1, se tivesse se declarado tipo 1.

Não é difícil de supor que este matching será objetado, pois grande parte dos jogadores tem incentivo de fazer arranjos subseqüentes, principalmente os jogadores de menor tipo. Concluindo, podemos dizer que, quando se adiciona probabilidade de erro por parte dos candidatos em relação aos seus tipos, mesmo que pequena, o mecanismo proposto, na melhor situação, ainda gera um conjunto de instabilidades graves, que envolvem inclusive as melhores Instituições e os melhores candidatos.

No mercado da ANPEC, apesar de supormos que os candidatos podem ter uma boa avaliação de seus tipos através de todos os instrumentos descritos anteriormente, não se pode afirmar, em hipótese alguma, que não exista a possibilidade de erro por partes deles. Por exemplo, um candidato que sempre foi um bom aluno durante o curso de graduação pode acreditar ser do tipo 1, mas, por não ter se preparado adequadamente para os exames, ou por não estar se sentindo bem durante a realização destes, pode ter como resultado graus que o coloquem como tipo 2 ou 3. Dessa forma, este candidato acredita ser do tipo 1, mas efetivamente é do tipo 2 ou 3. Portanto, se os candidatos se comportassem no mercado da ANPEC como neste caso 2, esperaríamos observar muitas instabilidades críticas nos matchings gerados pelo mecanismo, o que, fatalmente, resultaria em mudanças desse mecanismo de matching. No entanto, o atual mecanismo está em vigor há oito anos, aparentemente sem alterações, e não se observa nos matchings gerados Instituições de tipo 1 que ficam sem preencher grande parte de suas vagas, nem Instituições de tipo 3 que preencham suas vagas com candidatos de tipo 1 ou 2. Assim sendo, outra hipótese se faz necessária para explicar o comportamento dos participantes no mercado da ANPEC. Os demais matchings simulados com esta hipótese 2 são apresentados no apêndice C. 


\subsection{Hipótese 3: Os candidatos não conhecem seus tipos no momento de declarar suas} listas de Instituições aceitáveis

Agora supomos que os candidatos não sabem seus tipos no momento de declarar suas listas de Instituições aceitáveis. É razoável supormos que um dado candidato $c$ queira ter a chance de ser admitido por uma Instituição do mesmo tipo que o seu. Como ele não sabe seu tipo antes de declarar sua lista de aceitáveis, podemos considerar uma atitude racional para este candidato diversificar sua lista, incluindo uma Instituição de cada tipo nas três primeiras opções de sua lista. Supondo que todos os candidatos ajam com a mesma racionalidade e supondo ainda que cada candidato declare sua Instituição mais preferida de cada tipo nas três primeiras opções de sua lista, então, dada a estrutura de preferências dos candidatos, este candidato $c$ terá a mesma probabilidade de ser admitido em uma Instituição de mesmo tipo que o seu, para qualquer conjunto de três Instituições, sendo uma de cada tipo, que ele declarar. Então o melhor que $c$ pode fazer é declarar a Instituição mais preferida de cada tipo. Portanto, assumindo a racionalidade descrita acima, declarar a Instituição mais preferida de cada tipo nas três primeiras posições de sua lista é uma estratégia de “equilíbrio” para todos os candidatos.

Para a composição da quarta posição da lista de aceitáveis suporemos, como hipótese adicional, que existam candidatos otimistas, neutros e pessimistas, de tal forma que os candidatos otimistas sempre declaram um Centro tipo 1 na quarta posição de sua lista de aceitáveis, os candidatos neutros sempre declaram um Centro tipo 2 na quarta posição e os candidatos pessimistas sempre declaram um Centro tipo 3. Por fim, suporemos que cada candidato tem igual probabilidade de ser otimista, neutro ou pessimista. Fizemos então 10 simulações do modelo com as preferências dos candidatos sobre Centros do mesmo tipo e a definição de candidatos otimistas, neutros e pessimistas geradas aleatoriamente através do gerador de números aleatórios do software econométrico Eviews 4.0. Os resultados são apresentados na tabela 8. 
Tabela 8 - Número de instabilidades nos matchings simulados com a hipótese 3

\begin{tabular}{|l|c|c|c|c|c|c|c|c|c|c|c|}
\hline Matching & $\mu_{3 \mathrm{~A}}$ & $\mu_{3 \mathrm{~B}}$ & $\mu_{3 \mathrm{C}}$ & $\mu_{3 \mathrm{D}}$ & $\mu_{3 \mathrm{E}}$ & $\mu_{3 \mathrm{~F}}$ & $\mu_{3 \mathrm{G}}$ & $\mu_{3 \mathrm{H}}$ & $\mu_{3 \mathrm{I}}$ & $\mu_{3 \mathrm{~J}}$ & Média \\
\hline $\mathrm{N}^{\circ}$ total de instabilidades & 25 & 25 & 56 & 22 & 61 & 58 & 16 & 32 & 51 & 56 & 40.2 \\
\hline $\begin{array}{l}\mathrm{N}^{\circ} \text { de instabilidades } \\
\text { com Centros tipo 1 }\end{array}$ & 1 & 1 & 0 & 1 & 3 & 0 & 0 & 0 & 0 & 2 & 0.8 \\
\hline $\begin{array}{l}\mathrm{N}^{\circ} \text { de instabilidades } \\
\text { com Centros tipo 2 }\end{array}$ & 0 & 1 & 2 & 0 & 7 & 0 & 5 & 6 & 0 & 9 & 3.0 \\
\hline $\begin{array}{l}\mathrm{N}^{\circ} \text { de Instabilidades } \\
\text { com Centros tipo 3 }\end{array}$ & 24 & 23 & 54 & 21 & 51 & 58 & 11 & 26 & 51 & 45 & 36.4 \\
\hline $\begin{array}{l}\mathrm{N}^{\circ} \text { de instabilidades } \\
\text { com candidatos tipo 1 }\end{array}$ & 1 & 1 & 0 & 1 & 1 & 0 & 0 & 0 & 0 & 1 & 0.5 \\
\hline $\begin{array}{l}\mathrm{N}^{\circ} \text { de instabilidades } \\
\text { com candidatos tipo 2 }\end{array}$ & 0 & 1 & 1 & 0 & 3 & 0 & 2 & 4 & 0 & 5 & 1.6 \\
\hline $\begin{array}{l}\mathrm{N}^{\circ} \text { de instabilidades } \\
\text { com candidatos tipo 3 }\end{array}$ & 24 & 23 & 55 & 21 & 57 & 58 & 14 & 28 & 51 & 50 & 38.1 \\
\hline
\end{tabular}

Através dos resultados apresentados na tabela 8 observamos que o mecanismo não gerou nenhum matching estável. No entanto, a grande maioria das instabilidades ocorre entre Instituições de tipo 3 e candidatos de tipo 3 com piores colocações dentre aqueles que têm alguma Instituição tipo 3 alcançável. Mesmo as instabilidades que ocorrem entre os candidatos e Instituições de menor tipo podem ser consideradas, em sua grande maioria, “instabilidades suaves”, pois, para estas Instituições e candidatos, a distância, nas respectivas listas de preferências, entre os candidatos e Instituições alcançáveis mais preferidos e os pares recebidos pelo mecanismo não são significativamente grandes (este é um argumento qualitativo que indica que um participante, principalmente uma Instituição, têm “certa” indiferença entre os participantes do lado oposto que estão próximos em sua lista de prefefências. O argumento é apresentado de forma mais clara nos exemplos seguintes). O número médio de instabilidades no caso 3 é 40.2 contra 38.0 do caso 2, porém, a média de instabilidades envolvendo somente Instituições tipo 3 é 36.4 no primeiro caso contra 10.3 no segundo e a média envolvendo somente candidatos tipo 3 é, respectivamente, 38.1 contra 28.3. Ou seja, além das instabilidades no caso 3 serem mais freqüentes com Instituições e candidatos tipo 3, aquelas instabilidades que envolvem jogadores de menor tipo não geram grandes incentivos para esses participantes, principalmente as Instituições, realizarem arranjos subseqüentes e, portanto, podem ser consideradas “instabilidades suaves”. Para ilustrar este fato, vamos detalhar o matching $\mu_{3 B}$ que apresenta instabilidades com todos os tipos de Instituições e 
candidatos. A tabela a seguir apresenta a lista de preferências de cada candidato (construídas com o gerador de números aleatórios), a lista declarada segundo as Proposições 5, 6 e 7, e o matching resultante.

Tabela 9 - Matching $\mu_{3 \mathrm{~B}}$

\begin{tabular}{|c|c|c|c|}
\hline Candidato & Lista de Preferências & L. Declarada & Matching \\
\hline $\mathrm{c}_{11}$ & $i_{12}, i_{11}, i_{22}, i_{23}, i_{21}, i_{32}, i_{31}, i_{36}, i_{33}, i_{34}, i_{38}, i_{37}, i_{39}, i_{35}$ & $\mathrm{i}_{12}, \mathrm{i}_{22}, \mathrm{i}_{32}, \mathrm{i}_{23}$ & $\mathrm{i}_{12}$ \\
\hline $\mathrm{C}_{12}$ & $i_{12}, i_{11}, i_{22}, i_{21}, i_{23}, i_{38}, i_{37}, i_{32}, i_{36}, i_{33}, i_{34}, i_{35}, i_{39}, i_{31}$ & $\mathrm{i}_{12}, \mathrm{i}_{22}, \mathrm{i}_{38}, \mathrm{i}_{11}$ & $\mathrm{i}_{12}$ \\
\hline $\mathrm{c}_{13}$ & $i_{11}, i_{12}, i_{22}, i_{21}, i_{23}, i_{32}, i_{33}, i_{37}, i_{39}, i_{34}, i_{38}, i_{36}, i_{31}, i_{35}$ & $i_{11}, i_{22}, i_{32}, i_{33}$ & $\mathrm{i}_{11}$ \\
\hline $\mathrm{C}_{14}$ & $i_{12}, i_{11}, i_{22}, i_{23}, i_{21}, i_{37}, i_{36}, i_{32}, i_{31}, i_{34}, i_{33}, i_{35}, i_{38}, i_{39}$ & $\mathrm{i}_{12}, \mathrm{i}_{22}, \mathrm{i}_{37}, \mathrm{i}_{23}$ & $\mathrm{i}_{22}$ \\
\hline $\mathrm{C}_{21}$ & $i_{11}, i_{12}, i_{22}, i_{21}, i_{23}, i_{31}, i_{38}, i_{34}, i_{39}, i_{36}, i_{37}, i_{32}, i_{35}, i_{33}$ & $\mathrm{i}_{11}, \mathrm{i}_{22}, \mathrm{i}_{31}, \mathrm{i}_{21}$ & $\mathrm{i}_{11}$ \\
\hline $\mathrm{C}_{22}$ & $i_{12}, i_{11}, i_{23}, i_{21}, i_{22}, i_{38}, i_{33}, i_{39}, i_{31}, i_{32}, i_{35}, i_{34}, i_{36}, i_{37}$ & $\mathrm{i}_{12}, \mathrm{i}_{23}, \mathrm{i}_{38}, \mathrm{i}_{21}$ & $\mathrm{i}_{23}$ \\
\hline $\mathrm{C}_{23}$ & $i_{12}, i_{11}, i_{21}, i_{23}, i_{22}, i_{35}, i_{32}, i_{31}, i_{36}, i_{38}, i_{33}, i_{34}, i_{39}, i_{37}$ & $\mathrm{i}_{12}, \mathrm{i}_{21}, \mathrm{i}_{35}, \mathrm{i}_{23}$ & $\mathrm{i}_{21}$ \\
\hline $\mathrm{C}_{24}$ & $i_{11}, i_{12}, i_{23}, i_{21}, i_{22}, i_{36}, i_{38}, i_{35}, i_{33}, i_{32}, i_{39}, i_{31}, i_{34}, i_{37}$ & $\mathrm{i}_{11}, \mathrm{i}_{23}, \mathrm{i}_{36}, \mathrm{i}_{21}$ & $\mathrm{i}_{23}$ \\
\hline $\mathrm{C}_{25}$ & $i_{11}, i_{12}, i_{22}, i_{23}, i_{21}, i_{36}, i_{39}, i_{34}, i_{37}, i_{33}, i_{32}, i_{38}, i_{35}, i_{31}$ & $i_{11}, i_{22}, i_{36}, i_{39}$ & $\mathrm{i}_{22}$ \\
\hline $\mathrm{C}_{26}$ & $i_{12}, i_{11}, i_{22}, i_{23}, i_{21}, i_{38}, i_{33}, i_{35}, i_{39}, i_{37}, i_{34}, i_{31}, i_{32}, i_{36}$ & $\mathrm{i}_{12}, \mathrm{i}_{22}, \mathrm{i}_{38}, \mathrm{i}_{11}$ & $\mathrm{i}_{38}$ \\
\hline $\mathrm{C}_{31}$ & $i_{12}, i_{11}, i_{21}, i_{22}, i_{23}, i_{33}, i_{38}, i_{32}, i_{31}, i_{34}, i_{37}, i_{36}, i_{39}, i_{35}$ & $i_{12}, i_{21}, i_{33}, i_{38}$ & $\mathrm{i}_{21}$ \\
\hline $\mathrm{C}_{32}$ & $i_{12}, i_{11}, i_{21}, i_{23}, i_{22}, i_{31}, i_{39}, i_{36}, i_{33}, i_{34}, i_{32}, i_{37}, i_{38}, i_{35}$ & $\mathrm{i}_{12}, \mathrm{i}_{21}, \mathrm{i}_{31}, \mathrm{i}_{11}$ & $\mathrm{i}_{31}$ \\
\hline $\mathrm{C}_{33}$ & $i_{12}, i_{11}, i_{22}, i_{23}, i_{21}, i_{35}, i_{36}, i_{34}, i_{33}, i_{31}, i_{38}, i_{37}, i_{39}, i_{32}$ & $i_{12}, i_{22}, i_{35}, i_{36}$ & $\mathrm{i}_{35}$ \\
\hline $\mathrm{C}_{34}$ & $i_{11}, i_{12}, i_{21}, i_{23}, i_{22}, i_{35}, i_{31}, i_{38}, i_{33}, i_{39}, i_{32}, i_{34}, i_{36}, i_{37}$ & $\mathrm{i}_{11}, \mathrm{i}_{21}, \mathrm{i}_{35}, \mathrm{i}_{31}$ & $\mathrm{i}_{35}$ \\
\hline $\mathrm{C}_{35}$ & $i_{12}, i_{11}, i_{21}, i_{22}, i_{23}, i_{39}, i_{38}, i_{37}, i_{36}, i_{34}, i_{32}, i_{35}, i_{33}, i_{31}$ & $i_{12}, i_{21}, i_{39}, i_{22}$ & $\mathrm{i}_{39}$ \\
\hline $\mathrm{C}_{36}$ & $i_{11}, i_{12}, i_{23}, i_{21}, i_{22}, i_{37}, i_{34}, i_{39}, i_{32}, i_{33}, i_{31}, i_{35}, i_{36}, i_{38}$ & $\mathrm{i}_{11}, \mathrm{i}_{23}, \mathrm{i}_{37}, \mathrm{i}_{12}$ & $\mathrm{i}_{37}$ \\
\hline $\mathrm{C}_{37}$ & $i_{11}, i_{12}, i_{21}, i_{23}, i_{22}, i_{38}, i_{39}, i_{33}, i_{31}, i_{32}, i_{34}, i_{36}, i_{37}, i_{35}$ & $\mathrm{i}_{11}, \mathrm{i}_{21}, \mathrm{i}_{38}, \mathrm{i}_{39}$ & $\mathrm{i}_{38}$ \\
\hline $\mathrm{C}_{38}$ & $i_{12}, i_{11}, i_{22}, i_{23}, i_{21}, i_{39}, i_{32}, i_{35}, i_{36}, i_{37}, i_{31}, i_{38}, i_{34}, i_{33}$ & $i_{12}, i_{22}, i_{39}, i_{32}$ & $\mathrm{i}_{39}$ \\
\hline $\mathrm{C}_{39}$ & $i_{12}, i_{11}, i_{23}, i_{22}, i_{21}, i_{31}, i_{38}, i_{36}, i_{37}, i_{35}, i_{32}, i_{39}, i_{33}, i_{34}$ & $\mathrm{i}_{12}, \mathrm{i}_{23}, \mathrm{i}_{31}, \mathrm{i}_{22}$ & $\mathrm{i}_{31}$ \\
\hline $\mathrm{C}_{310}$ & $i_{12}, i_{11}, i_{21}, i_{23}, i_{22}, i_{33}, i_{35}, i_{34}, i_{32}, i_{31}, i_{36}, i_{38}, i_{37}, i_{39}$ & $i_{12}, i_{21}, i_{33}, i_{11}$ & $\mathrm{i}_{33}$ \\
\hline $\mathrm{C}_{311}$ & $i_{12}, i_{11}, i_{23}, i_{22}, i_{21}, i_{33}, i_{32}, i_{38}, i_{34}, i_{39}, i_{31}, i_{37}, i_{36}, i_{35}$ & $\mathrm{i}_{12}, \mathrm{i}_{23}, \mathrm{i}_{33}, \mathrm{i}_{11}$ & $\mathrm{i}_{33}$ \\
\hline $\mathrm{C}_{312}$ & $i_{11}, i_{12}, i_{21}, i_{23}, i_{22}, i_{33}, i_{31}, i_{35}, i_{32}, i_{36}, i_{38}, i_{34}, i_{39}, i_{37}$ & $\mathrm{i}_{11}, \mathrm{i}_{21}, \mathrm{i}_{33}, \mathrm{i}_{23}$ & $\mathrm{C}_{312}$ \\
\hline $\mathrm{C}_{313}$ & $i_{11}, i_{12}, i_{21}, i_{22}, i_{23}, i_{37}, i_{36}, i_{38}, i_{35}, i_{33}, i_{39}, i_{32}, i_{34}, i_{31}$ & $\mathrm{i}_{11}, \mathrm{i}_{21}, \mathrm{i}_{37}, \mathrm{i}_{36}$ & $\mathrm{i}_{37}$ \\
\hline $\mathrm{C}_{314}$ & $i_{12}, i_{11}, i_{21}, i_{22}, i_{23}, i_{36}, i_{38}, i_{34}, i_{33}, i_{35}, i_{39}, i_{37}, i_{31}, i_{32}$ & $i_{12}, i_{21}, i_{36}, i_{22}$ & $\mathrm{i}_{36}$ \\
\hline $\mathrm{C}_{315}$ & $i_{11}, i_{12}, i_{23}, i_{22}, i_{21}, i_{32}, i_{39}, i_{33}, i_{31}, i_{37}, i_{35}, i_{34}, i_{36}, i_{38}$ & $\mathrm{i}_{11}, \mathrm{i}_{23}, \mathrm{i}_{32}, \mathrm{i}_{12}$ & $\mathrm{i}_{32}$ \\
\hline $\mathrm{C}_{316}$ & $i_{12}, i_{11}, i_{23}, i_{22}, i_{21}, i_{36}, i_{32}, i_{33}, i_{35}, i_{34}, i_{38}, i_{31}, i_{39}, i_{37}$ & $i_{12}, i_{23}, i_{36}, i_{22}$ & $\mathrm{i}_{36}$ \\
\hline $\mathrm{C}_{317}$ & $i_{12}, i_{11}, i_{23}, i_{21}, i_{22}, i_{38}, i_{32}, i_{33}, i_{31}, i_{37}, i_{34}, i_{39}, i_{36}, i_{35}$ & $i_{12}, i_{23}, i_{38}, i_{32}$ & $\mathrm{i}_{32}$ \\
\hline $\mathrm{C}_{318}$ & $i_{11}, i_{12}, i_{23}, i_{21}, i_{22}, i_{38}, i_{35}, i_{31}, i_{32}, i_{37}, i_{33}, i_{36}, i_{39}, i_{34}$ & $\mathrm{i}_{11}, \mathrm{i}_{23}, \mathrm{i}_{38}, \mathrm{i}_{21}$ & $\mathrm{C}_{318}$ \\
\hline $\mathrm{C}_{319}$ & $\mathrm{i}_{11}, \mathrm{i}_{12}, \mathrm{i}_{23}, \mathrm{i}_{21}, \mathrm{i}_{22}, \mathrm{i}_{31}, \mathrm{i}_{33}, \mathrm{i}_{37}, \mathrm{i}_{38}, \mathrm{i}_{36}, \mathrm{i}_{35}, \mathrm{i}_{32}, \mathrm{i}_{39}, \mathrm{i}_{34}$ & $\mathrm{i}_{11}, \mathrm{i}_{23}, \mathrm{i}_{31}, \mathrm{i}_{21}$ & $\mathrm{C}_{319}$ \\
\hline
\end{tabular}




\begin{tabular}{|c|c|c|c|}
\hline $\mathrm{C}_{320}$ & $\mathrm{i}_{11}, \mathrm{i}_{12}, \mathrm{i}_{22}, \mathrm{i}_{23}, \mathrm{i}_{21}, \mathrm{i}_{35}, \mathrm{i}_{39}, \mathrm{i}_{33}, \mathrm{i}_{32}, \mathrm{i}_{37}, \mathrm{i}_{31}, \mathrm{i}_{38}, \mathrm{i}_{36}, \mathrm{i}_{34}$ & $i_{11}, i_{22}, i_{35}, i_{12}$ & $\mathrm{C}_{320}$ \\
\hline $\mathrm{C}_{321}$ & $\mathrm{i}_{12}, \mathrm{i}_{11}, \mathrm{i}_{23}, \mathrm{i}_{22}, \mathrm{i}_{21}, \mathrm{i}_{34}, \mathrm{i}_{38}, \mathrm{i}_{35}, \mathrm{i}_{39}, \mathrm{i}_{33}, \mathrm{i}_{32}, \mathrm{i}_{31}, \mathrm{i}_{37}, \mathrm{i}_{36}$ & $\mathrm{i}_{12}, \mathrm{i}_{23}, \mathrm{i}_{34}, \mathrm{i}_{22}$ & $\mathrm{i}_{34}$ \\
\hline $\mathrm{C}_{322}$ & $\mathrm{i}_{11}, \mathrm{i}_{12}, \mathrm{i}_{22}, \mathrm{i}_{21}, \mathrm{i}_{23}, \mathrm{i}_{33}, \mathrm{i}_{34}, \mathrm{i}_{37}, \mathrm{i}_{38}, \mathrm{i}_{39}, \mathrm{i}_{31}, \mathrm{i}_{32}, \mathrm{i}_{35}, \mathrm{i}_{36}$ & $i_{11}, i_{22}, i_{33}, i_{21}$ & $\mathrm{C}_{322}$ \\
\hline $\mathrm{C}_{323}$ & $\mathrm{i}_{12}, \mathrm{i}_{11}, \mathrm{i}_{21}, \mathrm{i}_{22}, \mathrm{i}_{23}, \mathrm{i}_{33}, \mathrm{i}_{32}, \mathrm{i}_{36}, \mathrm{i}_{39}, \mathrm{i}_{38}, \mathrm{i}_{34}, \mathrm{i}_{37}, \mathrm{i}_{31}, \mathrm{i}_{35}$ & $\mathrm{i}_{12}, \mathrm{i}_{21}, \mathrm{i}_{33}, \mathrm{i}_{22}$ & $\mathrm{C}_{323}$ \\
\hline $\mathrm{C}_{324}$ & $\mathrm{i}_{11}, \mathrm{i}_{12}, \mathrm{i}_{23}, \mathrm{i}_{21}, \mathrm{i}_{22}, \mathrm{i}_{32}, \mathrm{i}_{38}, \mathrm{i}_{34}, \mathrm{i}_{37}, \mathrm{i}_{39}, \mathrm{i}_{33}, \mathrm{i}_{31}, \mathrm{i}_{35}, \mathrm{i}_{36}$ & $\mathrm{i}_{11}, \mathrm{i}_{23}, \mathrm{i}_{32}, \mathrm{i}_{38}$ & $\mathrm{C}_{324}$ \\
\hline $\mathrm{C}_{325}$ & $\mathrm{i}_{11}, \mathrm{i}_{12}, \mathrm{i}_{23}, \mathrm{i}_{21}, \mathrm{i}_{22}, \mathrm{i}_{31}, \mathrm{i}_{34}, \mathrm{i}_{37}, \mathrm{i}_{36}, \mathrm{i}_{32}, \mathrm{i}_{35}, \mathrm{i}_{33}, \mathrm{i}_{39}, \mathrm{i}_{38}$ & $\mathrm{i}_{11}, \mathrm{i}_{23}, \mathrm{i}_{31}, \mathrm{i}_{21}$ & $\mathrm{C}_{325}$ \\
\hline $\mathrm{C}_{326}$ & $\mathrm{i}_{12}, \mathrm{i}_{11}, \mathrm{i}_{22}, \mathrm{i}_{21}, \mathrm{i}_{23}, \mathrm{i}_{31}, \mathrm{i}_{34}, \mathrm{i}_{32}, \mathrm{i}_{37}, \mathrm{i}_{33}, \mathrm{i}_{39}, \mathrm{i}_{35}, \mathrm{i}_{38}, \mathrm{i}_{36}$ & $\mathrm{i}_{12}, \mathrm{i}_{22}, \mathrm{i}_{31}, \mathrm{i}_{11}$ & $\mathrm{C}_{326}$ \\
\hline $\mathrm{C}_{327}$ & $\mathrm{i}_{11}, \mathrm{i}_{12}, \mathrm{i}_{22}, \mathrm{i}_{21}, \mathrm{i}_{23}, \mathrm{i}_{31}, \mathrm{i}_{33}, \mathrm{i}_{32}, \mathrm{i}_{37}, \mathrm{i}_{36}, \mathrm{i}_{34}, \mathrm{i}_{35}, \mathrm{i}_{39}, \mathrm{i}_{38}$ & $\mathrm{i}_{11}, \mathrm{i}_{22}, \mathrm{i}_{31}, \mathrm{i}_{21}$ & $\mathrm{C}_{327}$ \\
\hline $\mathrm{C}_{328}$ & $\mathrm{i}_{11}, \mathrm{i}_{12}, \mathrm{i}_{23}, \mathrm{i}_{21}, \mathrm{i}_{22}, \mathrm{i}_{32}, \mathrm{i}_{36}, \mathrm{i}_{38}, \mathrm{i}_{31}, \mathrm{i}_{35}, \mathrm{i}_{37}, \mathrm{i}_{39}, \mathrm{i}_{33}, \mathrm{i}_{34}$ & $\mathrm{i}_{11}, \mathrm{i}_{23}, \mathrm{i}_{32}, \mathrm{i}_{21}$ & $\mathrm{C}_{328}$ \\
\hline $\mathrm{C}_{329}$ & $\mathrm{i}_{12}, \mathrm{i}_{11}, \mathrm{i}_{23}, \mathrm{i}_{21}, \mathrm{i}_{22}, \mathrm{i}_{36}, \mathrm{i}_{34}, \mathrm{i}_{38}, \mathrm{i}_{32}, \mathrm{i}_{35}, \mathrm{i}_{39}, \mathrm{i}_{33}, \mathrm{i}_{37}, \mathrm{i}_{31}$ & $i_{12}, i_{23}, i_{36}, i_{11}$ & $\mathrm{C}_{329}$ \\
\hline $\mathrm{C}_{330}$ & $\mathrm{i}_{11}, \mathrm{i}_{12}, \mathrm{i}_{21}, \mathrm{i}_{22}, \mathrm{i}_{23}, \mathrm{i}_{31}, \mathrm{i}_{35}, \mathrm{i}_{33}, \mathrm{i}_{32}, \mathrm{i}_{34}, \mathrm{i}_{38}, \mathrm{i}_{37}, \mathrm{i}_{39}, \mathrm{i}_{36}$ & $\mathrm{i}_{11}, \mathrm{i}_{21}, \mathrm{i}_{31}, \mathrm{i}_{22}$ & $\mathrm{C}_{330}$ \\
\hline $\mathrm{C}_{331}$ & $i_{12}, i_{11}, i_{23}, i_{22}, i_{21}, i_{36}, i_{35}, i_{31}, i_{38}, i_{37}, i_{33}, i_{39}, i_{34}, i_{32}$ & $\mathrm{i}_{12}, \mathrm{i}_{23}, \mathrm{i}_{36}, \mathrm{i}_{11}$ & $\mathrm{C}_{331}$ \\
\hline $\mathrm{C}_{332}$ & $i_{12}, i_{11}, i_{21}, i_{22}, i_{23}, i_{31}, i_{32}, i_{38}, i_{39}, i_{34}, i_{37}, i_{33}, i_{36}, i_{35}$ & $\mathrm{i}_{12}, \mathrm{i}_{21}, \mathrm{i}_{31}, \mathrm{i}_{32}$ & $\mathrm{C}_{332}$ \\
\hline $\mathrm{C}_{333}$ & $\mathrm{i}_{12}, \mathrm{i}_{11}, \mathrm{i}_{21}, \mathrm{i}_{22}, \mathrm{i}_{23}, \mathrm{i}_{37}, \mathrm{i}_{31}, \mathrm{i}_{33}, \mathrm{i}_{32}, \mathrm{i}_{35}, \mathrm{i}_{36}, \mathrm{i}_{34}, \mathrm{i}_{39}, \mathrm{i}_{38}$ & $\mathrm{i}_{12}, \mathrm{i}_{21}, \mathrm{i}_{37}, \mathrm{i}_{22}$ & $\mathrm{C}_{333}$ \\
\hline $\mathrm{C}_{334}$ & $i_{11}, i_{12}, i_{23}, i_{21}, i_{22}, i_{37}, i_{33}, i_{32}, i_{38}, i_{31}, i_{39}, i_{36}, i_{34}, i_{35}$ & $\mathrm{i}_{11}, \mathrm{i}_{23}, \mathrm{i}_{37}, \mathrm{i}_{21}$ & $\mathrm{C}_{334}$ \\
\hline $\mathrm{C}_{335}$ & $\mathrm{i}_{12}, \mathrm{i}_{11}, \mathrm{i}_{23}, \mathrm{i}_{22}, \mathrm{i}_{21}, \mathrm{i}_{33}, \mathrm{i}_{32}, \mathrm{i}_{35}, \mathrm{i}_{37}, \mathrm{i}_{39}, \mathrm{i}_{38}, \mathrm{i}_{36}, \mathrm{i}_{34}, \mathrm{i}_{31}$ & $i_{12}, i_{23}, i_{33}, i_{22}$ & $\mathrm{C}_{335}$ \\
\hline $\mathrm{C}_{336}$ & $i_{11}, i_{12}, i_{21}, i_{23}, i_{22}, i_{39}, i_{31}, i_{38}, i_{33}, i_{32}, i_{35}, i_{37}, i_{34}, i_{36}$ & $\mathrm{i}_{11}, \mathrm{i}_{21}, \mathrm{i}_{39}, \mathrm{i}_{23}$ & $\mathrm{C}_{336}$ \\
\hline $\mathrm{C}_{337}$ & $\mathrm{i}_{12}, \mathrm{i}_{11}, \mathrm{i}_{21}, \mathrm{i}_{22}, \mathrm{i}_{23}, \mathrm{i}_{33}, \mathrm{i}_{36}, \mathrm{i}_{38}, \mathrm{i}_{32}, \mathrm{i}_{34}, \mathrm{i}_{39}, \mathrm{i}_{37}, \mathrm{i}_{31}, \mathrm{i}_{35}$ & $\mathrm{i}_{12}, \mathrm{i}_{21}, \mathrm{i}_{33}, \mathrm{i}_{22}$ & $\mathrm{C}_{337}$ \\
\hline $\mathrm{C}_{338}$ & $\mathrm{i}_{11}, \mathrm{i}_{12}, \mathrm{i}_{21}, \mathrm{i}_{23}, \mathrm{i}_{22}, \mathrm{i}_{34}, \mathrm{i}_{36}, \mathrm{i}_{35}, \mathrm{i}_{32}, \mathrm{i}_{38}, \mathrm{i}_{39}, \mathrm{i}_{31}, \mathrm{i}_{33}, \mathrm{i}_{37}$ & $\mathrm{i}_{11}, \mathrm{i}_{21}, \mathrm{i}_{34}, \mathrm{i}_{36}$ & $\mathrm{C}_{338}$ \\
\hline $\mathrm{C}_{339}$ & $\mathrm{i}_{12}, \mathrm{i}_{11}, \mathrm{i}_{21}, \mathrm{i}_{23}, \mathrm{i}_{22}, \mathrm{i}_{31}, \mathrm{i}_{32}, \mathrm{i}_{33}, \mathrm{i}_{38}, \mathrm{i}_{37}, \mathrm{i}_{34}, \mathrm{i}_{35}, \mathrm{i}_{39}, \mathrm{i}_{36}$ & $\mathrm{i}_{12}, \mathrm{i}_{21}, \mathrm{i}_{31}, \mathrm{i}_{23}$ & $\mathrm{C}_{339}$ \\
\hline $\mathrm{C}_{340}$ & $\mathrm{i}_{12}, \mathrm{i}_{11}, \mathrm{i}_{22}, \mathrm{i}_{23}, \mathrm{i}_{21}, \mathrm{i}_{38}, \mathrm{i}_{34}, \mathrm{i}_{31}, \mathrm{i}_{35}, \mathrm{i}_{32}, \mathrm{i}_{39}, \mathrm{i}_{37}, \mathrm{i}_{33}, \mathrm{i}_{36}$ & $\mathrm{i}_{12}, \mathrm{i}_{22}, \mathrm{i}_{38}, \mathrm{i}_{34}$ & $\mathrm{i}_{34}$ \\
\hline
\end{tabular}

Da tabela acima, observamos que a Instituição $i_{12}$ recebeu os dois melhores candidatos do tipo 1 enquanto a Instituição $i_{11}$ recebeu $c_{13}$ e $c_{21}$, que é o melhor candidato tipo 2 . O candidato $c_{14}$ não recebeu uma oferta de $i_{11}$ porque não a declarou em sua lista. No entanto, o mecanismo lhe deu $i_{22}$ que é sua Instituição tipo 2 mais preferida. Podemos supor então que o par $\left(i_{11}, c_{14}\right)$ forma uma instabilidade suave. A Instituição $i_{22}$ recebeu os candidatos $c_{14}$ e $c_{25}$, que é um resultado estável. A Instituição $i_{23}$ recebeu $c_{22}$ e $c_{24}$, que é um resultado estável. A Instituição $i_{21}$, por sua vez, recebeu $c_{23}$ e $c_{31}$, que é o melhor candidato tipo 3. Ela não fez uma oferta a $c_{26}$ por que ele não a declarou em sua lista. No entanto, $c_{26}$ recebeu $i_{38}$, que é sua Instituição tipo 3 mais preferida. Podemos supor então que o par $\left(i_{21}, c_{26}\right)$ forma uma instabilidade suave. As Instituições tipo 3, em sua maioria, recebem os candidatos tipo 3 melhor colocados. As instabilidades eventuais envolvem os candidatos com piores colocações. $\mathrm{O}$ candidato $c_{312}$ não recebe nenhuma oferta, pois a única Instituição tipo 3 que ele declarou preencheu suas vagas com candidatos melhor 
colocados que ele. Este candidato forma com $i_{32}, i_{36}$ e $i_{37}$, instabilidades que também podem ser consideradas instabilidades suaves. A exceção é a Instituição $i_{34}$ que recebe candidatos com colocação muito ruim. Portanto, as instabilidades entre as Instituições e candidatos de menor tipo são suaves e geram menores incentivos para arranjos subseqüentes.

Por outro lado, apesar de ser pouco provável, o modelo com a hipótese 3 ainda pode produzir instabilidades mais graves, como pode ser ilustrado pelo matching $\mu_{3 J}$, que apresenta o máximo de instabilidades envolvendo jogadores de menor tipo deste conjunto de simulações. A tabela a seguir apresenta a lista de preferências de cada candidato (construídas com o gerador de números aleatórios), a lista declarada segundo as Proposições 5, 6 e 7, e o matching resultante.

Tabela 10 - Matching $\mu_{3 J}$

\begin{tabular}{|c|c|c|c|}
\hline Candidato & Lista de Preferências & L. Declarada & Matching \\
\hline $\mathrm{C}_{11}$ & $\mathrm{i}_{11}, \mathrm{i}_{12}, \mathrm{i}_{22}, \mathrm{i}_{21}, \mathrm{i}_{23}, \mathrm{i}_{35}, \mathrm{i}_{32}, \mathrm{i}_{38}, \mathrm{i}_{37}, \mathrm{i}_{33}, \mathrm{i}_{36}, \mathrm{i}_{31}, \mathrm{i}_{34}, \mathrm{i}_{39}$ & $i_{11}, i_{22}, i_{35}, i_{32}$ & $\mathrm{i}_{11}$ \\
\hline $\mathrm{C}_{12}$ & $i_{11}, i_{12}, i_{21}, i_{23}, i_{22}, i_{31}, i_{36}, i_{38}, i_{39}, i_{32}, i_{33}, i_{34}, i_{35}, i_{37}$ & $i_{11}, i_{21}, i_{31}, i_{36}$ & $\mathrm{i}_{11}$ \\
\hline $\mathrm{c}_{13}$ & $i_{11}, i_{12}, i_{23}, i_{22}, i_{21}, i_{34}, i_{31}, i_{39}, i_{32}, i_{38}, i_{35}, i_{36}, i_{37}, i_{33}$ & $\mathrm{i}_{11}, \mathrm{i}_{23}, \mathrm{i}_{34}, \mathrm{i}_{31}$ & $\mathbf{i}_{23}$ \\
\hline $\mathrm{C}_{14}$ & $\mathrm{i}_{12}, \mathrm{i}_{11}, \mathrm{i}_{23}, \mathrm{i}_{21}, \mathrm{i}_{22}, \mathrm{i}_{36}, \mathrm{i}_{35}, \mathrm{i}_{32}, \mathrm{i}_{33}, \mathrm{i}_{34}, \mathrm{i}_{37}, \mathrm{i}_{38}, \mathrm{i}_{31}, \mathrm{i}_{39}$ & $i_{12}, i_{23}, i_{36}, i_{12}$ & $\mathrm{i}_{12}$ \\
\hline $\mathrm{C}_{21}$ & $i_{11}, i_{12}, i_{22}, i_{23}, i_{21}, i_{37}, i_{38}, i_{32}, i_{34}, i_{39}, i_{35}, i_{36}, i_{33}, i_{31}$ & $\mathrm{i}_{11}, \mathrm{i}_{22}, \mathrm{i}_{37}, \mathrm{i}_{23}$ & $\mathbf{i}_{22}$ \\
\hline $\mathrm{C}_{22}$ & $i_{12}, i_{11}, i_{22}, i_{21}, i_{23}, i_{32}, i_{36}, i_{38}, i_{37}, i_{35}, i_{34}, i_{31}, i_{39}, i_{33}$ & $i_{12}, i_{22}, i_{32}, i_{11}$ & $i_{12}$ \\
\hline $\mathrm{C}_{23}$ & $\mathrm{i}_{12}, \mathrm{i}_{11}, \mathrm{i}_{21}, \mathrm{i}_{23}, \mathrm{i}_{22}, \mathrm{i}_{37}, \mathrm{i}_{31}, \mathrm{i}_{34}, \mathrm{i}_{35}, \mathrm{i}_{33}, \mathrm{i}_{39}, \mathrm{i}_{38}, \mathrm{i}_{32}, \mathrm{i}_{36}$ & $\mathrm{i}_{12}, \mathrm{i}_{21}, \mathrm{i}_{37}, \mathrm{i}_{31}$ & $\mathrm{i}_{21}$ \\
\hline $\mathrm{C}_{24}$ & $i_{12}, i_{11}, i_{21}, i_{22}, i_{23}, i_{34}, i_{33}, i_{32}, i_{37}, i_{38}, i_{35}, i_{39}, i_{31}, i_{36}$ & $i_{12}, i_{21}, i_{34}, i_{22}$ & $\mathrm{i}_{21}$ \\
\hline $\mathrm{C}_{25}$ & $i_{12}, i_{11}, i_{21}, i_{23}, i_{22}, i_{34}, i_{36}, i_{32}, i_{33}, i_{35}, i_{39}, i_{38}, i_{31}, i_{37}$ & $\mathrm{i}_{12}, \mathrm{i}_{21}, \mathrm{i}_{34}, \mathrm{i}_{11}$ & $\mathrm{i}_{34}$ \\
\hline $\mathrm{C}_{26}$ & $i_{12}, i_{11}, i_{21}, i_{22}, i_{23}, i_{38}, i_{33}, i_{36}, i_{34}, i_{31}, i_{39}, i_{37}, i_{35}, i_{32}$ & $i_{12}, i_{21}, i_{38}, i_{33}$ & $\mathrm{i}_{38}$ \\
\hline $\mathrm{C}_{31}$ & $\mathrm{i}_{12}, \mathrm{i}_{11}, \mathrm{i}_{22}, \mathrm{i}_{21}, \mathrm{i}_{23}, \mathrm{i}_{36}, \mathrm{i}_{37}, \mathrm{i}_{31}, \mathrm{i}_{34}, \mathrm{i}_{33}, \mathrm{i}_{32}, \mathrm{i}_{35}, \mathrm{i}_{39}, \mathrm{i}_{38}$ & $\mathrm{i}_{12}, \mathrm{i}_{22}, \mathrm{i}_{36}, \mathrm{i}_{21}$ & $\mathrm{i}_{22}$ \\
\hline $\mathrm{C}_{32}$ & $i_{11}, i_{12}, i_{22}, i_{23}, i_{21}, i_{33}, i_{38}, i_{35}, i_{37}, i_{32}, i_{39}, i_{31}, i_{34}, i_{36}$ & $i_{11}, i_{22}, i_{33}, i_{12}$ & $i_{33}$ \\
\hline $\mathrm{C}_{33}$ & $\mathrm{i}_{12}, \mathrm{i}_{11}, \mathrm{i}_{21}, \mathrm{i}_{23}, \mathrm{i}_{22}, \mathrm{i}_{32}, \mathrm{i}_{31}, \mathrm{i}_{36}, \mathrm{i}_{34}, \mathrm{i}_{37}, \mathrm{i}_{39}, \mathrm{i}_{38}, \mathrm{i}_{33}, \mathrm{i}_{35}$ & $\mathrm{i}_{12}, \mathrm{i}_{21}, \mathrm{i}_{32}, \mathrm{i}_{11}$ & $i_{32}$ \\
\hline $\mathrm{C}_{34}$ & $i_{12}, i_{11}, i_{21}, i_{22}, i_{23}, i_{31}, i_{34}, i_{32}, i_{39}, i_{38}, i_{33}, i_{35}, i_{36}, i_{37}$ & $\mathrm{i}_{12}, \mathrm{i}_{21}, \mathrm{i}_{31}, \mathrm{i}_{11}$ & $i_{31}$ \\
\hline $\mathrm{C}_{35}$ & $\mathrm{i}_{11}, \mathrm{i}_{12}, \mathrm{i}_{22}, \mathrm{i}_{21}, \mathrm{i}_{23}, \mathrm{i}_{35}, \mathrm{i}_{39}, \mathrm{i}_{31}, \mathrm{i}_{37}, \mathrm{i}_{32}, \mathrm{i}_{36}, \mathrm{i}_{33}, \mathrm{i}_{34}, \mathrm{i}_{38}$ & $\mathrm{i}_{11}, \mathrm{i}_{22}, \mathrm{i}_{35}, \mathrm{i}_{21}$ & $\mathrm{i}_{35}$ \\
\hline $\mathrm{C}_{36}$ & $i_{12}, i_{11}, i_{22}, i_{23}, i_{21}, i_{32}, i_{34}, i_{39}, i_{38}, i_{36}, i_{35}, i_{33}, i_{37}, i_{31}$ & $i_{12}, i_{22}, i_{32}, i_{11}$ & $i_{32}$ \\
\hline $\mathrm{C}_{37}$ & $\mathrm{i}_{11}, \mathrm{i}_{12}, \mathrm{i}_{21}, \mathrm{i}_{23}, \mathrm{i}_{22}, \mathrm{i}_{39}, \mathrm{i}_{36}, \mathrm{i}_{35}, \mathrm{i}_{38}, \mathrm{i}_{33}, \mathrm{i}_{31}, \mathrm{i}_{34}, \mathrm{i}_{37}, \mathrm{i}_{32}$ & $\mathrm{i}_{11}, \mathrm{i}_{21}, \mathrm{i}_{39}, \mathrm{i}_{23}$ & $\mathrm{i}_{23}$ \\
\hline $\mathrm{C}_{38}$ & $\mathrm{i}_{12}, \mathrm{i}_{11}, \mathrm{i}_{22}, \mathrm{i}_{21}, \mathrm{i}_{23}, \mathrm{i}_{35}, \mathrm{i}_{39}, \mathrm{i}_{37}, \mathrm{i}_{32}, \mathrm{i}_{38}, \mathrm{i}_{31}, \mathrm{i}_{33}, \mathrm{i}_{34}, \mathrm{i}_{36}$ & $\mathrm{i}_{12}, \mathrm{i}_{22}, \mathrm{i}_{35}, \mathrm{i}_{39}$ & $\mathrm{i}_{35}$ \\
\hline $\mathrm{C}_{39}$ & $\mathrm{i}_{11}, \mathrm{i}_{12}, \mathrm{i}_{23}, \mathrm{i}_{21}, \mathrm{i}_{22}, \mathrm{i}_{33}, \mathrm{i}_{35}, \mathrm{i}_{36}, \mathrm{i}_{34}, \mathrm{i}_{39}, \mathrm{i}_{32}, \mathrm{i}_{31}, \mathrm{i}_{37}, \mathrm{i}_{38}$ & $\mathrm{i}_{11}, \mathrm{i}_{23}, \mathrm{i}_{33}, \mathrm{i}_{35}$ & $i_{33}$ \\
\hline $\mathrm{C}_{310}$ & $\mathrm{i}_{12}, \mathrm{i}_{11}, \mathrm{i}_{21}, \mathrm{i}_{22}, \mathrm{i}_{23}, \mathrm{i}_{34}, \mathrm{i}_{32}, \mathrm{i}_{31}, \mathrm{i}_{39}, \mathrm{i}_{33}, \mathrm{i}_{35}, \mathrm{i}_{38}, \mathrm{i}_{36}, \mathrm{i}_{37}$ & $\mathrm{i}_{12}, \mathrm{i}_{21}, \mathrm{i}_{34}, \mathrm{i}_{32}$ & $i_{34}$ \\
\hline $\mathrm{C}_{311}$ & $\mathrm{i}_{11}, \mathrm{i}_{12}, \mathrm{i}_{21}, \mathrm{i}_{23}, \mathrm{i}_{22}, \mathrm{i}_{37}, \mathrm{i}_{34}, \mathrm{i}_{31}, \mathrm{i}_{32}, \mathrm{i}_{33}, \mathrm{i}_{38}, \mathrm{i}_{35}, \mathrm{i}_{36}, \mathrm{i}_{39}$ & $\mathrm{i}_{11}, \mathrm{i}_{21}, \mathrm{i}_{37}, \mathrm{i}_{34}$ & $\mathrm{i}_{37}$ \\
\hline
\end{tabular}




\begin{tabular}{|c|c|c|c|}
\hline $\mathrm{C}_{312}$ & $i_{12}, i_{11}, i_{22}, i_{21}, i_{23}, i_{35}, i_{37}, i_{36}, i_{39}, i_{34}, i_{38}, i_{32}, i_{33}, i_{31}$ & $i_{12}, i_{22}, i_{35}, i_{21}$ & $\mathrm{C}_{312}$ \\
\hline $\mathrm{C}_{313}$ & $i_{11}, i_{12}, i_{23}, i_{21}, i_{22}, i_{33}, i_{34}, i_{36}, i_{35}, i_{32}, i_{37}, i_{38}, i_{39}, i_{31}$ & $\mathrm{i}_{11}, \mathrm{i}_{23}, \mathrm{i}_{33}, \mathrm{i}_{12}$ & $\mathrm{C}_{313}$ \\
\hline $\mathrm{C}_{314}$ & $i_{12}, i_{11}, i_{23}, i_{22}, i_{21}, i_{34}, i_{38}, i_{32}, i_{35}, i_{39}, i_{31}, i_{37}, i_{33}, i_{36}$ & $\mathrm{i}_{12}, \mathrm{i}_{23}, \mathrm{i}_{34}, \mathrm{i}_{38}$ & $\mathrm{i}_{38}$ \\
\hline $\mathrm{C}_{315}$ & $i_{11}, i_{12}, i_{22}, i_{23}, i_{21}, i_{37}, i_{38}, i_{39}, i_{36}, i_{34}, i_{31}, i_{35}, i_{32}, i_{33}$ & $\mathrm{i}_{11}, \mathrm{i}_{22}, \mathrm{i}_{37}, \mathrm{i}_{12}$ & $\mathrm{i}_{37}$ \\
\hline $\mathrm{C}_{316}$ & $i_{12}, i_{11}, i_{23}, i_{21}, i_{22}, i_{32}, i_{37}, i_{36}, i_{38}, i_{33}, i_{34}, i_{35}, i_{31}, i_{39}$ & $i_{12}, i_{23}, i_{32}, i_{37}$ & $\mathrm{C}_{316}$ \\
\hline $\mathrm{C}_{317}$ & $i_{11}, i_{12}, i_{22}, i_{21}, i_{23}, i_{33}, i_{32}, i_{39}, i_{35}, i_{36}, i_{34}, i_{37}, i_{38}, i_{31}$ & $i_{11}, i_{22}, i_{33}, i_{32}$ & $\mathrm{C}_{317}$ \\
\hline $\mathrm{C}_{318}$ & $i_{12}, i_{11}, i_{23}, i_{21}, i_{22}, i_{37}, i_{39}, i_{34}, i_{32}, i_{35}, i_{31}, i_{36}, i_{38}, i_{33}$ & $i_{12}, i_{23}, i_{37}, i_{11}$ & $\mathrm{C}_{318}$ \\
\hline $\mathrm{C}_{319}$ & $i_{11}, i_{12}, i_{21}, i_{22}, i_{23}, i_{32}, i_{31}, i_{34}, i_{39}, i_{35}, i_{37}, i_{33}, i_{38}, i_{36}$ & $\mathrm{i}_{11}, \mathrm{i}_{21}, \mathrm{i}_{32}, \mathrm{i}_{12}$ & $\mathrm{C}_{319}$ \\
\hline $\mathrm{C}_{320}$ & $\mathrm{i}_{12}, \mathrm{i}_{11}, \mathrm{i}_{23}, \mathrm{i}_{22}, \mathrm{i}_{21}, \mathrm{i}_{35}, \mathrm{i}_{34}, \mathrm{i}_{36}, \mathrm{i}_{31}, \mathrm{i}_{38}, \mathrm{i}_{37}, \mathrm{i}_{33}, \mathrm{i}_{32}, \mathrm{i}_{39}$ & $\mathrm{i}_{12}, \mathrm{i}_{23}, \mathrm{i}_{35}, \mathrm{i}_{34}$ & $\mathrm{C}_{320}$ \\
\hline $\mathrm{C}_{321}$ & $i_{12}, i_{11}, i_{21}, i_{23}, i_{22}, i_{35}, i_{31}, i_{36}, i_{32}, i_{33}, i_{34}, i_{39}, i_{37}, i_{38}$ & $i_{12}, i_{21}, i_{35}, i_{23}$ & $\mathrm{C}_{321}$ \\
\hline $\mathrm{C}_{322}$ & $i_{11}, i_{12}, i_{21}, i_{22}, i_{23}, i_{33}, i_{31}, i_{35}, i_{37}, i_{32}, i_{34}, i_{39}, i_{38}, i_{36}$ & $i_{11}, i_{21}, i_{33}, i_{31}$ & $\mathrm{i}_{31}$ \\
\hline $\mathrm{C}_{323}$ & $i_{12}, i_{11}, i_{23}, i_{22}, i_{21}, i_{31}, i_{33}, i_{34}, i_{32}, i_{36}, i_{38}, i_{35}, i_{37}, i_{39}$ & $\mathrm{i}_{12}, \mathrm{i}_{23}, \mathrm{i}_{31}, \mathrm{i}_{22}$ & $\mathrm{C}_{323}$ \\
\hline $\mathrm{C}_{324}$ & $i_{12}, i_{11}, i_{23}, i_{21}, i_{22}, i_{31}, i_{35}, i_{32}, i_{37}, i_{36}, i_{34}, i_{39}, i_{38}, i_{33}$ & $\mathrm{i}_{12}, \mathrm{i}_{23}, \mathrm{i}_{31}, \mathrm{i}_{11}$ & $\mathrm{C}_{324}$ \\
\hline $\mathrm{C}_{325}$ & $i_{11}, i_{12}, i_{22}, i_{23}, i_{21}, i_{32}, i_{36}, i_{35}, i_{38}, i_{34}, i_{37}, i_{31}, i_{39}, i_{33}$ & $\mathrm{i}_{11}, \mathrm{i}_{22}, \mathrm{i}_{32}, \mathrm{i}_{12}$ & $\mathrm{C}_{325}$ \\
\hline $\mathrm{C}_{326}$ & $\mathrm{i}_{12}, \mathrm{i}_{11}, \mathrm{i}_{23}, \mathrm{i}_{21}, \mathrm{i}_{22}, \mathrm{i}_{36}, \mathrm{i}_{33}, \mathrm{i}_{31}, \mathrm{i}_{32}, \mathrm{i}_{35}, \mathrm{i}_{38}, \mathrm{i}_{39}, \mathrm{i}_{34}, \mathrm{i}_{37}$ & $\mathrm{i}_{12}, \mathrm{i}_{23}, \mathrm{i}_{36}, \mathrm{i}_{21}$ & $\mathrm{i}_{36}$ \\
\hline $\mathrm{C}_{327}$ & $\mathrm{i}_{11}, \mathrm{i}_{12}, \mathrm{i}_{23}, \mathrm{i}_{22}, \mathrm{i}_{21}, \mathrm{i}_{36}, \mathrm{i}_{35}, \mathrm{i}_{34}, \mathrm{i}_{33}, \mathrm{i}_{37}, \mathrm{i}_{39}, \mathrm{i}_{38}, \mathrm{i}_{32}, \mathrm{i}_{31}$ & $\mathrm{i}_{11}, \mathrm{i}_{23}, \mathrm{i}_{36}, \mathrm{i}_{12}$ & $\mathrm{i}_{36}$ \\
\hline $\mathrm{C}_{328}$ & $\mathrm{i}_{11}, \mathrm{i}_{12}, \mathrm{i}_{21}, \mathrm{i}_{22}, \mathrm{i}_{23}, \mathrm{i}_{37}, \mathrm{i}_{32}, \mathrm{i}_{35}, \mathrm{i}_{31}, \mathrm{i}_{38}, \mathrm{i}_{39}, \mathrm{i}_{36}, \mathrm{i}_{34}, \mathrm{i}_{33}$ & $\mathrm{i}_{11}, \mathrm{i}_{21}, \mathrm{i}_{37}, \mathrm{i}_{22}$ & $\mathrm{C}_{328}$ \\
\hline $\mathrm{C}_{329}$ & $i_{11}, i_{12}, i_{23}, i_{22}, i_{21}, i_{35}, i_{34}, i_{33}, i_{32}, i_{38}, i_{31}, i_{37}, i_{36}, i_{39}$ & $i_{11}, i_{23}, i_{35}, i_{22}$ & $\mathrm{C}_{329}$ \\
\hline $\mathrm{C}_{330}$ & $i_{11}, i_{12}, i_{23}, i_{22}, i_{21}, i_{37}, i_{32}, i_{39}, i_{34}, i_{31}, i_{35}, i_{33}, i_{38}, i_{36}$ & $i_{11}, i_{23}, i_{37}, i_{22}$ & $\mathrm{C}_{330}$ \\
\hline $\mathrm{C}_{331}$ & $i_{12}, i_{11}, i_{23}, i_{22}, i_{21}, i_{38}, i_{34}, i_{37}, i_{33}, i_{35}, i_{31}, i_{39}, i_{32}, i_{36}$ & $i_{12}, i_{23}, i_{38}, i_{22}$ & $\mathrm{C}_{331}$ \\
\hline $\mathrm{C}_{332}$ & $\mathrm{i}_{12}, \mathrm{i}_{11}, \mathrm{i}_{21}, \mathrm{i}_{22}, \mathrm{i}_{23}, \mathrm{i}_{35}, \mathrm{i}_{39}, \mathrm{i}_{38}, \mathrm{i}_{34}, \mathrm{i}_{33}, \mathrm{i}_{31}, \mathrm{i}_{36}, \mathrm{i}_{37}, \mathrm{i}_{32}$ & $\mathrm{i}_{12}, \mathrm{i}_{21}, \mathrm{i}_{35}, \mathrm{i}_{22}$ & $\mathrm{C}_{332}$ \\
\hline $\mathrm{C}_{333}$ & $i_{12}, i_{11}, i_{22}, i_{23}, i_{21}, i_{32}, i_{31}, i_{39}, i_{34}, i_{35}, i_{37}, i_{38}, i_{36}, i_{33}$ & $i_{12}, i_{22}, i_{32}, i_{23}$ & $\mathrm{C}_{333}$ \\
\hline $\mathrm{C}_{334}$ & $\mathrm{i}_{11}, \mathrm{i}_{12}, \mathrm{i}_{22}, \mathrm{i}_{21}, \mathrm{i}_{23}, \mathrm{i}_{37}, \mathrm{i}_{32}, \mathrm{i}_{35}, \mathrm{i}_{31}, \mathrm{i}_{36}, \mathrm{i}_{33}, \mathrm{i}_{34}, \mathrm{i}_{39}, \mathrm{i}_{38}$ & $\mathrm{i}_{11}, \mathrm{i}_{22}, \mathrm{i}_{37}, \mathrm{i}_{21}$ & $\mathrm{C}_{334}$ \\
\hline $\mathrm{C}_{335}$ & $i_{11}, i_{12}, i_{23}, i_{22}, i_{21}, i_{38}, i_{35}, i_{37}, i_{31}, i_{36}, i_{32}, i_{33}, i_{34}, i_{39}$ & $\mathrm{i}_{11}, \mathrm{i}_{23}, \mathrm{i}_{38}, \mathrm{i}_{35}$ & $\mathrm{C}_{335}$ \\
\hline $\mathrm{C}_{336}$ & $i_{11}, i_{12}, i_{22}, i_{21}, i_{23}, i_{34}, i_{35}, i_{36}, i_{37}, i_{32}, i_{33}, i_{31}, i_{39}, i_{38}$ & $i_{11}, i_{22}, i_{34}, i_{35}$ & $\mathrm{C}_{336}$ \\
\hline $\mathrm{C}_{337}$ & $i_{12}, i_{11}, i_{21}, i_{23}, i_{22}, i_{35}, i_{34}, i_{39}, i_{33}, i_{31}, i_{36}, i_{37}, i_{32}, i_{38}$ & $\mathrm{i}_{12}, \mathrm{i}_{21}, \mathrm{i}_{35}, \mathrm{i}_{23}$ & $\mathrm{C}_{337}$ \\
\hline $\mathrm{C}_{338}$ & $\mathrm{i}_{12}, \mathrm{i}_{11}, \mathrm{i}_{22}, \mathrm{i}_{23}, \mathrm{i}_{21}, \mathrm{i}_{39}, \mathrm{i}_{36}, \mathrm{i}_{32}, \mathrm{i}_{33}, \mathrm{i}_{37}, \mathrm{i}_{35}, \mathrm{i}_{34}, \mathrm{i}_{31}, \mathrm{i}_{38}$ & $\mathrm{i}_{12}, \mathrm{i}_{22}, \mathrm{i}_{39}, \mathrm{i}_{11}$ & $\mathrm{i}_{39}$ \\
\hline $\mathrm{C}_{339}$ & $i_{12}, i_{11}, i_{22}, i_{21}, i_{23}, i_{34}, i_{37}, i_{35}, i_{36}, i_{38}, i_{33}, i_{31}, i_{32}, i_{39}$ & $i_{12}, i_{22}, i_{34}, i_{37}$ & $\mathrm{C}_{339}$ \\
\hline $\mathrm{C}_{340}$ & $i_{11}, i_{12}, i_{21}, i_{22}, i_{23}, i_{31}, i_{39}, i_{35}, i_{38}, i_{37}, i_{32}, i_{33}, i_{36}, i_{34}$ & $\mathrm{i}_{11}, \mathrm{i}_{21}, \mathrm{i}_{31}, \mathrm{i}_{39}$ & $i_{39}$ \\
\hline
\end{tabular}

Da tabela acima, observamos que a Instituição $i_{11}$ recebeu os dois melhores candidatos do tipo 1 enquanto a Instituição $i_{12}$ recebeu $c_{14}$ e $c_{22}$, que é o segundo melhor candidato tipo 2 . O candidato $c_{13}$ não recebeu uma oferta de $i_{12}$ porque não a declarou em sua lista. No entanto, o mecanismo lhe deu $i_{23}$ que é sua Instituição tipo 2 mais preferida. Podemos supor então que o par $\left(i_{12}, c_{13}\right)$ forma uma instabilidade suave. A Instituição $i_{21}$ recebeu $c_{23}$ e $c_{24}$, que é um resultado estável. A 
Instituição $i_{22}$ recebeu $c_{21}$ e $c_{31}$, quando poderia ter recebido $c_{25}$ e $c_{26}$, se estes candidatos a tivessem declarado em suas listas. No entanto, podemos considerar que os pares $\left(i_{22}, c_{25}\right)$ e $\left(i_{22}\right.$, $c_{26}$ ) são instabilidades suaves, pois $i_{22}$ recebeu o melhor candidato tipo 3 e os candidatos $c_{25}$ e $c_{26}$ receberam suas Instituições tipo 3 mais preferidas. A Instituição $i_{23}$, por sua vez, recebeu os candidatos $c_{13}$ e $c_{37}$, quando poderia ter recebido $c_{25}, c_{26}, c_{32}, c_{33}, c_{34}, c_{35}$ ou $c_{36}$. Estes candidatos formam com $i_{23}$ instabilidades mais críticas que nos casos anteriores, o que mostra que mesmo uma Instituição de menor tipo pode ter um resultado não muito satisfatório com esta hipótese 3. As Instituições tipo 3, em sua maioria, recebem os candidatos tipo 3 melhor colocados. As instabilidades eventuais envolvem os candidatos com piores colocações e, portanto, também podem ser consideradas instabilidades suaves. As exceções são as Instituições $i_{36}$ e $i_{39}$ que recebem candidatos com colocação muito ruim e, portanto, têm resultados não satisfatórios. No entanto, as exceções não invalidam o argumento a respeito das instabilidades suaves, principalmente para as Instituições de menor tipo, pois este matching $\mu_{3 J}$ é o pior dentre os 10 simulados e, na média, estas exceções não são muito freqüentes.

Em suma, podemos concluir que nesta hipótese, com os candidatos diversificando suas listas declaradas, o mecanismo descentralizado, na melhor situação, gera matchings com instabilidades suaves, nas quais os jogadores, principalmente as Instituições, têm poucos incentivos para formar arranjos subseqüentes. As instabilidades envolvem, em sua maioria, candidatos de tipo $3 \mathrm{com}$ piores colocações. Dessa forma, os matchings gerados, apesar de instáveis, podem ser aceitáveis para Instituições e candidatos quando uma alternativa mais eficiente não é vislumbrada pelo mercado. Conseqüentemente, este mecanismo pode se tornar duradouro. Os demais matchings simulados são apresentados no apêndice C.

\subsection{Comparação das simulações do modelo com o mercado da ANPEC}

Analisando as listas declaradas dos candidatos simulados, observamos que, nos casos 1 e 2, apenas uma minoria dos candidatos declaram as Instituições tipo 1 e 2 em suas listas. Isto decorre do fato de que todos os candidatos que se consideram tipo 3, que são a maioria, declaram somente Instituições tipo 3. Para o caso 3 temos uma realidade diferente, apresentada no gráfico 
4. Neste caso, a maioria dos candidatos declara as Instituições tipo 1 e 2 em suas listas, o que as tornam realmente mais procuradas. O resultado apresentado no gráfico 4 é similar aos dados reais do mercado da ANPEC, vistos anteriormente no gráfico 3.

Apesar de os candidatos terem todos os instrumentos de avaliação pessoal descritos anteriormente que os permitam ter uma boa intuição de seu tipo no mercado da ANPEC, é difícil de supor que eles tenham total certeza sobre essas avaliações. Mais ainda, que declarem suas listas de Instituições aceitáveis como se tivessem tal convicção. Mesmo um candidato que sempre foi um bom aluno durante a graduação corre o risco de não ter estudado o suficiente para os exames. Assim, ele deve ter uma insegurança sobre o resultado dos testes. Isto se torna mais crítico quando verificamos, através da hipótese 2 , os riscos que os candidatos correm frente a uma avaliação errada. Portanto, a hipótese 3 de que os candidatos diversificam suas listas emerge como a mais razoável. Essa conclusão se torna mais forte com a constatação anterior de que as estatísticas das declarações simuladas para os candidatos se aproximam das estatísticas reais. Por outro lado, observando as listas de aceitáveis dos candidatos do mercado da ANPEC nos últimos podemos constatar que, de fato, os candidatos tendem a diversificar suas listas. A incidência de candidatos que declaram pelo menos um Centro de cada tipo é muito grande.

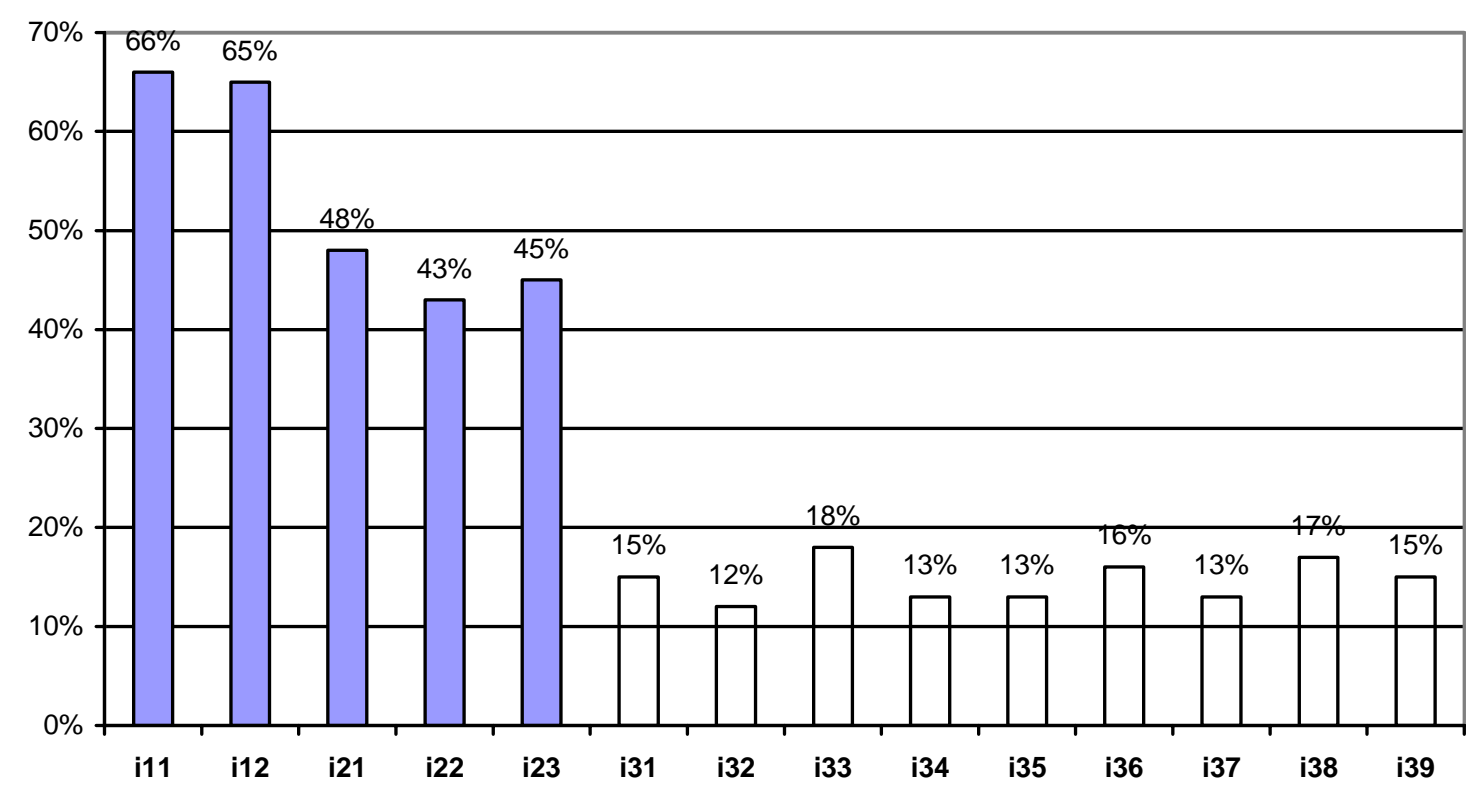

Gráfico 4 - Percentual médio de candidatos que declara cada Centro com a hipótese 3 
Também podemos observar através das ilustrações do apêndice B que, no mercado da ANPEC, as Instituições tipo 1 eventualmente completam suas listas com alguns dos melhores candidatos tipo 2, as Instituições tipo 2 recebem alguns poucos candidatos tipo 1 e 3, geralmente os piores do tipo 1 e os melhores do tipo 3, e as Instituições tipo 3 recebem candidatos tipo 2 com piores colocações. Ou seja, realmente ocorre uma superposição marginal dos tipos, como prevê a hipótese 3. Dessa forma, poderíamos considerar que o mecanismo atual da ANPEC, na melhor situação, se aproxima mais da hipótese 3, com a diferença de que as listas das Instituições não são rigorosamente iguais. Os matchings simulados apresentam instabilidades que são, em sua maioria, instabilidades suaves e, portanto, aceitáveis por candidatos e Instituições, principalmente para as Instituições de tipo 1 e 2. As Instituições do tipo 3 concentram a maioria das Instabilidades simuladas, inclusive instabilidades mais críticas.

No entanto, mesmo sob a hipótese 1, as Instituições do tipo 3 também recebem alocações instáveis. Isto decorre do fato de o total de Instituições tipo 3 ser muito superior à quantidade máxima de Instituições que pode ser declarada na lista de aceitáveis dos candidatos (9 Instituições tipo 3 contra 4 Instituições declaradas, para o modelo proposto; 16 contra 6, para o mercado da ANPEC). No caso do mercado da ANPEC, o fato das listas declaradas pelos estudantes conterem, no máximo, seis opções num universo de 24 Centros reduz o número de candidatos que declara cada Centro, principalmente os Centros tipo 3. Muitos candidatos que acabam não declarando determinado Centro tipo 3, devido à restrição da lista, poderiam ter interesse em ingressar neste Centro, se não fosse aceito pelos que listou.

Portanto, com os resultados do modelo proposto, poderíamos inferir que o mecanismo descentralizado da ANPEC se aproxima do modelo teórico com a hipótese 3. Para os Centros 1 e 2 o mecanismo simula de forma aproximada o algoritmo NRMP e as instabilidades geradas são, em sua grande maioria, instabilidades suaves. Portanto, estes Centros não têm grandes incentivos em operar mudanças no mecanismo. Por outro lado, os Centros tipo 3 são prejudicados pelo truncamento da lista de aceitáveis. Em função disso, uma parcela deles muda o prazo de resposta dado aos candidatos ano a ano, numa tentativa de se beneficiarem. 


\section{CONCLUSÃO E COMENTÁRIOS FINAIS}

Ao longo deste trabalho tratamos sobre mercados dois lados. Esses mercados são denominados assim porque os participantes são de dois tipos distintos, de forma que um agente de um tipo não pode agir como agente do outro tipo. Os exemplos mais comuns são os mercados de candidatos e Instituições.

Os mercados de dois lados se distinguem pela forma como o mercado é organizado. Os mercados descentralizados se comportam de forma descoordenada enquanto que os mercados centralizados são coordenados. Essa coordenação é executada, em sua maioria, por um agente superior, chamado "agente centralizador", que realiza o matching segundo as preferências de todos os outros participantes. Os registros da literatura mostram que os mercados de dois lados tendem a evoluir para a forma de organização centralizada. Quando chegam neste estágio, a grande maioria mantém o mecanismo centralizado de forma duradoura, enquanto alguns poucos retornam ao comportamento descoordenado.

O mercado da ANPEC é um mercado de dois lados que, historicamente, sempre se comportou de forma descoordenada, com várias mudanças nas regras do mecanismo até 1996. Em 1997 foi implementado um mecanismo centralizado que foi abandonado no ano seguinte. A partir de então, esse mercado sempre se comportou de forma descentralizada, mas com os procedimentos sendo mantidos, aparentemente, sem alterações.

Procuramos então desenvolver a teoria para explicar os fatos observados neste mercado da ANPEC. Inicialmente mostramos que a falha do mecanismo centralizado em 1997 não resultou de nenhuma das duas hipóteses sobre falhas em mecanismos centralizados apontadas em Roth (1989b) e McKinney, Niederle e Roth (2004), mas sim da implementação problemática do algoritmo e de uma tentativa de manipulação frustrada por parte de alguns Centros. Esta tentativa desencadeou uma série de instabilidades que prejudicaram a credibilidade do mecanismo. 
Posteriormente passamos a avaliar este mercado na sua fase descentralizada pós 1997. Apresentamos várias observações empíricas e construímos hipóteses que justificam, de forma racional, o comportamento dos participantes. A partir deste ponto enumeramos as características que diferenciam o mercado da ANPEC dos outros encontrados na literatura e compõem nossa resposta à questão 2.

1) É um mercado descentralizado que não experimenta o processo de antecipação nem ofertas explosivas

2) As informações sobre os candidatos já estão disponíveis para os Centros após a publicação dos resultados dos testes, enquanto que as informações sobre os Centros são disponibilizadas para os candidatos de forma gradual

3) Os candidatos estão dispostos a usar a ação “moderada”

4) Para os Centros tipo 1 e 2, o atual mecanismo descentralizado é uma simulação aproximada do algoritmo NRMP

5) Para os Centros tipo 3 essa conclusão não é clara

6) O fato das listas de Centros aceitáveis serem truncadas em até seis provoca problemas na alocação dos candidatos para os Centros tipo 3

O que ocorreu no mercado da ANPEC foi o seguinte: com o descarte do mecanismo centralizado em 1997, o procedimento descentralizado atual passou a ser repetido ano a ano. Com isso os participantes vêm aprendendo a jogar em “equilíbrio”. Os candidatos se tornaram encorajados a usar a ação “moderada” no segundo estágio do jogo. Consequentemente, os Centros tipo 1 e 2 passaram a dar tempo de resposta suficiente e a coordenar as datas das suas visitas. Alguns Centros tipo 3 também já concedem tempo de resposta suficiente, mas outros não. Imaginamos que estes Centros ainda estão em fase de aprendizado. Assim, para os Centros tipo 1 e 2, o atual mecanismo descentralizado é uma simulação aproximada do algoritmo NRMP, mas para os Centros tipo 3 essa conclusão não é clara. Por outro lado, o fato dos candidatos declararem listas de Centros aceitáveis truncadas desfavorece os Centros tipo 3. Como os candidatos não sabem seus tipos, eles diversificam suas listas. Para os Centros de menor tipo, o mecanismo descentralizado com as listas truncadas gera instabilidades suaves em pequena quantidade e, portanto, estes Centros não têm grandes incentivos em operar mudanças no mecanismo. Por outro 
lado, a quantidade de candidatos que delara cada Centro tipo 3 fica reduzida, e alguns deles mudam o prazo de resposta dado aos candidatos ano a ano. Isso conclui nossa resposta à questão 2: o atual mecanismo descentralizado aplicado pela ANPEC é satisfatório para os Centros tipo 1 e 2. Para eles não há mudanças e o mecanismo é duradouro. Para os Centros tipo 3 o atual mecanismo ainda não é duradouro. Alguns Centros mudam os prazos de resposta ano a ano, o que faz com que o mecanismo como um todo seja alterado.

Podemos esperar como a contituação do processo de aprendizado deste mercado que, no futuro, todos os Centros tipo 3 passem a dar tempo de resposta suficiente e que o limite das listas de Centros aceitáveis seja ampliado. Neste ponto teremos o mercado da ANPEC simulando rigorosamente o algoritmo NRMP, mas a um custo financeiro e operacional mais elevado que 0 atual. Basta vermos que, com a ampliação do limite da lista de aceitáveis, os Centros tipo 3 terão que entrar em contato com uma quantidade maior de candidatos, esperar eles responderem, entrar em contato com outros, esperar eles responderem, e assim por diante. Diante desta realizade, a alternativa natural para o mercado é realmente adotar o mecanismo centralizado.

Para chegarmos a estas conclusões apresentamos um modelo teórico que incorpora as observações feitas do mercado da ANPEC. O modelo classifica as Instituições e os candidatos em 3 tipos. Fizemos então simulações do modelo usando um gerador de números aleatórios para definir as preferências dos candidatos sobre as Instituições do mesmo tipo.

A simplicidade dos modelos pode ser questionada quando tentamos extrapolar os resultados para o mercado da ANPEC. A hipótese de que as preferências das Instituições são iguais não é verdadeira no mercado da ANPEC, no entanto, adicionar listas distintas para Instituições traria maior complexidade de simulação sem trazer ganhos de resultados, pois o que se deseja mostrar é que os resultados do mecanismo descentralizado são instáveis e, para isto, a hipótese mais simples é suficiente. É importante termos em mente que os modelos apresentados são modelos teóricos e, como tal, não são capazes de reproduzir toda a complexidade de um mercado real. No entanto, os resultados teóricos são sempre as melhores ferramentas disponíveis para entendermos o mundo real. 


\section{REFERÊNCIAS}

ALCALDE, Jose; BARBERÀ, Salvador. [1994]. Top dominance and the possibility of strategyproof stable solutions to the marriage problem. Journal of Economic Theory, 4, 417-435.

CLARK, Simon. [2004]. Uniqueness of equilibrium in two-sided matching, mimeog.

DEMANGE, Gabrielle; GALE, David. [1985]. The strategy structure of two-sided matching markets. Econometrica, 53, 873-888.

DEMANGE, Gabrielle; GALE, David; SOTOMAYOR, Marilda. [1986]. Multi-item auctions. Journal of Political Economy, 94, 863-872.

. [1987]. A further note on the stable matching problem. Discrete Applied Mathematics, 16, 217-222.

DUBINS, L. E.; FREEDMAN, D. A. [1981]. Machiavelli and the Gale-Shapley algorithm. American Mathematical Monthly, 88, 485-494.

FRECHETTE, Guilluame; ROTH, Alvin E.; UNVER, M. Utku. [2004]. Unraveling yields inefficient matching: evidence from post-season college football bowls, mimeog.

GALE, David; SHAPLEY, Lloyd. [1962]. College admissions and the stability of marriage. American Mathematical Monthly, 69, 9-15.

GALE, David; SOTOMAYOR, Marilda. [1985a]. Some remarks on the stable matching problem. Discrete Applied Mathematics, 11, 223-232. . [1985b]. Ms. Machiavelli and the stable matching problem. American Mathematical Monthly, 92, 261-268.

GRAHAM, Daniel A.; MARSHALL, Robert C. [1987]. Collusive bidder behavior at single object second price and english auctions. Journal of Political Economy, 95, 1217-1239.

HARUVY, Ernan; ROTH, Alvin E.; ÜNVER, M. Utku. [2005]. The dynamics of law clerk matching: an experimental and computational investigation of proposals for reform of the market. Journal of Economic Dynamics and Control, forthcoming, 2005. 
HATFIELD, John William. [2005]. Pairwise kidney exchange: comment. Working paper, Stanford University.

KAGEL, John H.; ROTH, Alvin E. [2000]. The dynamics of reorganization in matching markets: a laboratory experiment motivated by a natural experiment. Quarterly Journal of Economics, February, 2000, 201-235.

KLAUS, Bettina; KLIJN Flip. [2005]. Stable matchings and preferences of couples. Journal of Economic Theory, 121, 75-106.

KNUTH, Donald E. [1976]. Mariages Stables. Montreal: Les Presses de l'Universite de Montreal.

KNUTH, Donald E.; MOTWANI, Rajeev; PITTEL, Boris. [1990]. Stable husbands. Random Structures and Algorithms, 1, 1-14.

LI, Hao; ROSEN, Sherwin [1998]. Unraveling in matching markets. American Economic Review, 88, 3, June, 371-387.

MCKINNEY, C. Nicholas; NIEDERLE, Muriel; ROTH, Alvin E. [2004]. The collapse of a medical labor clearinghouse (and why such failures are rare). American Economic Review, forthcoming, 2005.

MONGELL, Susan J.; ROTH, Alvin E. [1991]. Sorority rush as a two-sided matching mechanism. American Economic Review, vol. 81, June 1991, 441-464.

NIEDERLE, Muriel; ROTH, Alvin E. [2003a]. Effect of a match on salaries for medical fellowsreply. JAMA. Journal of the American Medical Association, vol. 290, No. 18, November 12, 2003, 2408.

. [2003b]. Unraveling reduces mobility in a labor market: gastroenterology with and without a centralized match. Journal of Political Economy, vol. 111, No. 6, December 2003, 1342-1352.

- [2003c]. Market culture: how norms governing exploding offers affect market performance, mimeog.

. [2004]. The gastroenterology fellowship match: how it failed, and why it could succeed once again. Gastroenterology, 127, 2 August 2004, 658-666. 
ROTH, Alvin E. [1982a]. The economics of matching: stability and incentives. Mathematics of Operations Research, 7, 617-628.

. [1982b]. Incentive compatibility in a market with indivisible goods. Economics Letters, 9, 127-132.

. [1984a]. The evolution of the labor market for medical interns and residents. Journal of Political Economy, 92, 991-1016.

[1984b]. Misrepresentation and stability in the marriage problem. Journal of Economic Theory, 34, 383-387.

. [1985]. The college admissions problem is not equivalent to the marriage problem. Journal of Economic Theory, 36, 277-288.

. [1986]. On the allocation of residents to rural hospitals: a general property of two-sided matching markets. Econometrica, 54, 425-427.

[1989]. A natural experiment in the organization of entry level labor markets: regional markets for new physicians and surgeons in the U.K.. American Economic Review, vol. 81, June 1991, 415-440.

. [1990]. New physicians: a natural experiment in market organization. Science, 250, 1990, 1524-1528.

. [1995]. Proposed research program: evaluation of changes to be considered in the NRMP algorithm. Consultant's report, http://www.economics.harvard.edu/ aroth/nrmp.html.

. [1996]. The NRMP as a labor market. JAMA. Journal of the American Medical Association, 275, April 3, 1996, 1054-1056.

. [2002]. The economist as engineer: game theory, experimental economics and computation as tools of design economics. Fisher Schultz lecture, Econometrica, 70, 4, July 2002, 1341-1378.

. [2003]. The origins, history, and design of the resident match. JAMA. Journal of the American Medical Association, vol. 289, No. 7, February 19, 2003, 909-912.

ROTH, Alvin E.; PERANSON, Elliott. [1997]. The effects of the change in the NRMP matching algorithm. Journal of the American Medical Association, 278, 9, September 3, 1997, 729-732. 
. [1999]. The redesign of the matching market for american physicians: some engineering aspects of economic design. American Economic Review, 89, 4, September, 1999, 748-780.

ROTH, Alvin E.; SÖNMEZ, Tayfun; ÜNVER, M. Utku. [2004]. Kidney exchange. Quarterly Journal of Economics, 119, 2, May, 2004, 457-488.

ROTH, Alvin E.; SOTOMAYOR, Marilda. [1988]. Interior points in the core of two-sided matching problems. Journal of Economic Theory, 45, 85-101.

. [1989]. The college admissions problem revisited. Econometrica, 57, 559-570.

. [1990]. Two-sided matching: a study in game-theoretic modeling and analysis. Econometric Society Monographs, No. 18, publicado pela Cambridge University Press.

. [1992]. Two-Sided Matching. Handbook of Game Theory, vol. 1, R. J. Aumann and S. Hart, editors, Elsevier, 485-541.

ROTH, Alvin E.; XING, Xiaolin. [1994]. Jumping the gun: imperfections and institutions related to the timing of market transactions. American Economic Review, vol. 84, No. 4, September 1994, 992-1044.

. [1997]. Turnaround time and bottlenecks in market clearing: decentralized matching in the market for clinical psychologists. Journal of Political Economy, 105, April 1997, 284-329.

ROTH, Alvin E.; ROTHBLUM, Uriel. [1995]. Strategic behavior in low-information matching markets: in search of practical advice for participants, mimeog.

SOTOMAYOR, Marilda. [1996a]. Mecanismos de admissão de candidatos às instituições. Modelagem e análise à luz da teoria dos jogos. Revista de Econometria, vol. 16, No. 1, 25-63.

. [1996b]. A non constructive elementary proof of the existence of stable marriages. Games and Economic Behavior, 13, March, 135-7.

. [1999]. The lattice structure of the set of stable outcomes of the multiple partners assignment game. International Journal of Game Theory, 28, 567-583.

. [2004]. Implementation in the many-to-many matching market. Games and Economic Behavior, 46, 199-212. 
- [2005a]. On the core of coalitional games with non-transferable utility and a finite set o players. forthcoming.

[2005b]. On the core of coalitional games with transferable utility and a finite set $o$ players. forthcoming.

. [2005c]. An elementary non-constructive proof of the non-emptiness of the core of the housing market of Shapley and Scarf. Mathematical Social Sciences, forthcoming. 


\section{APÊNDICES}

APÊNDICE A - RESULTADOS JÁ CONHECIDOS

APÊNDICE B - DADOS SOBRE AS ALOCAÇÕES PRODUZIDAS PELO MECANISMO

DESCENTRALIZADO DA ANPEC NOS ÚLTIMOS ANOS

APÊNDICE C - TODOS OS MATCHINGS SIMULADOS DO MODELO TEÓRICO COM AS

HIPÓTESES 1, 2 E 3 


\section{APÊNDICE A - RESULTADOS JÁ CONHECIDOS}

Enunciamos aqui alguns resultados já conhecidos e que serão utilizados ao longo do trabalho.

Para onde vão os melhores candidatos e quais candidatos vão para as melhores Instituições? Se existe um consenso sobre o conjunto das $k$ melhores Instituições então é esperado que elas sejam as preferidas dos melhores candidatos. O Teorema A1 diz que as $t$ vagas dessas $k$ Instituições serão preenchidas pelos $t$ melhores candidatos, em qualquer matching estável.

Teorema A1. (Sotomayor (1996a)). Suponha que existam um conjunto de Instituições $I^{\prime}=\left\{i_{1}, \ldots\right.$, $\left.i_{k}\right\}$ e um conjunto de candidatos $C^{\prime}=\left(c_{1}, \ldots, c_{t}\right\}$, com $t=\Sigma q_{j}$ para $j=1,2, \ldots, k$, tais que $I^{\prime}$ é $o$ conjunto das $k$ primeiras Instituições aceitáveis da lista de qualquer candidato de C' (em qualquer ordem) e C'é o conjunto dos t primeiros candidatos aceitáveis da lista de qualquer Instituição em I' (em qualquer ordem). Então, se $\mu$ é um matching estável, $\mu\left(C^{\prime}\right)=I^{\prime}$.

Observação A1. Se no Teorema A1 tivermos $t>\Sigma q_{j}$ para $j=1,2, \ldots, k$, então $\mu(i) \subseteq C^{\prime}$ para todo $i$ $\in I^{\prime}$. A demonstração deste fato, que é tão simples quanto à do Teorema A1, é deixada ao leitor.

Proposição A1. (Gale e Sotomayor (1983)). Sejam $\mu$ um matching estável, $C(\mu)$ o conjunto dos candidatos admitidos a alguma Instituição segundo $\mu$ e $N_{i}$ o número de candidatos admitidos pela Instituição $i$. Então o conjunto $C(\mu)$ e os números $N_{i}$ são os mesmos para todo matching estável.

Proposição A2. (Roth (1986)). Seja $\mu$ um matching estável. Se a Instituição $i$ não preencheu todas as suas vagas em $\mu$, então ela admitirá o mesmo conjunto de candidatos em qualquer matching estável.

Proposição A3. (Gale e Sotomayor (1985a)). Suponha que $C \subseteq C^{\prime}$, que $\mu_{C}$ é o matching estável ótimo para os candidatos em $(C, I, P, q)$ e que $\mu_{C}{ }_{C}$ é o matching estável ótimo para os candidatos em $\left(C^{\prime}, I, P^{\prime}, q\right)$, onde $P^{\prime}=P$ em $C$. Então, $\mu_{C}^{\prime}(i) \geq_{i} \mu_{C}(i)$, para toda Instituição $i$. 
Observação A2. Decorre da demonstração da Proposição A5 que não somente $\mu_{C}{ }_{C}(i) \geq_{i} \mu_{C}(i)$, mas também que $i$ prefere fracamente todo candidato em $\mu_{C}^{\prime}(i)$ a algum candidato em $\mu_{C}(i)$.

Proposição A4. (Roth e Sotomayor (1989)). Se os candidatos têm preferências estritas sobre as Instituições e as Instituições têm preferências estritas sobre candidatos individuais, então as Instituições também têm preferências estritas sobre os grupos de candidatos alocados em matchings estáveis. Ou seja, dados $\mu$ e $\mu$ ' matchings estáveis, uma Instituição $i$ é indiferente entre $\mu(i)$ e $\mu^{\prime}(i)$ somente se $\mu(i)=\mu^{\prime}(i)$.

Proposição A5. (Roth e Sotomayor (1989)). Sejam $\mu$ e $\mu^{\prime}$ matchings estáveis e as preferências de candidatos e Instituições estritas sobre indivíduos. Se $\mu(i)>_{i} \mu^{\prime}(i)$, para alguma Instituição $i$, então $c>_{i} c^{\prime}$ para todo $c$ em $\mu(i)$ e $c^{\prime}$ em $\mu^{\prime}(i)-\mu(i)$.

Ou seja, se $i$ prefere o grupo de candidatos designados a ela por $\mu$ ao grupo de candidatos designados a ela por $\mu$ ', então ela prefere qualquer candidato do primeiro grupo a qualquer candidato do segundo grupo que não estiver no primeiro.

Proposição A6. (Gale e Shapley (1962)). Seja $\mu$ um matching estável. Então $\mu(c) \geq_{c} \mu_{I}(c)$, para todo $c$ em $C$, e $\mu(i) \geq_{i} \mu_{C}(i)$, para todo $i$ em I.

Neste ponto precisamos definir um outro mercado relacionado ao mercado de admissão às Instituições, formalizado na seção 2. Este outro mercado é chamado "Mercado do Casamento Relacionado" e é definido a partir do mercado de admissão às Instituições da seguinte forma: Seja o mercado de admissão $M=(C, I, P, q)$. Podemos “dividir” cada Instituição $i$ com cota $q_{i}$ em $q_{i}$ cópias de $i$, cada uma com uma única vaga. Ou seja, substituímos cada Instituição $i$ por $q_{i}$ vagas de $i$, denotadas por $i^{l}, i^{2}, i^{3}, \ldots, i^{q i}$. Cada uma dessas vagas tem preferências sobre os candidatos idênticas às preferências de $i$. Como cada vaga $i^{t}$ tem cota unitária, não precisamos considerar as preferências sobre grupos de candidatos. Os candidatos são, de fato, indiferentes entre as cópias de $i$. No entanto, para não complicarmos a exposição sobre os resultados nos quais a premissa de preferências estritas é necessária podemos, sem perda de generalidade, assumir que a lista de preferências de cada candidato é modificada substituindo $i$, quando $i$ está presente na 
lista original, pela sequência $i^{l}, i^{2}, i^{3}, \ldots, i^{q i}$, nesta ordem. Ou seja, se um candidato $c$ prefere $i$ a $i^{\prime}$ no mercado de admissão original, então, neste mercado do casamento relacionado, $c$ prefere qualquer vaga de $i$ a qualquer vaga de $i^{\prime}$, e ainda assumimos, por conveniência, que $c$ prefere estritamente $i^{l}$ a qualquer outra vaga de $i$ e assim por diante. Por fim, este mercado de candidatos e vagas com cota unitária, com as preferências definidas acima, é o mercado do casamento relacionado ao mercado de admissão às Instituições $M$. Seja $C$ o conjunto dos candidatos, $V$ o conjunto das vagas com cota unitária e $P^{+}$o conjunto das preferências dos candidatos e das vagas (como definido acima), então podemos representar o mercado do casamento relacionado ao mercado $M$ por $M^{+}=\left(C, V, P^{+}\right)$.

Se os candidatos têm preferências estritas sobre as Instituições e as Instituições têm preferências estritas sobre candidatos individuais no mercado $M$, então há uma correspondência natural entre matchings no mercado de admissão às Instituições original e matchings no mercado do casamento relacionado $M^{+}$. Ou seja, um matching $\mu$ no mercado $M$ que aloca a Instituição $i$ aos candidatos em $\mu(i)$, é correspondende ao matching $\mu^{+}$no mercado $M^{+}$que aloca os candidatos em $\mu(i)$, na ordem em que eles aparecem em $P(i)$, para as vagas ordenadas de $i$ (Ou seja, se $c$ é o candidato mais preferido por $i$ em $\mu(i)$, então $\mu^{+}(c)=i^{l}$, e assim por diante). Além disso, esta correspondência preserva a estabilidade do matching (Note que, como todas as vagas $i^{l}, i^{2}, i^{3}, \ldots$, $i^{q i}$ de $i$ têm as mesmas preferências sobre os candidatos, para que o matching $\mu^{+}$em $M^{+}$, correspondente a um matching estável $\mu$ em $M$, seja estável em $M^{+}$devemos ter o candidato mais preferido por $i$ em $\mu(i)$ alocado a $i^{l}$ por $\mu^{+}$, o segundo mais preferido por $i$ em $\mu(i)$ alocado a $i^{2}$ por $\mu^{+}$, e assim por diante).

Lema A1 - Lema da Decomposição. (Knuth (1976)). Sejam $\mu$ e $\mu^{`}$ matchings estáveis em $\left(C, V, P^{+}\right)$, com todas as preferências estritas. Seja $C(\mu)$ o conjunto dos candidatos que preferem $\mu$ a $\mu^{\prime}$ e $V(\mu)$ o conjunto das vagas que preferem $\mu$ a $\mu^{\prime}$. Analogamente definimos $C\left(\mu^{\prime}\right)$ e $V\left(\mu^{\prime}\right)$. Então $\mu$ e $\mu^{\prime}$ mapeiam $C\left(\mu^{\prime}\right)$ em $V(\mu)$ e $C(\mu)$ em $V\left(\mu^{\prime}\right)$. 
Proposição A7. Se os candidatos têm preferências estritas sobre as Instituições, as Instituições têm preferências estritas sobre candidatos individuais e as preferências dos participantes de um dos lados do mercado são coincidentes, então o conjunto dos matchings estáveis é unitário.

Demonstração: Sem perda de generalidade podemos supor que toda Instituição tem cota unitária, desde que se o resultado vale para o mercado do casamento relacionado então vale para o mercado de admissão às Instituições. Suponha que as Instituições tenham as mesmas preferências sobre os candidatos e que exista um matching $\mu$ tal que $\mu \neq \mu_{I}$. Então, $\mu_{I}(i) \geq_{i} \mu(i)$, para toda Instituição $i \in I$. Defina $I^{\prime}=\left\{i \in I ; \mu_{I}(i)>_{i} \mu(i)\right\}$ e $C_{I^{\prime}}=\left\{c \in C ; \mu(c)>_{c} \mu_{I}(c)\right\}$. Claramente, toda Instituição de $I^{\prime}$ preenche a sua vaga e todo candidato de $C_{I^{\prime}}$ é alocado a alguma Instituição. Pelo Lema da Decomposição, $\mu_{I}\left(I^{\prime}\right)=\mu\left(I^{\prime}\right)=C_{I^{\prime}}$. Seja $c_{0}$ o candidato menos preferido por todas as Instituições de $I^{\prime}$ dentre os de $C_{I^{\prime}}$. Como $c_{0} \in C_{I^{\prime}}$, deve existir $i_{0} \in I^{\prime}$ tal que $\mu_{I}\left(c_{0}\right)=i_{0}$. Seja $\mu_{I}\left(i_{0}\right)$ $=c$. Como $i_{0} \in I^{\prime}$, temos que $c \in C_{I^{\prime}}$ e que $i_{0}$ prefere $c_{0}$ a $c$, o que contradiz a definição de $c_{0}$ como o menos preferido por $I^{\prime}$ dentre os candidatos de $C_{I^{\prime}}$. 


\section{APÊNDICE B - DADOS SOBRE AS ALOCAÇÕES PRODUZIDAS PELO MECANISMO DESCENTRALIZADO DA ANPEC NOS ÚLTIMOS ANOS}

\section{Ilustração B1 - Número de candidatos admitidos pelos Centros tipo 1 por faixa de classificação segundo a ponderação de cada Centro}

PUC-RJ

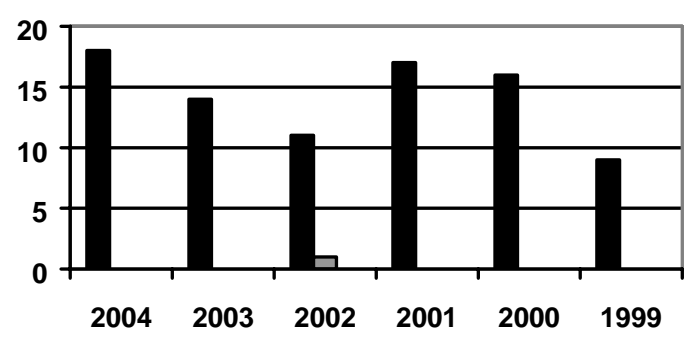

IPE/USP(TE)

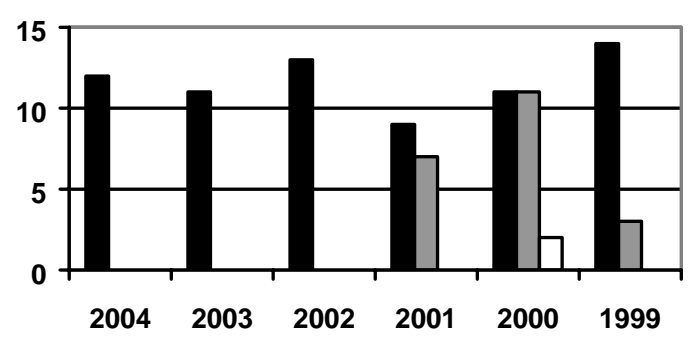

EPGE/FGV-RJ

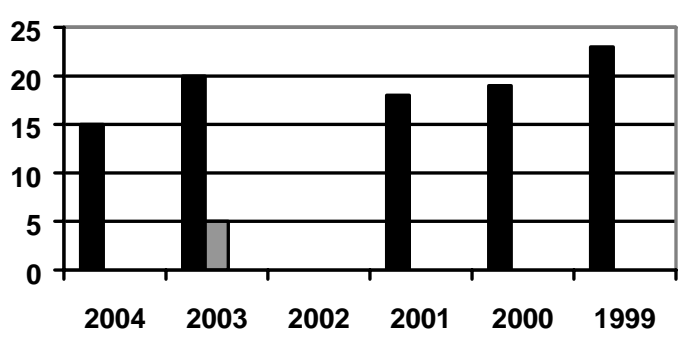

Legenda:

Candidatos classificados de 1 a 50

$\square$ Candidatos classificados de 51 a 120

$\square$ Candidatos classificados de 121 em diante

Observações:

1. Não temos dados sobre a EPGE/FGV para o ano de 2002.

2. Para os anos de 1999 e 2000 a ANPEC não discriminou, dentre os candidatos que foram admitidos pelo IPE/USP, quais foram para Teoria Econômica (TE) e quais foram para Economia das Instituições e Desenvolvimento (EID). Portanto, para esses anos os dados são referentes aos dois cursos. 
Ilustração B2 - Número de candidatos admitidos pelos Centros tipo 2 por faixa de classificação segundo a ponderação de cada Centro

UNB

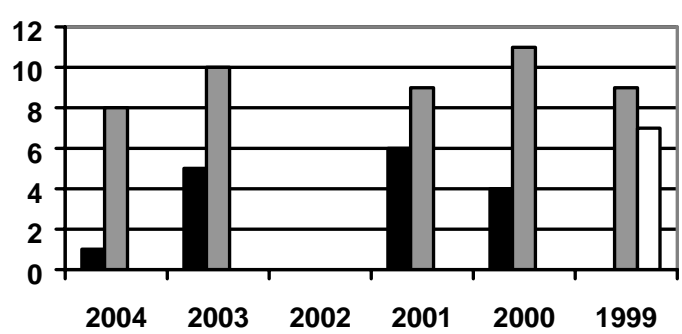

FGV-SP

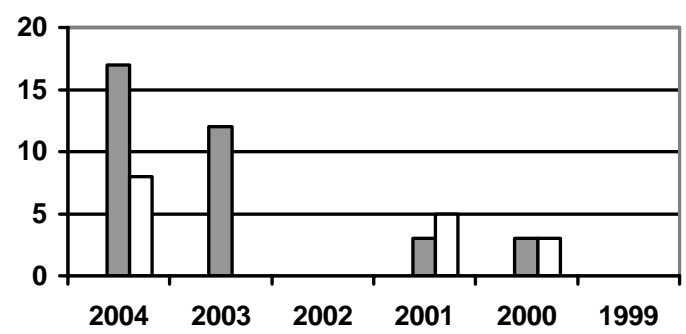

IE/UNICAMP

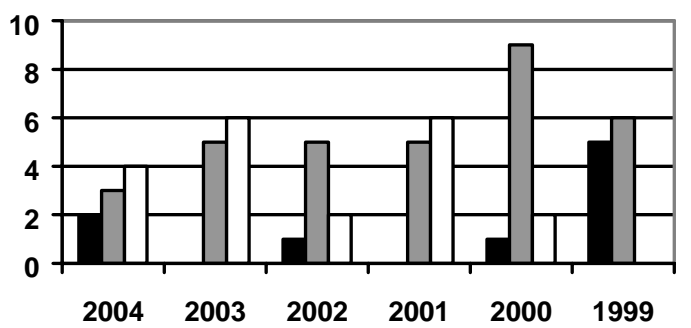

IPE/USP(EID)

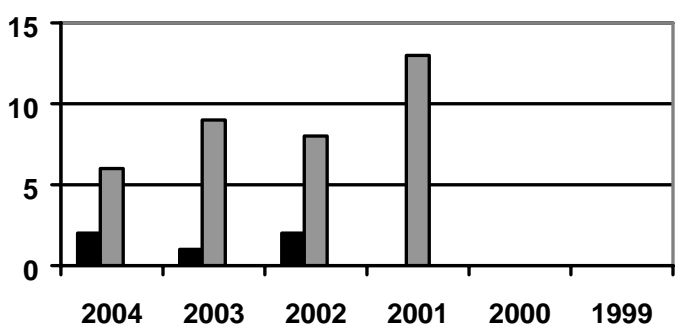

IE/UFRJ

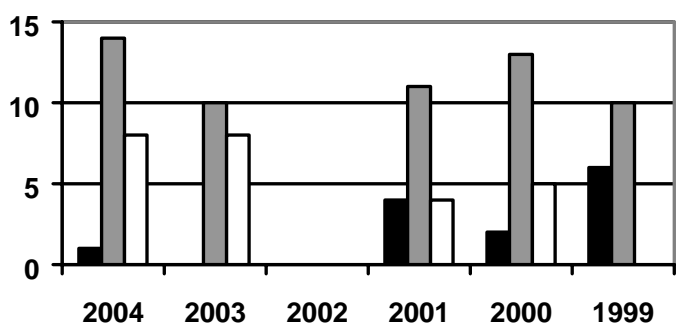

Legenda:

Candidatos classificados de 1 a 50

$\square$ Candidatos classificados de 51 a 120

$\square$ Candidatos classificados de 121 em diante

Observações:

1. Não temos os seguintes dados: UNB e IE/UFRJ para o ano de 2002; IPE/USP(EID) para os anos de 2000 e 1999 (visto na ilustração B1); FGV-SP para os anos de 2002 e 1999.

2. Em 2004 o IE/UNICAMP abriu outro curso de Mestrado em Desenvolvimento Econômico (MDE) oferecendo 20 vagas e com ponderação própria. O Mestrado em Economia (ME) continuou oferecendo 15 vagas como nos anos anteriores. Os dados apresentados referem-se somente ao curso de Mestrado em Economia (ME). 
Ilustração B3 - Número de candidatos admitidos pelos Centros tipo 3 por faixa de classificação segundo a ponderação de cada Centro

CEDEPLAR/UFMG

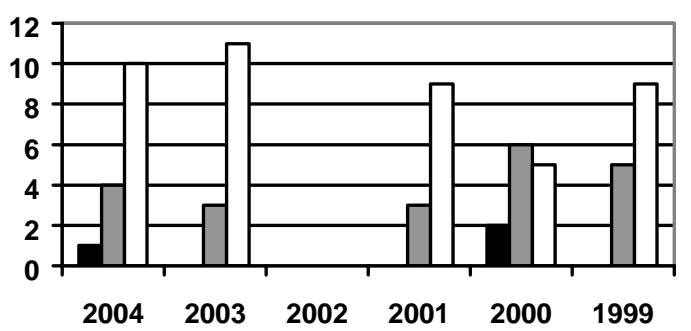

CAEN/UFC

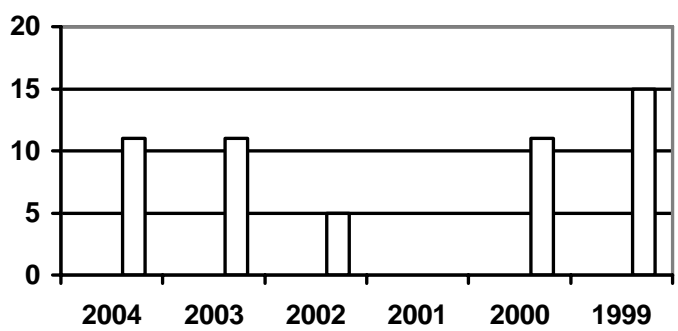

ME/UFES

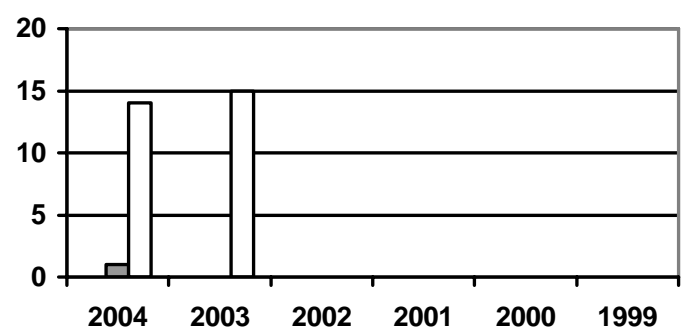

UCB

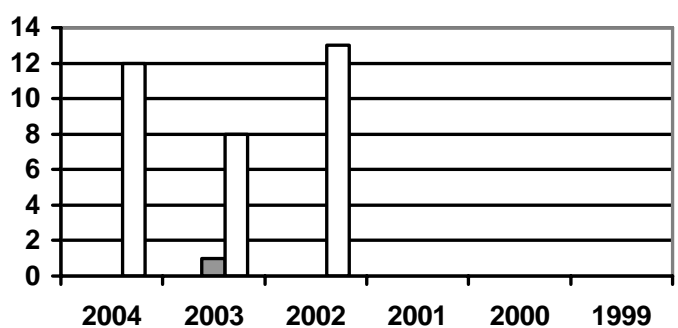

PPGE/UFRGS

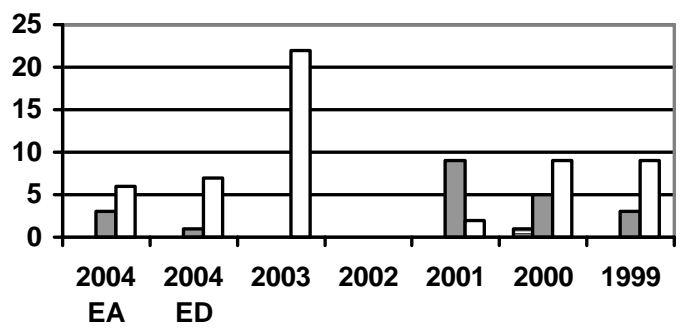

CME/UFBA

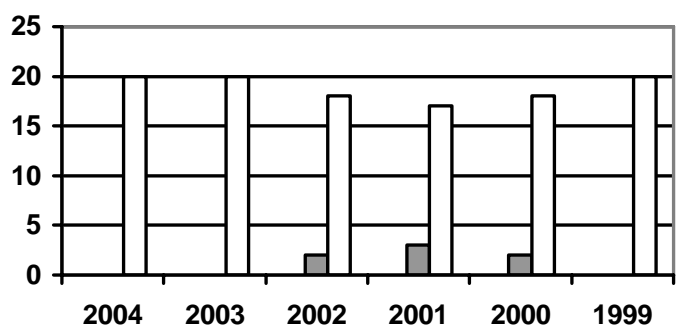

ME/UFU

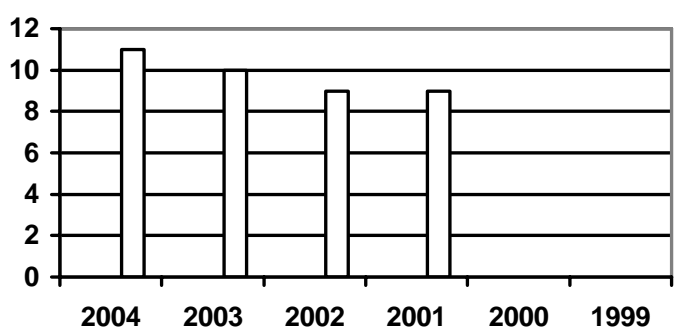

UFSC

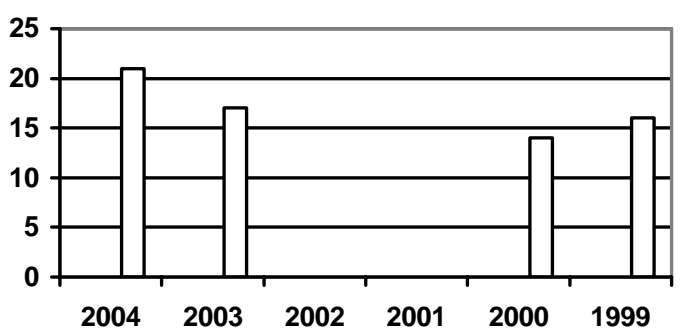


PUC-SP

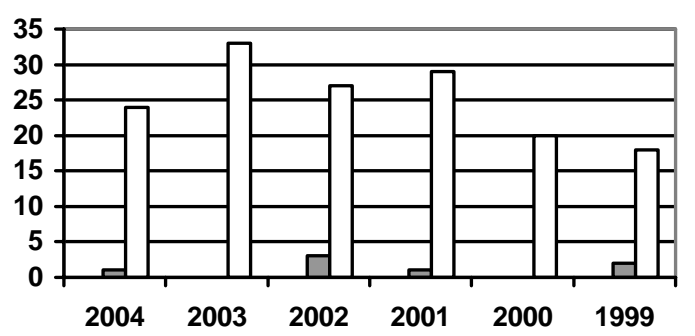

UFF

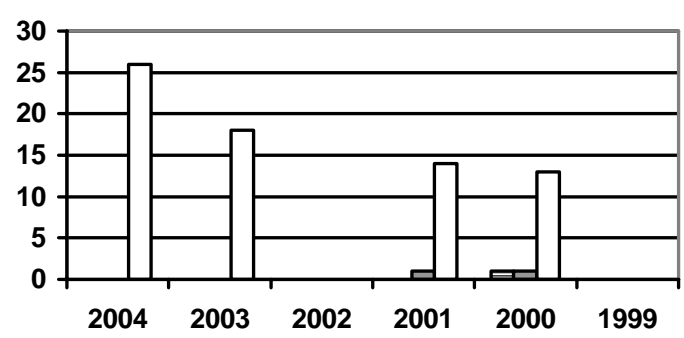

UFPR

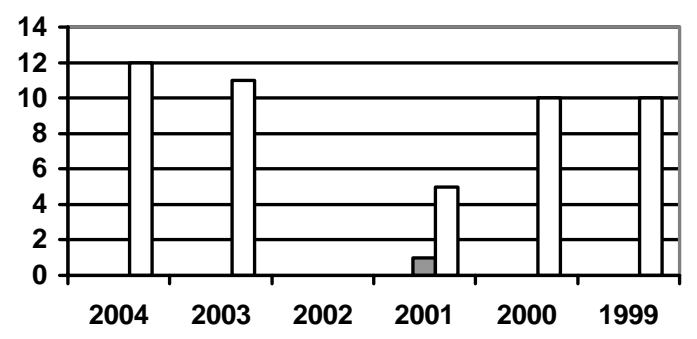

NAEA/UFPA

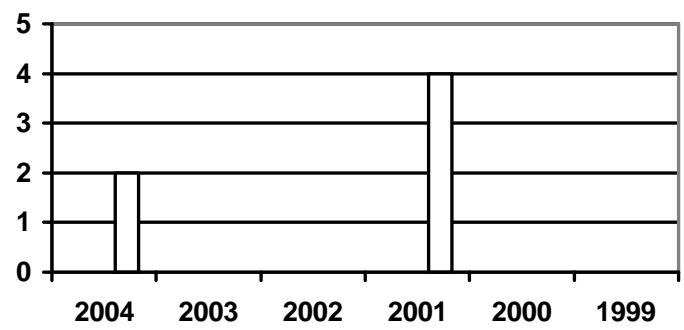

UEM-PR

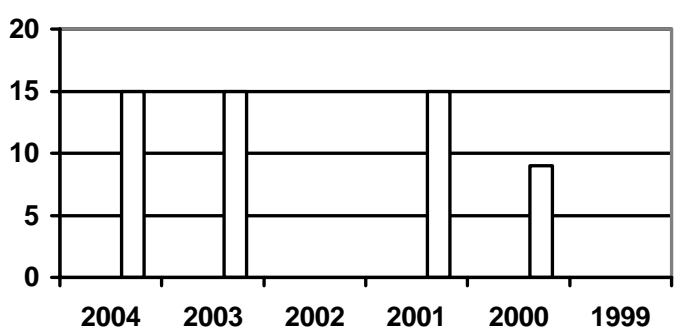

UFPB/JP

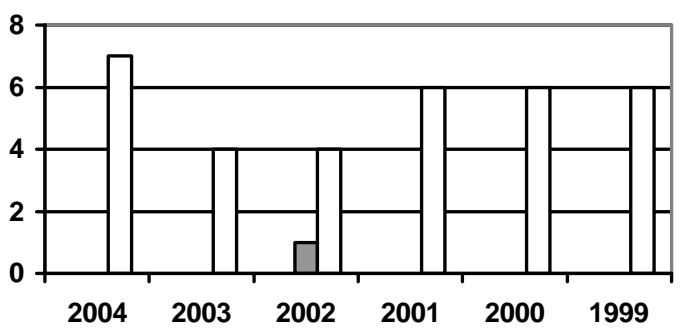

UNESPIAR

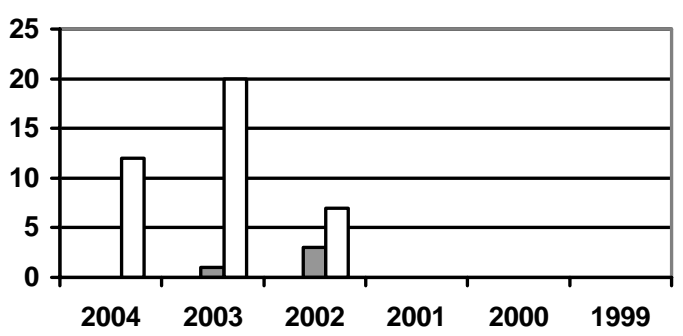

PIMES/UFPE

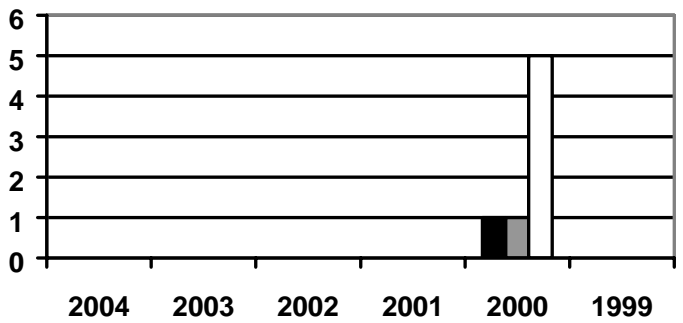


Legenda:

- Candidatos classificados de 1 a 50

$\square$ Candidatos classificados de 51 a 120

$\square$ Candidatos classificados de 121 em diante

Observações:

1. Não temos os seguintes dados: CEDEPLAR/UFMG para o ano de 2002; PPGE/UFRGS para o ano de 2002; CAEN/UFC para o ano de 2001; ME/UFES para os anos de 2002, 2001, 2000 e 1999; UFSC para os ano de 2002 e 2001; UEM-PR para os anos de 2002 e 1999; UFF para os anos de 2002 e 1999; UFPR para o ano de 2002; NAEA/UFPA para os anos de 2003, 2002, 2000 e 1999; PIMES/UFPE para os anos de 2004, 2003, 2002, 2001 e 1999.

2. O ME/UFU ingressou no mercado da ANPEC em 2001; a UCB ingressou em 2002; a UNESP/AR também ingressou no mercado em 2002.

3. Em 2004 o PPGE/UFRGS dividiu o mestrado em duas ênfases: Economia Aplicada (EA) e Economia do Desenvolvimento (ED), com ponderações específicas para cada uma e distintas da ponderação utilizada nos anos anetriores. Portanto os dados de 2004 não são totalmente comparáveis com os anos anteriores. No entanto, decidimos apresentá-los no gráfico a título de ilustração.

4. Também em 2004 a UFSC dividiu o mestrado em três áreas: Economia e Finanças (EcoF), Economia Industrial (EI) e Transformação do Capitalismo Contemporâneo (TCC). A primeira mantém a mesma ponderação utilizada nos anos anteriores e as outras duas têm ponderações distintas. No entanto, a ANPEC não discriminou, dentre os candidatos que foram admitidos pela UFSC, quais foram para cada uma das três áreas. Portanto, apresentamos todos os candidatos como admitidos pela UFSC (independenetemente da área) e utilizamos a ponderação da área de Economia e Finanças. 


\section{Ilustração B4 - Número de candidatos admitidos pelos Centros tipo 1 por faixa de classificação segundo a ponderação da ANPEC}

PUC-RJ

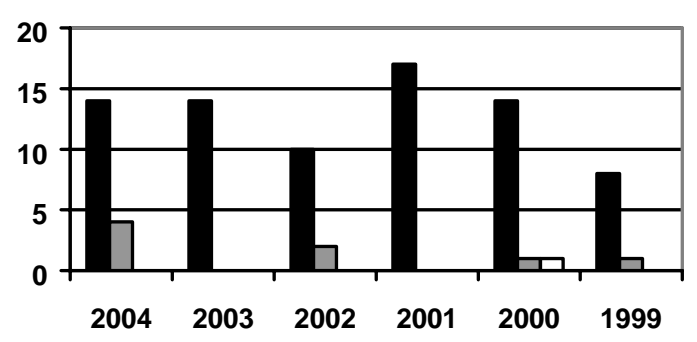

IPE/USP(TE)

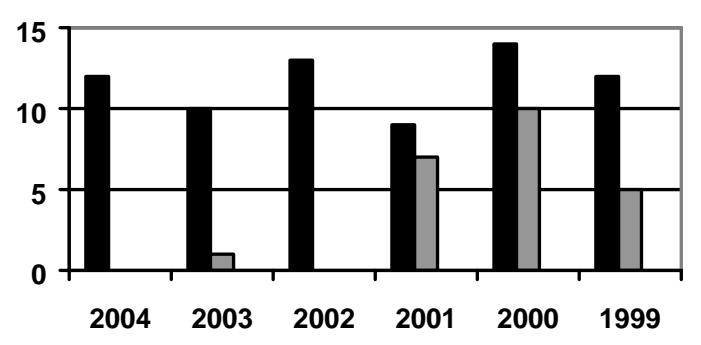

EPGE/FGV-RJ

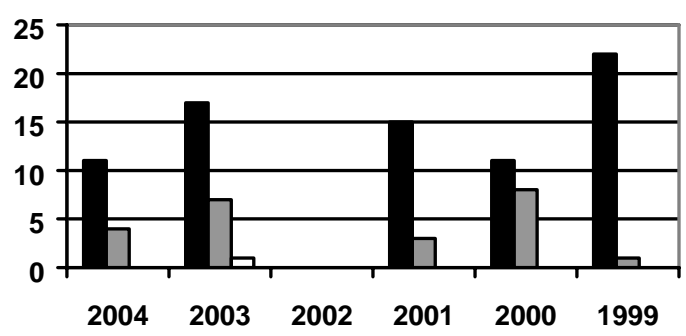

Legenda:

Candidatos classificados de 1 a 50

$\square$ Candidatos classificados de 51 a 120

$\square$ Candidatos classificados de 121 em diante

Observações:

1. Não temos dados sobre a EPGE/FGV para o ano de 2002.

2. Para os anos de 2001 e 2000 a ANPEC não discriminou, dentre os candidatos que foram admitidos pelo IPE/USP, quais foram para Teoria Econômica (TE) e quais foram para Economia das Instituições e Desenvolvimento (EID). Portanto, para esses anos os dados são referentes aos dois cursos. 


\section{Ilustração B5 - Número de candidatos admitidos pelos Centros tipo 2 por faixa de} classificação segundo a ponderação da ANPEC

UNB

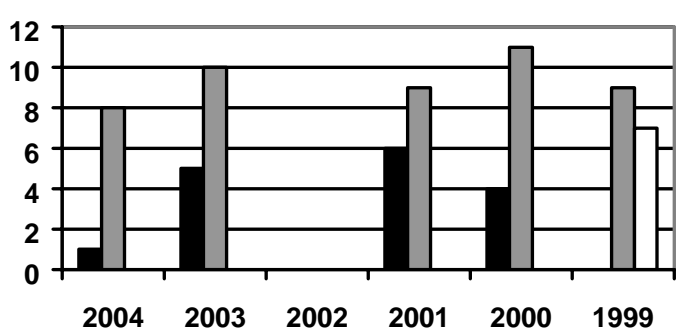

FGV-SP

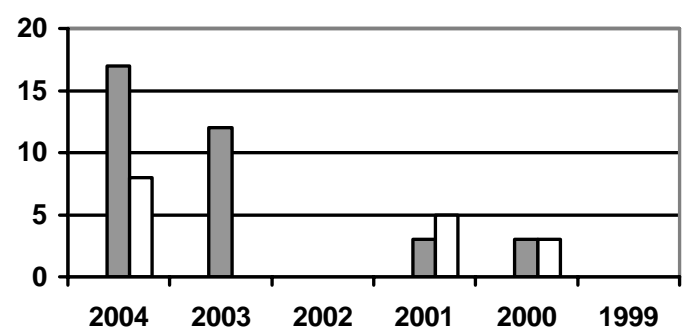

IE/UNICAMP

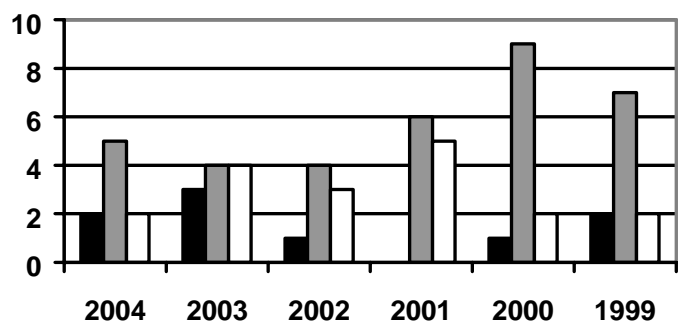

IPE/USP(EID)

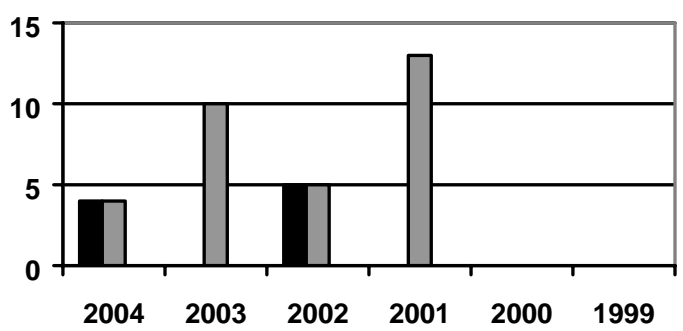

IE/UFRJ

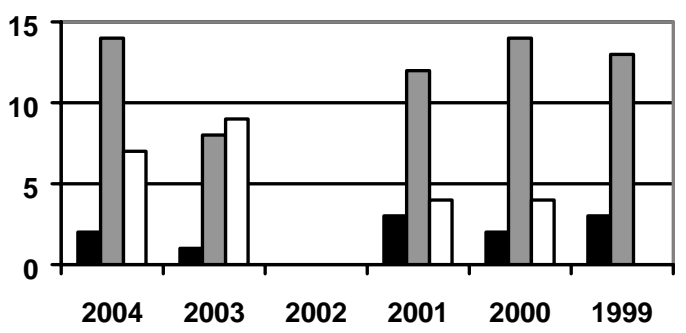

Legenda:

Candidatos classificados de 1 a 50

$\square$ Candidatos classificados de 51 a 120

$\square$ Candidatos classificados de 121 em diante

Observações:

1. Não temos os seguintes dados: UNB e IE/UFRJ para o ano de 2002; IPE/USP(EID) para os anos de 2000 e 1999 (visto na ilustração B4); FGV-SP para os anos de 2002 e 1999.

2. Em 2004 a IE/UNICAMP abriu outro curso de Mestrado em Desenvolvimento Econômico (MDE) oferecendo 20 vagas e com ponderação própria. O Mestrado em Economia (ME) continuou oferecendo 15 vagas como nos anos anteriores. Os dados apresentados referem-se somente ao curso de Mestrado em Economia (ME). 
Ilustração B6 - Número de candidatos admitidos pelos Centros tipo 3 por faixa de classificação segundo a ponderação da ANPEC

CEDEPLAR/UFMG

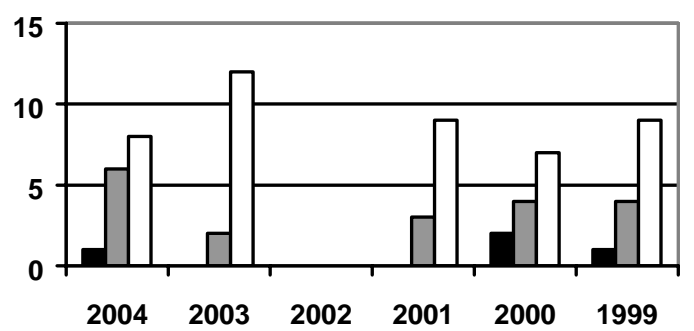

CAEN/UFC

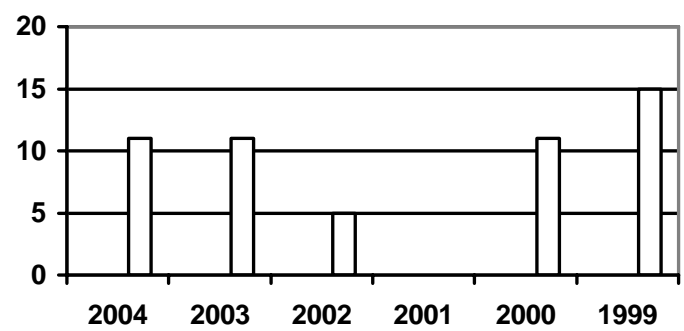

ME/UFES

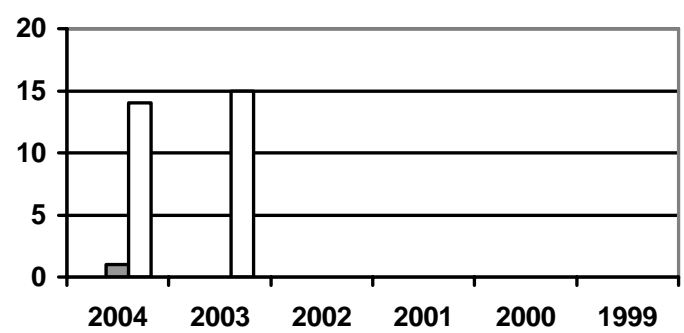

UCB

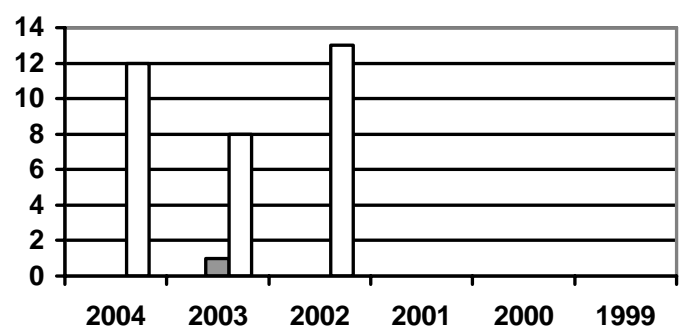

PPGE/UFRGS

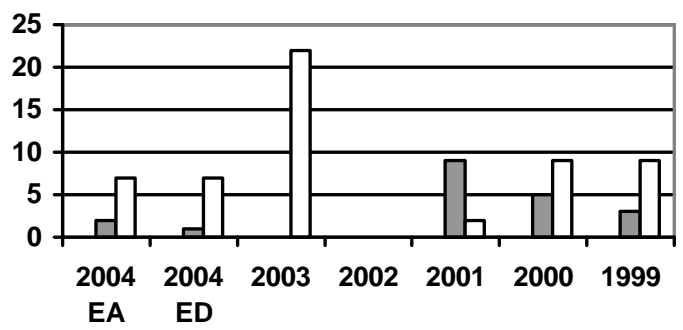

CME/UFBA

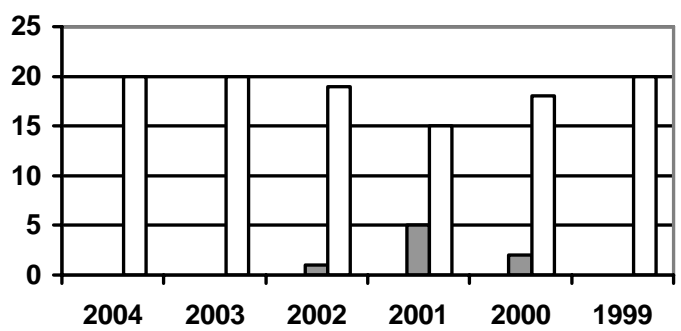

ME/UFU

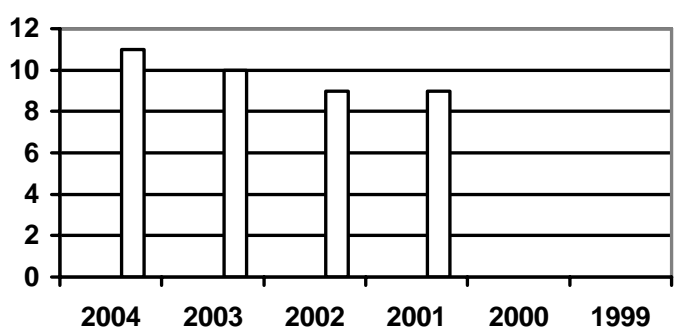

UFSC

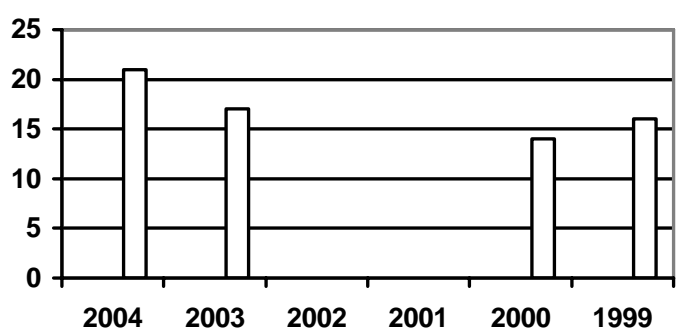


PUC-SP

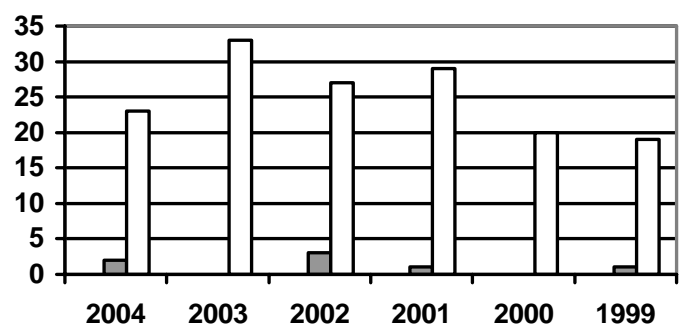

UFF

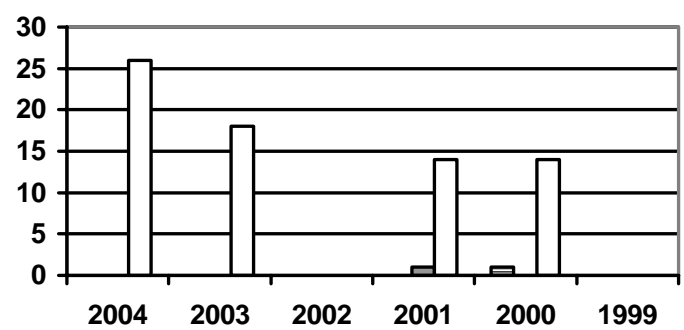

UFPR

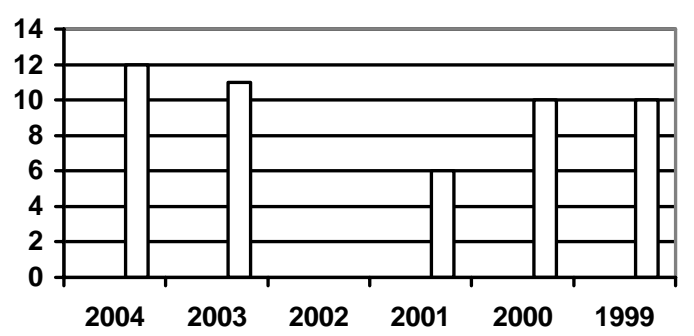

NAEA/UFPA

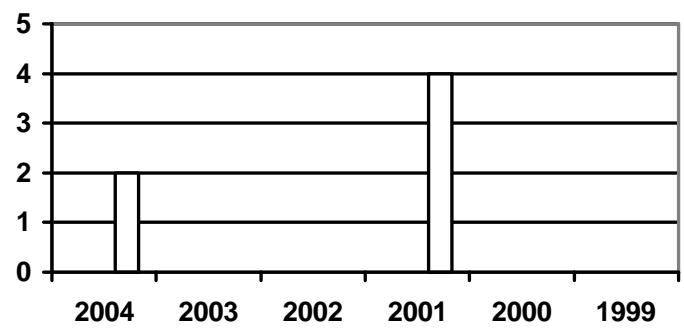

UEM-PR

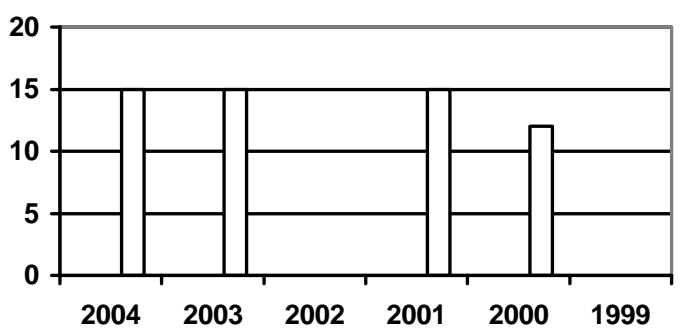

UFPB/JP

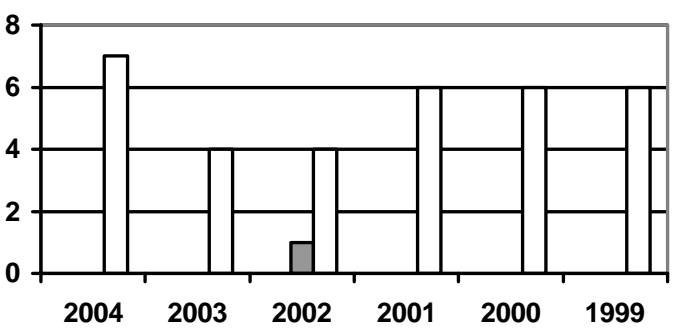

UNESPIAR

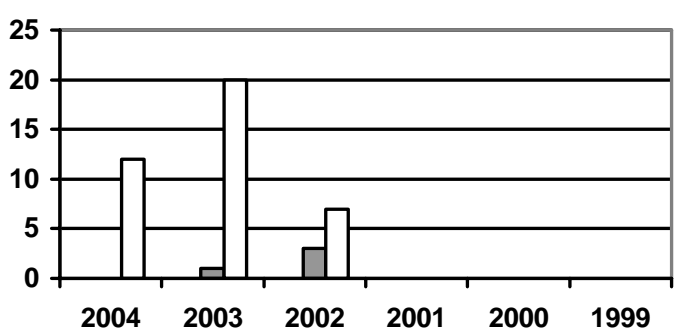

PIMES/UFPE

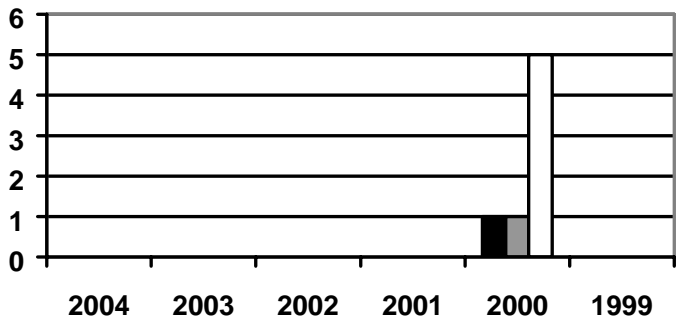


Legenda:

Candidatos classificados de 1 a 50

$\square$ Candidatos classificados de 51 a 120

$\square$ Candidatos classificados de 121 em diante

Observações:

1. Não temos os seguintes dados: CEDEPLAR/UFMG para o ano de 2002; PPGE/UFRGS para o ano de 2002; CAEN/UFC para o ano de 2001; ME/UFES para os anos de 2002, 2001, 2000 e 1999; UFSC para os anos de 2002 e 2001; UEM-PR para os anos de 2002 e 1999; UFF para os anos de 2002 e 1999; UFPR para o ano de 2002; NAEA/UFPA para os anos de 2003, 2002, 2000 e 1999; PIMES/UFPE para os anos de 2004, 2003, 2002, 2001 e 1999.

2. O ME/UFU ingressou no mercado da ANPEC em 2001; a UCB ingressou em 2002; a UNESP/AR também ingressou no mercado em 2002.

3. Em 2004 o PPGE/UFRGS dividiu o mestrado em duas ênfases: Economia Aplicada (EA) e Economia do Desenvolvimento (ED), com ponderações específicas para cada uma e distintas da ponderação utilizada nos anos anetriores. Portanto os dados de 2004 não são totalmente comparáveis com os anos anteriores. No entanto, decidimos apresentá-los no gráfico a título de ilustração.

4. Também em 2004 a UFSC dividiu o mestrado em três áreas: Economia e Finanças (EcoF), Economia Industrial (EI) e Transformação do Capitalismo Contemporâneo (TCC). A primeira mantém a mesma ponderação utilizada nos anos anteriores e as outras duas têm ponderações distintas. No entanto, a ANPEC não discriminou, dentre os candidatos que foram admitidos pela UFSC, quais foram para cada uma das três áreas. Portanto, apresentamos todos os candidatos como admitidos pela UFSC (independenetemente da área) e utilizamos a ponderação da área de Economia e Finanças. 
Tabela B1 - Intersecção das listas dos Centros por tipo dos candidatos

\begin{tabular}{|c|c|c|c|c|}
\hline & \multicolumn{4}{|c|}{ Média 1999 - 2004} \\
\hline Candidatos & $100 \%$ dos Centros & 90\% dos Centros & $80 \%$ dos Centros & $70 \%$ dos Centros \\
\hline Tipo 1 & $68 \%$ & $77 \%$ & $85 \%$ & $90 \%$ \\
\hline Tipo 2 & $45 \%$ & $59 \%$ & $74 \%$ & $85 \%$ \\
\hline \multirow[t]{2}{*}{\begin{tabular}{|l|} 
Tipo 3 \\
\end{tabular}} & $85 \%$ & $90 \%$ & $95 \%$ & $96 \%$ \\
\hline & \multicolumn{4}{|c|}{2004} \\
\hline Tipo 1 & $68 \%$ & $70 \%$ & $76 \%$ & $88 \%$ \\
\hline Tipo 2 & $49 \%$ & $54 \%$ & $67 \%$ & $79 \%$ \\
\hline \multirow[t]{2}{*}{ Tipo 3} & $89 \%$ & $89 \%$ & $93 \%$ & $96 \%$ \\
\hline & \multicolumn{4}{|c|}{2003} \\
\hline Tipo 1 & $72 \%$ & $76 \%$ & $86 \%$ & $90 \%$ \\
\hline Tipo 2 & $47 \%$ & $56 \%$ & $70 \%$ & $86 \%$ \\
\hline \multirow[t]{2}{*}{ Tipo 3} & $87 \%$ & $89 \%$ & $95 \%$ & $96 \%$ \\
\hline & \multicolumn{4}{|c|}{2002} \\
\hline Tipo 1 & $76 \%$ & $84 \%$ & $90 \%$ & $94 \%$ \\
\hline Tipo 2 & $53 \%$ & $64 \%$ & $77 \%$ & $89 \%$ \\
\hline \multirow[t]{2}{*}{ Tipo 3} & $85 \%$ & $89 \%$ & $97 \%$ & $97 \%$ \\
\hline & \multicolumn{4}{|c|}{2001} \\
\hline Tipo 1 & $68 \%$ & $80 \%$ & $92 \%$ & $94 \%$ \\
\hline Tipo 2 & $50 \%$ & $63 \%$ & $79 \%$ & $93 \%$ \\
\hline \multirow[t]{2}{*}{ Tipo 3} & $86 \%$ & $89 \%$ & $94 \%$ & $96 \%$ \\
\hline & \multicolumn{4}{|c|}{2000} \\
\hline Tipo 1 & $60 \%$ & $74 \%$ & $82 \%$ & $90 \%$ \\
\hline Tipo 2 & $40 \%$ & $57 \%$ & $76 \%$ & $84 \%$ \\
\hline \multirow[t]{2}{*}{ Tipo 3} & $86 \%$ & $92 \%$ & $95 \%$ & $97 \%$ \\
\hline & \multicolumn{4}{|c|}{1999} \\
\hline Tipo 1 & $64 \%$ & $76 \%$ & $84 \%$ & $86 \%$ \\
\hline Tipo 2 & $34 \%$ & $59 \%$ & $76 \%$ & $80 \%$ \\
\hline Tipo 3 & $81 \%$ & $92 \%$ & $96 \%$ & $96 \%$ \\
\hline
\end{tabular}


Observações:

1. A tabela apresenta o percentual dos candidatos classificados como tipo j pelo critério da ANPEC que também são classificados como tipo j pelo critério dos Centros. A primeira coluna apresenta este percentual para $100 \%$ dos Centros, a segunda para $90 \%$, a terceira para $80 \%$ e a quarta para $70 \%$ dos Centros.

2. São apresentados os valores médios para período de 1999 a 2004 e os dados de cada ano individualmente.

3. As estatísticas sobre os candidatos tipo 3 consideram somente os candidatos classificados até a posição 300 pelo critério da ANPEC, pois todos os candidatos classificados além de 300 pelo critério da ANPEC também são classificados como tipo 3 em todos os Centros. 


\section{APÊNDICE C - TODOS OS MATCHINGS SIMULADOS DO MODELO TEÓRICO COM AS HIPÓTESES 1, 2 E 3}

\section{Tabela C1 - Matching $\mu_{1 \mathrm{~A}}$}

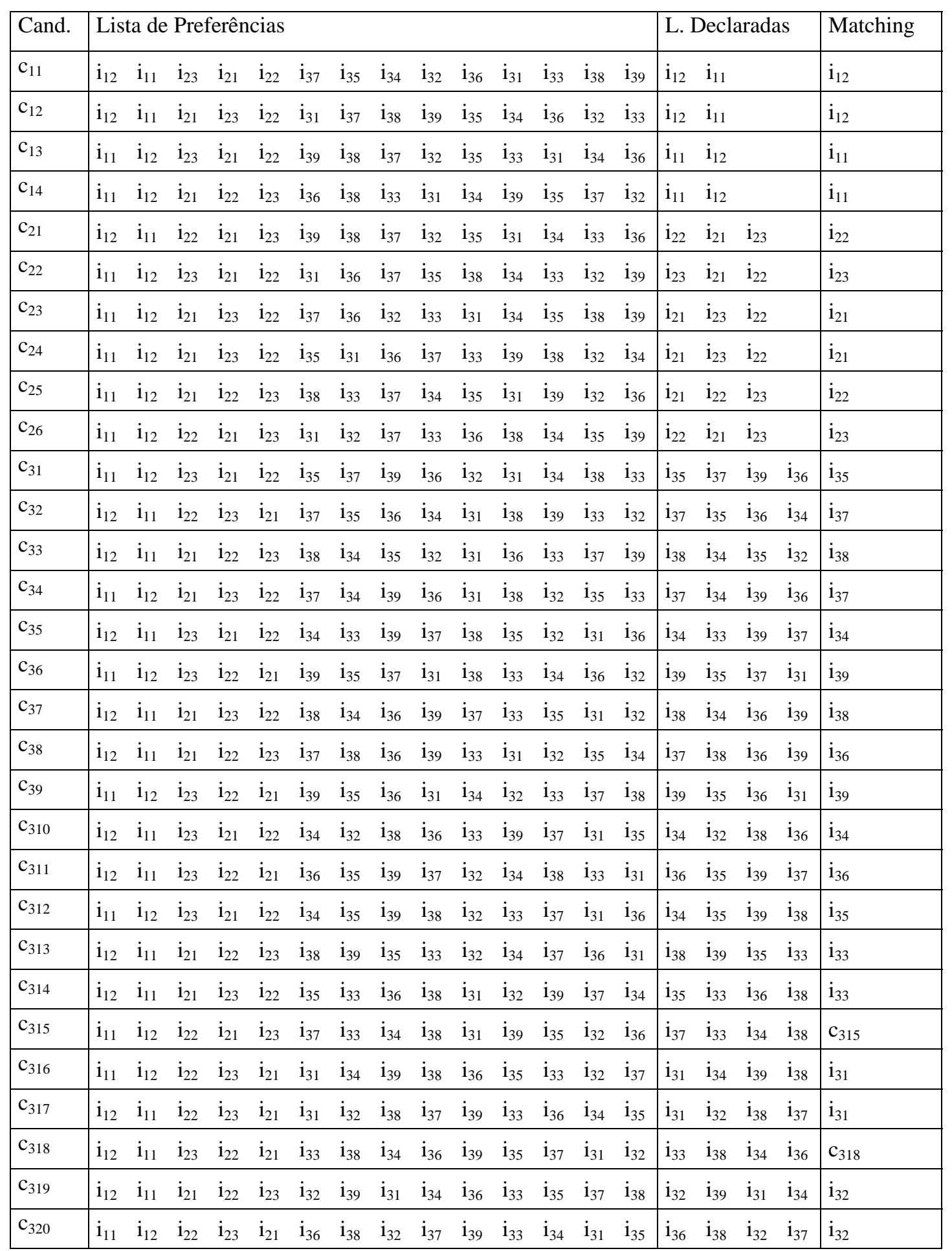




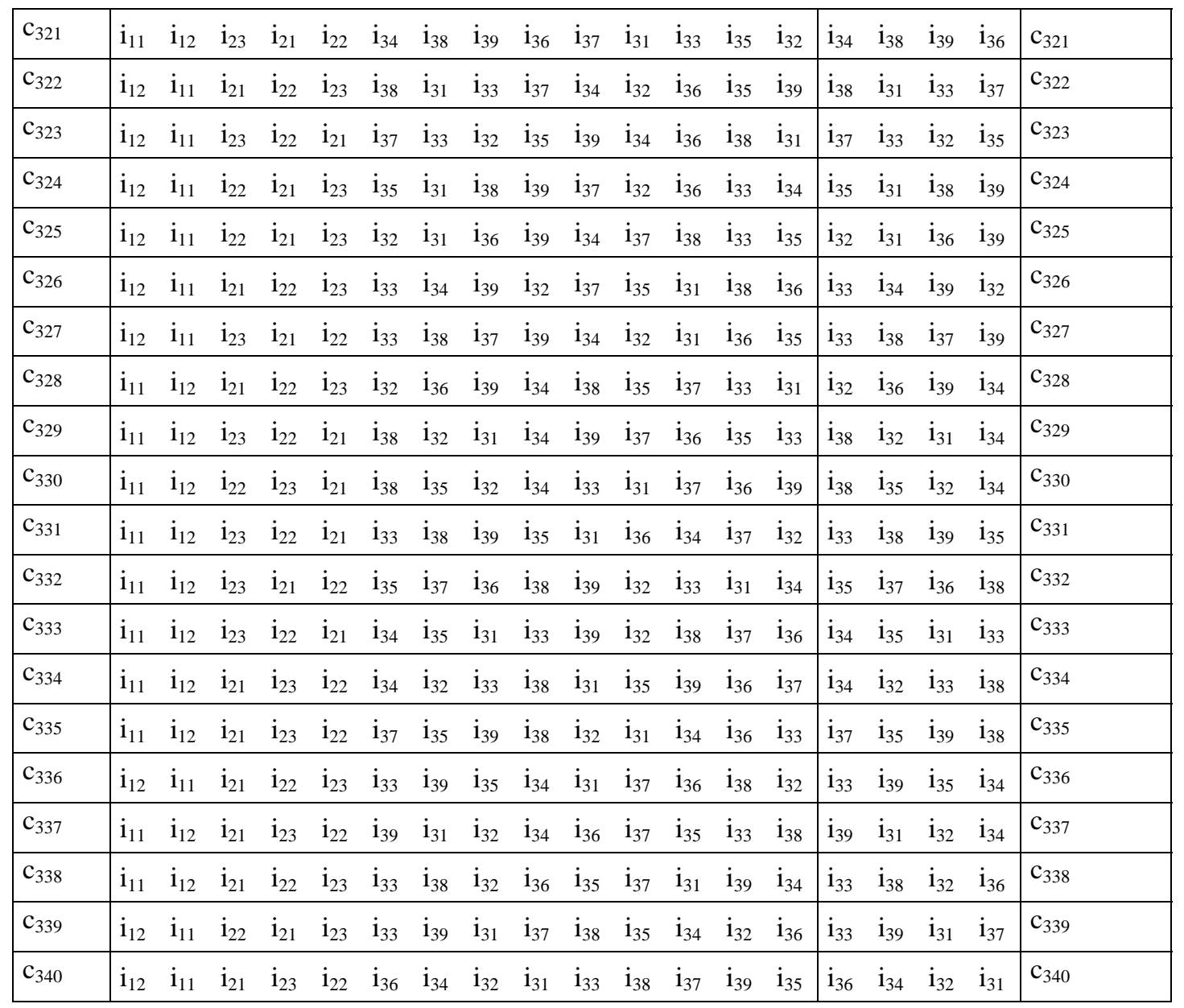


Tabela C2 - Matching $\mu_{1 \mathrm{~B}}$

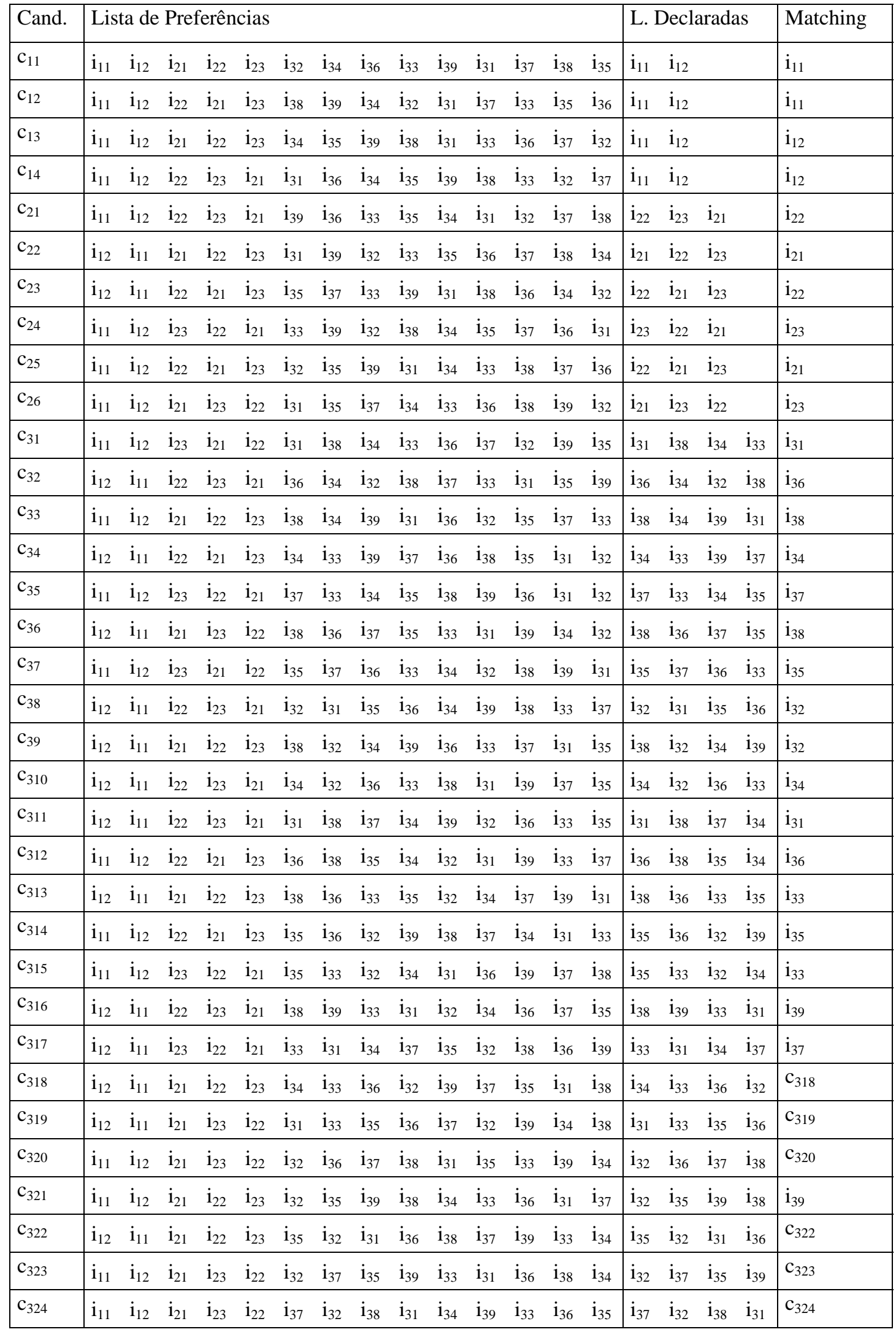




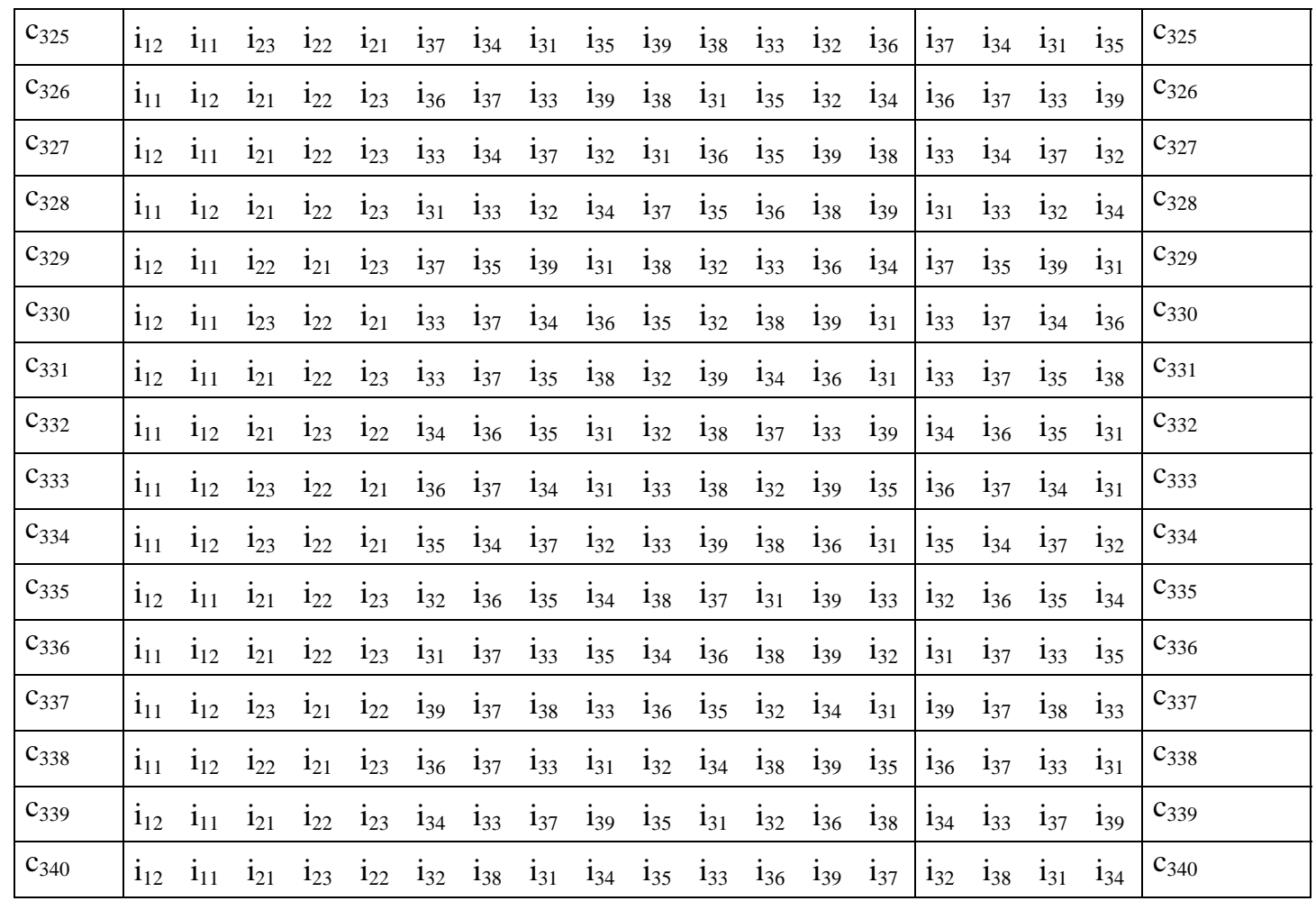


Tabela C3 - Matching $\mu_{1 \mathrm{C}}$

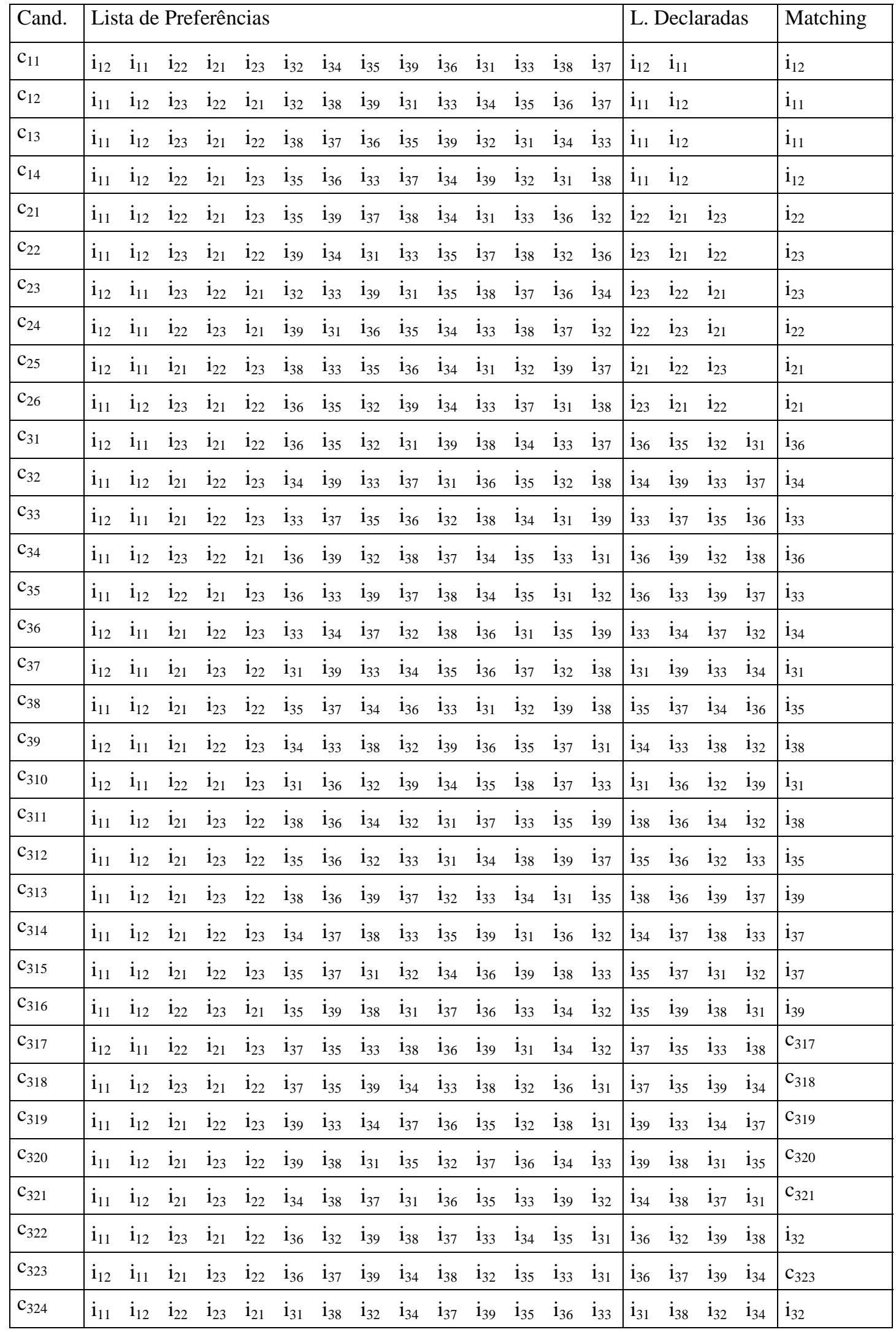




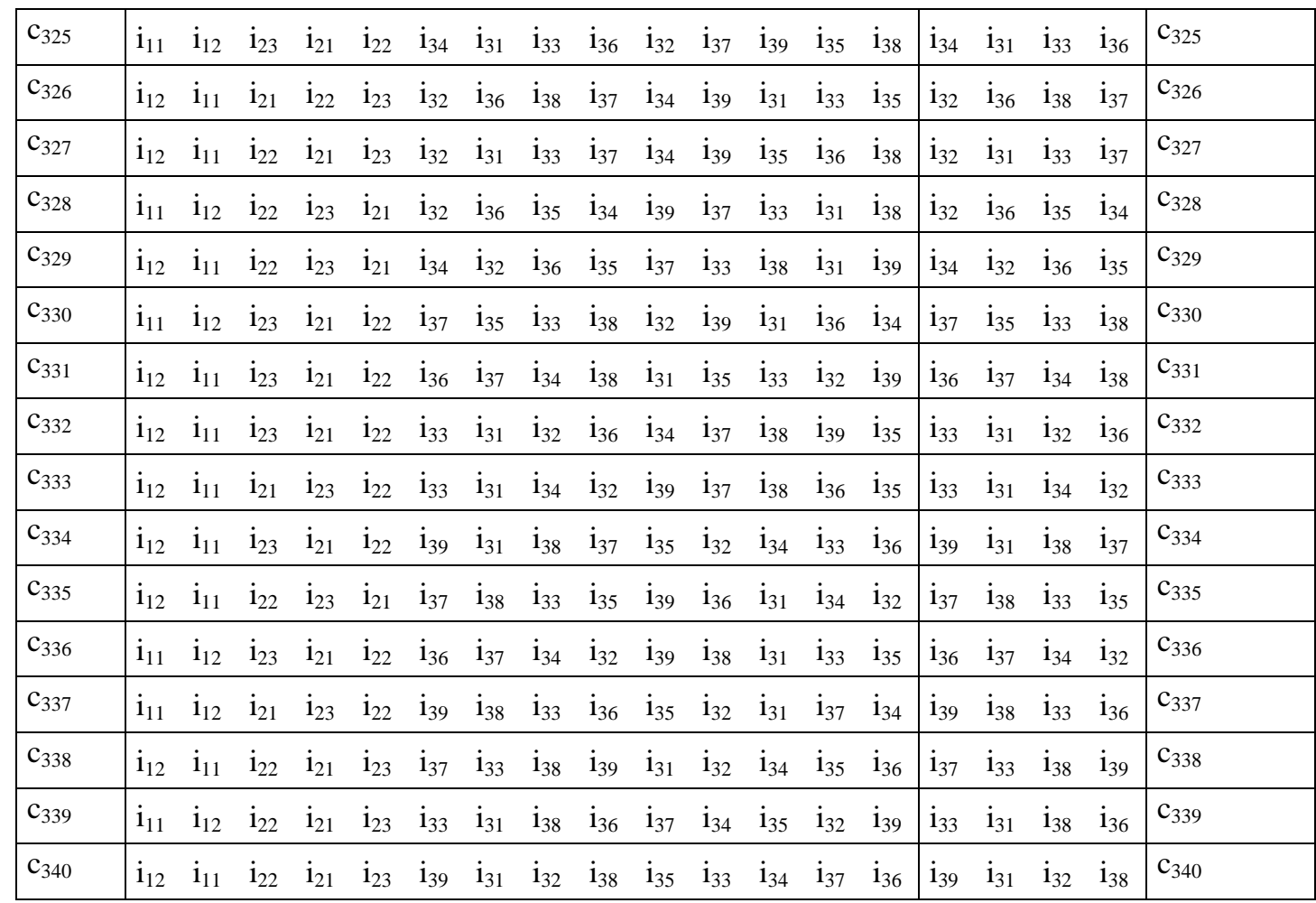


Tabela C4 - Matching $\mu_{1 \mathrm{D}}$

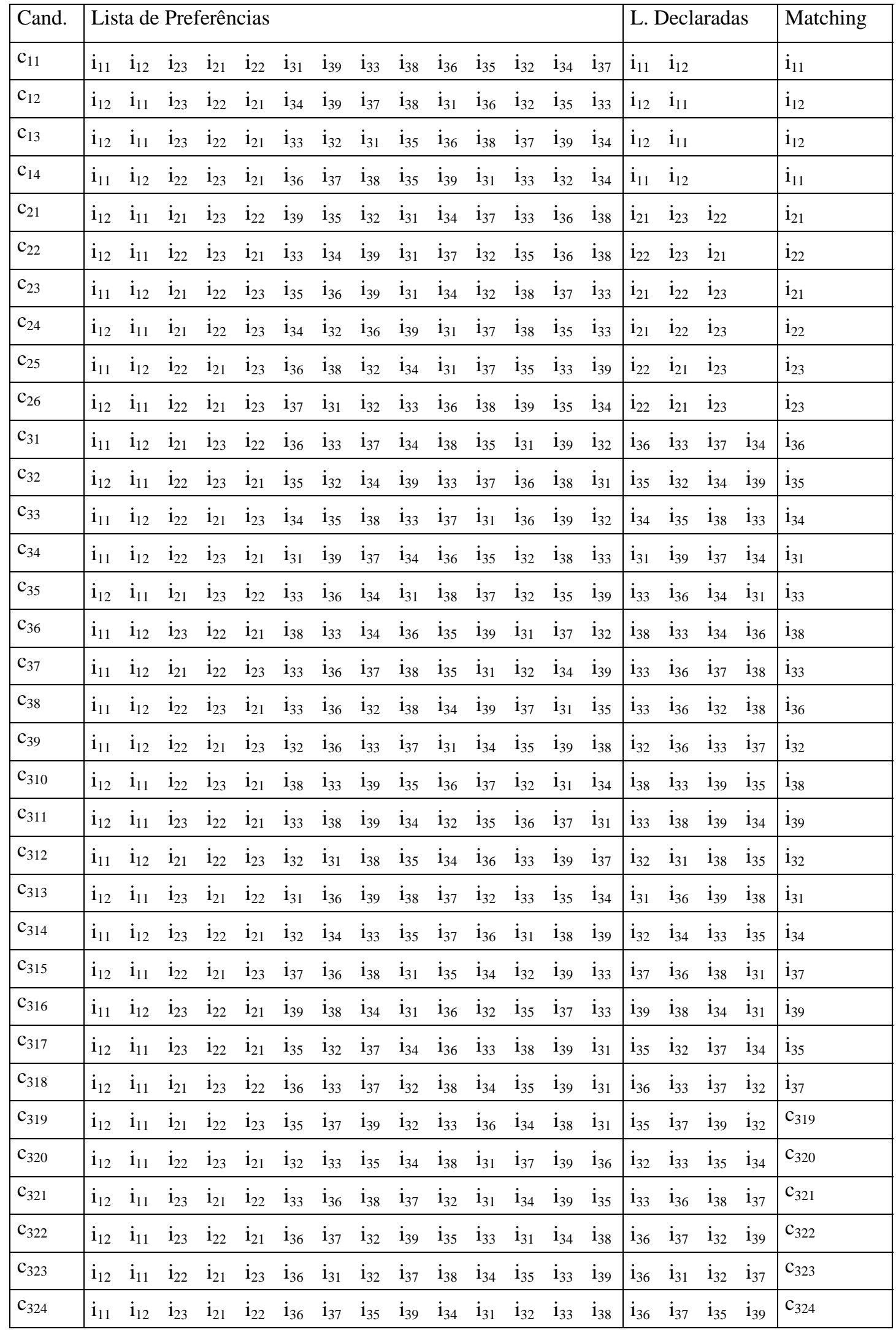




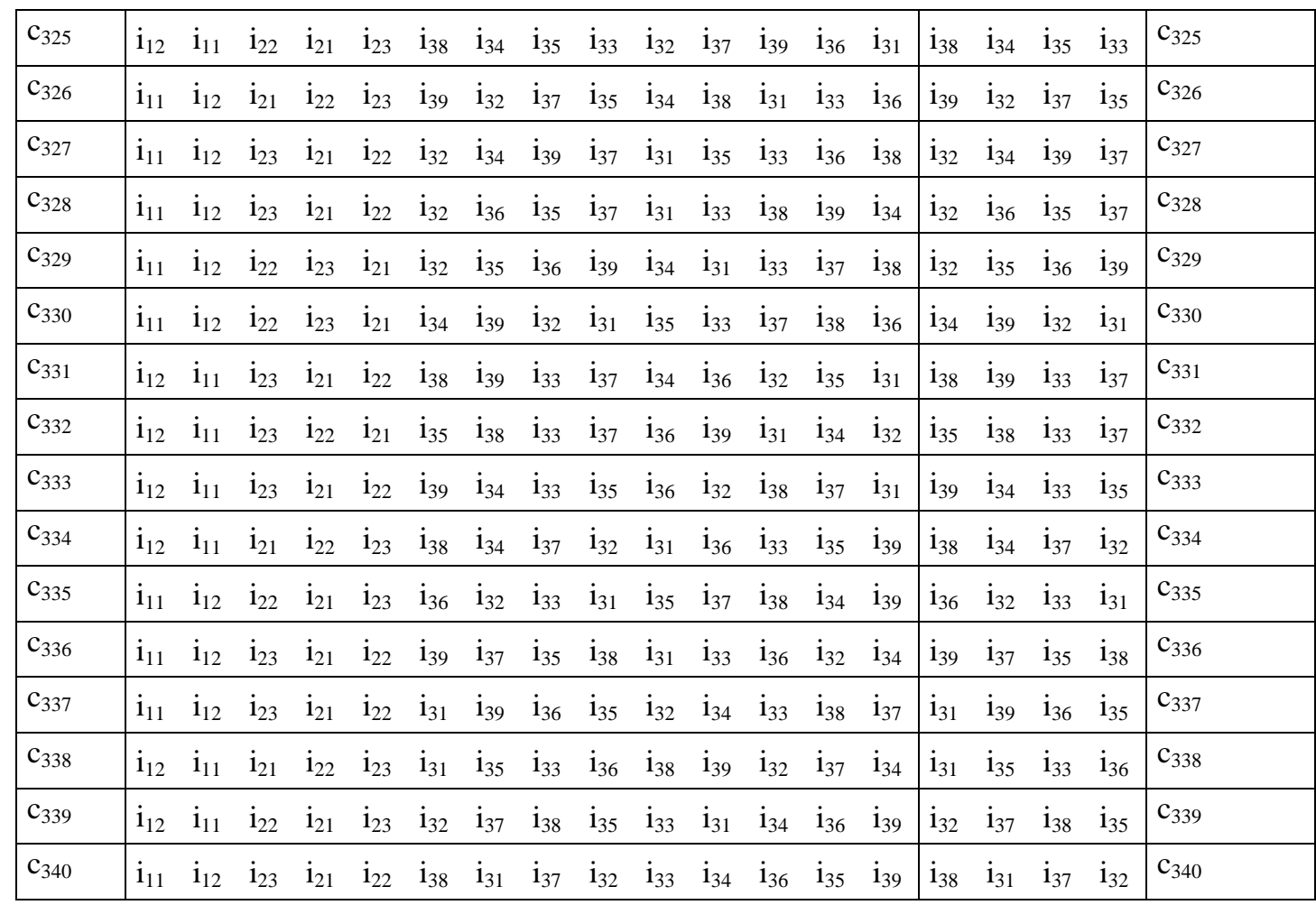


Tabela C5 - Matching $\mu_{1 \mathrm{E}}$

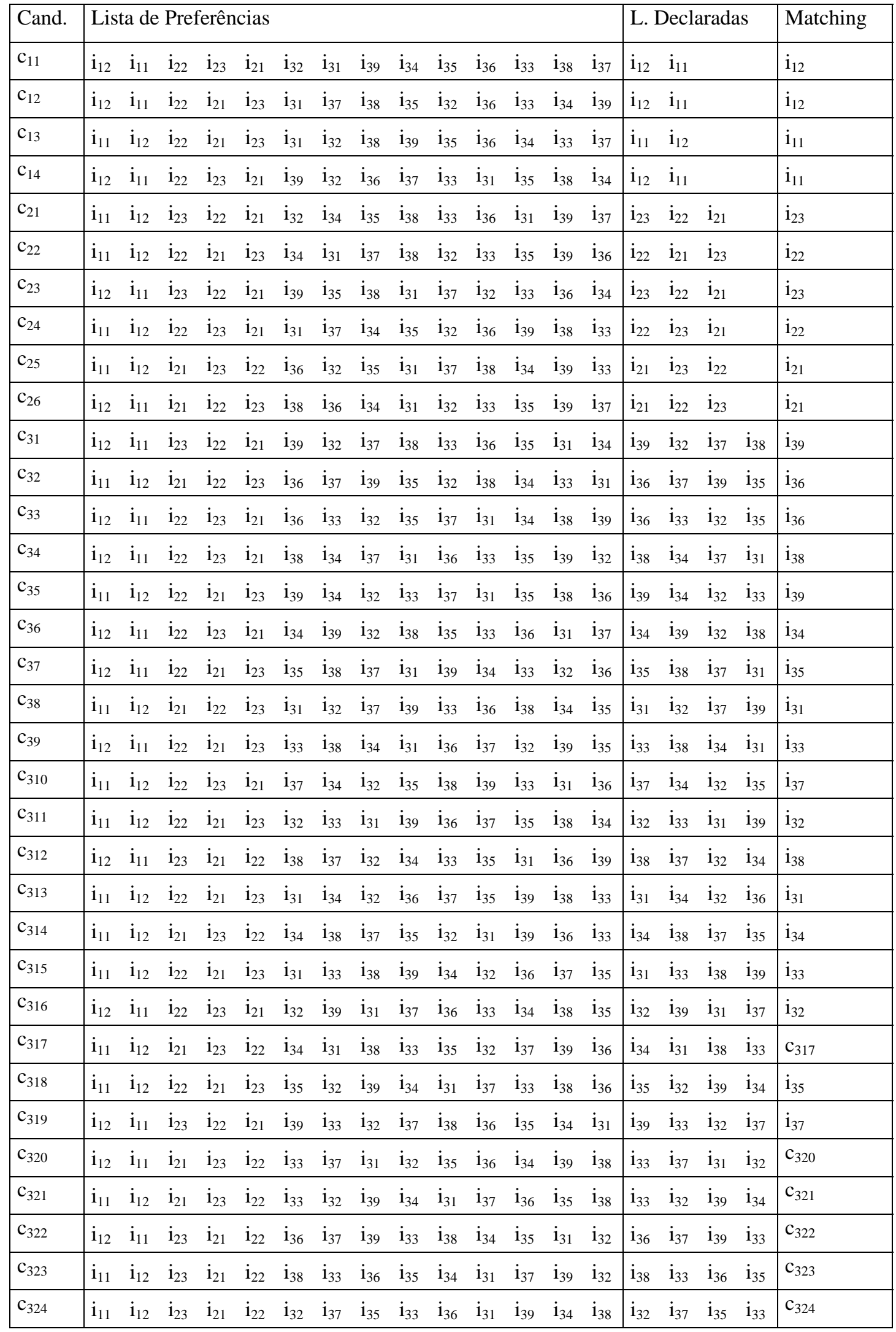




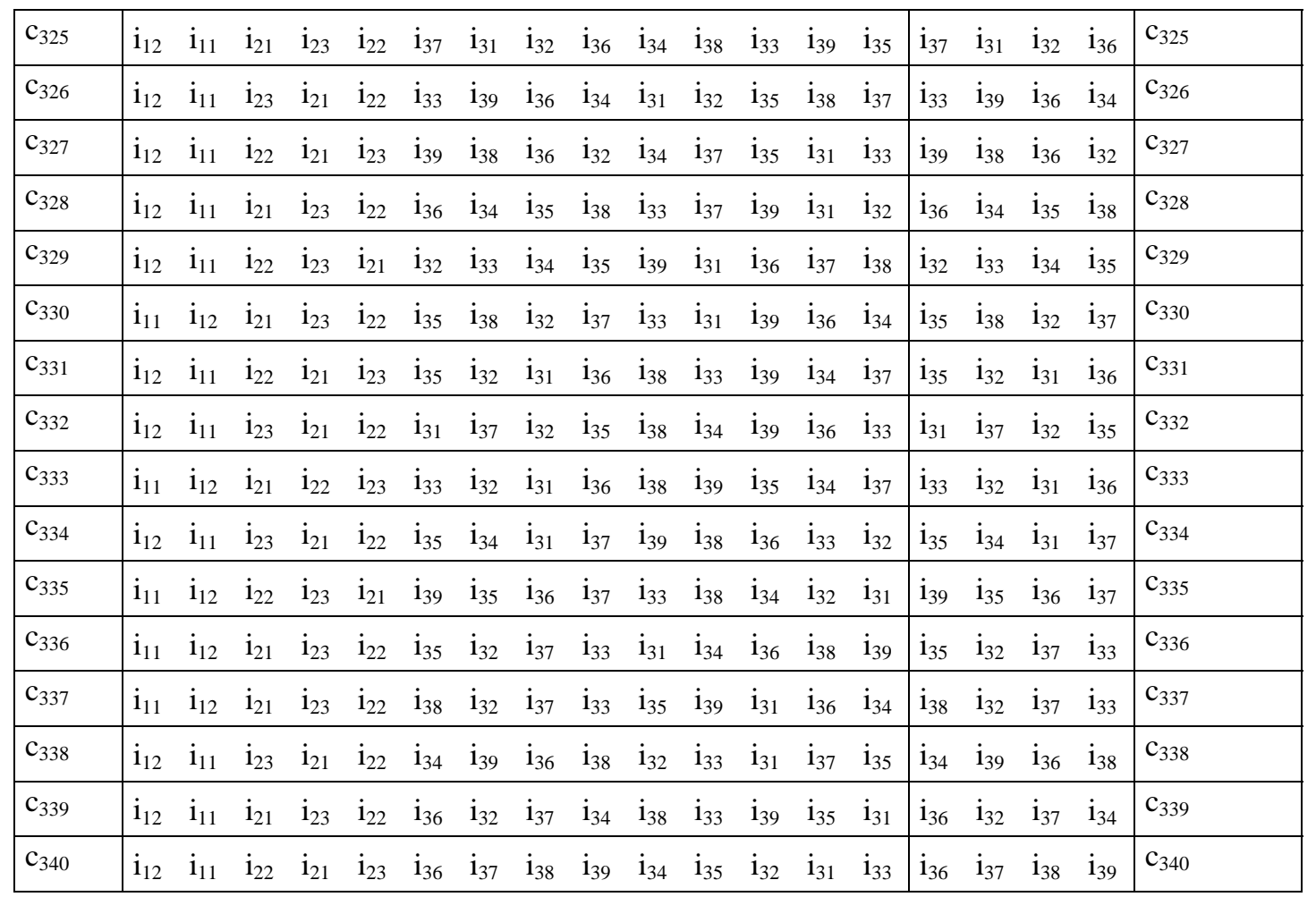


Tabela C6 - Matching $\mu_{1 F}$

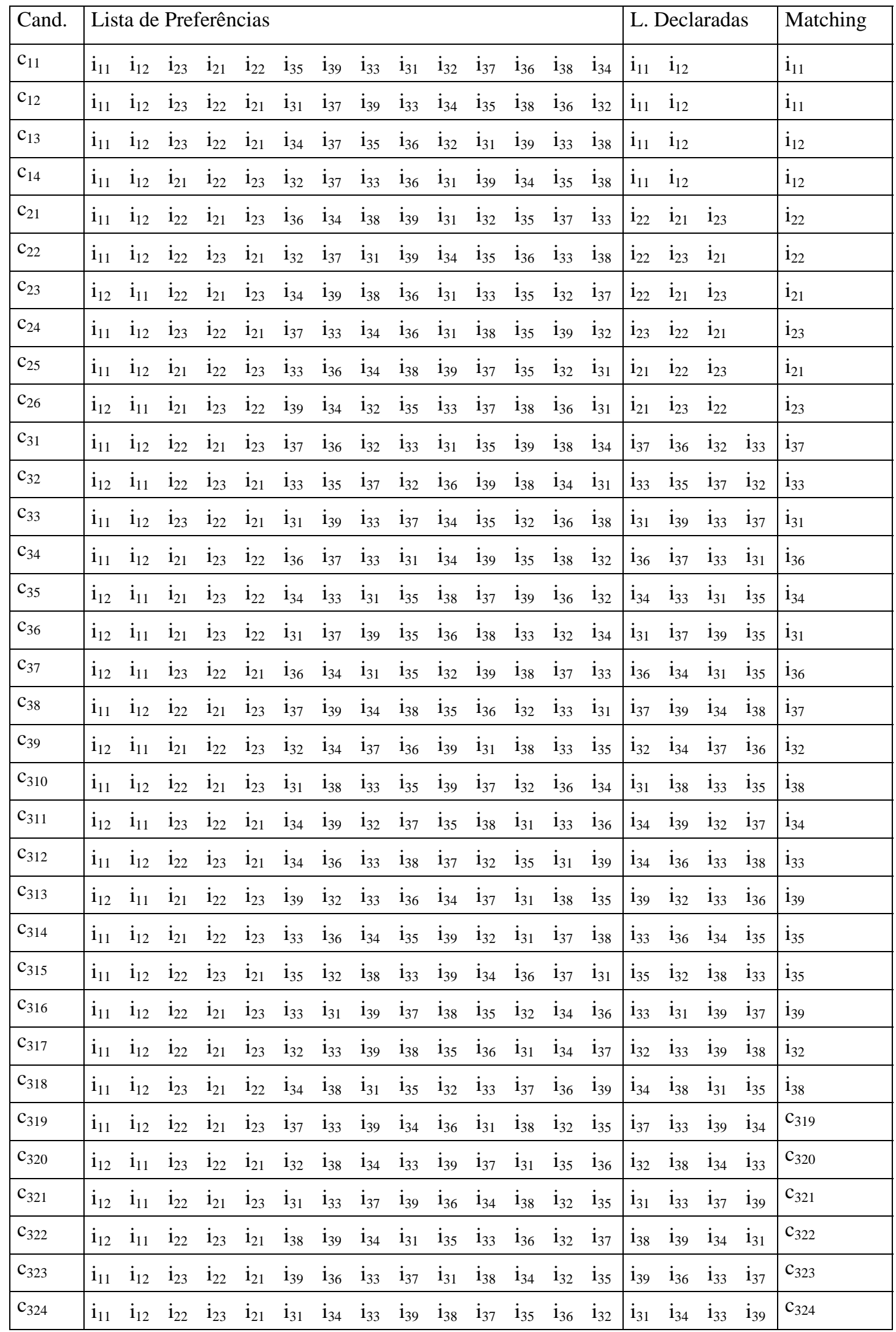




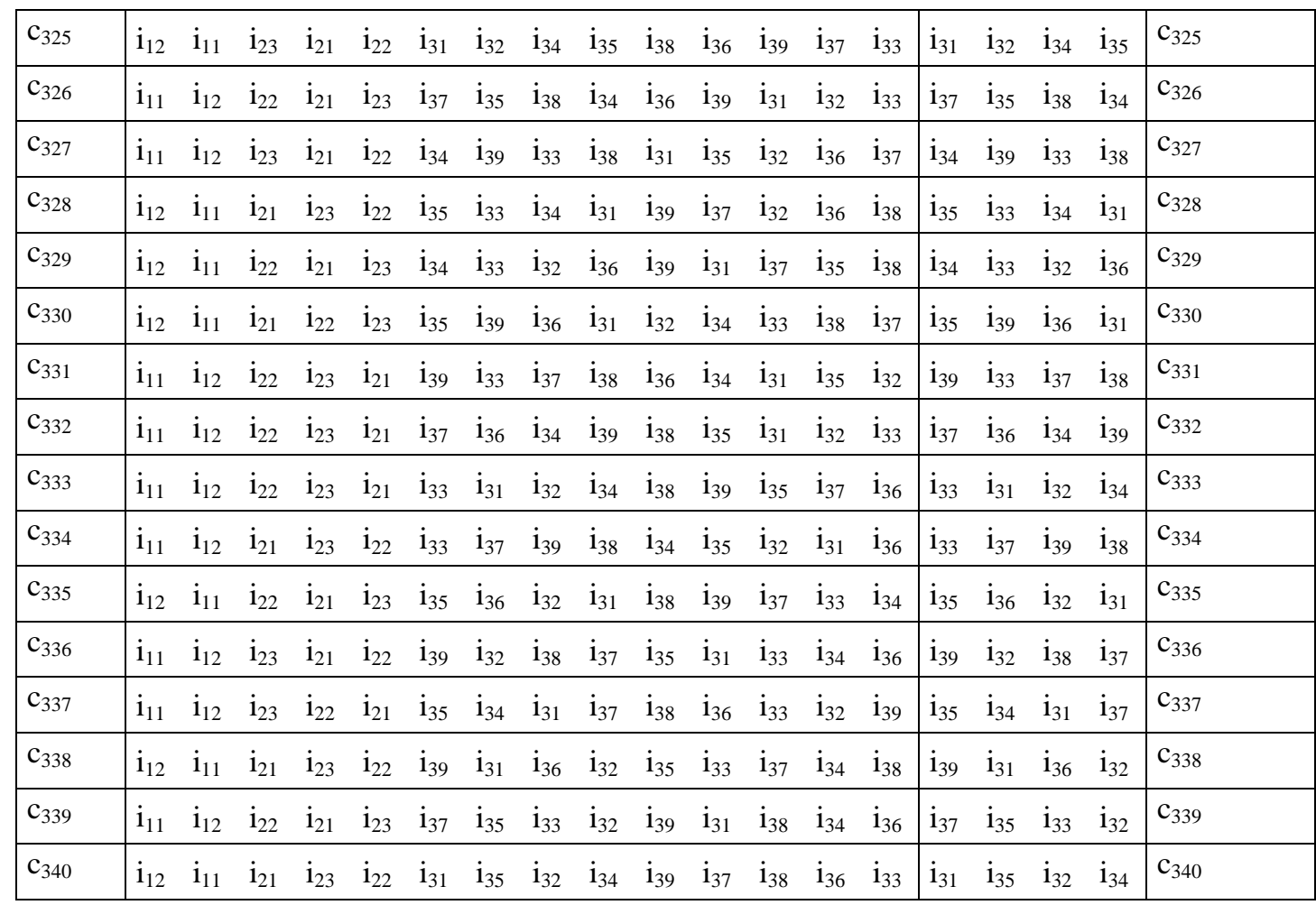


Tabela C7 - Matching $\mu_{1 \mathrm{H}}$

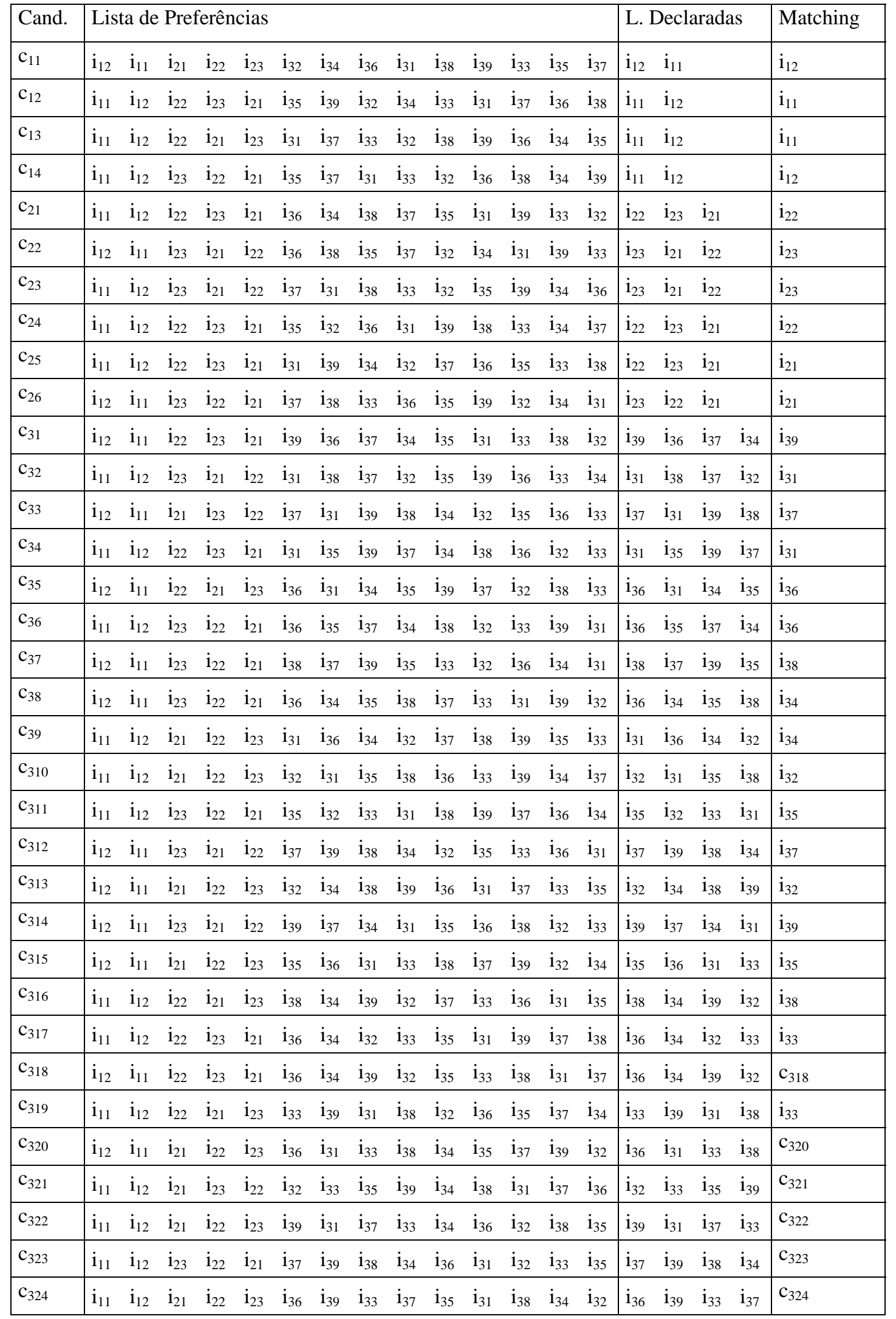




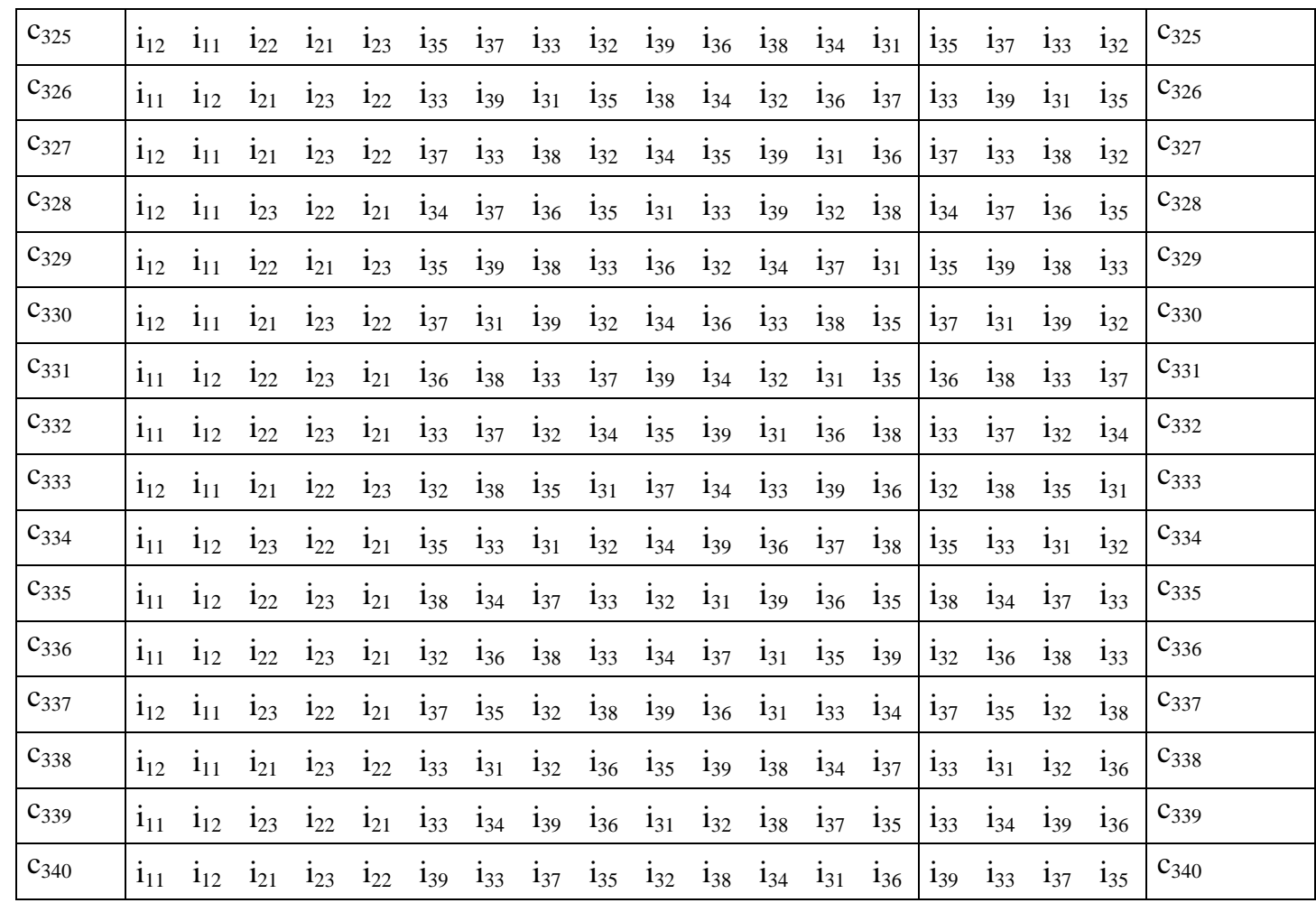


Tabela C8 - Matching $\mu_{1 I}$

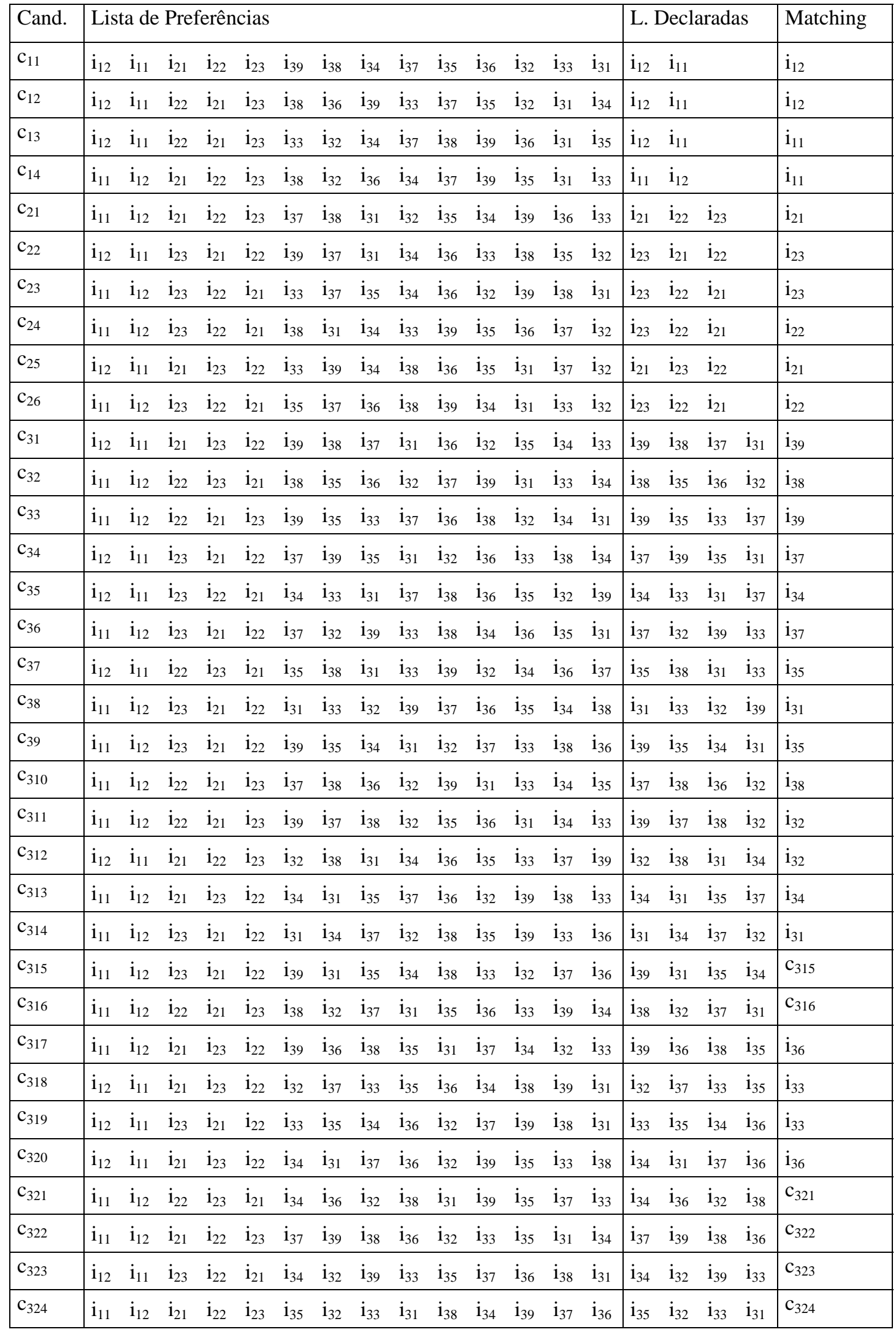




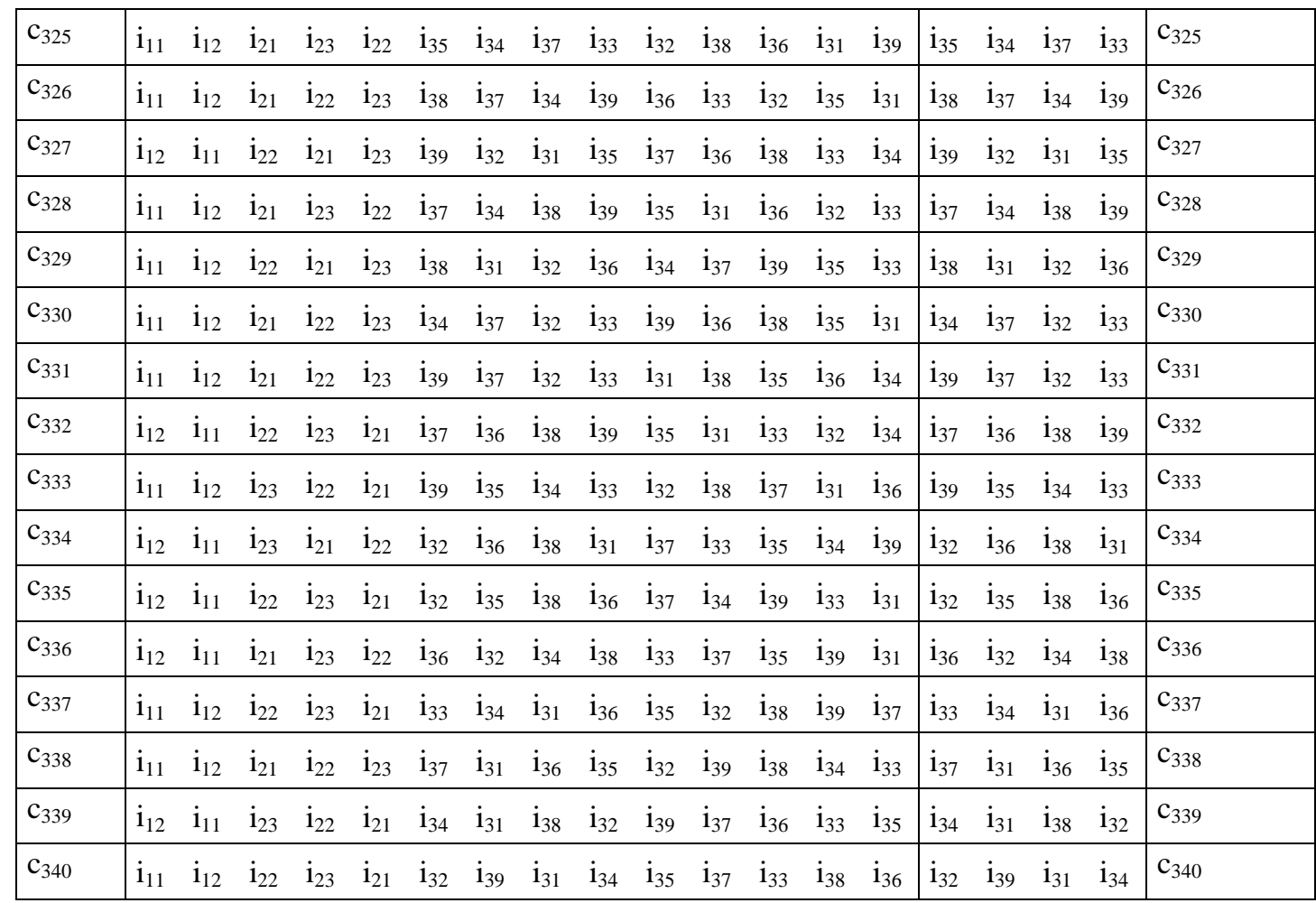


Tabela C9 - Matching $\mu_{1 \mathrm{~J}}$

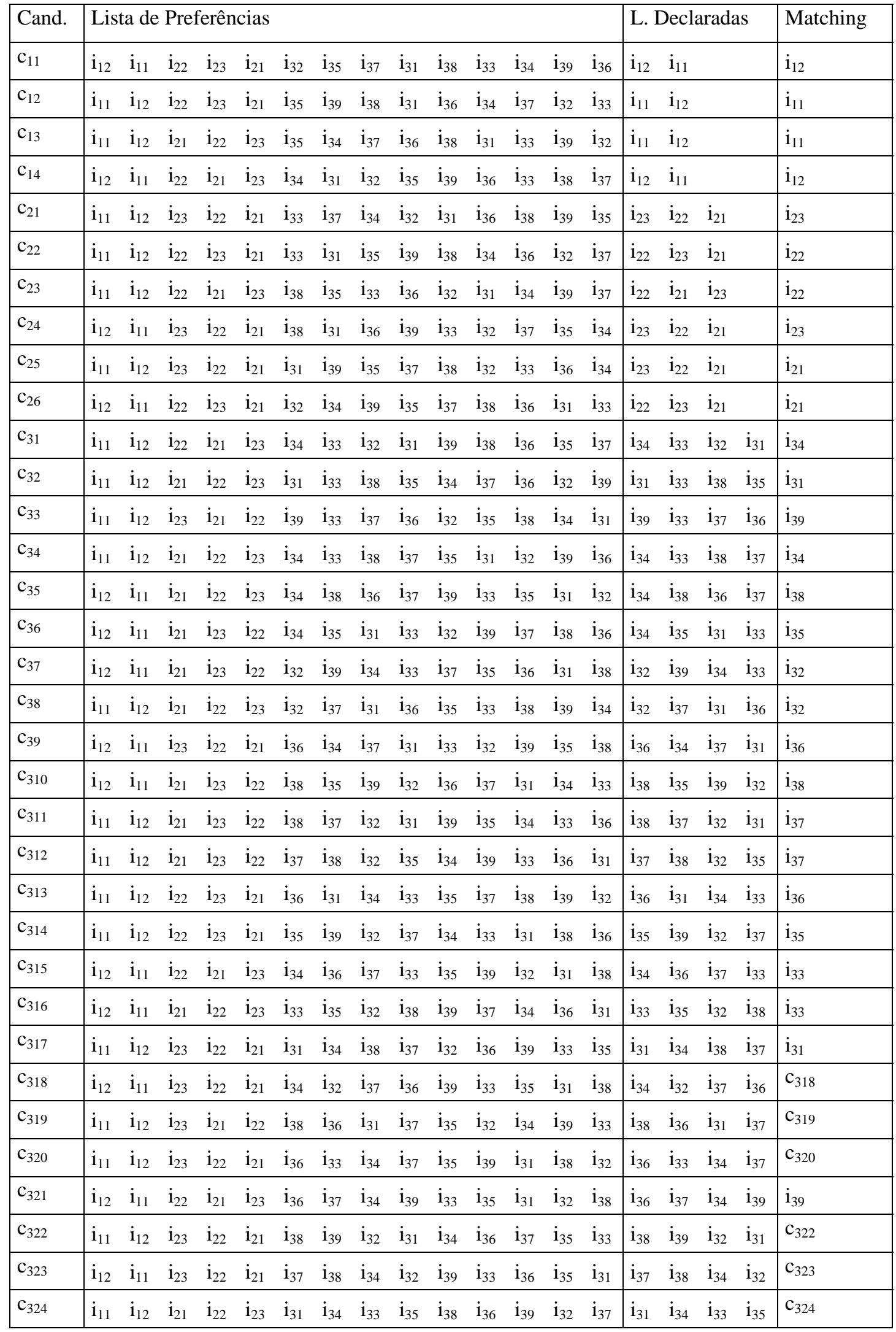




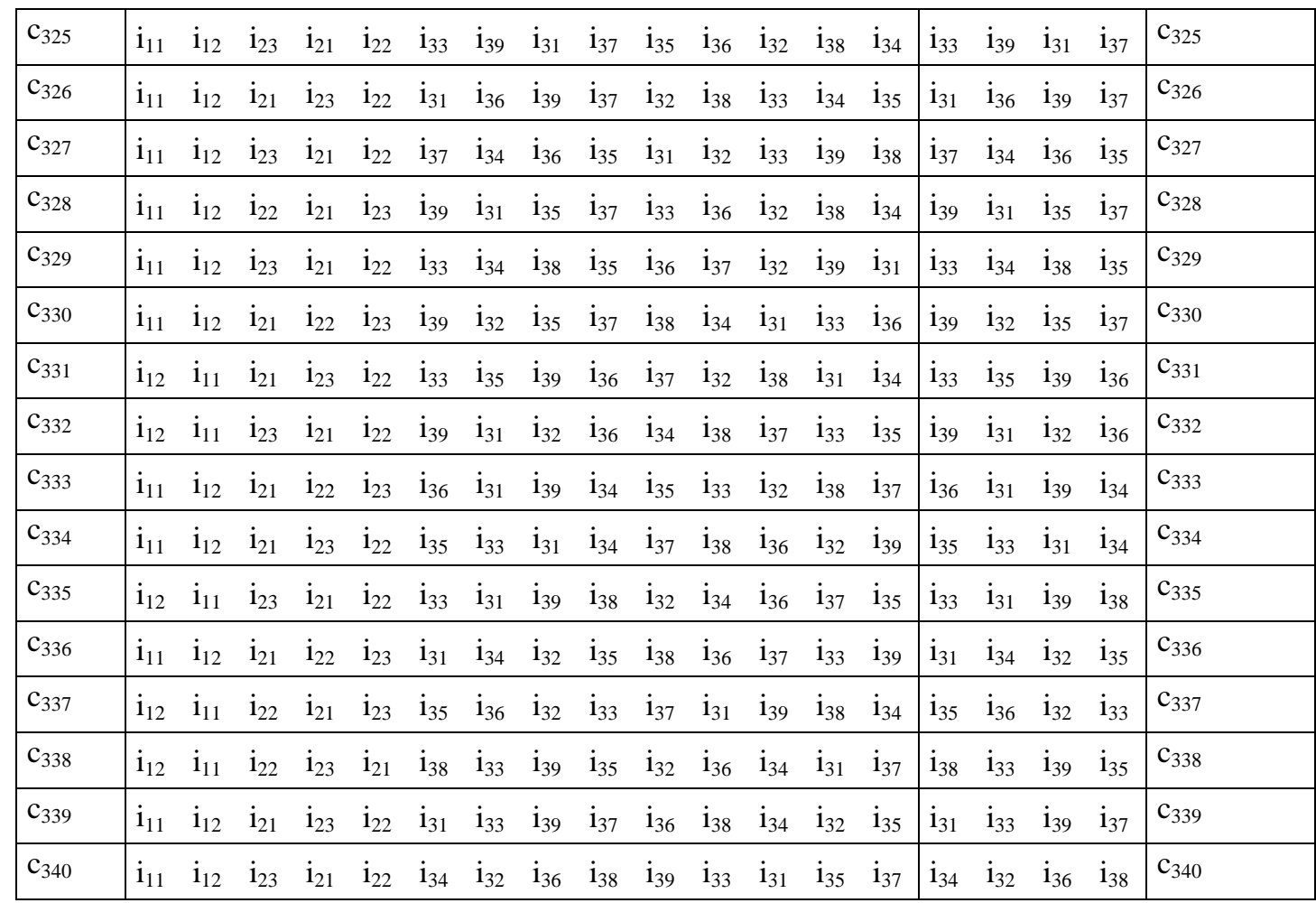


Tabela C10 - Matching $\mu_{2 A}$

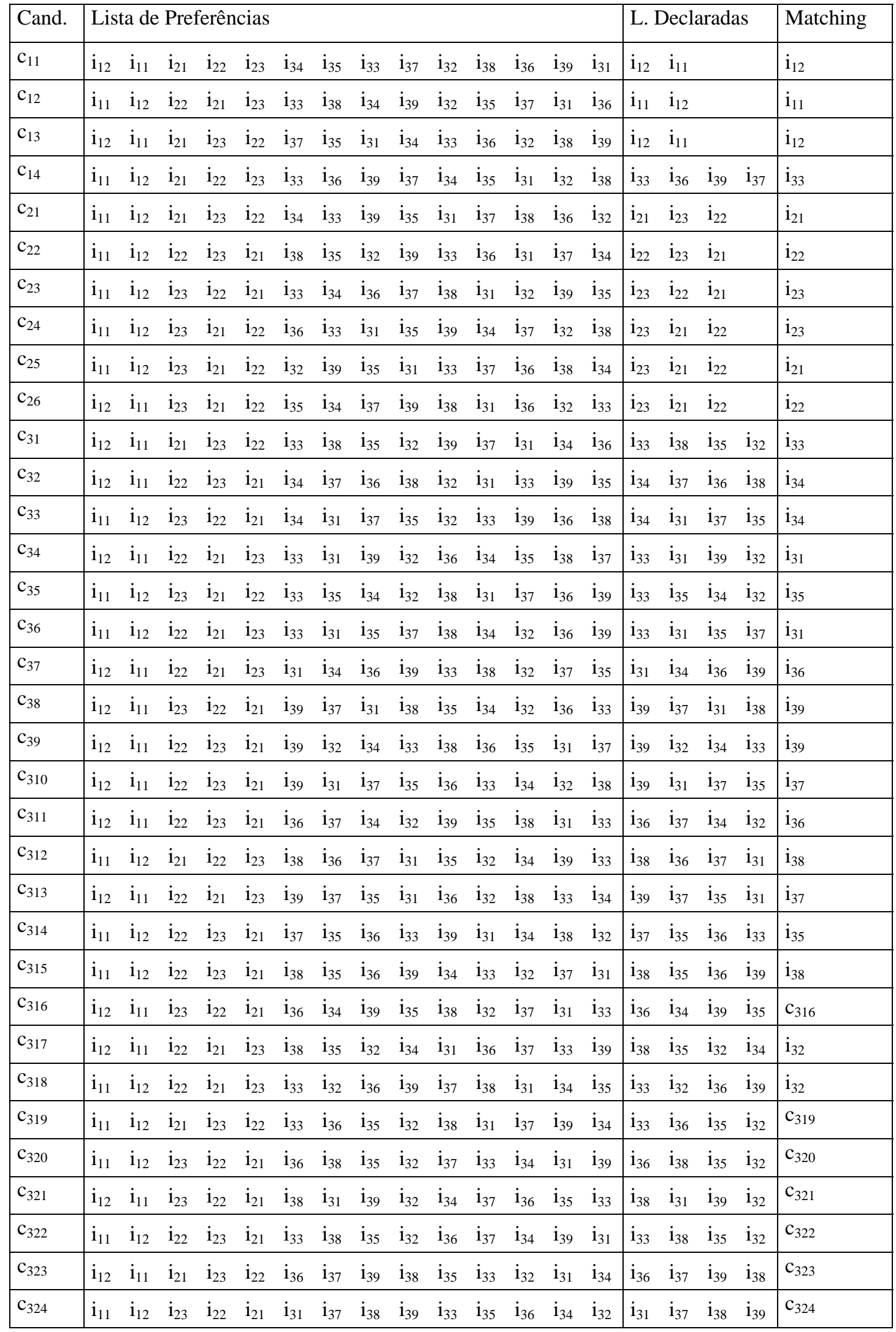




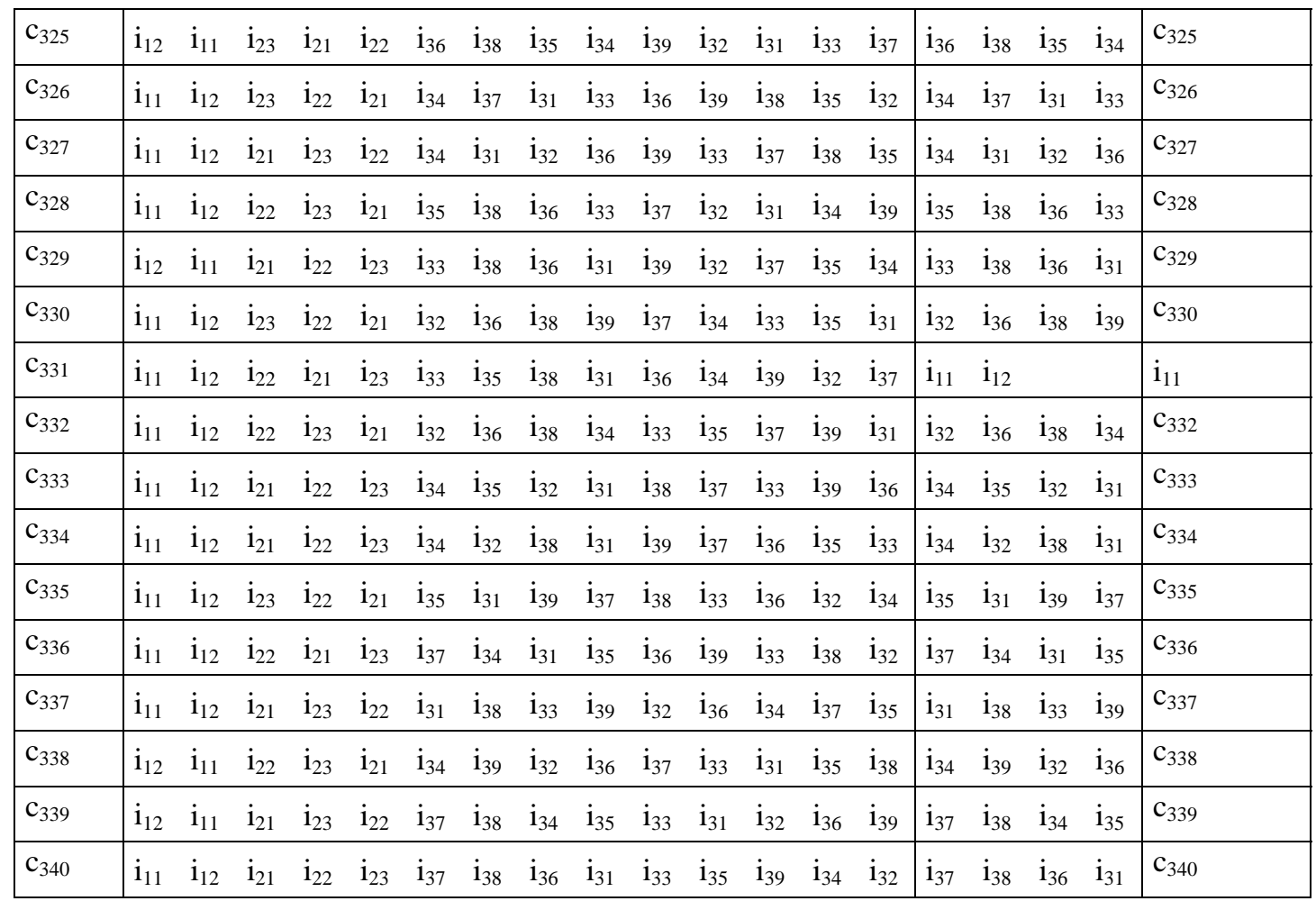


Tabela C11 - Matching $\mu_{2 \mathrm{~B}}$

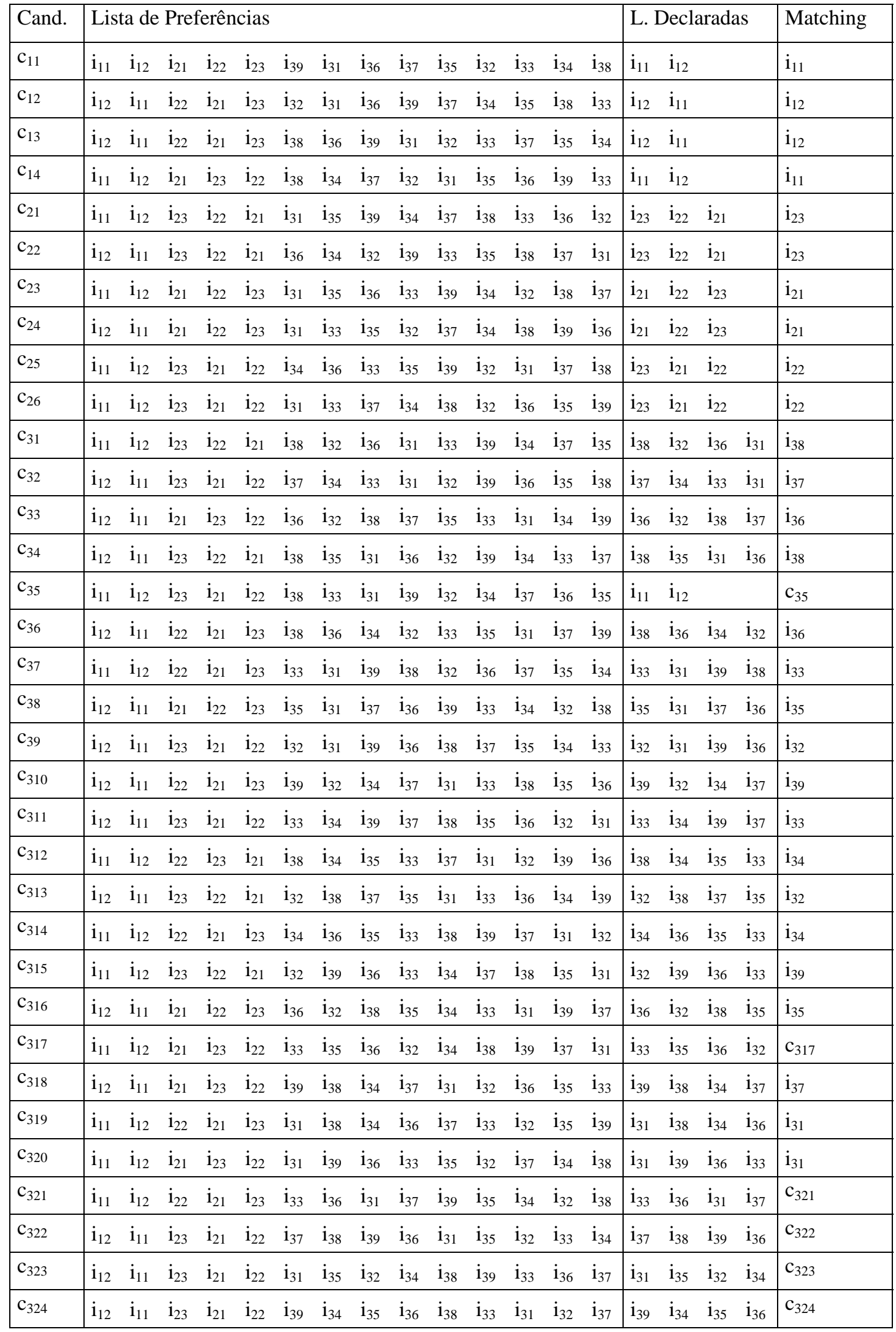




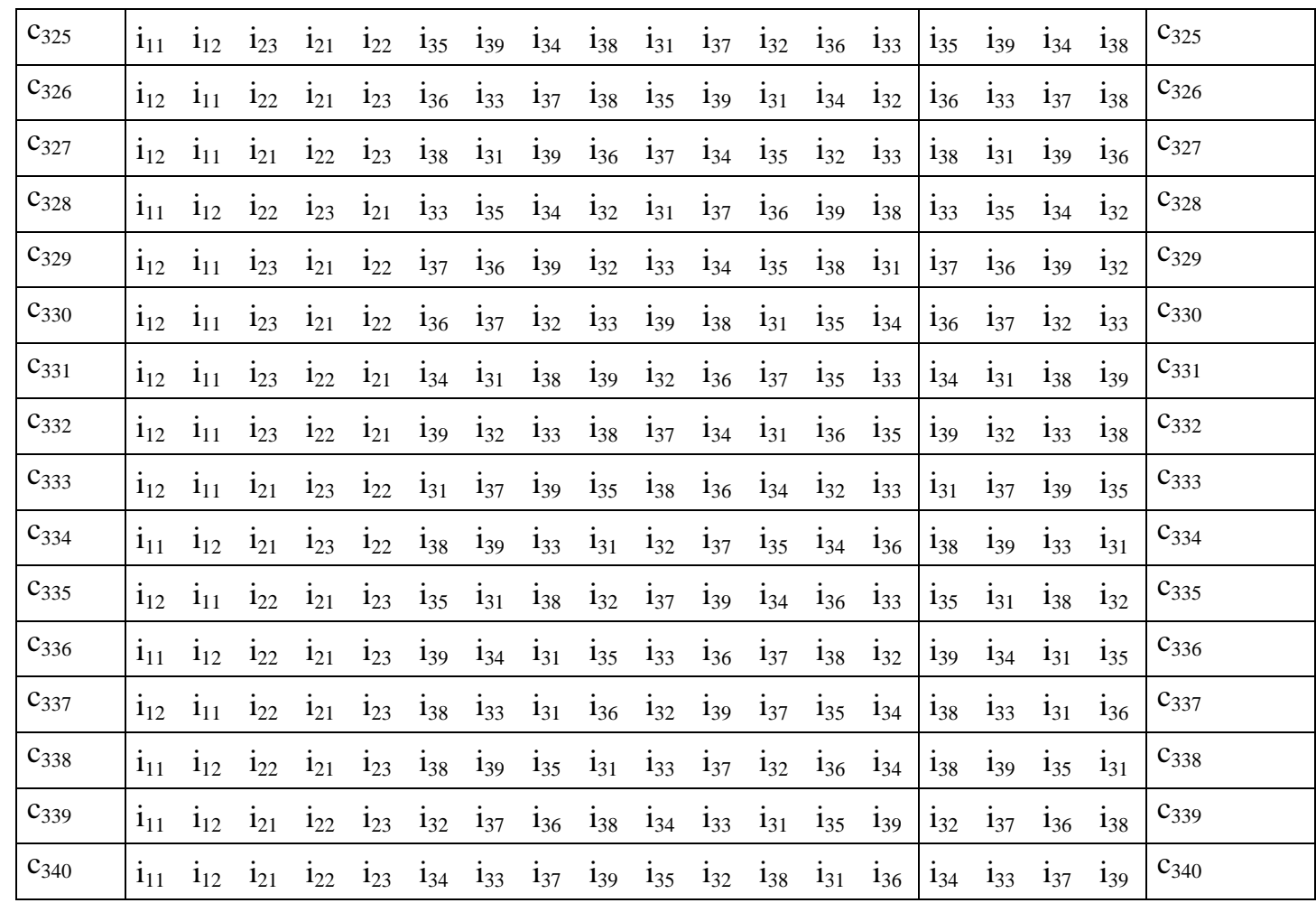


Tabela C12 - Matching $\mu_{2 \mathrm{C}}$

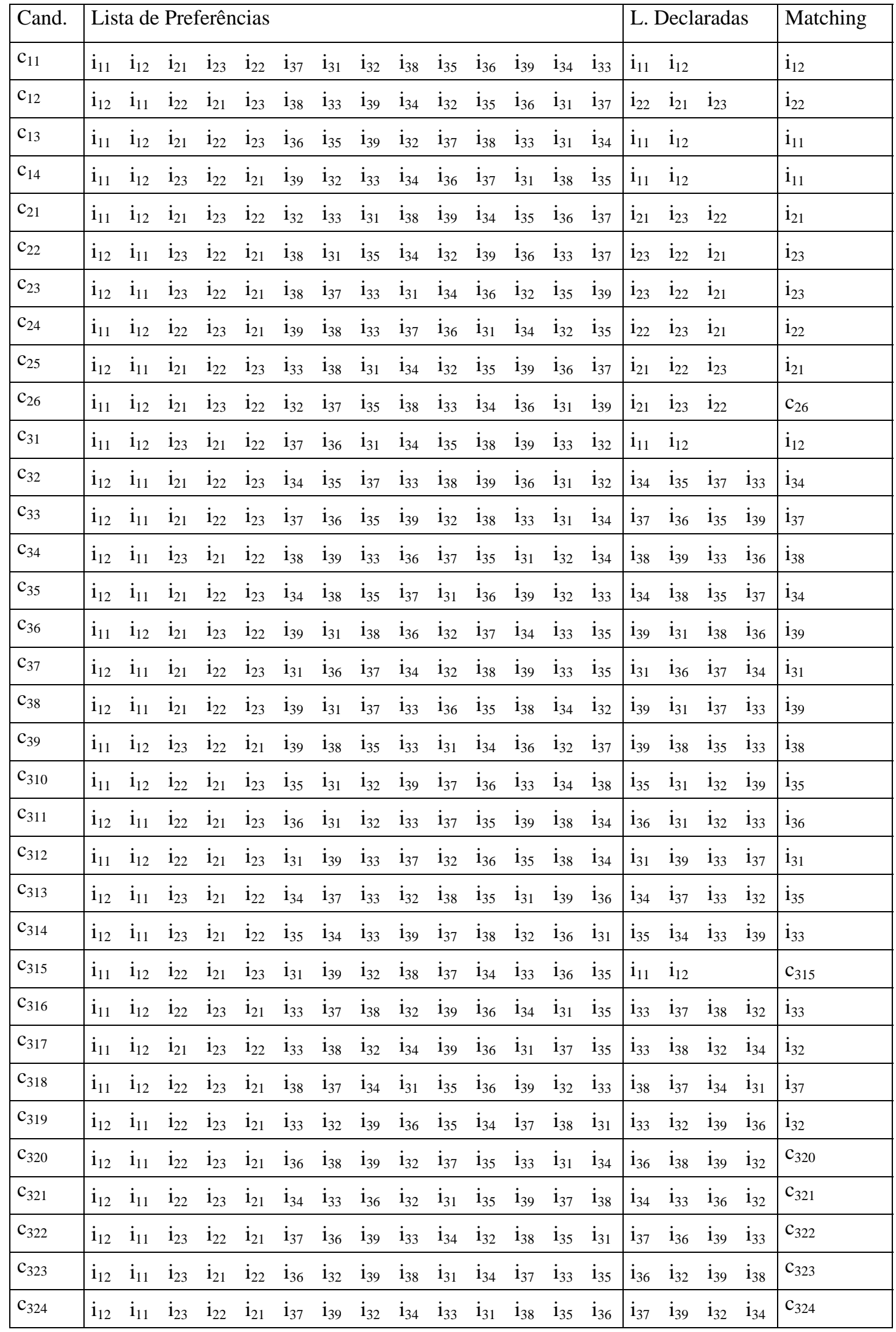




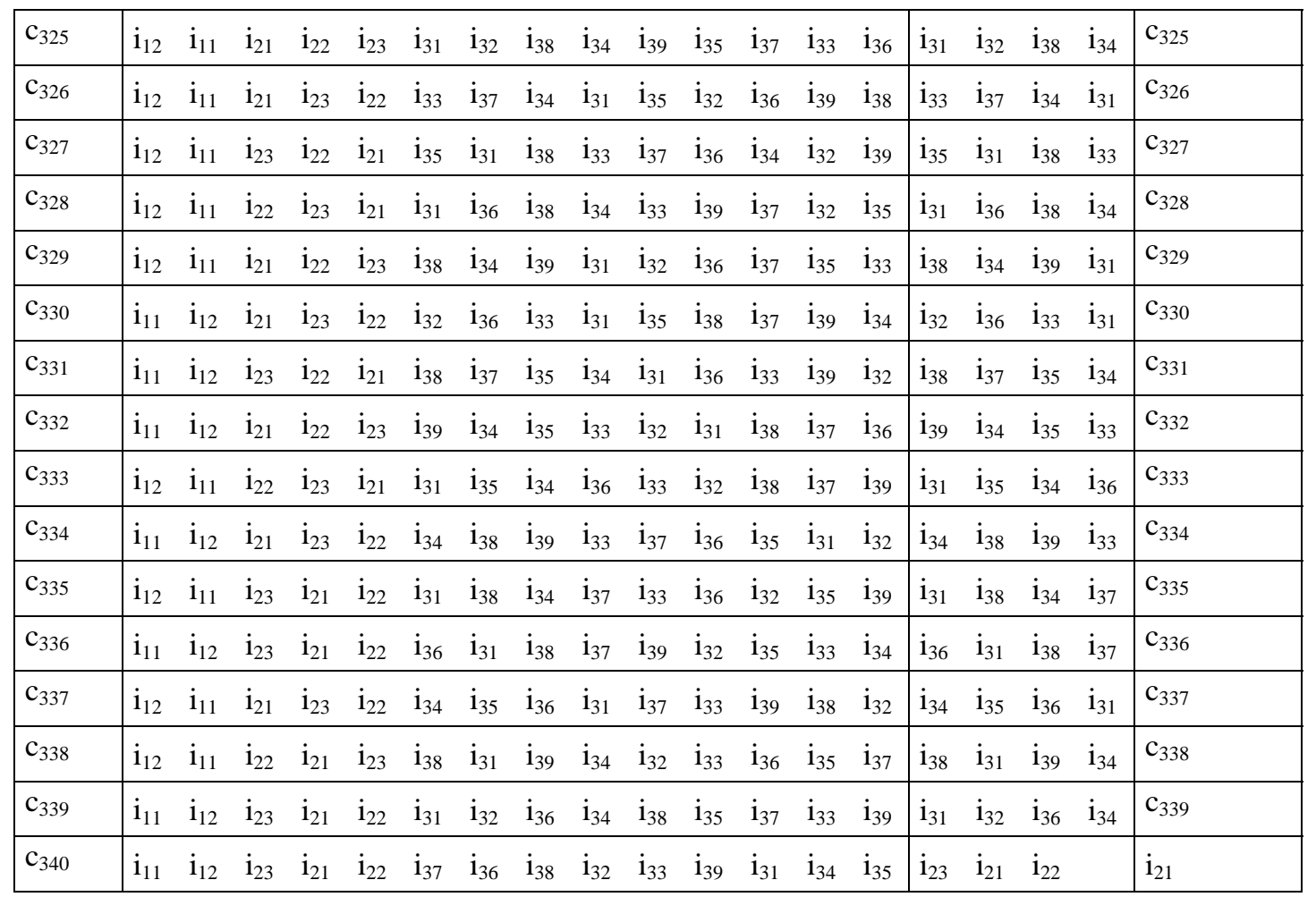


Tabela C13 - Matching $\mu_{2 \mathrm{D}}$

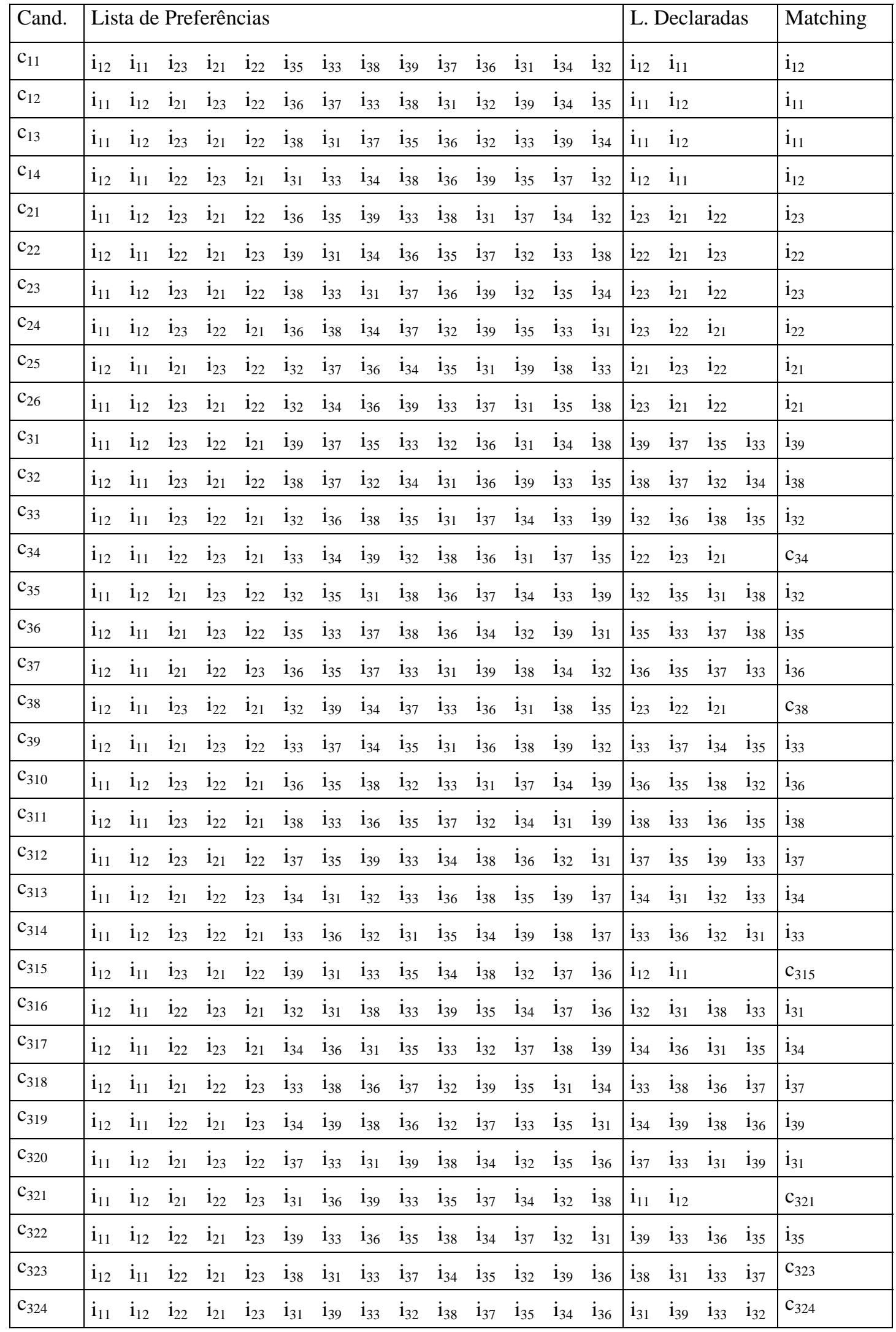




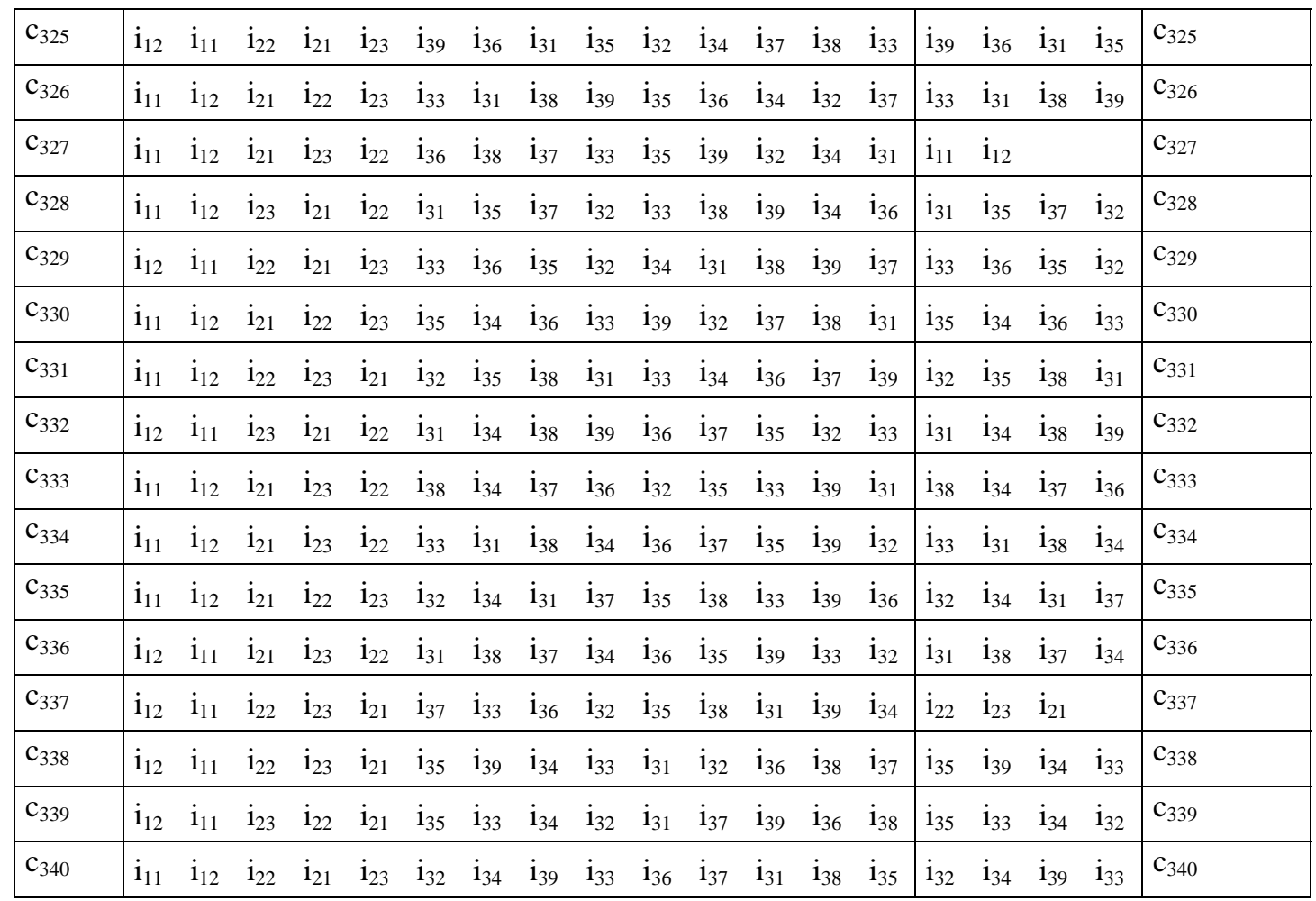


Tabela C14 - Matching $\mu_{2 E}$

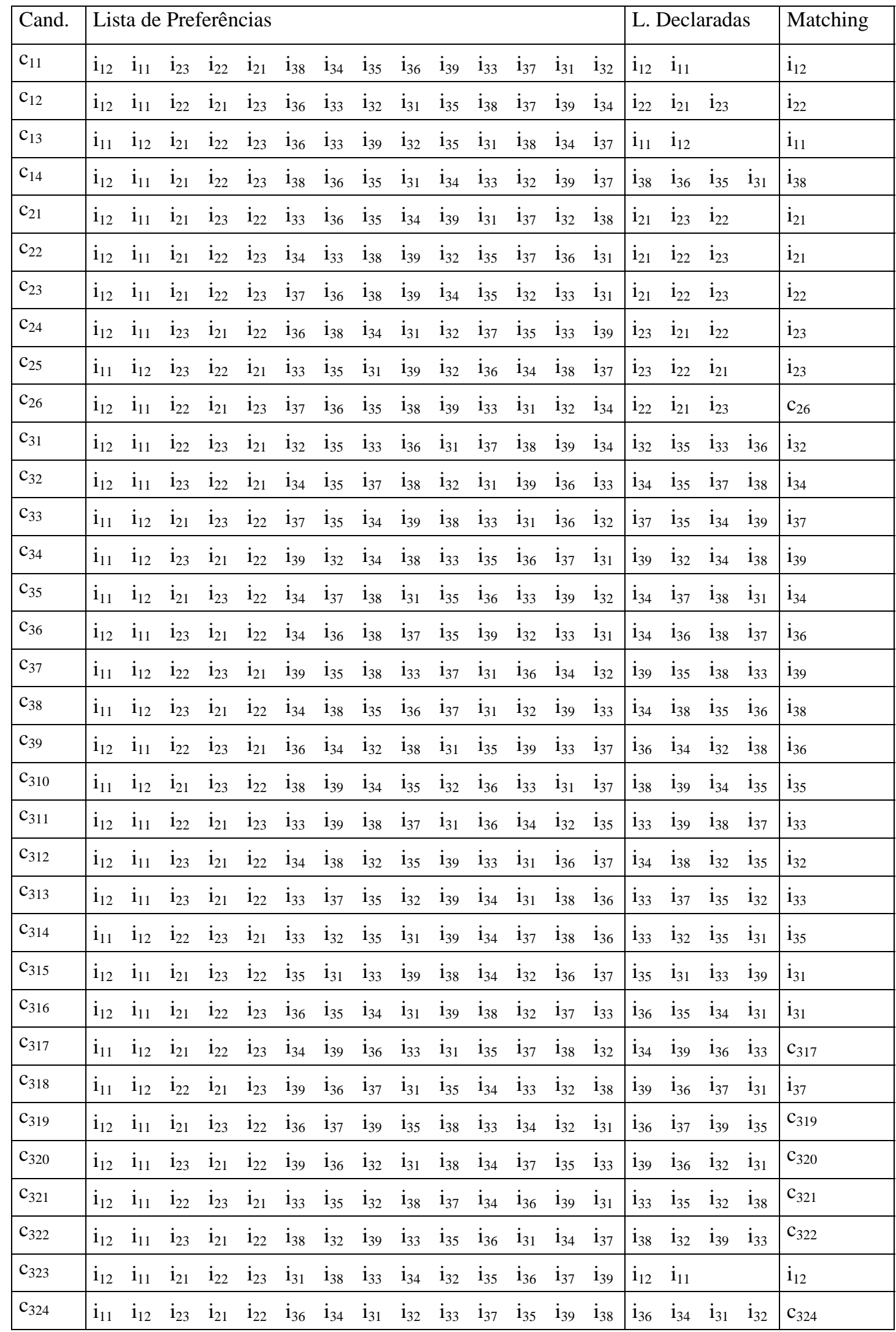




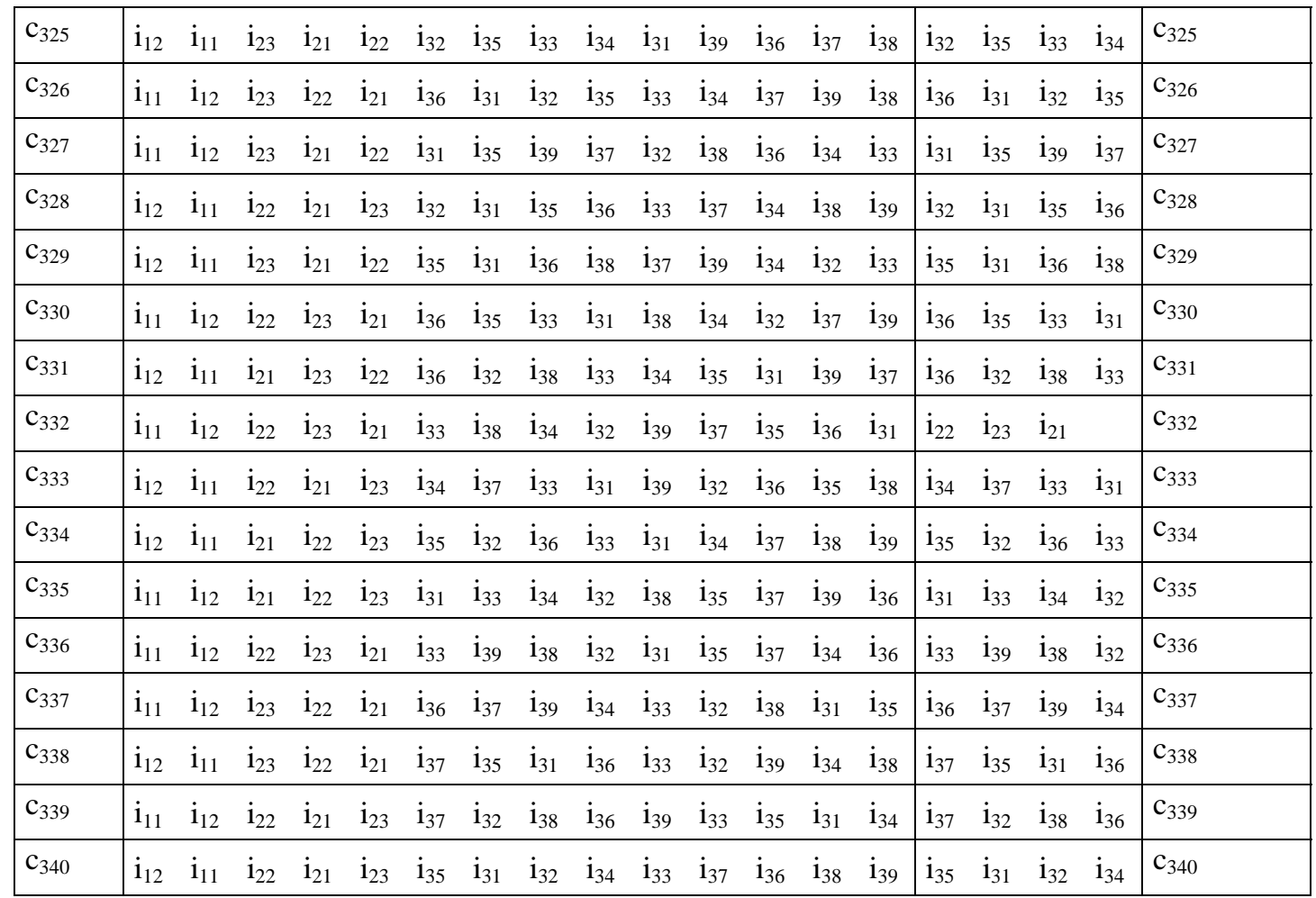


Tabela C15 - Matching $\mu_{2 \mathrm{G}}$

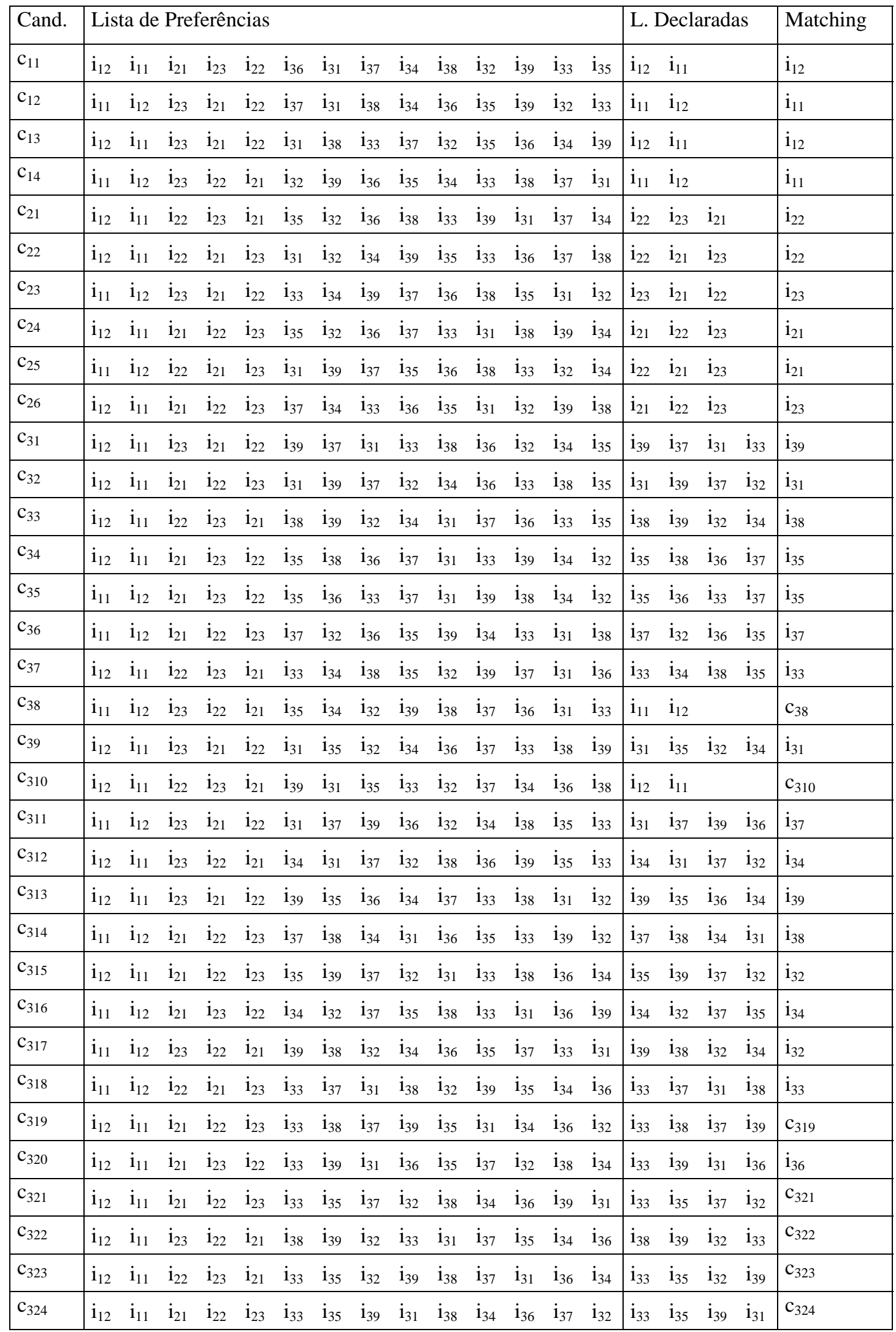




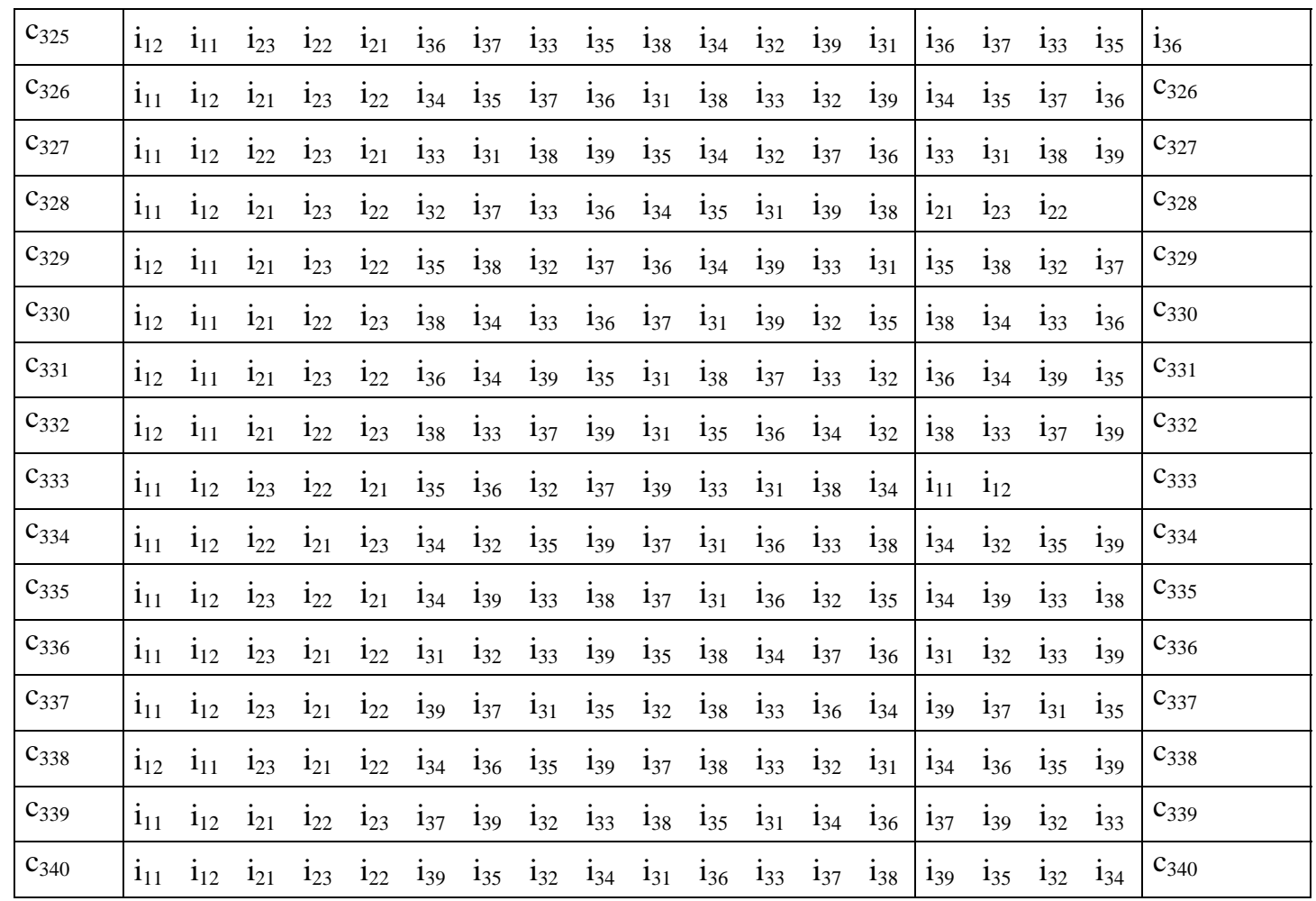


Tabela C16 - Matching $\mu_{2 \mathrm{H}}$

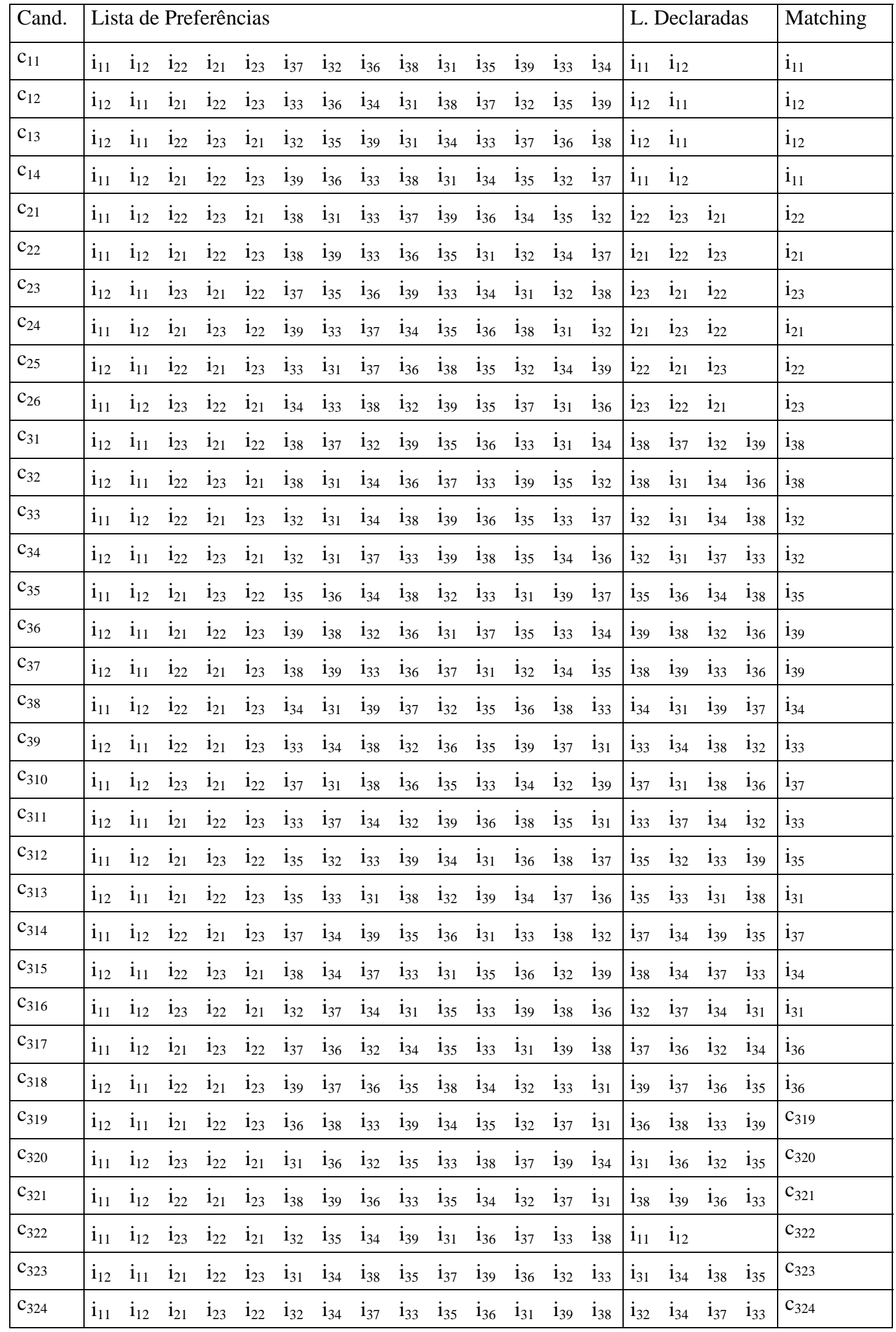




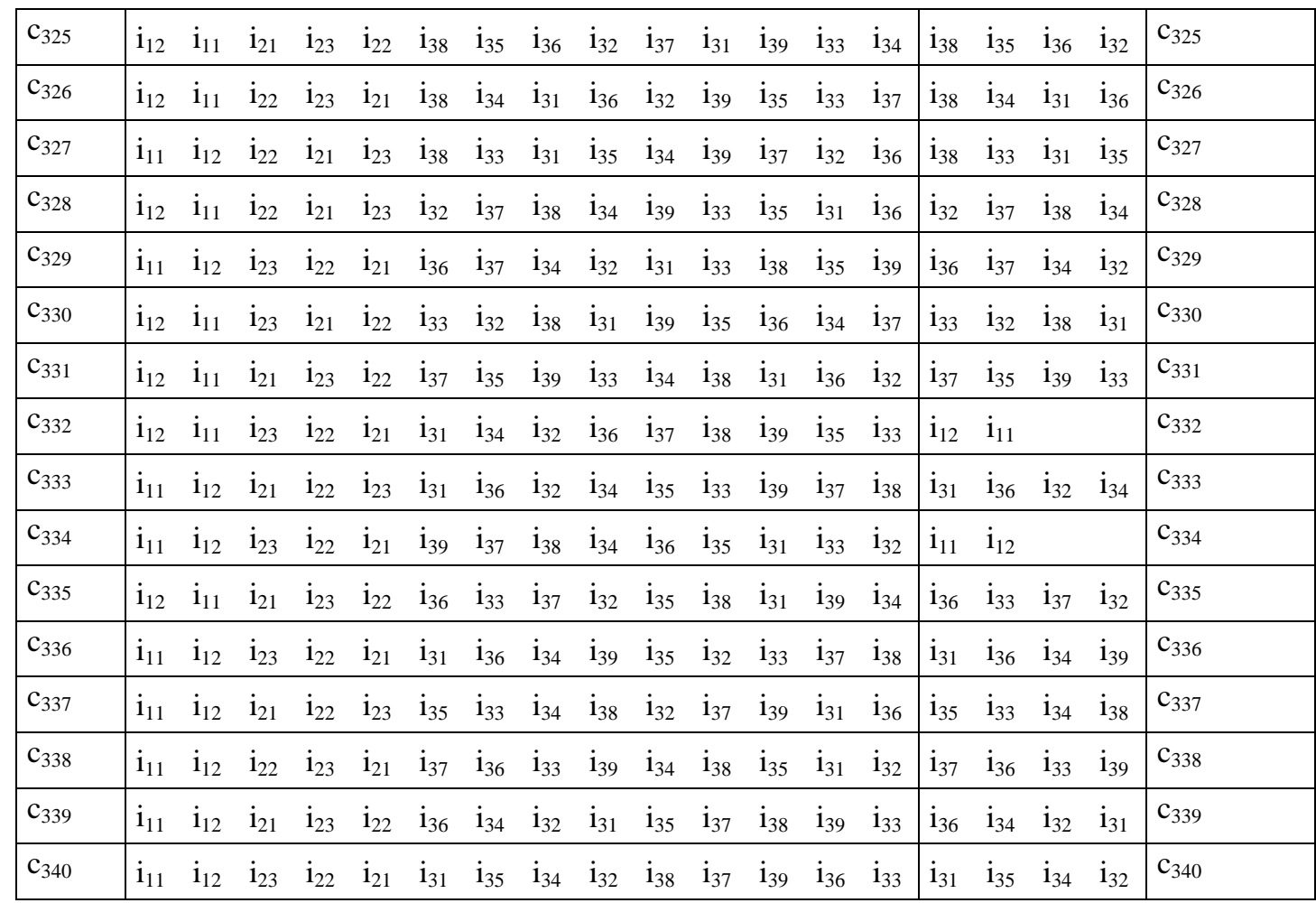


Tabela C17 - Matching $\mu_{2 \mathrm{I}}$

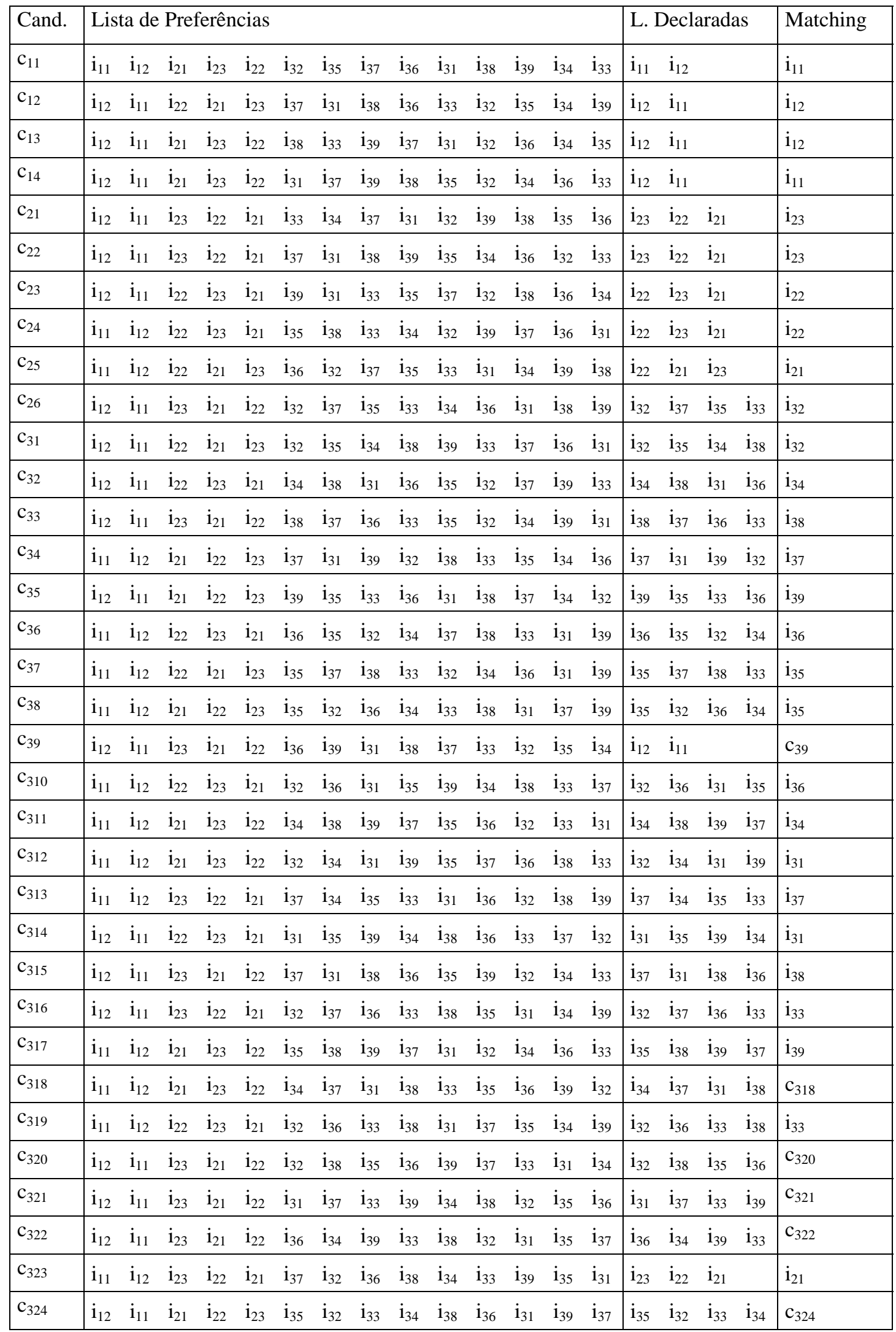




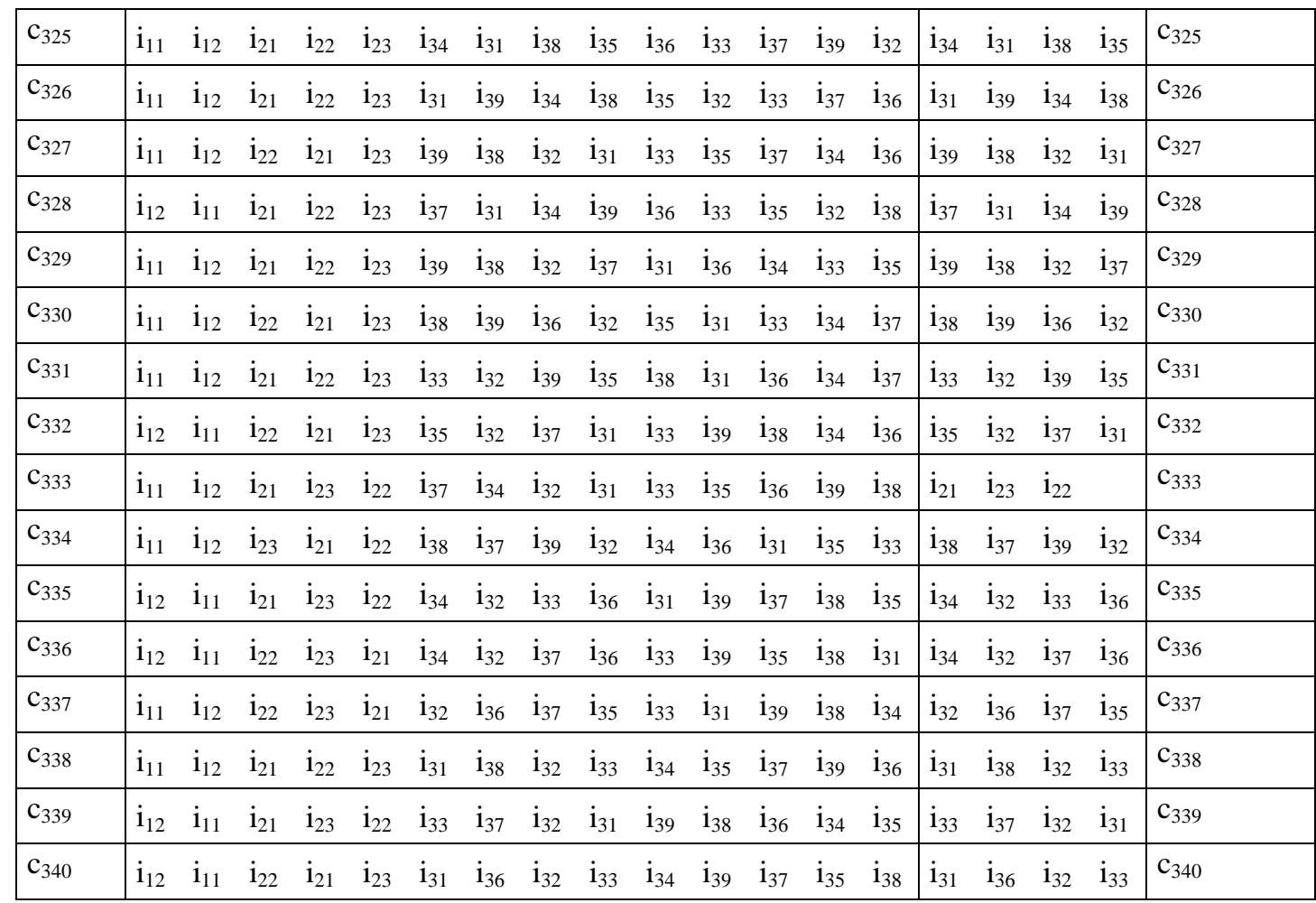


Tabela C18 - Matching $\mu_{2 \mathrm{~J}}$

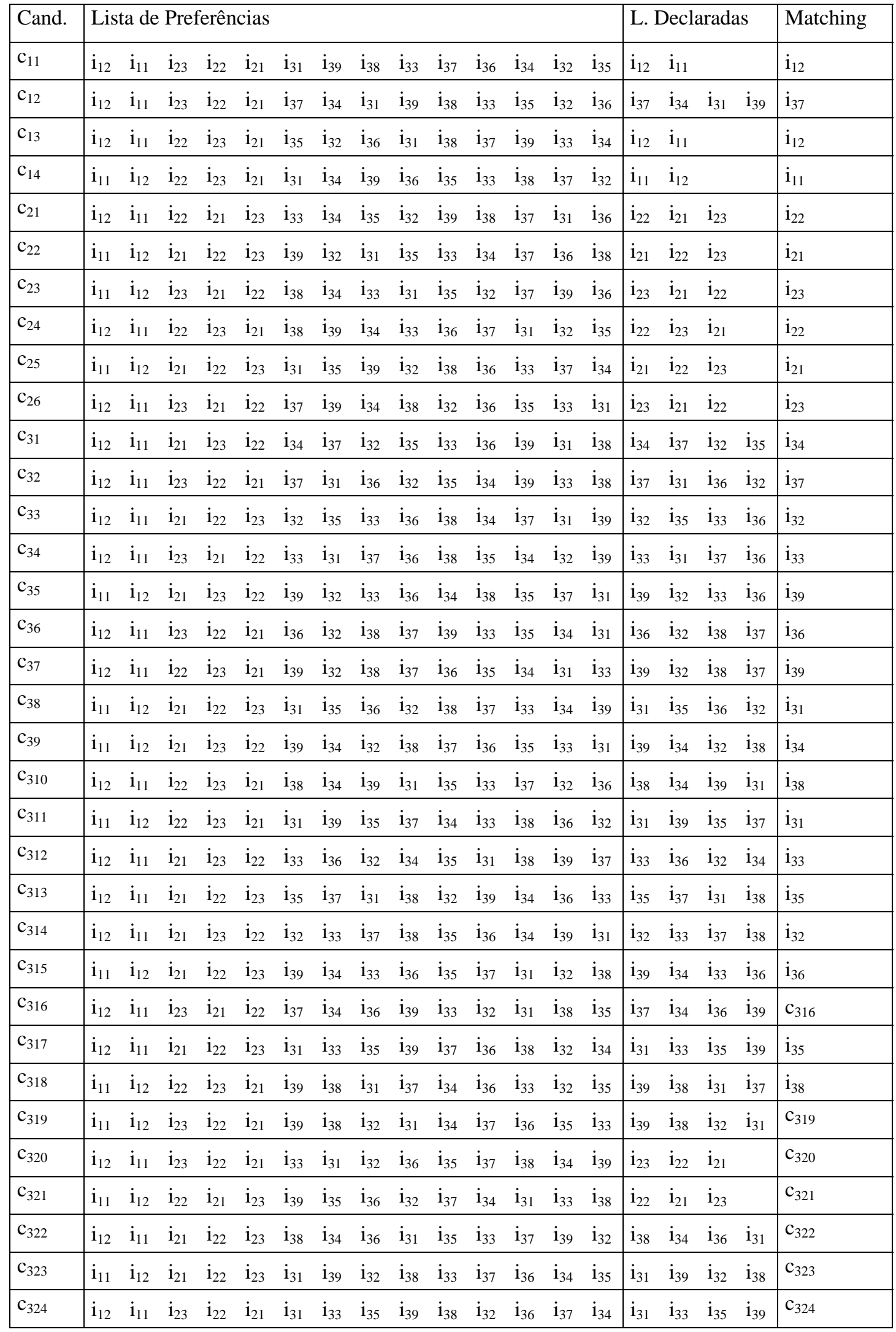




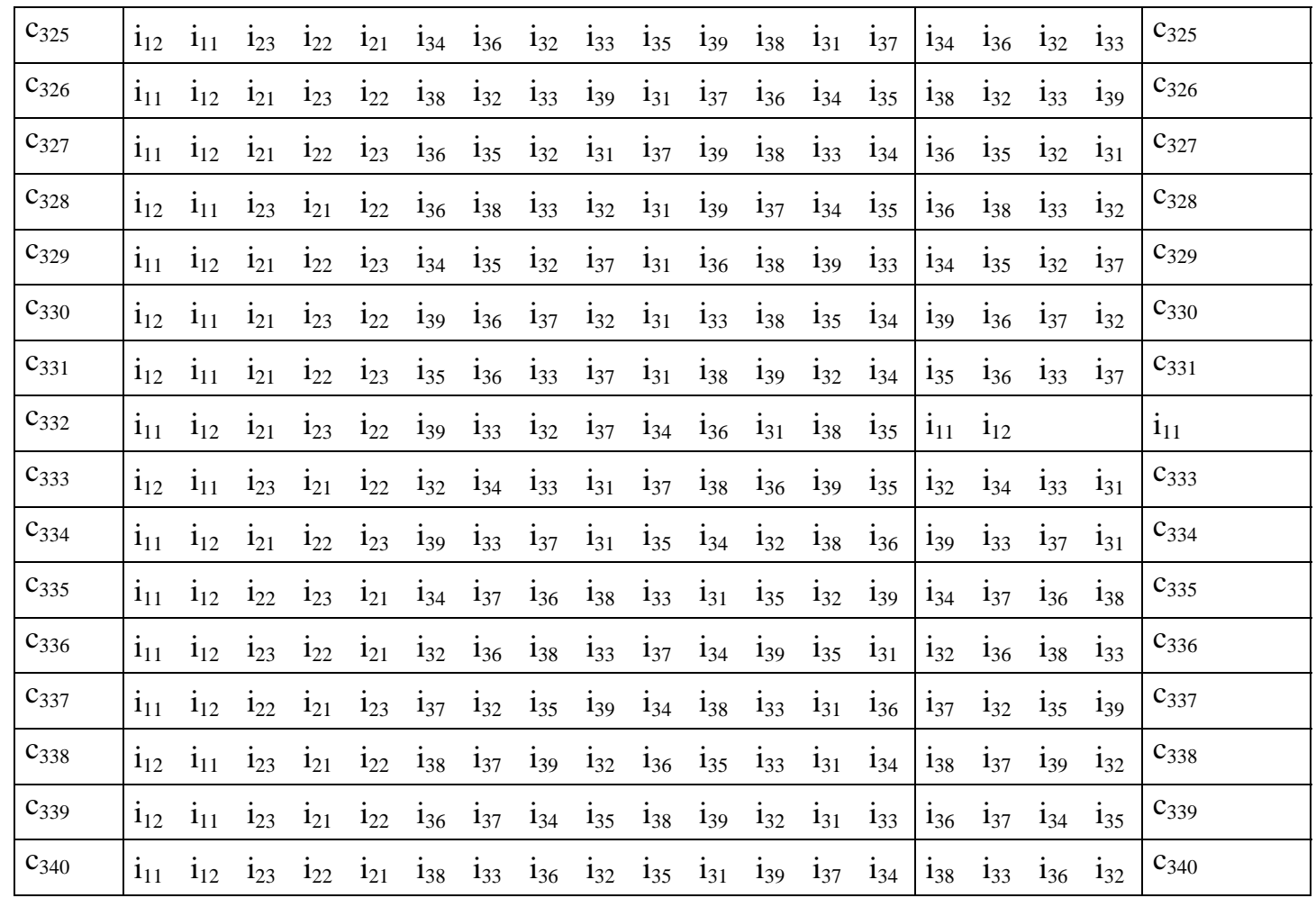


Tabela C19 - Matching $\mu_{3 \mathrm{~A}}$

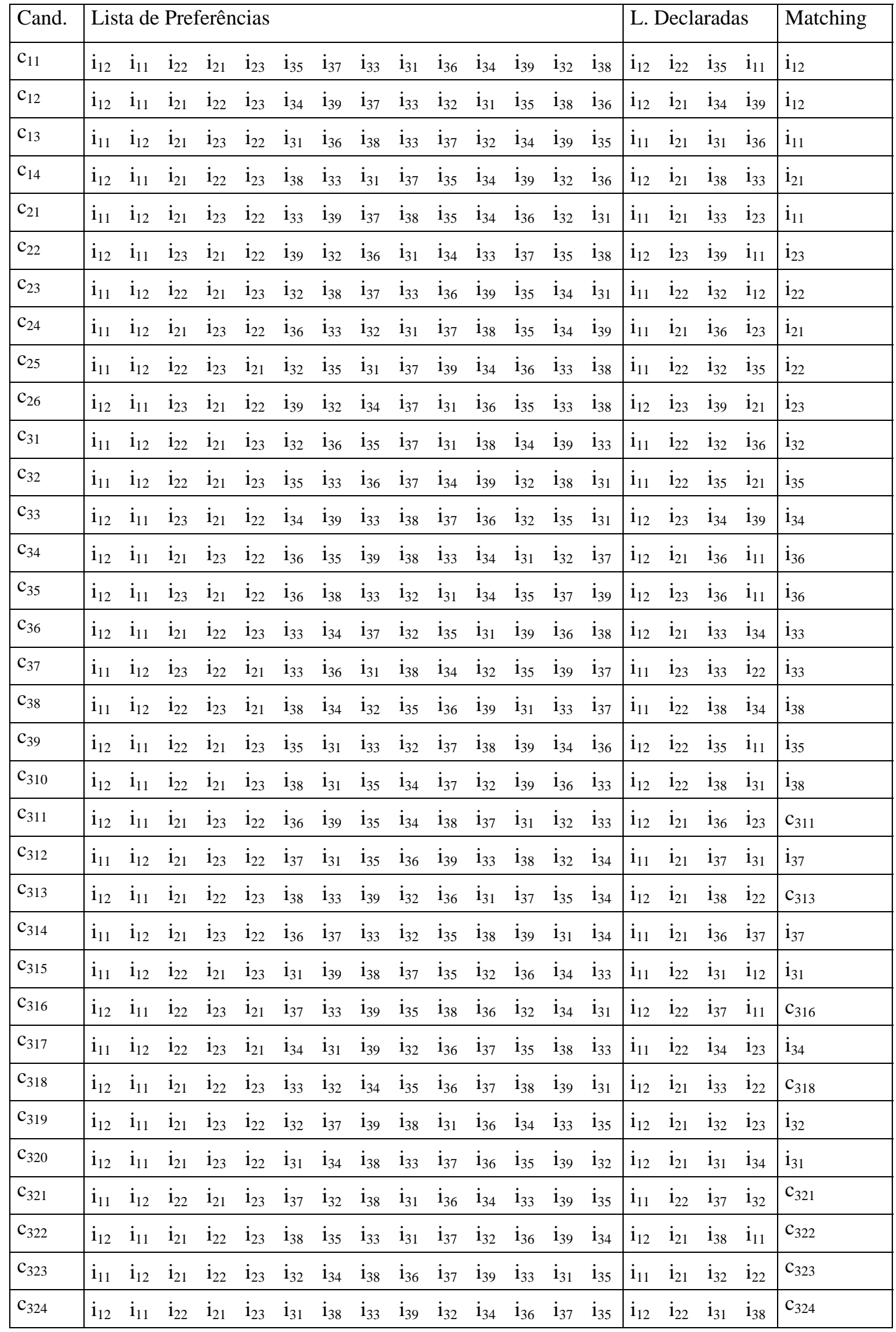




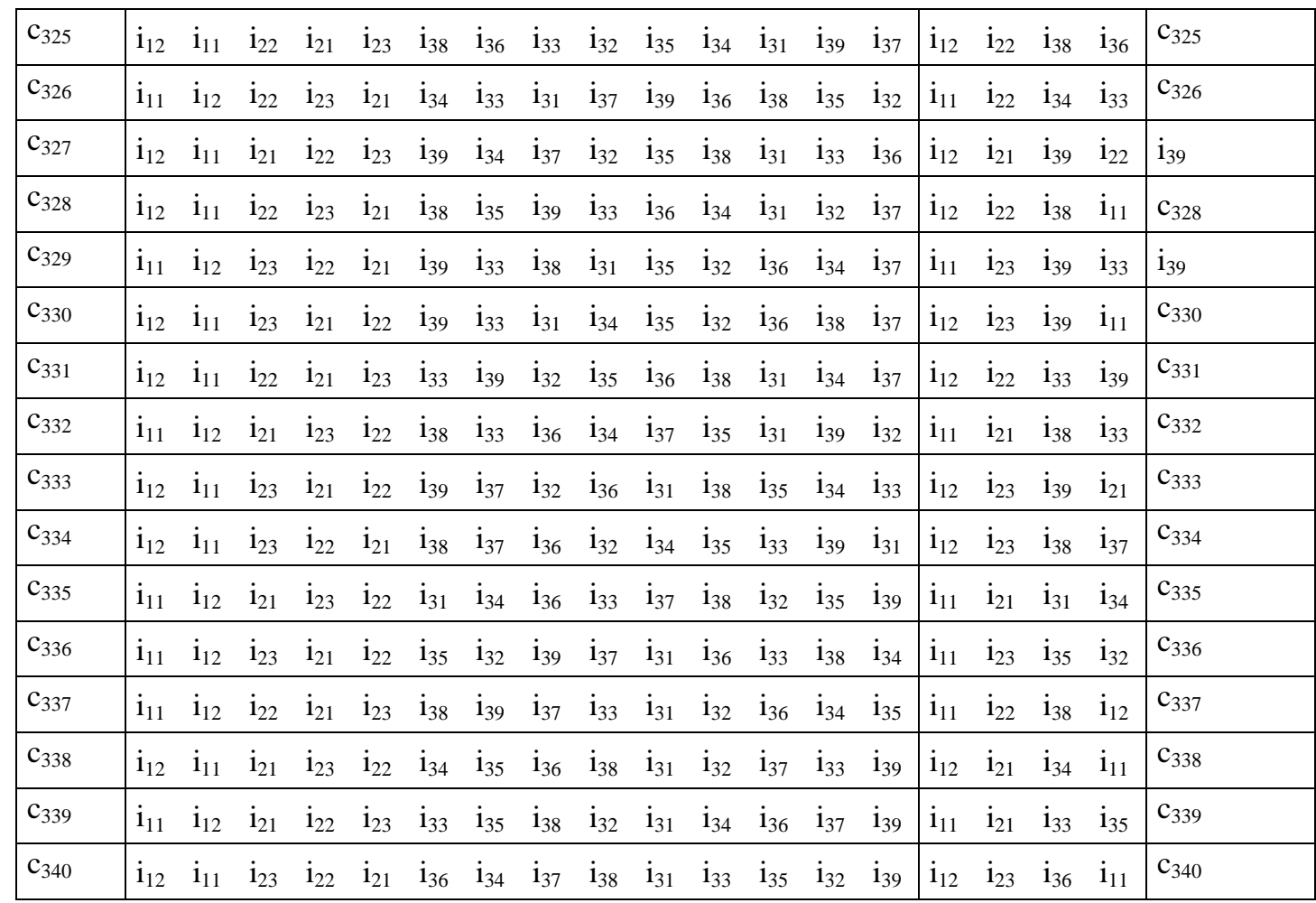


Tabela C20 - Matching $\mu_{3 \mathrm{~B}}$

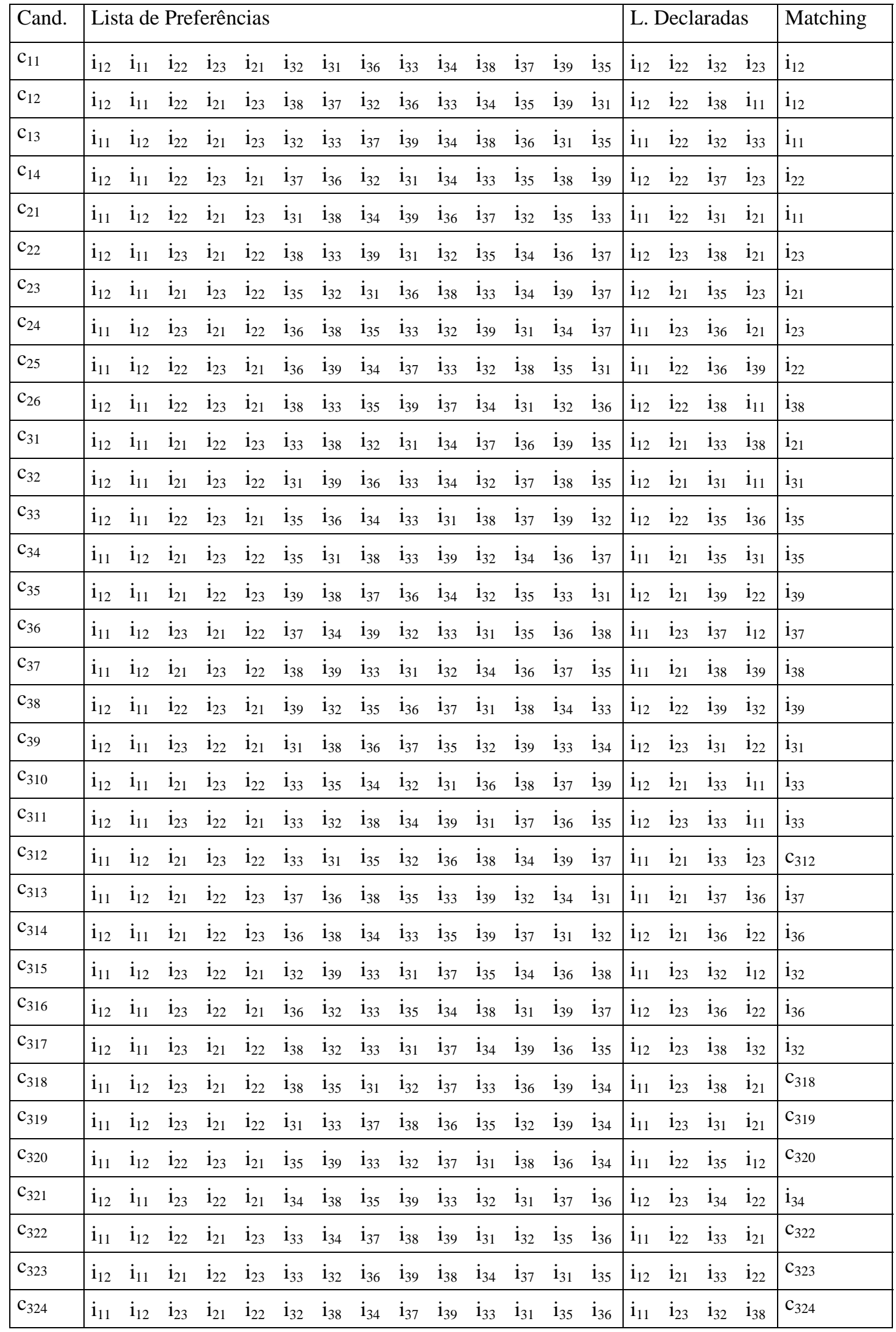




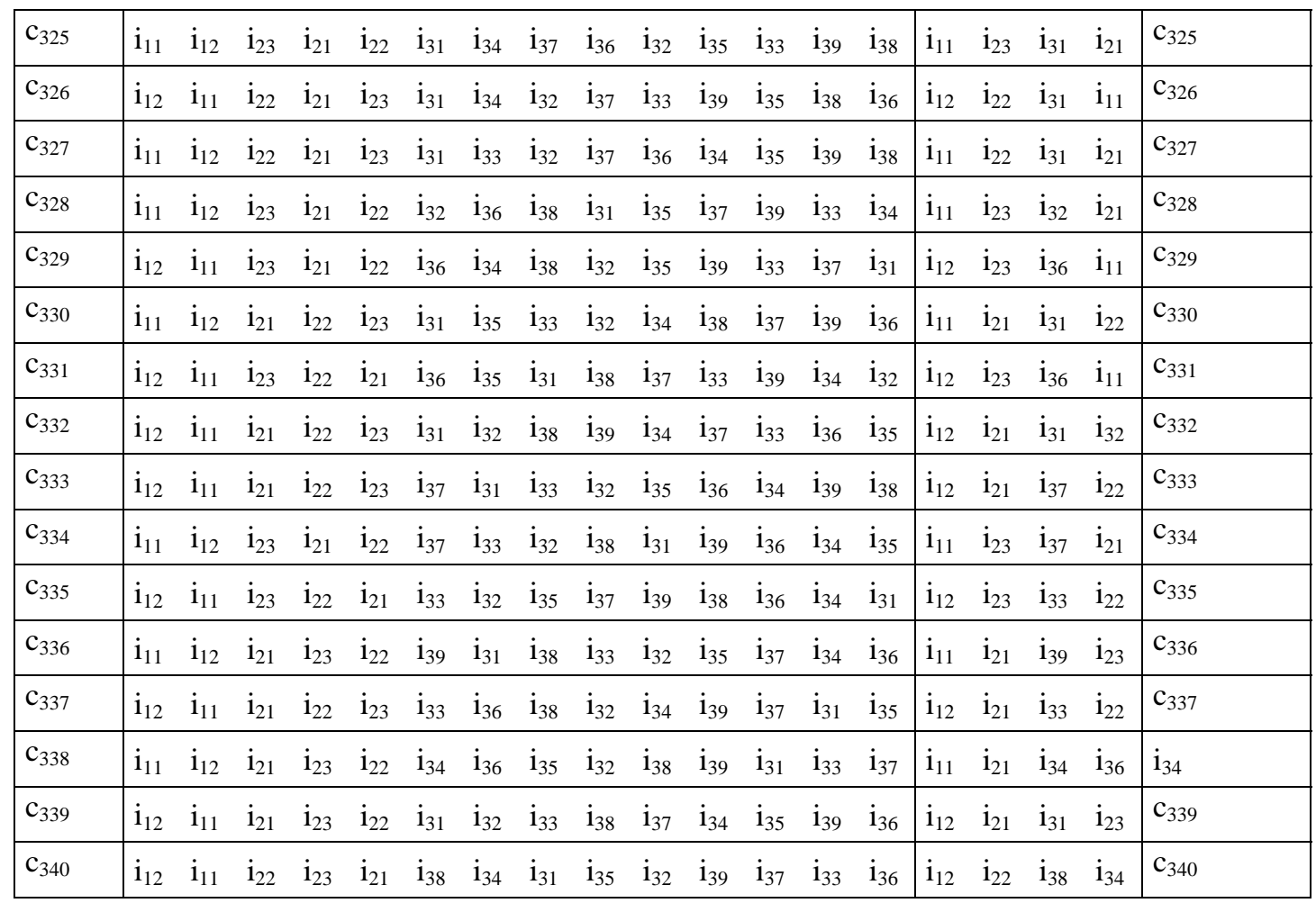


Tabela C21 - Matching $\mu_{3 \mathrm{C}}$

\begin{tabular}{|c|c|c|c|}
\hline Cand. & Lista de Preferências & L. Declaradas & Matching \\
\hline $\mathrm{C}_{11}$ & 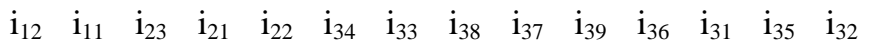 & $\mathrm{i}_{12} \quad \mathrm{i}_{23} \quad \mathrm{i}_{34} \quad \mathrm{i}_{21}$ & $i_{12}$ \\
\hline $\mathrm{C}_{12}$ & $\begin{array}{llllllllllllll}\mathrm{i}_{11} & \mathrm{i}_{12} & \mathrm{i}_{21} & \mathrm{i}_{22} & \mathrm{i}_{23} & \mathrm{i}_{35} & \mathrm{i}_{37} & \mathrm{i}_{31} & \mathrm{i}_{32} & \mathrm{i}_{39} & \mathrm{i}_{38} & \mathrm{i}_{33} & \mathrm{i}_{36} & \mathrm{i}_{34}\end{array}$ & $\mathrm{i}_{11} \quad \mathrm{i}_{21} \quad \mathrm{i}_{35} \quad \mathrm{i}_{12}$ & $\mathrm{i}_{11}$ \\
\hline $\mathrm{C}_{13}$ & $\begin{array}{llllllllllllll}\mathrm{i}_{12} & \mathrm{i}_{11} & \mathrm{i}_{23} & \mathrm{i}_{21} & \mathrm{i}_{22} & \mathrm{i}_{32} & \mathrm{i}_{35} & \mathrm{i}_{39} & \mathrm{i}_{33} & \mathrm{i}_{36} & \mathrm{i}_{38} & \mathrm{i}_{31} & \mathrm{i}_{37} & \mathrm{i}_{34}\end{array}$ & $\mathrm{i}_{12} \quad \mathrm{i}_{23} \quad \mathrm{i}_{32} \quad \mathrm{i}_{21}$ & $\mathrm{i}_{12}$ \\
\hline $\mathrm{C}_{14}$ & $\begin{array}{llllllllllllll}\mathrm{i}_{12} & \mathrm{i}_{11} & \mathrm{i}_{22} & \mathrm{i}_{23} & \mathrm{i}_{21} & \mathrm{i}_{35} & \mathrm{i}_{33} & \mathrm{i}_{32} & \mathrm{i}_{38} & \mathrm{i}_{36} & \mathrm{i}_{37} & \mathrm{i}_{34} & \mathrm{i}_{39} & \mathrm{i}_{31}\end{array}$ & $\mathrm{i}_{12} \quad \mathrm{i}_{22} \quad \mathrm{i}_{35} \quad \mathrm{i}_{11}$ & $i_{11}$ \\
\hline $\mathrm{C}_{21}$ & $\begin{array}{llllllllllllll}\mathrm{i}_{11} & \mathrm{i}_{12} & \mathrm{i}_{23} & \mathrm{i}_{21} & \mathrm{i}_{22} & \mathrm{i}_{39} & \mathrm{i}_{37} & \mathrm{i}_{38} & \mathrm{i}_{34} & \mathrm{i}_{35} & \mathrm{i}_{33} & \mathrm{i}_{31} & \mathrm{i}_{32} & \mathrm{i}_{36}\end{array}$ & $\mathrm{i}_{11} \quad \mathrm{i}_{23} \quad \mathrm{i}_{39} \quad \mathrm{i}_{21}$ & $\mathrm{i}_{23}$ \\
\hline $\mathrm{C}_{22}$ & $\begin{array}{llllllllllllll}\mathrm{i}_{11} & \mathrm{i}_{12} & \mathrm{i}_{21} & \mathrm{i}_{22} & \mathrm{i}_{23} & \mathrm{i}_{36} & \mathrm{i}_{35} & \mathrm{i}_{34} & \mathrm{i}_{32} & \mathrm{i}_{31} & \mathrm{i}_{33} & \mathrm{i}_{39} & \mathrm{i}_{38} & \mathrm{i}_{37}\end{array}$ & $\mathrm{i}_{11} \quad \mathrm{i}_{21} \quad \mathrm{i}_{36} \quad \mathrm{i}_{35}$ & $\mathrm{i}_{21}$ \\
\hline $\mathrm{C}_{23}$ & $\begin{array}{llllllllllllll}\mathrm{i}_{12} & \mathrm{i}_{11} & \mathrm{i}_{23} & \mathrm{i}_{21} & \mathrm{i}_{22} & \mathrm{i}_{37} & \mathrm{i}_{36} & \mathrm{i}_{34} & \mathrm{i}_{39} & \mathrm{i}_{31} & \mathrm{i}_{35} & \mathrm{i}_{33} & \mathrm{i}_{38} & \mathrm{i}_{32}\end{array}$ & $\mathrm{i}_{12} \quad \mathrm{i}_{23} \quad \mathrm{i}_{37} \quad \mathrm{i}_{11}$ & $\mathrm{i}_{23}$ \\
\hline $\mathrm{C}_{24}$ & $\begin{array}{llllllllllllll}\mathrm{i}_{12} & \mathrm{i}_{11} & \mathrm{i}_{23} & \mathrm{i}_{21} & \mathrm{i}_{22} & \mathrm{i}_{35} & \mathrm{i}_{37} & \mathrm{i}_{39} & \mathrm{i}_{32} & \mathrm{i}_{33} & \mathrm{i}_{31} & \mathrm{i}_{36} & \mathrm{i}_{38} & \mathrm{i}_{34}\end{array}$ & $\mathrm{i}_{12} \quad \mathrm{i}_{23} \quad \mathrm{i}_{35} \quad \mathrm{i}_{21}$ & $\mathrm{i}_{21}$ \\
\hline $\mathrm{C}_{25}$ & 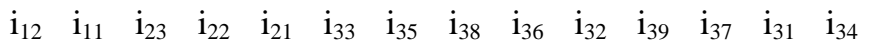 & $\mathrm{i}_{12} \quad \mathrm{i}_{23} \quad \mathrm{i}_{33} \quad \mathrm{i}_{22}$ & $\mathrm{i}_{22}$ \\
\hline $\mathrm{C}_{26}$ & $\begin{array}{llllllllllllll}\mathrm{i}_{11} & \mathrm{i}_{12} & \mathrm{i}_{23} & \mathrm{i}_{21} & \mathrm{i}_{22} & \mathrm{i}_{39} & \mathrm{i}_{33} & \mathrm{i}_{37} & \mathrm{i}_{31} & \mathrm{i}_{35} & \mathrm{i}_{34} & \mathrm{i}_{38} & \mathrm{i}_{36} & \mathrm{i}_{32}\end{array}$ & $\mathrm{i}_{11} \quad \mathrm{i}_{23} \quad \mathrm{i}_{39} \quad \mathrm{i}_{21}$ & $i_{39}$ \\
\hline $\mathrm{C}_{31}$ & $\begin{array}{llllllllllllll}\mathrm{i}_{11} & \mathrm{i}_{12} & \mathrm{i}_{23} & \mathrm{i}_{22} & \mathrm{i}_{21} & \mathrm{i}_{33} & \mathrm{i}_{39} & \mathrm{i}_{32} & \mathrm{i}_{36} & \mathrm{i}_{34} & \mathrm{i}_{35} & \mathrm{i}_{37} & \mathrm{i}_{38} & \mathrm{i}_{31}\end{array}$ & $\begin{array}{llll}\mathrm{i}_{11} & \mathrm{i}_{23} & \mathrm{i}_{33} & \mathrm{i}_{12}\end{array}$ & $i_{33}$ \\
\hline $\mathrm{C}_{32}$ & $\begin{array}{llllllllllllll}\mathrm{i}_{12} & \mathrm{i}_{11} & \mathrm{i}_{23} & \mathrm{i}_{22} & \mathrm{i}_{21} & \mathrm{i}_{32} & \mathrm{i}_{36} & \mathrm{i}_{39} & \mathrm{i}_{37} & \mathrm{i}_{31} & \mathrm{i}_{38} & \mathrm{i}_{33} & \mathrm{i}_{34} & \mathrm{i}_{35}\end{array}$ & $\mathrm{i}_{12} \quad \mathrm{i}_{23} \quad \mathrm{i}_{32} \quad \mathrm{i}_{22}$ & $i_{22}$ \\
\hline $\mathrm{C}_{33}$ & $\begin{array}{llllllllllllll}\mathrm{i}_{12} & \mathrm{i}_{11} & \mathrm{i}_{21} & \mathrm{i}_{22} & \mathrm{i}_{23} & \mathrm{i}_{33} & \mathrm{i}_{38} & \mathrm{i}_{37} & \mathrm{i}_{32} & \mathrm{i}_{36} & \mathrm{i}_{39} & \mathrm{i}_{35} & \mathrm{i}_{34} & \mathrm{i}_{31}\end{array}$ & $\mathrm{i}_{12} \quad \mathrm{i}_{21} \quad \mathrm{i}_{33} \quad \mathrm{i}_{11}$ & $\mathrm{i}_{33}$ \\
\hline $\mathrm{C}_{34}$ & $\begin{array}{llllllllllllll}\mathrm{i}_{12} & \mathrm{i}_{11} & \mathrm{i}_{22} & \mathrm{i}_{21} & \mathrm{i}_{23} & \mathrm{i}_{39} & \mathrm{i}_{32} & \mathrm{i}_{34} & \mathrm{i}_{31} & \mathrm{i}_{33} & \mathrm{i}_{38} & \mathrm{i}_{37} & \mathrm{i}_{35} & \mathrm{i}_{36}\end{array}$ & $\mathrm{i}_{12} \quad \mathrm{i}_{22} \quad \mathrm{i}_{39} \quad \mathrm{i}_{21}$ & $i_{39}$ \\
\hline $\mathrm{C}_{35}$ & $\begin{array}{llllllllllllll}\mathrm{i}_{11} & \mathrm{i}_{12} & \mathrm{i}_{21} & \mathrm{i}_{22} & \mathrm{i}_{23} & \mathrm{i}_{35} & \mathrm{i}_{32} & \mathrm{i}_{38} & \mathrm{i}_{33} & \mathrm{i}_{36} & \mathrm{i}_{31} & \mathrm{i}_{39} & \mathrm{i}_{34} & \mathrm{i}_{37}\end{array}$ & $\mathrm{i}_{11} \quad \mathrm{i}_{21} \quad \mathrm{i}_{35} \quad \mathrm{i}_{32}$ & $i_{35}$ \\
\hline $\mathrm{C}_{36}$ & $\begin{array}{llllllllllllll}\mathrm{i}_{11} & \mathrm{i}_{12} & \mathrm{i}_{22} & \mathrm{i}_{21} & \mathrm{i}_{23} & \mathrm{i}_{36} & \mathrm{i}_{38} & \mathrm{i}_{31} & \mathrm{i}_{37} & \mathrm{i}_{34} & \mathrm{i}_{32} & \mathrm{i}_{35} & \mathrm{i}_{39} & \mathrm{i}_{33}\end{array}$ & $\mathrm{i}_{11} \quad \mathrm{i}_{22} \quad \mathrm{i}_{36} \quad \mathrm{i}_{21}$ & $\mathrm{i}_{36}$ \\
\hline $\mathrm{C}_{37}$ & $\begin{array}{llllllllllllll}\mathrm{i}_{12} & \mathrm{i}_{11} & \mathrm{i}_{21} & \mathrm{i}_{23} & \mathrm{i}_{22} & \mathrm{i}_{31} & \mathrm{i}_{36} & \mathrm{i}_{32} & \mathrm{i}_{35} & \mathrm{i}_{38} & \mathrm{i}_{33} & \mathrm{i}_{34} & \mathrm{i}_{39} & \mathrm{i}_{37}\end{array}$ & $\mathrm{i}_{12} \quad \mathrm{i}_{21} \quad \mathrm{i}_{31} \quad \mathrm{i}_{23}$ & $i_{31}$ \\
\hline $\mathrm{C}_{38}$ & $\begin{array}{llllllllllllll}\mathrm{i}_{12} & \mathrm{i}_{11} & \mathrm{i}_{23} & \mathrm{i}_{21} & \mathrm{i}_{22} & \mathrm{i}_{39} & \mathrm{i}_{37} & \mathrm{i}_{31} & \mathrm{i}_{34} & \mathrm{i}_{35} & \mathrm{i}_{38} & \mathrm{i}_{33} & \mathrm{i}_{32} & \mathrm{i}_{36}\end{array}$ & $\mathrm{i}_{12} \quad \mathrm{i}_{23} \quad \mathrm{i}_{39} \quad \mathrm{i}_{37}$ & $i_{37}$ \\
\hline $\mathrm{C}_{39}$ & $\begin{array}{llllllllllllll}\mathrm{i}_{12} & \mathrm{i}_{11} & \mathrm{i}_{21} & \mathrm{i}_{23} & \mathrm{i}_{22} & \mathrm{i}_{39} & \mathrm{i}_{32} & \mathrm{i}_{38} & \mathrm{i}_{34} & \mathrm{i}_{33} & \mathrm{i}_{35} & \mathrm{i}_{37} & \mathrm{i}_{36} & \mathrm{i}_{31}\end{array}$ & $\mathrm{i}_{12} \quad \mathrm{i}_{21} \quad \mathrm{i}_{39} \quad \mathrm{i}_{11}$ & $\mathrm{C}_{39}$ \\
\hline $\mathrm{C}_{310}$ & $\begin{array}{llllllllllllll}\mathrm{i}_{11} & \mathrm{i}_{12} & \mathrm{i}_{23} & \mathrm{i}_{21} & \mathrm{i}_{22} & \mathrm{i}_{37} & \mathrm{i}_{31} & \mathrm{i}_{38} & \mathrm{i}_{33} & \mathrm{i}_{35} & \mathrm{i}_{32} & \mathrm{i}_{39} & \mathrm{i}_{36} & \mathrm{i}_{34}\end{array}$ & $\mathrm{i}_{11} \quad \mathrm{i}_{23} \quad \mathrm{i}_{37} \quad \mathrm{i}_{21}$ & $i_{37}$ \\
\hline $\mathrm{C}_{311}$ & $\begin{array}{llllllllllllll}\mathrm{i}_{12} & \mathrm{i}_{11} & \mathrm{i}_{21} & \mathrm{i}_{22} & \mathrm{i}_{23} & \mathrm{i}_{39} & \mathrm{i}_{34} & \mathrm{i}_{31} & \mathrm{i}_{36} & \mathrm{i}_{33} & \mathrm{i}_{35} & \mathrm{i}_{32} & \mathrm{i}_{38} & \mathrm{i}_{37}\end{array}$ & $\mathrm{i}_{12} \quad \mathrm{i}_{21} \quad \mathrm{i}_{39} \quad \mathrm{i}_{22}$ & $\mathrm{C}_{311}$ \\
\hline $\mathrm{C}_{312}$ & $\begin{array}{llllllllllllll}\mathrm{i}_{11} & \mathrm{i}_{12} & \mathrm{i}_{21} & \mathrm{i}_{23} & \mathrm{i}_{22} & \mathrm{i}_{31} & \mathrm{i}_{39} & \mathrm{i}_{37} & \mathrm{i}_{32} & \mathrm{i}_{33} & \mathrm{i}_{38} & \mathrm{i}_{35} & \mathrm{i}_{34} & \mathrm{i}_{36}\end{array}$ & $\mathrm{i}_{11} \quad \mathrm{i}_{21} \quad \mathrm{i}_{31} \quad \mathrm{i}_{23}$ & $i_{31}$ \\
\hline $\mathrm{C}_{313}$ & $\begin{array}{llllllllllllll}\mathrm{i}_{12} & \mathrm{i}_{11} & \mathrm{i}_{21} & \mathrm{i}_{23} & \mathrm{i}_{22} & \mathrm{i}_{34} & \mathrm{i}_{36} & \mathrm{i}_{35} & \mathrm{i}_{39} & \mathrm{i}_{37} & \mathrm{i}_{32} & \mathrm{i}_{38} & \mathrm{i}_{33} & \mathrm{i}_{31}\end{array}$ & $\mathrm{i}_{12} \quad \mathrm{i}_{21} \quad \mathrm{i}_{34} \quad \mathrm{i}_{36}$ & $\mathrm{i}_{34}$ \\
\hline $\mathrm{C}_{314}$ & $\begin{array}{llllllllllllll}\mathrm{i}_{12} & \mathrm{i}_{11} & \mathrm{i}_{21} & \mathrm{i}_{22} & \mathrm{i}_{23} & \mathrm{i}_{39} & \mathrm{i}_{36} & \mathrm{i}_{33} & \mathrm{i}_{34} & \mathrm{i}_{38} & \mathrm{i}_{31} & \mathrm{i}_{37} & \mathrm{i}_{32} & \mathrm{i}_{35}\end{array}$ & $\mathrm{i}_{12} \quad \mathrm{i}_{21} \quad \mathrm{i}_{39} \quad \mathrm{i}_{11}$ & $\mathrm{C}_{314}$ \\
\hline $\mathrm{C}_{315}$ & $\begin{array}{llllllllllllll}\mathrm{i}_{12} & \mathrm{i}_{11} & \mathrm{i}_{22} & \mathrm{i}_{21} & \mathrm{i}_{23} & \mathrm{i}_{36} & \mathrm{i}_{31} & \mathrm{i}_{39} & \mathrm{i}_{35} & \mathrm{i}_{33} & \mathrm{i}_{34} & \mathrm{i}_{37} & \mathrm{i}_{32} & \mathrm{i}_{38}\end{array}$ & $\mathrm{i}_{12} \quad \mathrm{i}_{22} \quad \mathrm{i}_{36} \quad \mathrm{i}_{11}$ & $\mathrm{i}_{36}$ \\
\hline $\mathrm{C}_{316}$ & $\begin{array}{llllllllllllll}\mathrm{i}_{12} & \mathrm{i}_{11} & \mathrm{i}_{22} & \mathrm{i}_{21} & \mathrm{i}_{23} & \mathrm{i}_{34} & \mathrm{i}_{31} & \mathrm{i}_{32} & \mathrm{i}_{35} & \mathrm{i}_{38} & \mathrm{i}_{39} & \mathrm{i}_{37} & \mathrm{i}_{33} & \mathrm{i}_{36}\end{array}$ & $\mathrm{i}_{12} \quad \mathrm{i}_{22} \quad \mathrm{i}_{34} \quad \mathrm{i}_{11}$ & $\mathrm{i}_{34}$ \\
\hline $\mathrm{C}_{317}$ & $\begin{array}{llllllllllllll}\mathrm{i}_{11} & \mathrm{i}_{12} & \mathrm{i}_{23} & \mathrm{i}_{21} & \mathrm{i}_{22} & \mathrm{i}_{34} & \mathrm{i}_{31} & \mathrm{i}_{32} & \mathrm{i}_{33} & \mathrm{i}_{38} & \mathrm{i}_{36} & \mathrm{i}_{37} & \mathrm{i}_{39} & \mathrm{i}_{35}\end{array}$ & $\begin{array}{llll}\mathrm{i}_{11} & \mathrm{i}_{23} & \mathrm{i}_{34} & \mathrm{i}_{31} \\
\end{array}$ & $\mathrm{C}_{317}$ \\
\hline $\mathrm{C}_{318}$ & $\begin{array}{llllllllllllll}\mathrm{i}_{11} & \mathrm{i}_{12} & \mathrm{i}_{23} & \mathrm{i}_{21} & \mathrm{i}_{22} & \mathrm{i}_{32} & \mathrm{i}_{38} & \mathrm{i}_{39} & \mathrm{i}_{31} & \mathrm{i}_{37} & \mathrm{i}_{36} & \mathrm{i}_{34} & \mathrm{i}_{35} & \mathrm{i}_{33}\end{array}$ & $\mathrm{i}_{11} \quad \mathrm{i}_{23} \quad \mathrm{i}_{32} \quad \mathrm{i}_{21}$ & $\mathrm{i}_{32}$ \\
\hline $\mathrm{C}_{319}$ & $\begin{array}{llllllllllllll}\mathrm{i}_{12} & \mathrm{i}_{11} & \mathrm{i}_{23} & \mathrm{i}_{21} & \mathrm{i}_{22} & \mathrm{i}_{33} & \mathrm{i}_{31} & \mathrm{i}_{34} & \mathrm{i}_{36} & \mathrm{i}_{39} & \mathrm{i}_{37} & \mathrm{i}_{38} & \mathrm{i}_{32} & \mathrm{i}_{35}\end{array}$ & $\mathrm{i}_{12} \quad \mathrm{i}_{23} \quad \mathrm{i}_{33} \quad \mathrm{i}_{11}$ & $\mathrm{C}_{319}$ \\
\hline $\mathrm{C}_{320}$ & $\begin{array}{llllllllllllll}\mathrm{i}_{12} & \mathrm{i}_{11} & \mathrm{i}_{21} & \mathrm{i}_{23} & \mathrm{i}_{22} & \mathrm{i}_{38} & \mathrm{i}_{31} & \mathrm{i}_{33} & \mathrm{i}_{36} & \mathrm{i}_{32} & \mathrm{i}_{39} & \mathrm{i}_{37} & \mathrm{i}_{35} & \mathrm{i}_{34}\end{array}$ & $\mathrm{i}_{12} \quad \mathrm{i}_{21} \quad \mathrm{i}_{38} \quad \mathrm{i}_{11}$ & $\mathrm{i}_{38}$ \\
\hline $\mathrm{C}_{321}$ & $\begin{array}{llllllllllllll}\mathrm{i}_{12} & \mathrm{i}_{11} & \mathrm{i}_{22} & \mathrm{i}_{23} & \mathrm{i}_{21} & \mathrm{i}_{33} & \mathrm{i}_{32} & \mathrm{i}_{31} & \mathrm{i}_{36} & \mathrm{i}_{34} & \mathrm{i}_{39} & \mathrm{i}_{38} & \mathrm{i}_{35} & \mathrm{i}_{37}\end{array}$ & $\mathrm{i}_{12} \quad \mathrm{i}_{22} \quad \mathrm{i}_{33} \quad \mathrm{i}_{11}$ & $\mathrm{C}_{321}$ \\
\hline $\mathrm{C}_{322}$ & $\begin{array}{llllllllllllll}\mathrm{i}_{11} & \mathrm{i}_{12} & \mathrm{i}_{23} & \mathrm{i}_{21} & \mathrm{i}_{22} & \mathrm{i}_{33} & \mathrm{i}_{36} & \mathrm{i}_{39} & \mathrm{i}_{31} & \mathrm{i}_{32} & \mathrm{i}_{35} & \mathrm{i}_{34} & \mathrm{i}_{38} & \mathrm{i}_{37}\end{array}$ & $\mathrm{i}_{11} \quad \mathrm{i}_{23} \quad \mathrm{i}_{33} \quad \mathrm{i}_{12}$ & $\mathrm{C}_{322}$ \\
\hline $\mathrm{C}_{323}$ & $\begin{array}{llllllllllllll}\mathrm{i}_{12} & \mathrm{i}_{11} & \mathrm{i}_{22} & \mathrm{i}_{23} & \mathrm{i}_{21} & \mathrm{i}_{34} & \mathrm{i}_{35} & \mathrm{i}_{33} & \mathrm{i}_{32} & \mathrm{i}_{31} & \mathrm{i}_{39} & \mathrm{i}_{36} & \mathrm{i}_{38} & \mathrm{i}_{37}\end{array}$ & $\mathrm{i}_{12} \quad \mathrm{i}_{22} \quad \mathrm{i}_{34} \quad \mathrm{i}_{23}$ & $\mathrm{C}_{323}$ \\
\hline $\mathrm{C}_{324}$ & $\begin{array}{llllllllllllll}\mathrm{i}_{12} & \mathrm{i}_{11} & \mathrm{i}_{23} & \mathrm{i}_{22} & \mathrm{i}_{21} & \mathrm{i}_{38} & \mathrm{i}_{32} & \mathrm{i}_{36} & \mathrm{i}_{35} & \mathrm{i}_{37} & \mathrm{i}_{31} & \mathrm{i}_{39} & \mathrm{i}_{33} & \mathrm{i}_{34}\end{array}$ & $\mathrm{i}_{12} \quad \mathrm{i}_{23} \quad \mathrm{i}_{38} \quad \mathrm{i}_{22}$ & $\mathrm{i}_{38}$ \\
\hline
\end{tabular}




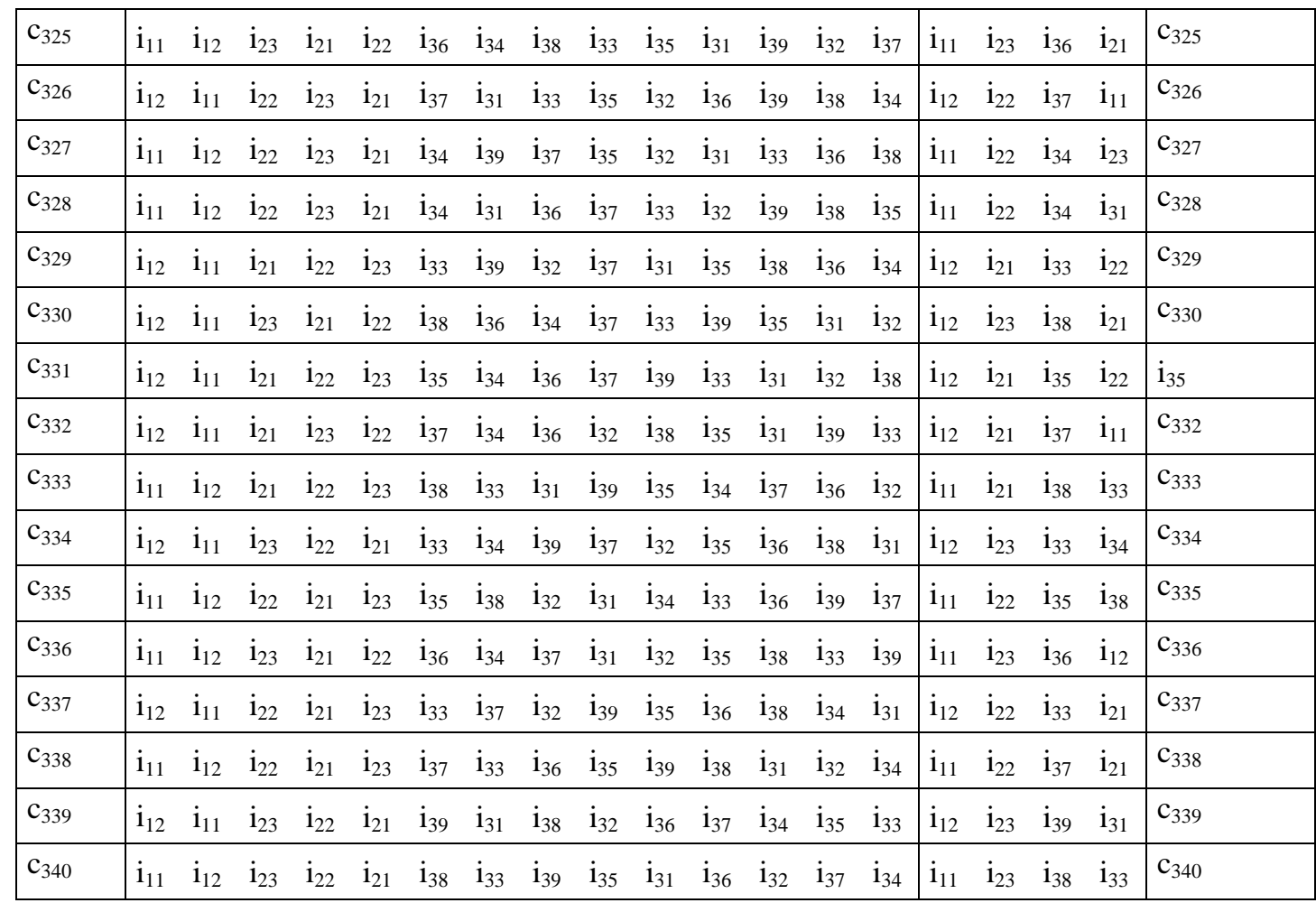


Tabela C22 - Matching $\mu_{3 D}$

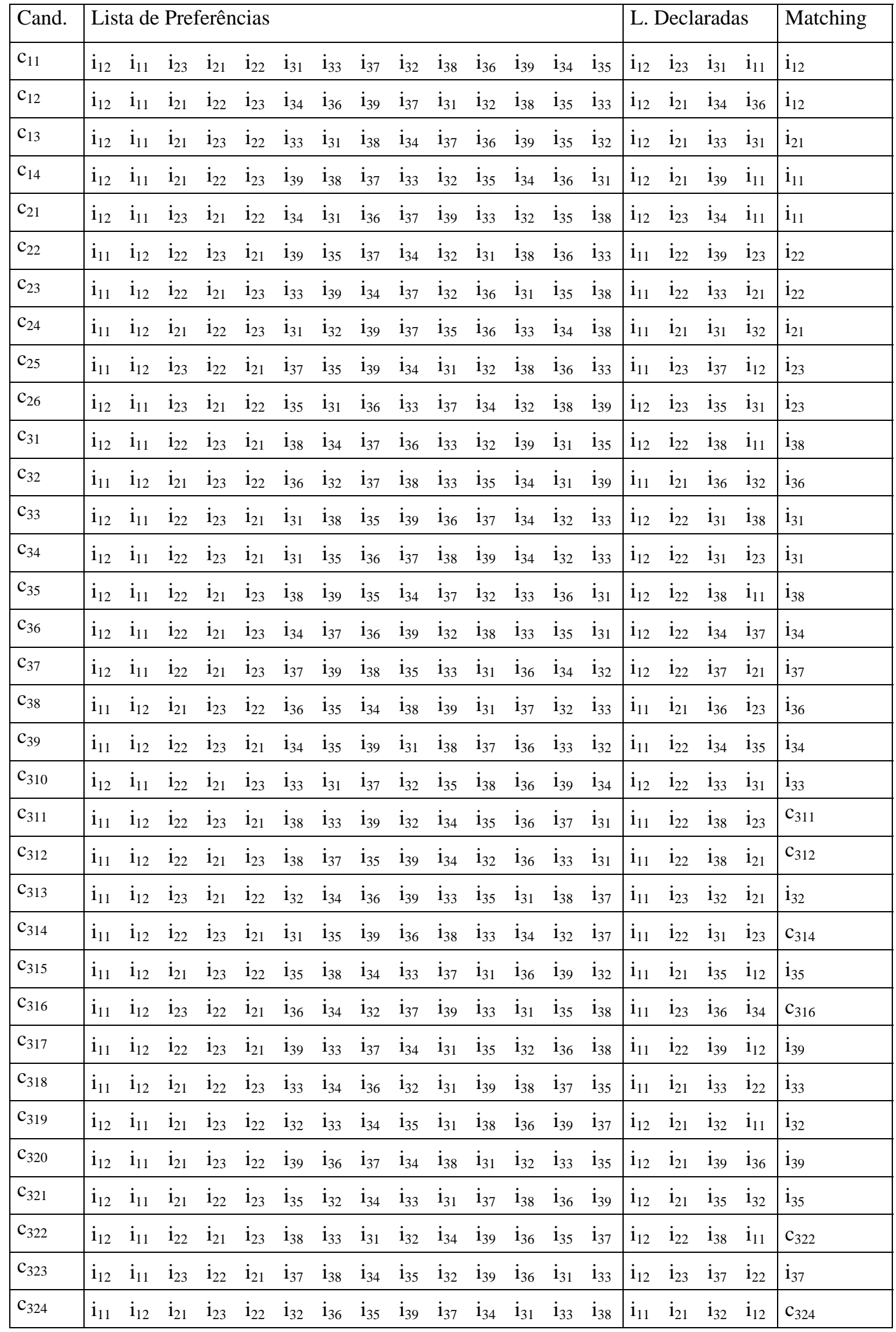




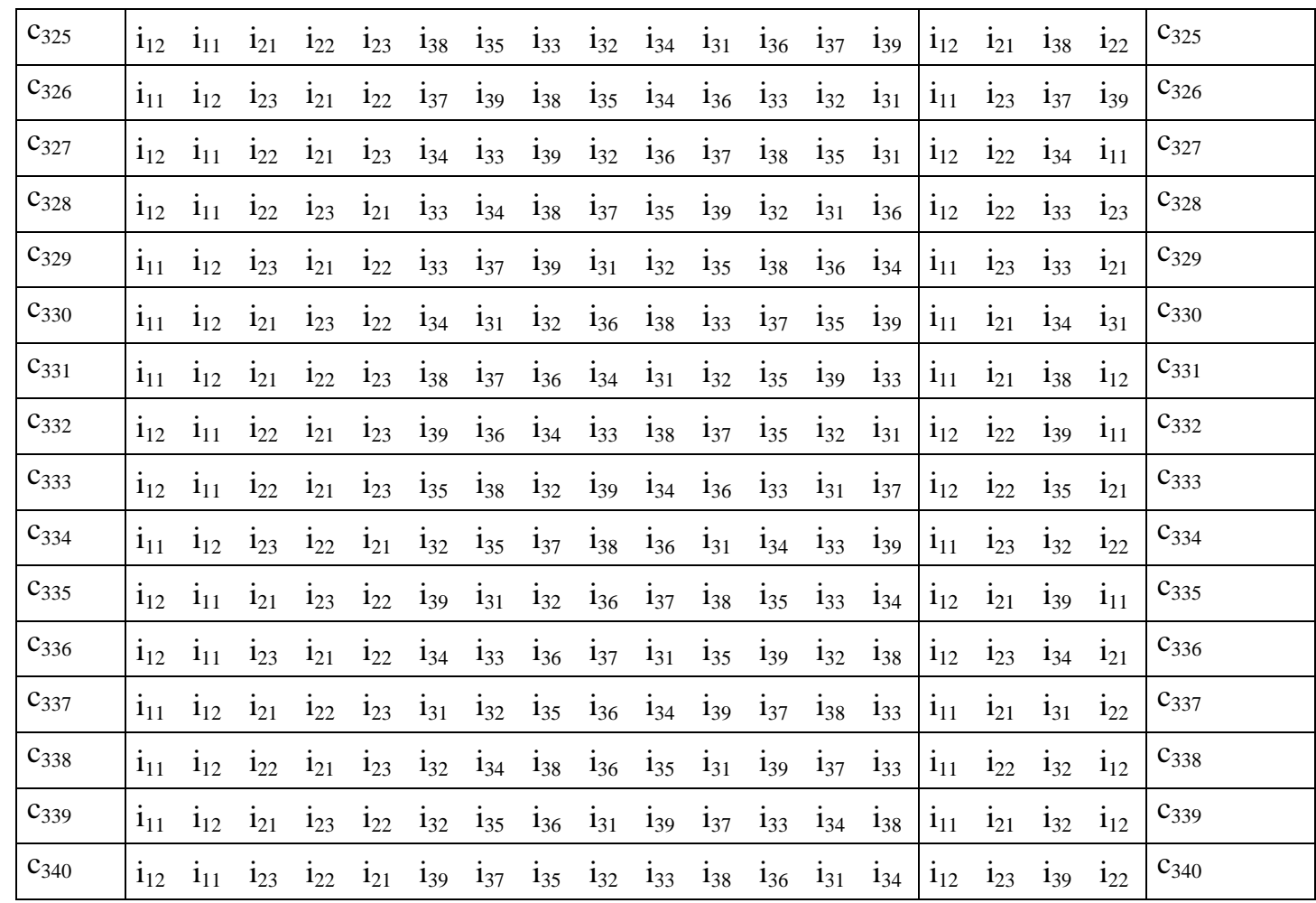


Tabela C23 - Matching $\mu_{3 \mathrm{E}}$

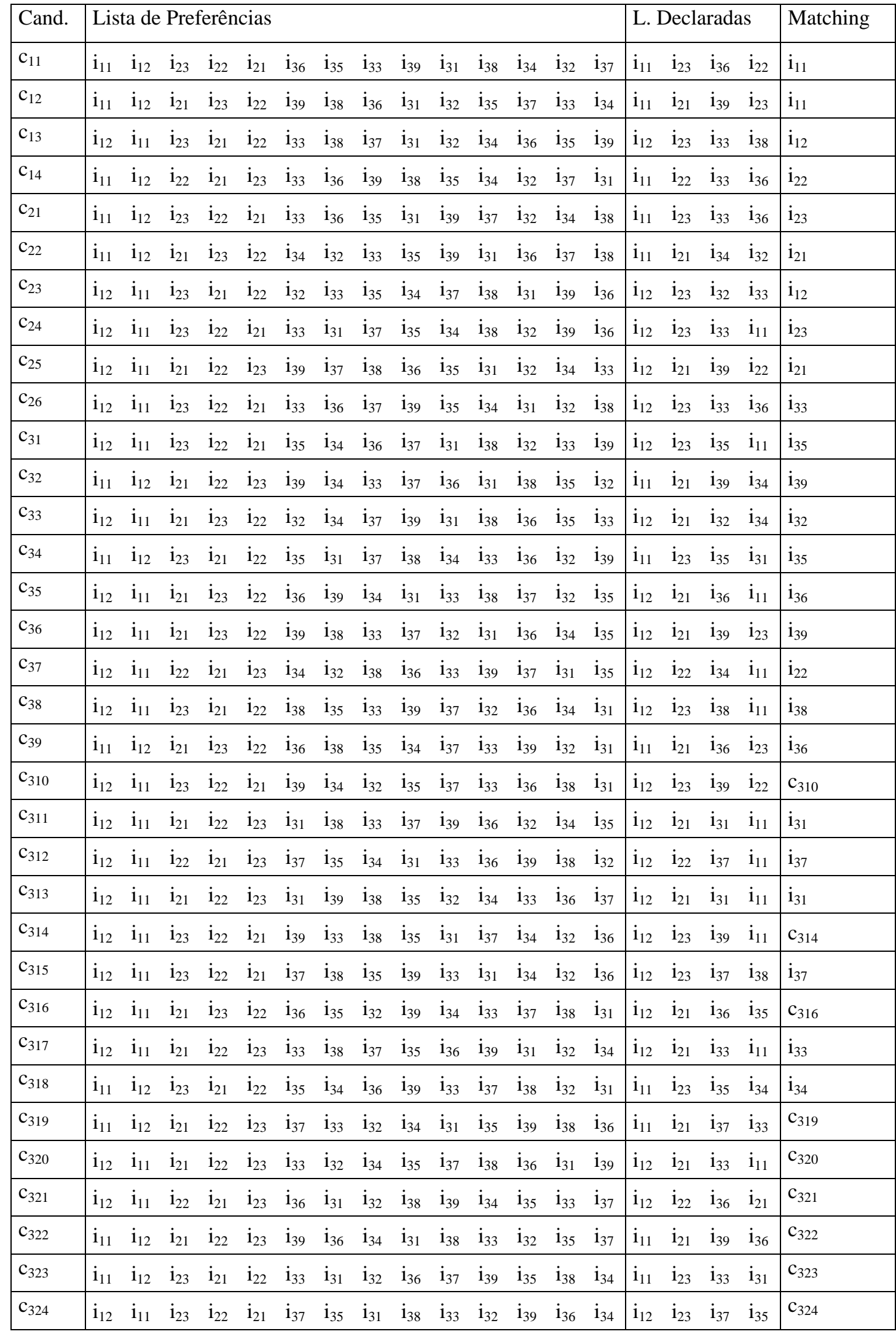




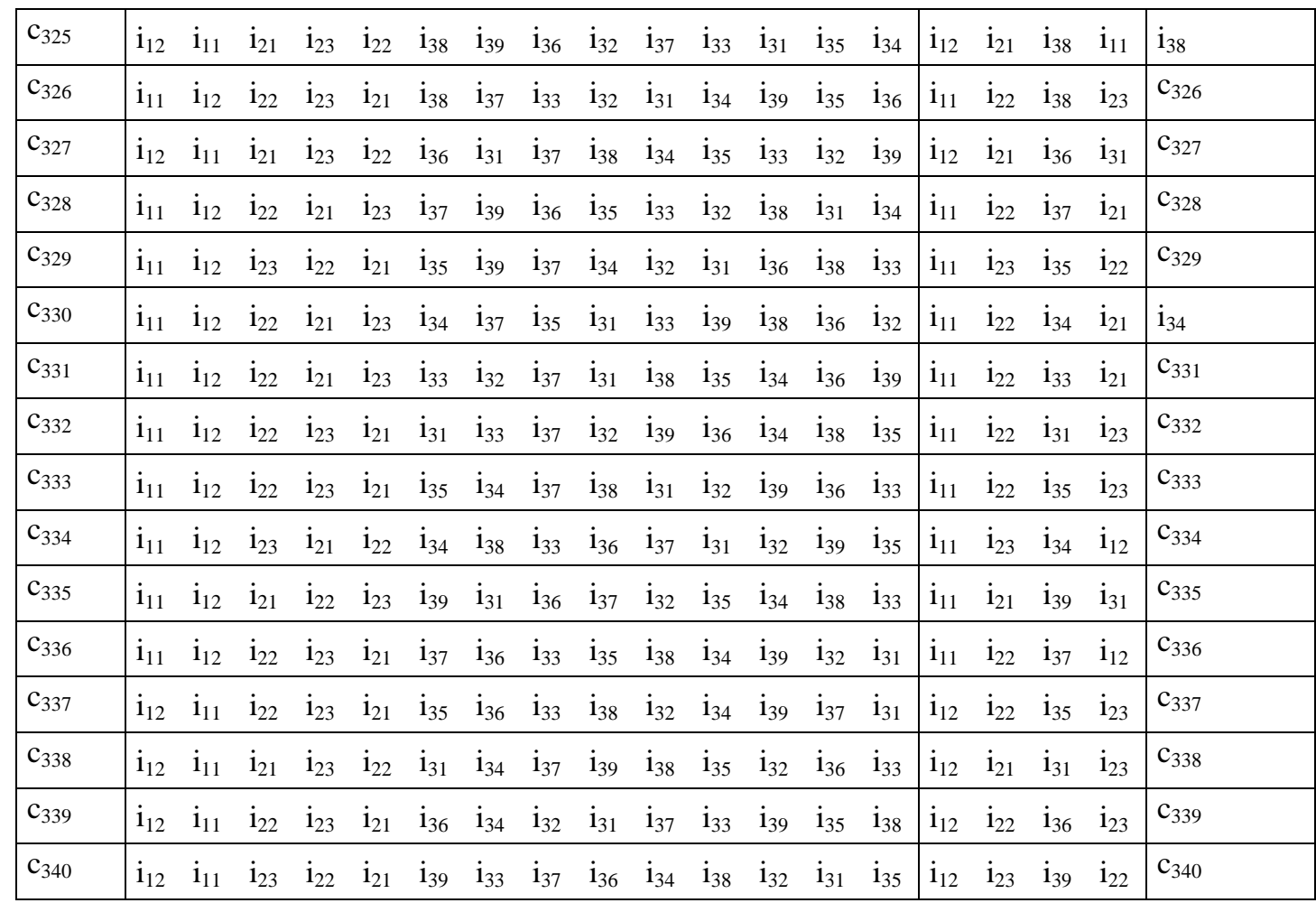


Tabela C24 - Matching $\mu_{3 F}$

\begin{tabular}{|c|c|c|c|}
\hline Cand. & Lista de Preferências & L. Declaradas & Matching \\
\hline $\mathrm{C}_{11}$ & 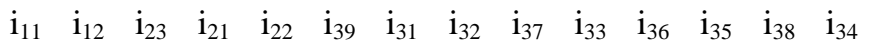 & $\mathrm{i}_{11} \quad \mathrm{i}_{23} \quad \mathrm{i}_{39} \quad \mathrm{i}_{21}$ & $i_{11}$ \\
\hline $\mathrm{C}_{12}$ & $\begin{array}{llllllllllllll}\mathrm{i}_{11} & \mathrm{i}_{12} & \mathrm{i}_{22} & \mathrm{i}_{23} & \mathrm{i}_{21} & \mathrm{i}_{36} & \mathrm{i}_{37} & \mathrm{i}_{35} & \mathrm{i}_{34} & \mathrm{i}_{33} & \mathrm{i}_{38} & \mathrm{i}_{31} & \mathrm{i}_{32} & \mathrm{i}_{39}\end{array}$ & $\mathrm{i}_{11} \quad \mathrm{i}_{22} \quad \mathrm{i}_{36} \quad \mathrm{i}_{37}$ & $\mathrm{i}_{11}$ \\
\hline $\mathrm{C}_{13}$ & $\begin{array}{llllllllllllll}\mathrm{i}_{12} & \mathrm{i}_{11} & \mathrm{i}_{22} & \mathrm{i}_{21} & \mathrm{i}_{23} & \mathrm{i}_{35} & \mathrm{i}_{39} & \mathrm{i}_{33} & \mathrm{i}_{37} & \mathrm{i}_{34} & \mathrm{i}_{32} & \mathrm{i}_{36} & \mathrm{i}_{38} & \mathrm{i}_{31}\end{array}$ & $\mathrm{i}_{12} \quad \mathrm{i}_{22} \quad \mathrm{i}_{35} \quad \mathrm{i}_{11}$ & $i_{12}$ \\
\hline $\mathrm{C}_{14}$ & 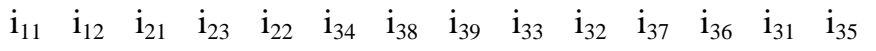 & $\mathrm{i}_{11} \quad \mathrm{i}_{21} \quad \mathrm{i}_{34} \quad \mathrm{i}_{12}$ & $i_{12}$ \\
\hline $\mathrm{C}_{21}$ & $\begin{array}{llllllllllllll}\mathrm{i}_{12} & \mathrm{i}_{11} & \mathrm{i}_{22} & \mathrm{i}_{23} & \mathrm{i}_{21} & \mathrm{i}_{33} & \mathrm{i}_{37} & \mathrm{i}_{32} & \mathrm{i}_{34} & \mathrm{i}_{39} & \mathrm{i}_{38} & \mathrm{i}_{35} & \mathrm{i}_{36} & \mathrm{i}_{31}\end{array}$ & $\mathrm{i}_{12} \quad \mathrm{i}_{22} \quad \mathrm{i}_{33} \quad \mathrm{i}_{37}$ & $\mathrm{i}_{22}$ \\
\hline $\mathrm{C}_{22}$ & 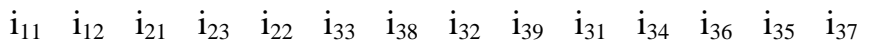 & $\mathrm{i}_{11} \quad \mathrm{i}_{21} \quad \mathrm{i}_{33} \quad \mathrm{i}_{38}$ & $\mathrm{i}_{21}$ \\
\hline $\mathrm{C}_{23}$ & $\begin{array}{llllllllllllll}\mathrm{i}_{12} & \mathrm{i}_{11} & \mathrm{i}_{23} & \mathrm{i}_{21} & \mathrm{i}_{22} & \mathrm{i}_{39} & \mathrm{i}_{31} & \mathrm{i}_{33} & \mathrm{i}_{38} & \mathrm{i}_{35} & \mathrm{i}_{34} & \mathrm{i}_{36} & \mathrm{i}_{32} & \mathrm{i}_{37}\end{array}$ & $\mathrm{i}_{12} \quad \mathrm{i}_{23} \quad \mathrm{i}_{39} \quad \mathrm{i}_{11}$ & $\mathrm{i}_{23}$ \\
\hline $\mathrm{C}_{24}$ & $\begin{array}{llllllllllllll}\mathrm{i}_{12} & \mathrm{i}_{11} & \mathrm{i}_{23} & \mathrm{i}_{22} & \mathrm{i}_{21} & \mathrm{i}_{33} & \mathrm{i}_{31} & \mathrm{i}_{35} & \mathrm{i}_{37} & \mathrm{i}_{39} & \mathrm{i}_{34} & \mathrm{i}_{38} & \mathrm{i}_{32} & \mathrm{i}_{36}\end{array}$ & $\mathrm{i}_{12} \quad \mathrm{i}_{23} \quad \mathrm{i}_{33} \quad \mathrm{i}_{31}$ & $\mathrm{i}_{23}$ \\
\hline $\mathrm{C}_{25}$ & 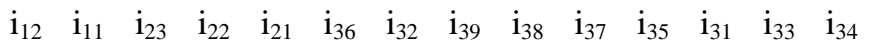 & $\mathrm{i}_{12} \quad \mathrm{i}_{23} \quad \mathrm{i}_{36} \quad \mathrm{i}_{22}$ & $\mathrm{i}_{22}$ \\
\hline $\mathrm{C}_{26}$ & $\begin{array}{llllllllllllll}\mathrm{i}_{12} & \mathrm{i}_{11} & \mathrm{i}_{21} & \mathrm{i}_{22} & \mathrm{i}_{23} & \mathrm{i}_{31} & \mathrm{i}_{33} & \mathrm{i}_{38} & \mathrm{i}_{37} & \mathrm{i}_{36} & \mathrm{i}_{32} & \mathrm{i}_{39} & \mathrm{i}_{35} & \mathrm{i}_{34}\end{array}$ & $\mathrm{i}_{12} \quad \mathrm{i}_{21} \mathrm{i}_{31} \quad \mathrm{i}_{33}$ & $\mathrm{i}_{21}$ \\
\hline $\mathrm{C}_{31}$ & $\begin{array}{llllllllllllll}\mathrm{i}_{12} & \mathrm{i}_{11} & \mathrm{i}_{23} & \mathrm{i}_{22} & \mathrm{i}_{21} & \mathrm{i}_{34} & \mathrm{i}_{39} & \mathrm{i}_{31} & \mathrm{i}_{36} & \mathrm{i}_{35} & \mathrm{i}_{37} & \mathrm{i}_{33} & \mathrm{i}_{32} & \mathrm{i}_{38}\end{array}$ & $\mathrm{i}_{12} \quad \mathrm{i}_{23} \quad \mathrm{i}_{34} \quad \mathrm{i}_{22}$ & $\mathrm{i}_{34}$ \\
\hline $\mathrm{C}_{32}$ & $\begin{array}{llllllllllllll}\mathrm{i}_{11} & \mathrm{i}_{12} & \mathrm{i}_{21} & \mathrm{i}_{23} & \mathrm{i}_{22} & \mathrm{i}_{38} & \mathrm{i}_{36} & \mathrm{i}_{31} & \mathrm{i}_{39} & \mathrm{i}_{35} & \mathrm{i}_{32} & \mathrm{i}_{33} & \mathrm{i}_{34} & \mathrm{i}_{37}\end{array}$ & $\mathrm{i}_{11} \quad \mathrm{i}_{21} \quad \mathrm{i}_{38} \quad \mathrm{i}_{12}$ & $i_{38}$ \\
\hline $\mathrm{C}_{33}$ & $\begin{array}{llllllllllllll}\mathrm{i}_{12} & \mathrm{i}_{11} & \mathrm{i}_{21} & \mathrm{i}_{22} & \mathrm{i}_{23} & \mathrm{i}_{36} & \mathrm{i}_{35} & \mathrm{i}_{39} & \mathrm{i}_{31} & \mathrm{i}_{32} & \mathrm{i}_{37} & \mathrm{i}_{33} & \mathrm{i}_{34} & \mathrm{i}_{38}\end{array}$ & $\mathrm{i}_{12} \quad \mathrm{i}_{21} \mathrm{i}_{36} \quad \mathrm{i}_{22}$ & $\mathrm{i}_{36}$ \\
\hline $\mathrm{C}_{34}$ & $\begin{array}{llllllllllllll}\mathrm{i}_{11} & \mathrm{i}_{12} & \mathrm{i}_{21} & \mathrm{i}_{23} & \mathrm{i}_{22} & \mathrm{i}_{37} & \mathrm{i}_{39} & \mathrm{i}_{33} & \mathrm{i}_{36} & \mathrm{i}_{38} & \mathrm{i}_{35} & \mathrm{i}_{31} & \mathrm{i}_{32} & \mathrm{i}_{34}\end{array}$ & $\mathrm{i}_{11} \quad \mathrm{i}_{21} \quad \mathrm{i}_{37} \quad \mathrm{i}_{39}$ & $\mathrm{i}_{37}$ \\
\hline $\mathrm{C}_{35}$ & $\begin{array}{llllllllllllll}\mathrm{i}_{11} & \mathrm{i}_{12} & \mathrm{i}_{22} & \mathrm{i}_{23} & \mathrm{i}_{21} & \mathrm{i}_{38} & \mathrm{i}_{39} & \mathrm{i}_{36} & \mathrm{i}_{33} & \mathrm{i}_{31} & \mathrm{i}_{34} & \mathrm{i}_{35} & \mathrm{i}_{32} & \mathrm{i}_{37}\end{array}$ & $\mathrm{i}_{11} \quad \mathrm{i}_{22} \quad \mathrm{i}_{38} \quad \mathrm{i}_{23}$ & $i_{38}$ \\
\hline $\mathrm{C}_{36}$ & $\begin{array}{llllllllllllll}\mathrm{i}_{12} & \mathrm{i}_{11} & \mathrm{i}_{23} & \mathrm{i}_{21} & \mathrm{i}_{22} & \mathrm{i}_{38} & \mathrm{i}_{33} & \mathrm{i}_{32} & \mathrm{i}_{39} & \mathrm{i}_{37} & \mathrm{i}_{35} & \mathrm{i}_{36} & \mathrm{i}_{31} & \mathrm{i}_{34}\end{array}$ & $\mathrm{i}_{12} \quad \mathrm{i}_{23} \quad \mathrm{i}_{38} \quad \mathrm{i}_{21}$ & $\mathrm{C}_{36}$ \\
\hline $\mathrm{C}_{37}$ & $\begin{array}{llllllllllllll}\mathrm{i}_{12} & \mathrm{i}_{11} & \mathrm{i}_{21} & \mathrm{i}_{22} & \mathrm{i}_{23} & \mathrm{i}_{38} & \mathrm{i}_{33} & \mathrm{i}_{39} & \mathrm{i}_{37} & \mathrm{i}_{35} & \mathrm{i}_{32} & \mathrm{i}_{36} & \mathrm{i}_{34} & \mathrm{i}_{31}\end{array}$ & $\mathrm{i}_{12} \quad \mathrm{i}_{21} \quad \mathrm{i}_{38} \quad \mathrm{i}_{22}$ & $\mathrm{C}_{37}$ \\
\hline $\mathrm{C}_{38}$ & $\begin{array}{llllllllllllll}\mathrm{i}_{12} & \mathrm{i}_{11} & \mathrm{i}_{23} & \mathrm{i}_{22} & \mathrm{i}_{21} & \mathrm{i}_{36} & \mathrm{i}_{33} & \mathrm{i}_{38} & \mathrm{i}_{39} & \mathrm{i}_{32} & \mathrm{i}_{34} & \mathrm{i}_{31} & \mathrm{i}_{35} & \mathrm{i}_{37}\end{array}$ & $\mathrm{i}_{12} \quad \mathrm{i}_{23} \quad \mathrm{i}_{36} \quad \mathrm{i}_{11}$ & $\mathrm{i}_{36}$ \\
\hline $\mathrm{C}_{39}$ & $\begin{array}{llllllllllllll}\mathrm{i}_{12} & \mathrm{i}_{11} & \mathrm{i}_{21} & \mathrm{i}_{23} & \mathrm{i}_{22} & \mathrm{i}_{37} & \mathrm{i}_{33} & \mathrm{i}_{34} & \mathrm{i}_{39} & \mathrm{i}_{35} & \mathrm{i}_{38} & \mathrm{i}_{31} & \mathrm{i}_{36} & \mathrm{i}_{32}\end{array}$ & $\mathrm{i}_{12} \quad \mathrm{i}_{21} \quad \mathrm{i}_{37} \quad \mathrm{i}_{33}$ & $\mathrm{i}_{37}$ \\
\hline $\mathrm{C}_{310}$ & $\begin{array}{llllllllllllll}\mathrm{i}_{11} & \mathrm{i}_{12} & \mathrm{i}_{22} & \mathrm{i}_{23} & \mathrm{i}_{21} & \mathrm{i}_{32} & \mathrm{i}_{36} & \mathrm{i}_{35} & \mathrm{i}_{37} & \mathrm{i}_{34} & \mathrm{i}_{31} & \mathrm{i}_{33} & \mathrm{i}_{39} & \mathrm{i}_{38}\end{array}$ & $\mathrm{i}_{11} \quad \mathrm{i}_{22} \quad \mathrm{i}_{32} \quad \mathrm{i}_{36}$ & $\mathrm{i}_{32}$ \\
\hline $\mathrm{C}_{311}$ & $\begin{array}{llllllllllllll}\mathrm{i}_{12} & \mathrm{i}_{11} & \mathrm{i}_{22} & \mathrm{i}_{21} & \mathrm{i}_{23} & \mathrm{i}_{37} & \mathrm{i}_{35} & \mathrm{i}_{38} & \mathrm{i}_{34} & \mathrm{i}_{31} & \mathrm{i}_{32} & \mathrm{i}_{36} & \mathrm{i}_{39} & \mathrm{i}_{33}\end{array}$ & $\mathrm{i}_{12} \quad \mathrm{i}_{22} \quad \mathrm{i}_{37} \quad \mathrm{i}_{11}$ & $\mathrm{C}_{311}$ \\
\hline $\mathrm{C}_{312}$ & $\begin{array}{llllllllllllll}\mathrm{i}_{11} & \mathrm{i}_{12} & \mathrm{i}_{21} & \mathrm{i}_{22} & \mathrm{i}_{23} & \mathrm{i}_{35} & \mathrm{i}_{39} & \mathrm{i}_{36} & \mathrm{i}_{38} & \mathrm{i}_{37} & \mathrm{i}_{32} & \mathrm{i}_{34} & \mathrm{i}_{33} & \mathrm{i}_{31}\end{array}$ & $\mathrm{i}_{11} \quad \mathrm{i}_{21} \quad \mathrm{i}_{35} \quad \mathrm{i}_{22}$ & $\mathrm{i}_{35}$ \\
\hline $\mathrm{C}_{313}$ & $\begin{array}{llllllllllllll}\mathrm{i}_{11} & \mathrm{i}_{12} & \mathrm{i}_{23} & \mathrm{i}_{21} & \mathrm{i}_{22} & \mathrm{i}_{38} & \mathrm{i}_{36} & \mathrm{i}_{37} & \mathrm{i}_{31} & \mathrm{i}_{33} & \mathrm{i}_{35} & \mathrm{i}_{34} & \mathrm{i}_{39} & \mathrm{i}_{32}\end{array}$ & $\mathrm{i}_{11} \quad \mathrm{i}_{23} \quad \mathrm{i}_{38} \quad \mathrm{i}_{12}$ & $\mathrm{C}_{313}$ \\
\hline $\mathrm{C}_{314}$ & $\begin{array}{llllllllllllll}\mathrm{i}_{11} & \mathrm{i}_{12} & \mathrm{i}_{22} & \mathrm{i}_{21} & \mathrm{i}_{23} & \mathrm{i}_{34} & \mathrm{i}_{36} & \mathrm{i}_{38} & \mathrm{i}_{32} & \mathrm{i}_{39} & \mathrm{i}_{37} & \mathrm{i}_{31} & \mathrm{i}_{35} & \mathrm{i}_{33}\end{array}$ & $\mathrm{i}_{11} \quad \mathrm{i}_{22} \quad \mathrm{i}_{34} \quad \mathrm{i}_{36}$ & $\mathrm{i}_{34}$ \\
\hline $\mathrm{C}_{315}$ & $\begin{array}{llllllllllllll}\mathrm{i}_{11} & \mathrm{i}_{12} & \mathrm{i}_{22} & \mathrm{i}_{23} & \mathrm{i}_{21} & \mathrm{i}_{35} & \mathrm{i}_{32} & \mathrm{i}_{31} & \mathrm{i}_{34} & \mathrm{i}_{38} & \mathrm{i}_{37} & \mathrm{i}_{39} & \mathrm{i}_{36} & \mathrm{i}_{33}\end{array}$ & $\begin{array}{llll}\mathrm{i}_{11} & \mathrm{i}_{22} & \mathrm{i}_{35} & \mathrm{i}_{12}\end{array}$ & $\mathrm{i}_{35}$ \\
\hline $\mathrm{C}_{316}$ & $\begin{array}{llllllllllllll}\mathrm{i}_{12} & \mathrm{i}_{11} & \mathrm{i}_{21} & \mathrm{i}_{22} & \mathrm{i}_{23} & \mathrm{i}_{38} & \mathrm{i}_{33} & \mathrm{i}_{37} & \mathrm{i}_{31} & \mathrm{i}_{35} & \mathrm{i}_{36} & \mathrm{i}_{32} & \mathrm{i}_{34} & \mathrm{i}_{39}\end{array}$ & $\mathrm{i}_{12} \quad \mathrm{i}_{21} \quad \mathrm{i}_{38} \quad \mathrm{i}_{11}$ & $\mathrm{C}_{316}$ \\
\hline $\mathrm{C}_{317}$ & $\begin{array}{llllllllllllll}\mathrm{i}_{11} & \mathrm{i}_{12} & \mathrm{i}_{23} & \mathrm{i}_{22} & \mathrm{i}_{21} & \mathrm{i}_{31} & \mathrm{i}_{32} & \mathrm{i}_{37} & \mathrm{i}_{33} & \mathrm{i}_{36} & \mathrm{i}_{35} & \mathrm{i}_{38} & \mathrm{i}_{34} & \mathrm{i}_{39}\end{array}$ & $\mathrm{i}_{11} \mathrm{i}_{23} \quad \mathrm{i}_{31} \quad \mathrm{i}_{32}$ & $\mathrm{i}_{31}$ \\
\hline $\mathrm{C}_{318}$ & $\begin{array}{llllllllllllll}\mathrm{i}_{12} & \mathrm{i}_{11} & \mathrm{i}_{22} & \mathrm{i}_{21} & \mathrm{i}_{23} & \mathrm{i}_{38} & \mathrm{i}_{35} & \mathrm{i}_{31} & \mathrm{i}_{36} & \mathrm{i}_{39} & \mathrm{i}_{37} & \mathrm{i}_{34} & \mathrm{i}_{33} & \mathrm{i}_{32}\end{array}$ & $\mathrm{i}_{12} \quad \mathrm{i}_{22} \quad \mathrm{i}_{38} \quad \mathrm{i}_{11}$ & $\mathrm{C}_{318}$ \\
\hline $\mathrm{C}_{319}$ & $\begin{array}{llllllllllllll}\mathrm{i}_{11} & \mathrm{i}_{12} & \mathrm{i}_{23} & \mathrm{i}_{21} & \mathrm{i}_{22} & \mathrm{i}_{38} & \mathrm{i}_{35} & \mathrm{i}_{31} & \mathrm{i}_{37} & \mathrm{i}_{32} & \mathrm{i}_{34} & \mathrm{i}_{33} & \mathrm{i}_{36} & \mathrm{i}_{39}\end{array}$ & $\mathrm{i}_{11} \quad \mathrm{i}_{23} \quad \mathrm{i}_{38} \quad \mathrm{i}_{12}$ & $\mathrm{C}_{319}$ \\
\hline $\mathrm{C}_{320}$ & $\begin{array}{llllllllllllll}\mathrm{i}_{11} & \mathrm{i}_{12} & \mathrm{i}_{23} & \mathrm{i}_{21} & \mathrm{i}_{22} & \mathrm{i}_{32} & \mathrm{i}_{36} & \mathrm{i}_{39} & \mathrm{i}_{33} & \mathrm{i}_{38} & \mathrm{i}_{34} & \mathrm{i}_{37} & \mathrm{i}_{35} & \mathrm{i}_{31}\end{array}$ & $\mathrm{i}_{11} \quad \mathrm{i}_{23} \quad \mathrm{i}_{32} \quad \mathrm{i}_{12}$ & $\mathrm{i}_{32}$ \\
\hline $\mathrm{C}_{321}$ & $\begin{array}{llllllllllllll}\mathrm{i}_{11} & \mathrm{i}_{12} & \mathrm{i}_{23} & \mathrm{i}_{21} & \mathrm{i}_{22} & \mathrm{i}_{36} & \mathrm{i}_{39} & \mathrm{i}_{31} & \mathrm{i}_{35} & \mathrm{i}_{34} & \mathrm{i}_{32} & \mathrm{i}_{33} & \mathrm{i}_{37} & \mathrm{i}_{38}\end{array}$ & $i_{11} \quad i_{23} \quad i_{36} \quad i_{39}$ & $\mathrm{i}_{39}$ \\
\hline $\mathrm{C}_{322}$ & $\begin{array}{llllllllllllll}\mathrm{i}_{12} & \mathrm{i}_{11} & \mathrm{i}_{23} & \mathrm{i}_{21} & \mathrm{i}_{22} & \mathrm{i}_{37} & \mathrm{i}_{32} & \mathrm{i}_{36} & \mathrm{i}_{39} & \mathrm{i}_{34} & \mathrm{i}_{35} & \mathrm{i}_{31} & \mathrm{i}_{38} & \mathrm{i}_{33}\end{array}$ & $i_{12} \quad i_{23} \quad i_{37} \quad i_{11}$ & $\mathrm{C}_{322}$ \\
\hline $\mathrm{C}_{323}$ & $\begin{array}{llllllllllllll}\mathrm{i}_{11} & \mathrm{i}_{12} & \mathrm{i}_{23} & \mathrm{i}_{22} & \mathrm{i}_{21} & \mathrm{i}_{35} & \mathrm{i}_{32} & \mathrm{i}_{37} & \mathrm{i}_{31} & \mathrm{i}_{38} & \mathrm{i}_{39} & \mathrm{i}_{34} & \mathrm{i}_{33} & \mathrm{i}_{36}\end{array}$ & $\mathrm{i}_{11} \quad \mathrm{i}_{23} \quad \mathrm{i}_{35} \quad \mathrm{i}_{12}$ & $\mathrm{C}_{323}$ \\
\hline $\mathrm{C}_{324}$ & $\begin{array}{llllllllllllll}\mathrm{i}_{11} & \mathrm{i}_{12} & \mathrm{i}_{21} & \mathrm{i}_{22} & \mathrm{i}_{23} & \mathrm{i}_{34} & \mathrm{i}_{37} & \mathrm{i}_{31} & \mathrm{i}_{33} & \mathrm{i}_{32} & \mathrm{i}_{36} & \mathrm{i}_{35} & \mathrm{i}_{39} & \mathrm{i}_{38}\end{array}$ & $\mathrm{i}_{11} \quad \mathrm{i}_{21} \mathrm{i}_{34} \quad \mathrm{i}_{12}$ & $\mathrm{C}_{324}$ \\
\hline
\end{tabular}




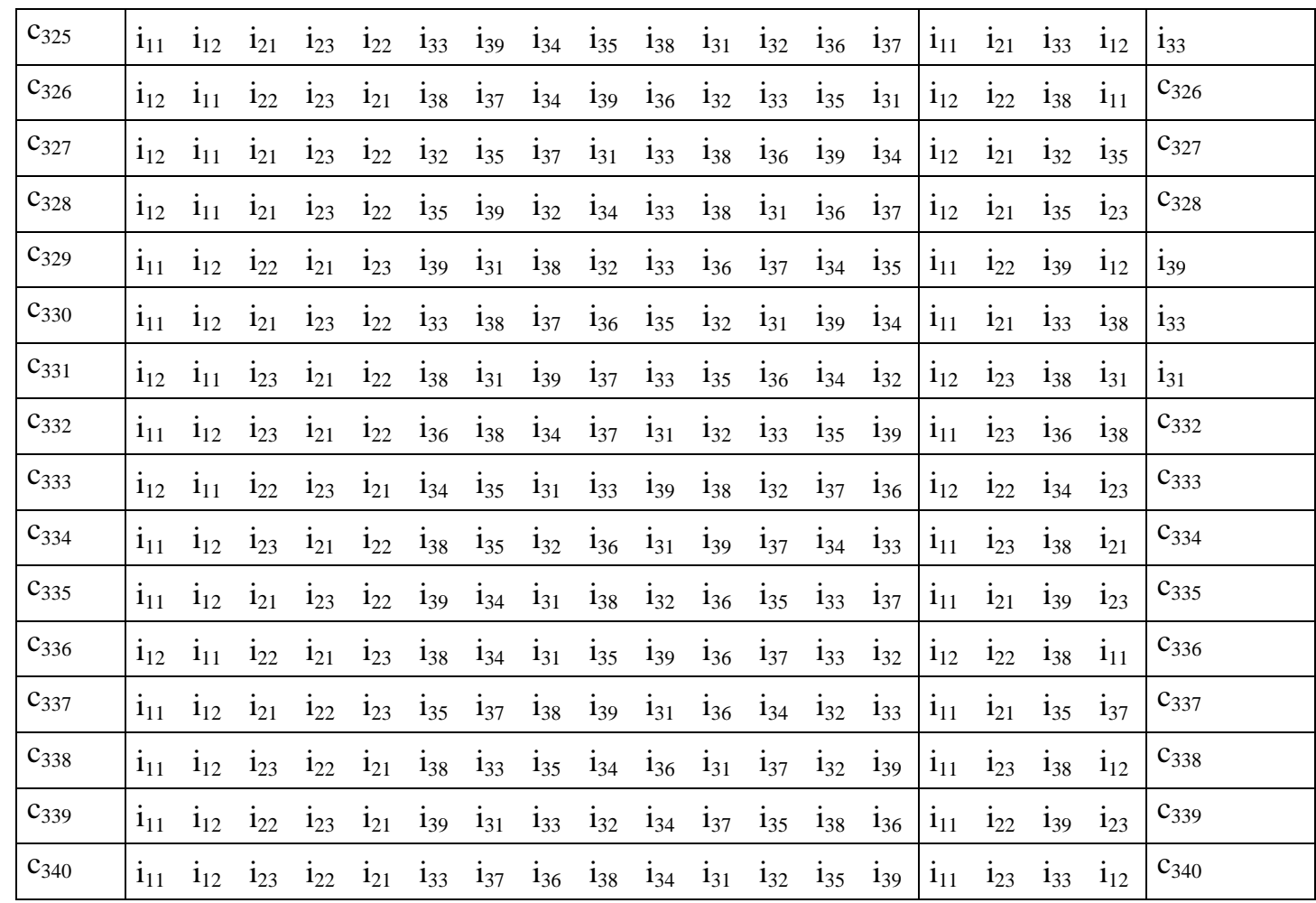


Tabela C25 - Matching $\mu_{3 G}$

\begin{tabular}{|c|c|c|c|}
\hline Cand. & Lista de Preferências & L. Declaradas & Matching \\
\hline $\mathrm{C}_{11}$ & $\begin{array}{llllllllllllll}\mathrm{i}_{11} & \mathrm{i}_{12} & \mathrm{i}_{23} & \mathrm{i}_{21} & \mathrm{i}_{22} & \mathrm{i}_{31} & \mathrm{i}_{39} & \mathrm{i}_{34} & \mathrm{i}_{36} & \mathrm{i}_{37} & \mathrm{i}_{35} & \mathrm{i}_{38} & \mathrm{i}_{32} & \mathrm{i}_{33}\end{array}$ & $\mathrm{i}_{11} \quad \mathrm{i}_{23} \quad \mathrm{i}_{31} \quad \mathrm{i}_{21}$ & $i_{11}$ \\
\hline $\mathrm{C}_{12}$ & $\begin{array}{llllllllllllll}\mathrm{i}_{11} & \mathrm{i}_{12} & \mathrm{i}_{21} & \mathrm{i}_{23} & \mathrm{i}_{22} & \mathrm{i}_{38} & \mathrm{i}_{33} & \mathrm{i}_{34} & \mathrm{i}_{37} & \mathrm{i}_{31} & \mathrm{i}_{39} & \mathrm{i}_{36} & \mathrm{i}_{35} & \mathrm{i}_{32}\end{array}$ & $\mathrm{i}_{11} \quad \mathrm{i}_{21} \quad \mathrm{i}_{38} \quad \mathrm{i}_{23}$ & $\mathrm{i}_{11}$ \\
\hline $\mathrm{C}_{13}$ & $\begin{array}{llllllllllllll}\mathrm{i}_{12} & \mathrm{i}_{11} & \mathrm{i}_{21} & \mathrm{i}_{22} & \mathrm{i}_{23} & \mathrm{i}_{31} & \mathrm{i}_{36} & \mathrm{i}_{33} & \mathrm{i}_{37} & \mathrm{i}_{38} & \mathrm{i}_{34} & \mathrm{i}_{32} & \mathrm{i}_{39} & \mathrm{i}_{35}\end{array}$ & $\mathrm{i}_{12} \quad \mathrm{i}_{21} \quad \mathrm{i}_{31} \quad \mathrm{i}_{36}$ & $i_{12}$ \\
\hline $\mathrm{C}_{14}$ & $\begin{array}{llllllllllllll}\mathrm{i}_{12} & \mathrm{i}_{11} & \mathrm{i}_{21} & \mathrm{i}_{22} & \mathrm{i}_{23} & \mathrm{i}_{38} & \mathrm{i}_{31} & \mathrm{i}_{33} & \mathrm{i}_{35} & \mathrm{i}_{36} & \mathrm{i}_{39} & \mathrm{i}_{37} & \mathrm{i}_{32} & \mathrm{i}_{34}\end{array}$ & $\mathrm{i}_{12} \quad \mathrm{i}_{21} \quad \mathrm{i}_{38} \quad \mathrm{i}_{11}$ & $\mathrm{i}_{12}$ \\
\hline $\mathrm{C}_{21}$ & $\begin{array}{llllllllllllll}\mathrm{i}_{11} & \mathrm{i}_{12} & \mathrm{i}_{22} & \mathrm{i}_{21} & \mathrm{i}_{23} & \mathrm{i}_{36} & \mathrm{i}_{34} & \mathrm{i}_{35} & \mathrm{i}_{32} & \mathrm{i}_{39} & \mathrm{i}_{37} & \mathrm{i}_{33} & \mathrm{i}_{38} & \mathrm{i}_{31}\end{array}$ & $\mathrm{i}_{11} \quad \mathrm{i}_{22} \quad \mathrm{i}_{36} \quad \mathrm{i}_{34}$ & $\mathrm{i}_{22}$ \\
\hline $\mathrm{C}_{22}$ & $\begin{array}{llllllllllllll}\mathrm{i}_{11} & \mathrm{i}_{12} & \mathrm{i}_{23} & \mathrm{i}_{21} & \mathrm{i}_{22} & \mathrm{i}_{32} & \mathrm{i}_{38} & \mathrm{i}_{39} & \mathrm{i}_{33} & \mathrm{i}_{35} & \mathrm{i}_{37} & \mathrm{i}_{36} & \mathrm{i}_{31} & \mathrm{i}_{34}\end{array}$ & $\mathrm{i}_{11} \quad \mathrm{i}_{23} \quad \mathrm{i}_{32} \quad \mathrm{i}_{38}$ & $\mathrm{i}_{23}$ \\
\hline $\mathrm{C}_{23}$ & $\begin{array}{llllllllllllll}\mathrm{i}_{11} & \mathrm{i}_{12} & \mathrm{i}_{23} & \mathrm{i}_{22} & \mathrm{i}_{21} & \mathrm{i}_{38} & \mathrm{i}_{32} & \mathrm{i}_{39} & \mathrm{i}_{34} & \mathrm{i}_{35} & \mathrm{i}_{31} & \mathrm{i}_{36} & \mathrm{i}_{37} & \mathrm{i}_{33}\end{array}$ & $\mathrm{i}_{11} \quad \mathrm{i}_{23} \quad \mathrm{i}_{38} \quad \mathrm{i}_{32}$ & $\mathrm{i}_{23}$ \\
\hline $\mathrm{C}_{24}$ & $\begin{array}{llllllllllllll}\mathrm{i}_{12} & \mathrm{i}_{11} & \mathrm{i}_{21} & \mathrm{i}_{22} & \mathrm{i}_{23} & \mathrm{i}_{33} & \mathrm{i}_{37} & \mathrm{i}_{39} & \mathrm{i}_{31} & \mathrm{i}_{34} & \mathrm{i}_{38} & \mathrm{i}_{32} & \mathrm{i}_{35} & \mathrm{i}_{36}\end{array}$ & $\mathrm{i}_{12} \quad \mathrm{i}_{21} \quad \mathrm{i}_{33} \quad \mathrm{i}_{22}$ & $\mathrm{i}_{21}$ \\
\hline $\mathrm{C}_{25}$ & $\begin{array}{llllllllllllll}\mathrm{i}_{11} & \mathrm{i}_{12} & \mathrm{i}_{23} & \mathrm{i}_{21} & \mathrm{i}_{22} & \mathrm{i}_{38} & \mathrm{i}_{31} & \mathrm{i}_{33} & \mathrm{i}_{35} & \mathrm{i}_{34} & \mathrm{i}_{39} & \mathrm{i}_{32} & \mathrm{i}_{37} & \mathrm{i}_{36}\end{array}$ & $\mathrm{i}_{11} \quad \mathrm{i}_{23} \quad \mathrm{i}_{38} \quad \mathrm{i}_{31}$ & $i_{38}$ \\
\hline $\mathrm{C}_{26}$ & $\begin{array}{llllllllllllll}\mathrm{i}_{11} & \mathrm{i}_{12} & \mathrm{i}_{21} & \mathrm{i}_{23} & \mathrm{i}_{22} & \mathrm{i}_{32} & \mathrm{i}_{34} & \mathrm{i}_{39} & \mathrm{i}_{38} & \mathrm{i}_{37} & \mathrm{i}_{31} & \mathrm{i}_{33} & \mathrm{i}_{35} & \mathrm{i}_{36}\end{array}$ & $\mathrm{i}_{11} \quad \mathrm{i}_{21} \quad \mathrm{i}_{32} \quad \mathrm{i}_{34}$ & $\mathrm{i}_{21}$ \\
\hline $\mathrm{C}_{31}$ & $\begin{array}{llllllllllllll}\mathrm{i}_{12} & \mathrm{i}_{11} & \mathrm{i}_{21} & \mathrm{i}_{23} & \mathrm{i}_{22} & \mathrm{i}_{31} & \mathrm{i}_{37} & \mathrm{i}_{39} & \mathrm{i}_{36} & \mathrm{i}_{33} & \mathrm{i}_{34} & \mathrm{i}_{32} & \mathrm{i}_{38} & \mathrm{i}_{35}\end{array}$ & $\mathrm{i}_{12} \quad \mathrm{i}_{21} \quad \mathrm{i}_{31} \quad \mathrm{i}_{37}$ & $i_{31}$ \\
\hline $\mathrm{C}_{32}$ & $\begin{array}{llllllllllllll}\mathrm{i}_{12} & \mathrm{i}_{11} & \mathrm{i}_{21} & \mathrm{i}_{22} & \mathrm{i}_{23} & \mathrm{i}_{35} & \mathrm{i}_{36} & \mathrm{i}_{39} & \mathrm{i}_{34} & \mathrm{i}_{38} & \mathrm{i}_{32} & \mathrm{i}_{37} & \mathrm{i}_{33} & \mathrm{i}_{31}\end{array}$ & $\mathrm{i}_{12} \quad \mathrm{i}_{21} \quad \mathrm{i}_{35} \quad \mathrm{i}_{36}$ & $\mathrm{i}_{35}$ \\
\hline $\mathrm{C}_{33}$ & $\begin{array}{llllllllllllll}\mathrm{i}_{11} & \mathrm{i}_{12} & \mathrm{i}_{21} & \mathrm{i}_{23} & \mathrm{i}_{22} & \mathrm{i}_{38} & \mathrm{i}_{33} & \mathrm{i}_{39} & \mathrm{i}_{31} & \mathrm{i}_{35} & \mathrm{i}_{34} & \mathrm{i}_{36} & \mathrm{i}_{37} & \mathrm{i}_{32}\end{array}$ & $\mathrm{i}_{11} \quad \mathrm{i}_{21} \quad \mathrm{i}_{38} \quad \mathrm{i}_{12}$ & $i_{38}$ \\
\hline $\mathrm{C}_{34}$ & $\begin{array}{llllllllllllll}\mathrm{i}_{11} & \mathrm{i}_{12} & \mathrm{i}_{22} & \mathrm{i}_{21} & \mathrm{i}_{23} & \mathrm{i}_{36} & \mathrm{i}_{38} & \mathrm{i}_{33} & \mathrm{i}_{34} & \mathrm{i}_{39} & \mathrm{i}_{37} & \mathrm{i}_{35} & \mathrm{i}_{31} & \mathrm{i}_{32}\end{array}$ & $\mathrm{i}_{11} \quad \mathrm{i}_{22} \quad \mathrm{i}_{36} \quad \mathrm{i}_{21}$ & $\mathrm{i}_{22}$ \\
\hline $\mathrm{C}_{35}$ & $\begin{array}{llllllllllllll}\mathrm{i}_{11} & \mathrm{i}_{12} & \mathrm{i}_{23} & \mathrm{i}_{22} & \mathrm{i}_{21} & \mathrm{i}_{34} & \mathrm{i}_{38} & \mathrm{i}_{35} & \mathrm{i}_{32} & \mathrm{i}_{39} & \mathrm{i}_{33} & \mathrm{i}_{37} & \mathrm{i}_{31} & \mathrm{i}_{36}\end{array}$ & $\mathrm{i}_{11} \quad \mathrm{i}_{23} \quad \mathrm{i}_{34} \quad \mathrm{i}_{38}$ & $\mathrm{i}_{34}$ \\
\hline $\mathrm{C}_{36}$ & $\begin{array}{llllllllllllll}\mathrm{i}_{12} & \mathrm{i}_{11} & \mathrm{i}_{21} & \mathrm{i}_{22} & \mathrm{i}_{23} & \mathrm{i}_{33} & \mathrm{i}_{31} & \mathrm{i}_{37} & \mathrm{i}_{39} & \mathrm{i}_{35} & \mathrm{i}_{32} & \mathrm{i}_{38} & \mathrm{i}_{34} & \mathrm{i}_{36}\end{array}$ & $\mathrm{i}_{12} \quad \mathrm{i}_{21} \quad \mathrm{i}_{33} \quad \mathrm{i}_{11}$ & $\mathrm{i}_{33}$ \\
\hline $\mathrm{C}_{37}$ & $\begin{array}{llllllllllllll}\mathrm{i}_{11} & \mathrm{i}_{12} & \mathrm{i}_{23} & \mathrm{i}_{22} & \mathrm{i}_{21} & \mathrm{i}_{32} & \mathrm{i}_{35} & \mathrm{i}_{36} & \mathrm{i}_{34} & \mathrm{i}_{38} & \mathrm{i}_{37} & \mathrm{i}_{39} & \mathrm{i}_{31} & \mathrm{i}_{33}\end{array}$ & $\mathrm{i}_{11} \quad \mathrm{i}_{23} \quad \mathrm{i}_{32} \quad \mathrm{i}_{12}$ & $i_{32}$ \\
\hline $\mathrm{C}_{38}$ & $\begin{array}{llllllllllllll}\mathrm{i}_{12} & \mathrm{i}_{11} & \mathrm{i}_{23} & \mathrm{i}_{22} & \mathrm{i}_{21} & \mathrm{i}_{38} & \mathrm{i}_{34} & \mathrm{i}_{39} & \mathrm{i}_{36} & \mathrm{i}_{33} & \mathrm{i}_{37} & \mathrm{i}_{35} & \mathrm{i}_{32} & \mathrm{i}_{31}\end{array}$ & $\mathrm{i}_{12} \quad \mathrm{i}_{23} \quad \mathrm{i}_{38} \quad \mathrm{i}_{34}$ & $\mathrm{i}_{34}$ \\
\hline $\mathrm{C}_{39}$ & $\begin{array}{llllllllllllll}\mathrm{i}_{12} & \mathrm{i}_{11} & \mathrm{i}_{21} & \mathrm{i}_{22} & \mathrm{i}_{23} & \mathrm{i}_{33} & \mathrm{i}_{39} & \mathrm{i}_{38} & \mathrm{i}_{31} & \mathrm{i}_{34} & \mathrm{i}_{37} & \mathrm{i}_{32} & \mathrm{i}_{35} & \mathrm{i}_{36}\end{array}$ & $\mathrm{i}_{12} \quad \mathrm{i}_{21} \quad \mathrm{i}_{33} \quad \mathrm{i}_{22}$ & $i_{33}$ \\
\hline $\mathrm{C}_{310}$ & $\begin{array}{llllllllllllll}\mathrm{i}_{11} & \mathrm{i}_{12} & \mathrm{i}_{21} & \mathrm{i}_{23} & \mathrm{i}_{22} & \mathrm{i}_{38} & \mathrm{i}_{35} & \mathrm{i}_{34} & \mathrm{i}_{31} & \mathrm{i}_{37} & \mathrm{i}_{39} & \mathrm{i}_{36} & \mathrm{i}_{33} & \mathrm{i}_{32}\end{array}$ & $\mathrm{i}_{11} \quad \mathrm{i}_{21} \quad \mathrm{i}_{38} \quad \mathrm{i}_{23}$ & $C_{310}$ \\
\hline $\mathrm{C}_{311}$ & $\begin{array}{llllllllllllll}\mathrm{i}_{12} & \mathrm{i}_{11} & \mathrm{i}_{23} & \mathrm{i}_{22} & \mathrm{i}_{21} & \mathrm{i}_{37} & \mathrm{i}_{33} & \mathrm{i}_{39} & \mathrm{i}_{32} & \mathrm{i}_{38} & \mathrm{i}_{35} & \mathrm{i}_{34} & \mathrm{i}_{31} & \mathrm{i}_{36}\end{array}$ & $\mathrm{i}_{12} \quad \mathrm{i}_{23} \quad \mathrm{i}_{37} \quad \mathrm{i}_{33}$ & $i_{37}$ \\
\hline $\mathrm{C}_{312}$ & $\begin{array}{llllllllllllll}\mathrm{i}_{12} & \mathrm{i}_{11} & \mathrm{i}_{21} & \mathrm{i}_{22} & \mathrm{i}_{23} & \mathrm{i}_{31} & \mathrm{i}_{37} & \mathrm{i}_{34} & \mathrm{i}_{39} & \mathrm{i}_{38} & \mathrm{i}_{32} & \mathrm{i}_{33} & \mathrm{i}_{35} & \mathrm{i}_{36}\end{array}$ & $\mathrm{i}_{12} \quad \mathrm{i}_{21} \quad \mathrm{i}_{31} \quad \mathrm{i}_{11}$ & $\mathrm{i}_{31}$ \\
\hline $\mathrm{C}_{313}$ & $\begin{array}{llllllllllllll}\mathrm{i}_{11} & \mathrm{i}_{12} & \mathrm{i}_{23} & \mathrm{i}_{22} & \mathrm{i}_{21} & \mathrm{i}_{36} & \mathrm{i}_{35} & \mathrm{i}_{38} & \mathrm{i}_{32} & \mathrm{i}_{31} & \mathrm{i}_{34} & \mathrm{i}_{37} & \mathrm{i}_{39} & \mathrm{i}_{33}\end{array}$ & $\mathrm{i}_{11} \quad \mathrm{i}_{23} \quad \mathrm{i}_{36} \quad \mathrm{i}_{22}$ & $i_{36}$ \\
\hline $\mathrm{C}_{314}$ & $\begin{array}{llllllllllllll}\mathrm{i}_{11} & \mathrm{i}_{12} & \mathrm{i}_{23} & \mathrm{i}_{22} & \mathrm{i}_{21} & \mathrm{i}_{34} & \mathrm{i}_{35} & \mathrm{i}_{32} & \mathrm{i}_{39} & \mathrm{i}_{31} & \mathrm{i}_{33} & \mathrm{i}_{37} & \mathrm{i}_{38} & \mathrm{i}_{36}\end{array}$ & $\mathrm{i}_{11} \quad \mathrm{i}_{23} \quad \mathrm{i}_{34} \quad \mathrm{i}_{35}$ & $\mathrm{i}_{35}$ \\
\hline $\mathrm{C}_{315}$ & $\begin{array}{llllllllllllll}\mathrm{i}_{11} & \mathrm{i}_{12} & \mathrm{i}_{21} & \mathrm{i}_{22} & \mathrm{i}_{23} & \mathrm{i}_{37} & \mathrm{i}_{36} & \mathrm{i}_{32} & \mathrm{i}_{35} & \mathrm{i}_{31} & \mathrm{i}_{39} & \mathrm{i}_{34} & \mathrm{i}_{33} & \mathrm{i}_{38}\end{array}$ & $\mathrm{i}_{11} \quad \mathrm{i}_{21} \quad \mathrm{i}_{37} \quad \mathrm{i}_{36}$ & $\mathrm{i}_{37}$ \\
\hline $\mathrm{C}_{316}$ & $\begin{array}{llllllllllllll}\mathrm{i}_{11} & \mathrm{i}_{12} & \mathrm{i}_{23} & \mathrm{i}_{21} & \mathrm{i}_{22} & \mathrm{i}_{39} & \mathrm{i}_{36} & \mathrm{i}_{31} & \mathrm{i}_{33} & \mathrm{i}_{35} & \mathrm{i}_{34} & \mathrm{i}_{38} & \mathrm{i}_{32} & \mathrm{i}_{37}\end{array}$ & $\mathrm{i}_{11} \quad \mathrm{i}_{23} \quad \mathrm{i}_{39} \quad \mathrm{i}_{12}$ & $\mathrm{i}_{39}$ \\
\hline $\mathrm{C}_{317}$ & $\begin{array}{llllllllllllll}\mathrm{i}_{11} & \mathrm{i}_{12} & \mathrm{i}_{22} & \mathrm{i}_{23} & \mathrm{i}_{21} & \mathrm{i}_{38} & \mathrm{i}_{37} & \mathrm{i}_{34} & \mathrm{i}_{31} & \mathrm{i}_{32} & \mathrm{i}_{35} & \mathrm{i}_{36} & \mathrm{i}_{33} & \mathrm{i}_{39}\end{array}$ & $\begin{array}{llll}\mathrm{i}_{11} & \mathrm{i}_{22} & \mathrm{i}_{38} & \mathrm{i}_{37}\end{array}$ & $\mathrm{C}_{317}$ \\
\hline $\mathrm{C}_{318}$ & $\begin{array}{llllllllllllll}\mathrm{i}_{12} & \mathrm{i}_{11} & \mathrm{i}_{21} & \mathrm{i}_{23} & \mathrm{i}_{22} & \mathrm{i}_{32} & \mathrm{i}_{35} & \mathrm{i}_{33} & \mathrm{i}_{39} & \mathrm{i}_{34} & \mathrm{i}_{37} & \mathrm{i}_{31} & \mathrm{i}_{38} & \mathrm{i}_{36}\end{array}$ & $\mathrm{i}_{12} \quad \mathrm{i}_{21} \quad \mathrm{i}_{32} \quad \mathrm{i}_{23}$ & $\mathrm{i}_{32}$ \\
\hline $\mathrm{C}_{319}$ & $\begin{array}{llllllllllllll}\mathrm{i}_{12} & \mathrm{i}_{11} & \mathrm{i}_{21} & \mathrm{i}_{22} & \mathrm{i}_{23} & \mathrm{i}_{33} & \mathrm{i}_{36} & \mathrm{i}_{31} & \mathrm{i}_{35} & \mathrm{i}_{37} & \mathrm{i}_{32} & \mathrm{i}_{34} & \mathrm{i}_{38} & \mathrm{i}_{39}\end{array}$ & $\mathrm{i}_{12} \quad \mathrm{i}_{21} \quad \mathrm{i}_{33} \quad \mathrm{i}_{36}$ & $i_{36}$ \\
\hline $\mathrm{C}_{320}$ & $\begin{array}{llllllllllllll}\mathrm{i}_{12} & \mathrm{i}_{11} & \mathrm{i}_{23} & \mathrm{i}_{22} & \mathrm{i}_{21} & \mathrm{i}_{39} & \mathrm{i}_{38} & \mathrm{i}_{33} & \mathrm{i}_{34} & \mathrm{i}_{36} & \mathrm{i}_{37} & \mathrm{i}_{31} & \mathrm{i}_{35} & \mathrm{i}_{32}\end{array}$ & $\mathrm{i}_{12} \quad \mathrm{i}_{23} \quad \mathrm{i}_{39} \quad \mathrm{i}_{11}$ & $\mathrm{i}_{39}$ \\
\hline $\mathrm{C}_{321}$ & $\begin{array}{llllllllllllll}\mathrm{i}_{11} & \mathrm{i}_{12} & \mathrm{i}_{21} & \mathrm{i}_{23} & \mathrm{i}_{22} & \mathrm{i}_{35} & \mathrm{i}_{34} & \mathrm{i}_{39} & \mathrm{i}_{33} & \mathrm{i}_{37} & \mathrm{i}_{36} & \mathrm{i}_{38} & \mathrm{i}_{31} & \mathrm{i}_{32}\end{array}$ & $\mathrm{i}_{11} \quad \mathrm{i}_{21} \quad \mathrm{i}_{35} \quad \mathrm{i}_{23}$ & $\mathrm{C}_{321}$ \\
\hline $\mathrm{C}_{322}$ & $\begin{array}{llllllllllllll}\mathrm{i}_{11} & \mathrm{i}_{12} & \mathrm{i}_{23} & \mathrm{i}_{22} & \mathrm{i}_{21} & \mathrm{i}_{31} & \mathrm{i}_{39} & \mathrm{i}_{37} & \mathrm{i}_{36} & \mathrm{i}_{33} & \mathrm{i}_{35} & \mathrm{i}_{34} & \mathrm{i}_{38} & \mathrm{i}_{32}\end{array}$ & $\mathrm{i}_{11} \quad \mathrm{i}_{23} \quad \mathrm{i}_{31} \quad \mathrm{i}_{39}$ & $\mathrm{C}_{322}$ \\
\hline $\mathrm{C}_{323}$ & $\begin{array}{llllllllllllll}\mathrm{i}_{12} & \mathrm{i}_{11} & \mathrm{i}_{22} & \mathrm{i}_{21} & \mathrm{i}_{23} & \mathrm{i}_{36} & \mathrm{i}_{39} & \mathrm{i}_{32} & \mathrm{i}_{34} & \mathrm{i}_{38} & \mathrm{i}_{37} & \mathrm{i}_{33} & \mathrm{i}_{31} & \mathrm{i}_{35}\end{array}$ & $\mathrm{i}_{12} \quad \mathrm{i}_{22} \quad \mathrm{i}_{36} \quad \mathrm{i}_{21}$ & $\mathrm{C}_{323}$ \\
\hline $\mathrm{C}_{324}$ & $\begin{array}{llllllllllllll}\mathrm{i}_{12} & \mathrm{i}_{11} & \mathrm{i}_{23} & \mathrm{i}_{21} & \mathrm{i}_{22} & \mathrm{i}_{38} & \mathrm{i}_{34} & \mathrm{i}_{37} & \mathrm{i}_{31} & \mathrm{i}_{35} & \mathrm{i}_{33} & \mathrm{i}_{32} & \mathrm{i}_{36} & \mathrm{i}_{39}\end{array}$ & $\mathrm{i}_{12} \quad \mathrm{i}_{23} \quad \mathrm{i}_{38} \quad \mathrm{i}_{21}$ & $\mathrm{C}_{324}$ \\
\hline
\end{tabular}




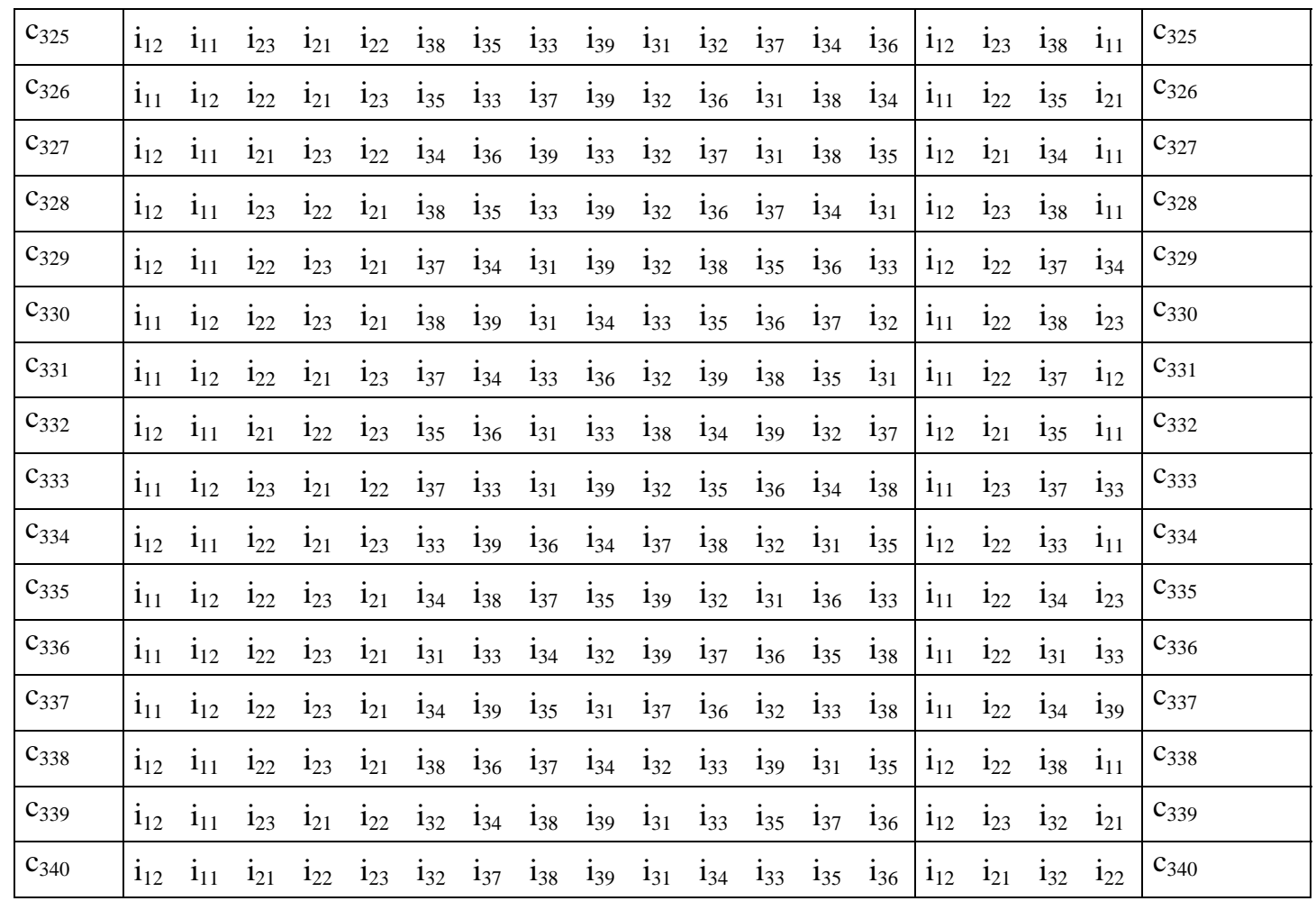


Tabela C26 - Matching $\mu_{3 \mathrm{H}}$

\begin{tabular}{|c|c|c|c|}
\hline Cand. & Lista de Preferências & L. Declaradas & Matching \\
\hline $\mathrm{C}_{11}$ & $\begin{array}{llllllllllllll}\mathrm{i}_{12} & \mathrm{i}_{11} & \mathrm{i}_{22} & \mathrm{i}_{23} & \mathrm{i}_{21} & \mathrm{i}_{36} & \mathrm{i}_{37} & \mathrm{i}_{39} & \mathrm{i}_{38} & \mathrm{i}_{34} & \mathrm{i}_{35} & \mathrm{i}_{31} & \mathrm{i}_{32} & \mathrm{i}_{33}\end{array}$ & $\mathrm{i}_{12} \quad \mathrm{i}_{22} \quad \mathrm{i}_{36} \quad \mathrm{i}_{23}$ & $i_{12}$ \\
\hline $\mathrm{C}_{12}$ & $\begin{array}{llllllllllllll}\mathrm{i}_{12} & \mathrm{i}_{11} & \mathrm{i}_{21} & \mathrm{i}_{23} & \mathrm{i}_{22} & \mathrm{i}_{33} & \mathrm{i}_{37} & \mathrm{i}_{36} & \mathrm{i}_{38} & \mathrm{i}_{35} & \mathrm{i}_{32} & \mathrm{i}_{34} & \mathrm{i}_{39} & \mathrm{i}_{31}\end{array}$ & $\mathrm{i}_{12} \quad \mathrm{i}_{21} \quad \mathrm{i}_{33} \quad \mathrm{i}_{11}$ & $\mathrm{i}_{12}$ \\
\hline $\mathrm{C}_{13}$ & $\begin{array}{llllllllllllll}\mathrm{i}_{12} & \mathrm{i}_{11} & \mathrm{i}_{23} & \mathrm{i}_{22} & \mathrm{i}_{21} & \mathrm{i}_{39} & \mathrm{i}_{34} & \mathrm{i}_{31} & \mathrm{i}_{37} & \mathrm{i}_{33} & \mathrm{i}_{32} & \mathrm{i}_{35} & \mathrm{i}_{36} & \mathrm{i}_{38}\end{array}$ & $\mathrm{i}_{12} \quad \mathrm{i}_{23} \quad \mathrm{i}_{39} \quad \mathrm{i}_{11}$ & $i_{11}$ \\
\hline $\mathrm{C}_{14}$ & $\begin{array}{llllllllllllll}\mathrm{i}_{12} & \mathrm{i}_{11} & \mathrm{i}_{21} & \mathrm{i}_{23} & \mathrm{i}_{22} & \mathrm{i}_{33} & \mathrm{i}_{35} & \mathrm{i}_{34} & \mathrm{i}_{36} & \mathrm{i}_{32} & \mathrm{i}_{38} & \mathrm{i}_{31} & \mathrm{i}_{37} & \mathrm{i}_{39}\end{array}$ & $\mathrm{i}_{12} \quad \mathrm{i}_{21} \quad \mathrm{i}_{33} \quad \mathrm{i}_{11}$ & $\mathrm{i}_{11}$ \\
\hline $\mathrm{C}_{21}$ & $\begin{array}{llllllllllllll}\mathrm{i}_{12} & \mathrm{i}_{11} & \mathrm{i}_{23} & \mathrm{i}_{21} & \mathrm{i}_{22} & \mathrm{i}_{35} & \mathrm{i}_{37} & \mathrm{i}_{32} & \mathrm{i}_{33} & \mathrm{i}_{36} & \mathrm{i}_{34} & \mathrm{i}_{38} & \mathrm{i}_{31} & \mathrm{i}_{39}\end{array}$ & $\mathrm{i}_{12} \quad \mathrm{i}_{23} \quad \mathrm{i}_{35} \quad \mathrm{i}_{21}$ & $\mathrm{i}_{23}$ \\
\hline $\mathrm{C}_{22}$ & $\begin{array}{llllllllllllll}\mathrm{i}_{11} & \mathrm{i}_{12} & \mathrm{i}_{22} & \mathrm{i}_{23} & \mathrm{i}_{21} & \mathrm{i}_{35} & \mathrm{i}_{39} & \mathrm{i}_{31} & \mathrm{i}_{33} & \mathrm{i}_{34} & \mathrm{i}_{37} & \mathrm{i}_{32} & \mathrm{i}_{38} & \mathrm{i}_{36}\end{array}$ & $\mathrm{i}_{11} \quad \mathrm{i}_{22} \quad \mathrm{i}_{35} \quad \mathrm{i}_{12}$ & $\mathrm{i}_{22}$ \\
\hline $\mathrm{C}_{23}$ & $\begin{array}{llllllllllllll}\mathrm{i}_{11} & \mathrm{i}_{12} & \mathrm{i}_{23} & \mathrm{i}_{21} & \mathrm{i}_{22} & \mathrm{i}_{36} & \mathrm{i}_{39} & \mathrm{i}_{33} & \mathrm{i}_{37} & \mathrm{i}_{31} & \mathrm{i}_{38} & \mathrm{i}_{32} & \mathrm{i}_{35} & \mathrm{i}_{34}\end{array}$ & $\mathrm{i}_{11} \quad \mathrm{i}_{23} \quad \mathrm{i}_{36} \quad \mathrm{i}_{39}$ & $\mathrm{i}_{23}$ \\
\hline $\mathrm{C}_{24}$ & $\begin{array}{llllllllllllll}\mathrm{i}_{12} & \mathrm{i}_{11} & \mathrm{i}_{21} & \mathrm{i}_{22} & \mathrm{i}_{23} & \mathrm{i}_{37} & \mathrm{i}_{32} & \mathrm{i}_{38} & \mathrm{i}_{35} & \mathrm{i}_{31} & \mathrm{i}_{36} & \mathrm{i}_{34} & \mathrm{i}_{33} & \mathrm{i}_{39}\end{array}$ & $\mathrm{i}_{12} \quad \mathrm{i}_{21} \quad \mathrm{i}_{37} \quad \mathrm{i}_{11}$ & $\mathrm{i}_{21}$ \\
\hline $\mathrm{C}_{25}$ & $\begin{array}{llllllllllllll}\mathrm{i}_{12} & \mathrm{i}_{11} & \mathrm{i}_{23} & \mathrm{i}_{21} & \mathrm{i}_{22} & \mathrm{i}_{39} & \mathrm{i}_{32} & \mathrm{i}_{38} & \mathrm{i}_{35} & \mathrm{i}_{34} & \mathrm{i}_{31} & \mathrm{i}_{37} & \mathrm{i}_{33} & \mathrm{i}_{36}\end{array}$ & $\mathrm{i}_{12} \quad \mathrm{i}_{23} \quad \mathrm{i}_{39} \quad \mathrm{i}_{32}$ & $\mathrm{i}_{39}$ \\
\hline $\mathrm{C}_{26}$ & $\begin{array}{llllllllllllll}\mathrm{i}_{12} & \mathrm{i}_{11} & \mathrm{i}_{23} & \mathrm{i}_{21} & \mathrm{i}_{22} & \mathrm{i}_{32} & \mathrm{i}_{38} & \mathrm{i}_{33} & \mathrm{i}_{34} & \mathrm{i}_{35} & \mathrm{i}_{31} & \mathrm{i}_{37} & \mathrm{i}_{36} & \mathrm{i}_{39}\end{array}$ & $\mathrm{i}_{12} \quad \mathrm{i}_{23} \quad \mathrm{i}_{32} \quad \mathrm{i}_{11}$ & $\mathrm{i}_{32}$ \\
\hline $\mathrm{C}_{31}$ & $\begin{array}{llllllllllllll}\mathrm{i}_{12} & \mathrm{i}_{11} & \mathrm{i}_{21} & \mathrm{i}_{22} & \mathrm{i}_{23} & \mathrm{i}_{31} & \mathrm{i}_{36} & \mathrm{i}_{37} & \mathrm{i}_{38} & \mathrm{i}_{32} & \mathrm{i}_{35} & \mathrm{i}_{39} & \mathrm{i}_{33} & \mathrm{i}_{34}\end{array}$ & $\mathrm{i}_{12} \quad \mathrm{i}_{21} \quad \mathrm{i}_{31} \quad \mathrm{i}_{11}$ & $i_{21}$ \\
\hline $\mathrm{C}_{32}$ & $\begin{array}{llllllllllllll}\mathrm{i}_{11} & \mathrm{i}_{12} & \mathrm{i}_{23} & \mathrm{i}_{22} & \mathrm{i}_{21} & \mathrm{i}_{37} & \mathrm{i}_{35} & \mathrm{i}_{36} & \mathrm{i}_{31} & \mathrm{i}_{38} & \mathrm{i}_{33} & \mathrm{i}_{34} & \mathrm{i}_{32} & \mathrm{i}_{39}\end{array}$ & $\mathrm{i}_{11} \quad \mathrm{i}_{23} \quad \mathrm{i}_{37} \quad \mathrm{i}_{12}$ & $\mathrm{i}_{37}$ \\
\hline $\mathrm{C}_{33}$ & $\begin{array}{llllllllllllll}\mathrm{i}_{11} & \mathrm{i}_{12} & \mathrm{i}_{21} & \mathrm{i}_{23} & \mathrm{i}_{22} & \mathrm{i}_{35} & \mathrm{i}_{32} & \mathrm{i}_{34} & \mathrm{i}_{33} & \mathrm{i}_{36} & \mathrm{i}_{37} & \mathrm{i}_{38} & \mathrm{i}_{31} & \mathrm{i}_{39}\end{array}$ & $\mathrm{i}_{11} \quad \mathrm{i}_{21} \quad \mathrm{i}_{35} \quad \mathrm{i}_{12}$ & $i_{35}$ \\
\hline $\mathrm{C}_{34}$ & $\begin{array}{llllllllllllll}\mathrm{i}_{11} & \mathrm{i}_{12} & \mathrm{i}_{23} & \mathrm{i}_{22} & \mathrm{i}_{21} & \mathrm{i}_{35} & \mathrm{i}_{39} & \mathrm{i}_{33} & \mathrm{i}_{38} & \mathrm{i}_{36} & \mathrm{i}_{32} & \mathrm{i}_{31} & \mathrm{i}_{37} & \mathrm{i}_{34}\end{array}$ & $\mathrm{i}_{11} \quad \mathrm{i}_{23} \quad \mathrm{i}_{35} \quad \mathrm{i}_{22}$ & $\mathrm{i}_{22}$ \\
\hline $\mathrm{C}_{35}$ & $\begin{array}{llllllllllllll}\mathrm{i}_{12} & \mathrm{i}_{11} & \mathrm{i}_{21} & \mathrm{i}_{22} & \mathrm{i}_{23} & \mathrm{i}_{39} & \mathrm{i}_{36} & \mathrm{i}_{37} & \mathrm{i}_{38} & \mathrm{i}_{32} & \mathrm{i}_{34} & \mathrm{i}_{31} & \mathrm{i}_{33} & \mathrm{i}_{35}\end{array}$ & $\begin{array}{llll}\mathrm{i}_{12} & \mathrm{i}_{21} & \mathrm{i}_{39} & \mathrm{i}_{22}\end{array}$ & $\mathrm{i}_{39}$ \\
\hline $\mathrm{C}_{36}$ & $\begin{array}{llllllllllllll}\mathrm{i}_{12} & \mathrm{i}_{11} & \mathrm{i}_{22} & \mathrm{i}_{21} & \mathrm{i}_{23} & \mathrm{i}_{34} & \mathrm{i}_{37} & \mathrm{i}_{39} & \mathrm{i}_{35} & \mathrm{i}_{31} & \mathrm{i}_{32} & \mathrm{i}_{38} & \mathrm{i}_{36} & \mathrm{i}_{33}\end{array}$ & $\mathrm{i}_{12} \quad \mathrm{i}_{22} \quad \mathrm{i}_{34} \quad \mathrm{i}_{11}$ & $\mathrm{i}_{34}$ \\
\hline $\mathrm{C}_{37}$ & $\begin{array}{llllllllllllll}\mathrm{i}_{11} & \mathrm{i}_{12} & \mathrm{i}_{23} & \mathrm{i}_{21} & \mathrm{i}_{22} & \mathrm{i}_{31} & \mathrm{i}_{36} & \mathrm{i}_{34} & \mathrm{i}_{35} & \mathrm{i}_{39} & \mathrm{i}_{33} & \mathrm{i}_{32} & \mathrm{i}_{37} & \mathrm{i}_{38}\end{array}$ & $\mathrm{i}_{11} \quad \mathrm{i}_{23} \quad \mathrm{i}_{31} \quad \mathrm{i}_{36}$ & $i_{31}$ \\
\hline $\mathrm{C}_{38}$ & $\begin{array}{llllllllllllll}\mathrm{i}_{12} & \mathrm{i}_{11} & \mathrm{i}_{21} & \mathrm{i}_{23} & \mathrm{i}_{22} & \mathrm{i}_{39} & \mathrm{i}_{32} & \mathrm{i}_{34} & \mathrm{i}_{35} & \mathrm{i}_{37} & \mathrm{i}_{31} & \mathrm{i}_{38} & \mathrm{i}_{36} & \mathrm{i}_{33}\end{array}$ & $\mathrm{i}_{12} \quad \mathrm{i}_{21} \quad \mathrm{i}_{39} \quad \mathrm{i}_{11}$ & $\mathrm{C}_{38}$ \\
\hline $\mathrm{C}_{39}$ & $\begin{array}{llllllllllllll}\mathrm{i}_{12} & \mathrm{i}_{11} & \mathrm{i}_{21} & \mathrm{i}_{22} & \mathrm{i}_{23} & \mathrm{i}_{38} & \mathrm{i}_{36} & \mathrm{i}_{32} & \mathrm{i}_{31} & \mathrm{i}_{34} & \mathrm{i}_{35} & \mathrm{i}_{37} & \mathrm{i}_{39} & \mathrm{i}_{33}\end{array}$ & $\mathrm{i}_{12} \quad \mathrm{i}_{21} \quad \mathrm{i}_{38} \quad \mathrm{i}_{36}$ & $i_{38}$ \\
\hline $\mathrm{C}_{310}$ & $\begin{array}{llllllllllllll}\mathrm{i}_{11} & \mathrm{i}_{12} & \mathrm{i}_{23} & \mathrm{i}_{22} & \mathrm{i}_{21} & \mathrm{i}_{37} & \mathrm{i}_{35} & \mathrm{i}_{32} & \mathrm{i}_{34} & \mathrm{i}_{39} & \mathrm{i}_{33} & \mathrm{i}_{31} & \mathrm{i}_{36} & \mathrm{i}_{38}\end{array}$ & $\mathrm{i}_{11} \quad \mathrm{i}_{23} \quad \mathrm{i}_{37} \quad \mathrm{i}_{22}$ & $\mathrm{i}_{37}$ \\
\hline $\mathrm{C}_{311}$ & $\begin{array}{llllllllllllll}\mathrm{i}_{12} & \mathrm{i}_{11} & \mathrm{i}_{21} & \mathrm{i}_{22} & \mathrm{i}_{23} & \mathrm{i}_{32} & \mathrm{i}_{36} & \mathrm{i}_{31} & \mathrm{i}_{39} & \mathrm{i}_{33} & \mathrm{i}_{37} & \mathrm{i}_{35} & \mathrm{i}_{38} & \mathrm{i}_{34}\end{array}$ & $\mathrm{i}_{12} \quad \mathrm{i}_{21} \quad \mathrm{i}_{32} \quad \mathrm{i}_{11}$ & $i_{32}$ \\
\hline $\mathrm{C}_{312}$ & $\begin{array}{llllllllllllll}\mathrm{i}_{12} & \mathrm{i}_{11} & \mathrm{i}_{22} & \mathrm{i}_{21} & \mathrm{i}_{23} & \mathrm{i}_{37} & \mathrm{i}_{31} & \mathrm{i}_{39} & \mathrm{i}_{38} & \mathrm{i}_{32} & \mathrm{i}_{33} & \mathrm{i}_{35} & \mathrm{i}_{34} & \mathrm{i}_{36}\end{array}$ & $\mathrm{i}_{12} \quad \mathrm{i}_{22} \quad \mathrm{i}_{37} \quad \mathrm{i}_{31}$ & $\mathrm{i}_{31}$ \\
\hline $\mathrm{C}_{313}$ & $\begin{array}{llllllllllllll}\mathrm{i}_{12} & \mathrm{i}_{11} & \mathrm{i}_{22} & \mathrm{i}_{23} & \mathrm{i}_{21} & \mathrm{i}_{35} & \mathrm{i}_{37} & \mathrm{i}_{34} & \mathrm{i}_{32} & \mathrm{i}_{39} & \mathrm{i}_{38} & \mathrm{i}_{36} & \mathrm{i}_{33} & \mathrm{i}_{31}\end{array}$ & $\mathrm{i}_{12} \quad \mathrm{i}_{22} \quad \mathrm{i}_{35} \quad \mathrm{i}_{11}$ & $i_{35}$ \\
\hline $\mathrm{C}_{314}$ & $\begin{array}{llllllllllllll}\mathrm{i}_{12} & \mathrm{i}_{11} & \mathrm{i}_{22} & \mathrm{i}_{23} & \mathrm{i}_{21} & \mathrm{i}_{39} & \mathrm{i}_{34} & \mathrm{i}_{35} & \mathrm{i}_{37} & \mathrm{i}_{31} & \mathrm{i}_{33} & \mathrm{i}_{38} & \mathrm{i}_{36} & \mathrm{i}_{32}\end{array}$ & $\mathrm{i}_{12} \quad \mathrm{i}_{22} \quad \mathrm{i}_{39} \quad \mathrm{i}_{34}$ & $\mathrm{i}_{34}$ \\
\hline $\mathrm{C}_{315}$ & $\begin{array}{llllllllllllll}\mathrm{i}_{12} & \mathrm{i}_{11} & \mathrm{i}_{22} & \mathrm{i}_{23} & \mathrm{i}_{21} & \mathrm{i}_{36} & \mathrm{i}_{32} & \mathrm{i}_{37} & \mathrm{i}_{39} & \mathrm{i}_{31} & \mathrm{i}_{33} & \mathrm{i}_{35} & \mathrm{i}_{34} & \mathrm{i}_{38}\end{array}$ & $\mathrm{i}_{12} \quad \mathrm{i}_{22} \quad \mathrm{i}_{36} \quad \mathrm{i}_{23}$ & $\mathrm{i}_{36}$ \\
\hline $\mathrm{C}_{316}$ & $\begin{array}{llllllllllllll}\mathrm{i}_{11} & \mathrm{i}_{12} & \mathrm{i}_{21} & \mathrm{i}_{23} & \mathrm{i}_{22} & \mathrm{i}_{32} & \mathrm{i}_{39} & \mathrm{i}_{38} & \mathrm{i}_{33} & \mathrm{i}_{37} & \mathrm{i}_{36} & \mathrm{i}_{31} & \mathrm{i}_{34} & \mathrm{i}_{35}\end{array}$ & $\mathrm{i}_{11} \quad \mathrm{i}_{21} \quad \mathrm{i}_{32} \quad \mathrm{i}_{39}$ & $\mathrm{C}_{316}$ \\
\hline $\mathrm{C}_{317}$ & $\begin{array}{llllllllllllll}\mathrm{i}_{12} & \mathrm{i}_{11} & \mathrm{i}_{21} & \mathrm{i}_{22} & \mathrm{i}_{23} & \mathrm{i}_{31} & \mathrm{i}_{33} & \mathrm{i}_{34} & \mathrm{i}_{35} & \mathrm{i}_{32} & \mathrm{i}_{38} & \mathrm{i}_{37} & \mathrm{i}_{36} & \mathrm{i}_{39}\end{array}$ & $\mathrm{i}_{12} \quad \mathrm{i}_{21} \quad \mathrm{i}_{31} \quad \mathrm{i}_{11}$ & $\mathrm{C}_{317}$ \\
\hline $\mathrm{C}_{318}$ & $\begin{array}{llllllllllllll}\mathrm{i}_{12} & \mathrm{i}_{11} & \mathrm{i}_{22} & \mathrm{i}_{21} & \mathrm{i}_{23} & \mathrm{i}_{36} & \mathrm{i}_{38} & \mathrm{i}_{31} & \mathrm{i}_{32} & \mathrm{i}_{33} & \mathrm{i}_{34} & \mathrm{i}_{35} & \mathrm{i}_{37} & \mathrm{i}_{39}\end{array}$ & $\mathrm{i}_{12} \quad \mathrm{i}_{22} \quad \mathrm{i}_{36} \quad \mathrm{i}_{21}$ & $\mathrm{i}_{36}$ \\
\hline $\mathrm{C}_{319}$ & $\begin{array}{llllllllllllll}\mathrm{i}_{11} & \mathrm{i}_{12} & \mathrm{i}_{22} & \mathrm{i}_{21} & \mathrm{i}_{23} & \mathrm{i}_{36} & \mathrm{i}_{37} & \mathrm{i}_{33} & \mathrm{i}_{34} & \mathrm{i}_{31} & \mathrm{i}_{35} & \mathrm{i}_{39} & \mathrm{i}_{32} & \mathrm{i}_{38}\end{array}$ & $\begin{array}{llll}\mathrm{i}_{11} & \mathrm{i}_{22} & \mathrm{i}_{36} & \mathrm{i}_{21}\end{array}$ & $\mathrm{C}_{319}$ \\
\hline $\mathrm{C}_{320}$ & $\begin{array}{llllllllllllll}\mathrm{i}_{11} & \mathrm{i}_{12} & \mathrm{i}_{22} & \mathrm{i}_{21} & \mathrm{i}_{23} & \mathrm{i}_{36} & \mathrm{i}_{38} & \mathrm{i}_{35} & \mathrm{i}_{33} & \mathrm{i}_{32} & \mathrm{i}_{34} & \mathrm{i}_{31} & \mathrm{i}_{37} & \mathrm{i}_{39}\end{array}$ & $\mathrm{i}_{11} \quad \mathrm{i}_{22} \quad \mathrm{i}_{36} \quad \mathrm{i}_{21}$ & $\mathrm{C}_{320}$ \\
\hline $\mathrm{C}_{321}$ & $\begin{array}{llllllllllllll}\mathrm{i}_{11} & \mathrm{i}_{12} & \mathrm{i}_{23} & \mathrm{i}_{22} & \mathrm{i}_{21} & \mathrm{i}_{31} & \mathrm{i}_{37} & \mathrm{i}_{33} & \mathrm{i}_{34} & \mathrm{i}_{35} & \mathrm{i}_{36} & \mathrm{i}_{38} & \mathrm{i}_{39} & \mathrm{i}_{32}\end{array}$ & $\mathrm{i}_{11} \quad \mathrm{i}_{23} \quad \mathrm{i}_{31} \quad \mathrm{i}_{12}$ & $\mathrm{C}_{321}$ \\
\hline $\mathrm{C}_{322}$ & $\begin{array}{llllllllllllll}\mathrm{i}_{11} & \mathrm{i}_{12} & \mathrm{i}_{21} & \mathrm{i}_{23} & \mathrm{i}_{22} & \mathrm{i}_{39} & \mathrm{i}_{33} & \mathrm{i}_{36} & \mathrm{i}_{34} & \mathrm{i}_{32} & \mathrm{i}_{37} & \mathrm{i}_{38} & \mathrm{i}_{31} & \mathrm{i}_{35}\end{array}$ & $\mathrm{i}_{11} \quad \mathrm{i}_{21} \quad \mathrm{i}_{39} \quad \mathrm{i}_{23}$ & $\mathrm{C}_{322}$ \\
\hline $\mathrm{C}_{323}$ & $\begin{array}{llllllllllllll}\mathrm{i}_{12} & \mathrm{i}_{11} & \mathrm{i}_{21} & \mathrm{i}_{22} & \mathrm{i}_{23} & \mathrm{i}_{34} & \mathrm{i}_{35} & \mathrm{i}_{33} & \mathrm{i}_{31} & \mathrm{i}_{32} & \mathrm{i}_{39} & \mathrm{i}_{36} & \mathrm{i}_{38} & \mathrm{i}_{37}\end{array}$ & $\mathrm{i}_{12} \quad \mathrm{i}_{21} \quad \mathrm{i}_{34} \quad \mathrm{i}_{35}$ & $\mathrm{C}_{323}$ \\
\hline $\mathrm{C}_{324}$ & $\begin{array}{llllllllllllll}\mathrm{i}_{12} & \mathrm{i}_{11} & \mathrm{i}_{21} & \mathrm{i}_{22} & \mathrm{i}_{23} & \mathrm{i}_{35} & \mathrm{i}_{33} & \mathrm{i}_{37} & \mathrm{i}_{34} & \mathrm{i}_{31} & \mathrm{i}_{36} & \mathrm{i}_{32} & \mathrm{i}_{38} & \mathrm{i}_{39}\end{array}$ & $\mathrm{i}_{12} \quad \mathrm{i}_{21} \quad \mathrm{i}_{35} \quad \mathrm{i}_{33}$ & $\mathrm{i}_{33}$ \\
\hline
\end{tabular}




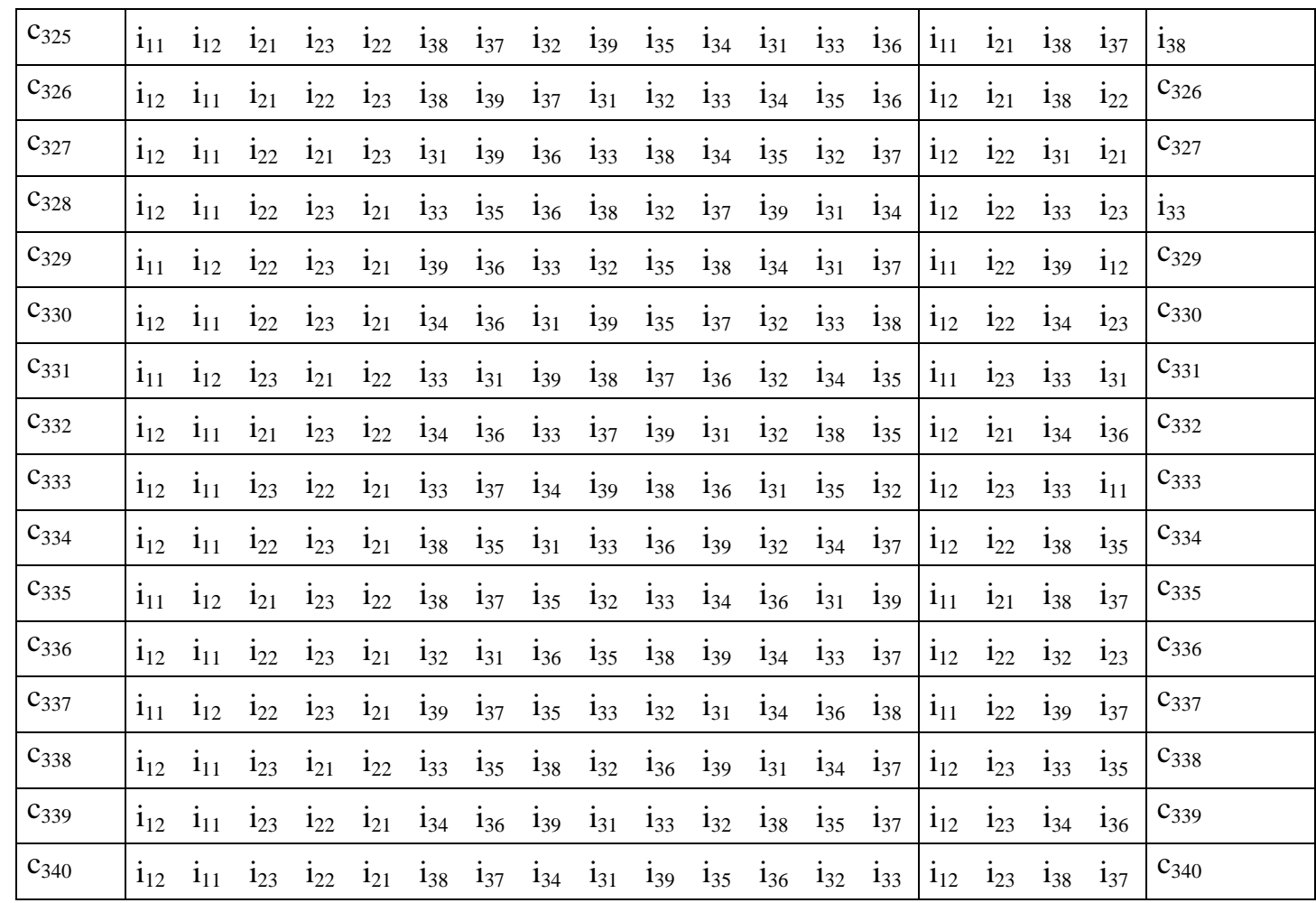


Tabela C27 - Matching $\mu_{3 \mathrm{I}}$

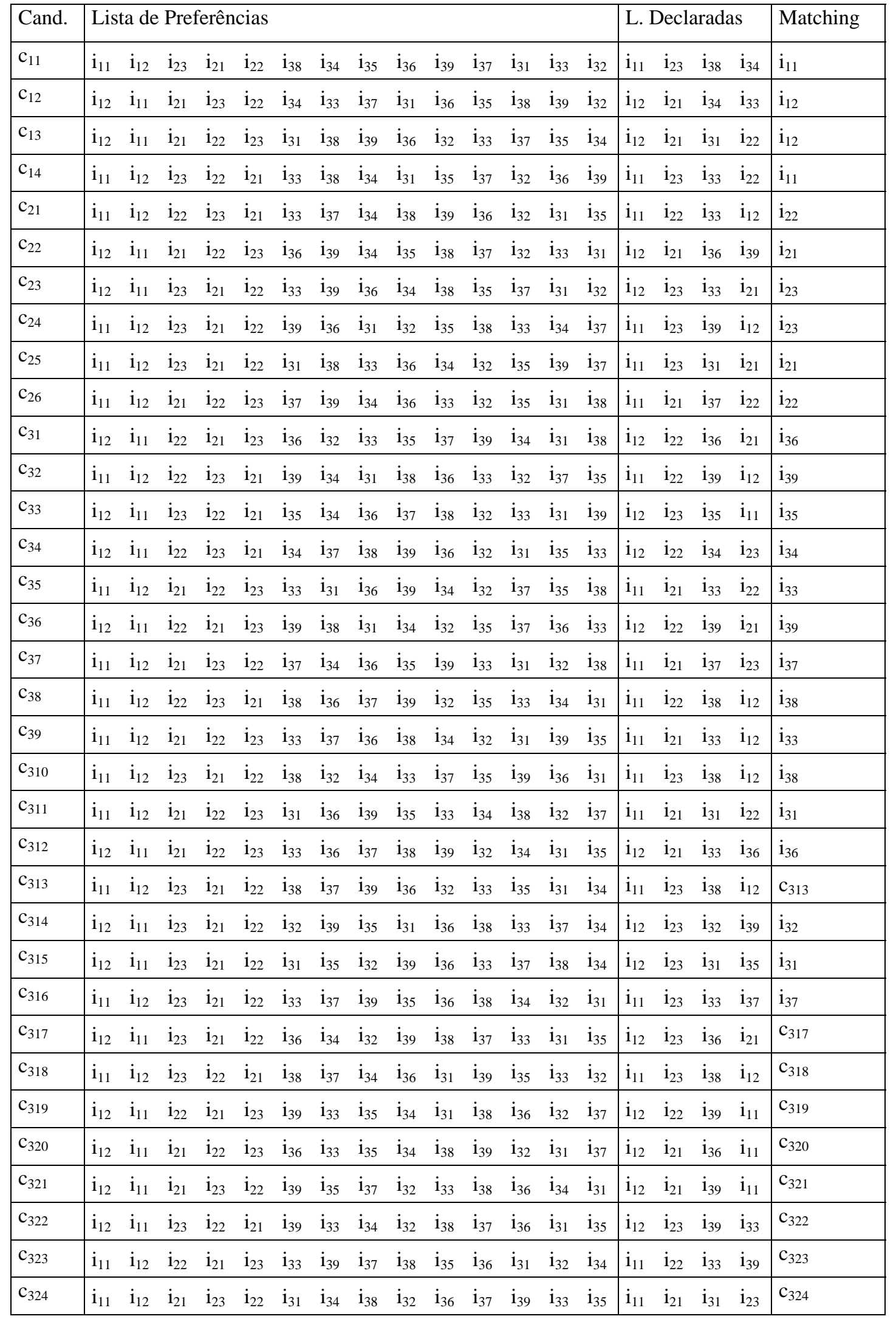




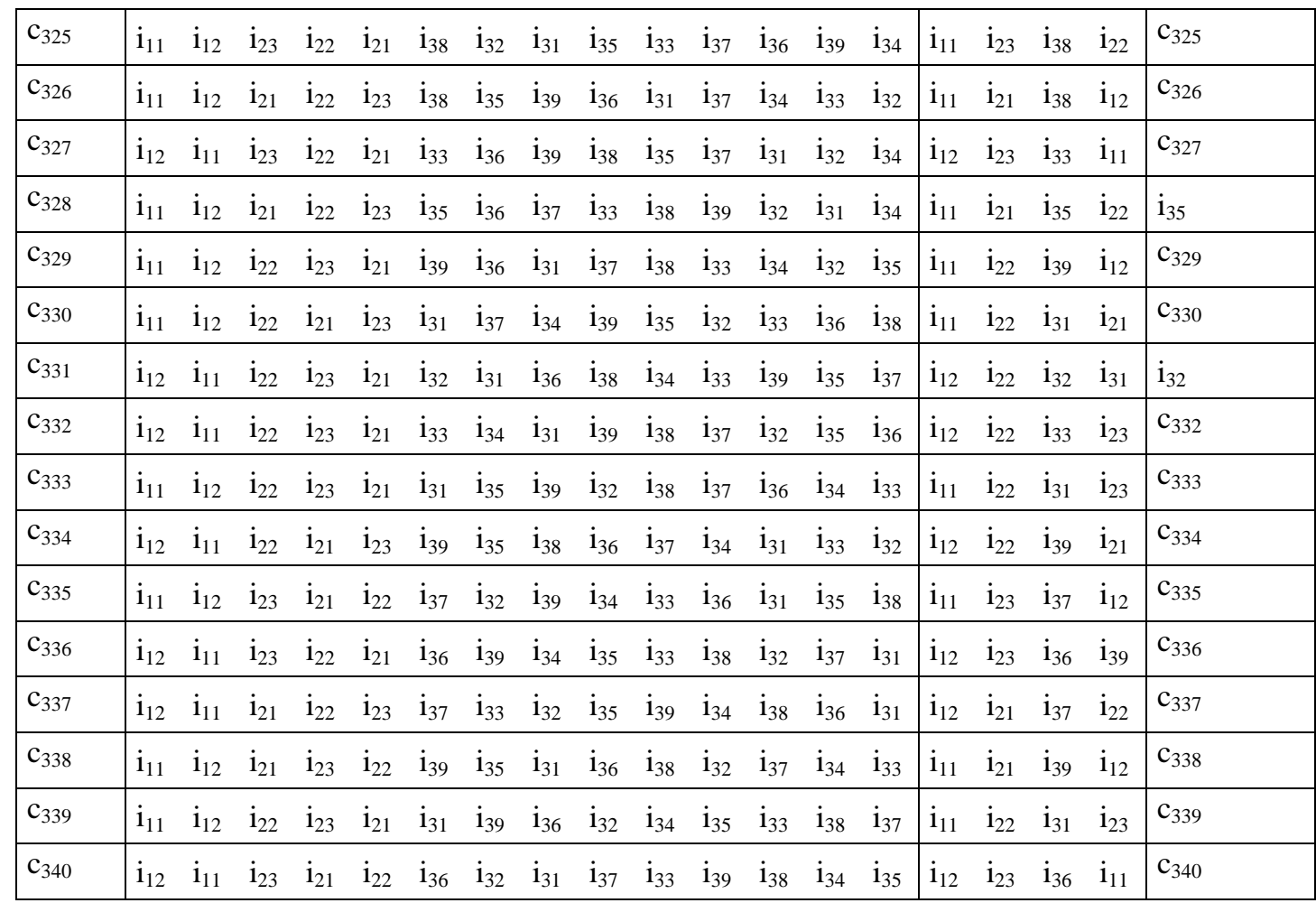

